Pontifícia Universidade Católica $_{\text {do Rio de Janeiro }}$

Renê Alberto Moritz da Silva e Forster

ASPECTOS DO PROCESSAMENTO DE ORAÇÕES
RELATIVAS: ANTECIPAÇÃO DE REFERENTES E
INTEGRAÇÃO DE INFORMAÇÃO CONTEXTUAL

Tese de Doutorado

Tese apresentada ao Programa de Pósgraduação em Estudos da Linguagem do Departamento de Letras da PUC-Rio como parte dos requisitos parciais para obtenção do título de Doutor em Letras/Estudos da Linguagem.

Orientador: Letícia Maria Sicuro Corrêa 
Pontifícia Universidade C atólica $_{\text {a }}$

DO RIO DE JANEIRO

Renê Alberto Moritz da Silva e Forster

\title{
ASPECTOS DO PROCESSAMENTO DE ORAÇÕES RELATIVAS: ANTECIPAÇÃO DE REFERENTES E INTEGRAÇÃO DE INFORMAÇÃO CONTEXTUAL
}

\begin{abstract}
Tese apresentada como requisito parcial para obtenção do grau de Doutor pelo Programa de Pós-Graduação em Estudos da Linguagem do Departamento de Letras do Centro de Teologia e Ciências Humanas da PUC-Rio. Aprovada pela Comissão Examinadora abaixo assinada.
\end{abstract}

Profa. Letícia Maria Sicuro Corrêa

Orientadora

Departamento de Letras - PUC-Rio

Profa. Erica dos Santos Rodrigues

Departamento de Letras - PUC-Rio

Profa. Maria Luiza Gonçalves Aragão da Cunha Lima UFMG

Prof. Marcus Antonio Rezende Maia

UFRJ

Prof. Eduardo Kenedy Nunes Areas

UFF

Profa. Denise Berruezo Portinari Coordenadora Setorial do Centro de Teologia e Ciências Humanas - PUC-Rio

Rio de Janeiro, 24 de abril de 2013. 
Todos os direitos reservados. É proibida a reprodução total ou parcial do trabalho sem autorização do autor, da orientadora e da universidade.

\section{Renê Alberto Moritz da Silva e Forster}

Graduou-se como bacharel em Letras pela Universidade do Estado do Rio de Janeiro em 2005. Pela mesma instituição, obteve título de Licenciado em Letras, em 2005, e concluiu o Mestrado em Letras (área de concentração: Linguística), em 2008. Em 2013, concluiu, na PUC-Rio, o Doutorado em Letras (área de concentração: Estudos da Linguagem). Atua no Grupo de Pesquisa do LAPAL - Laboratório de Psicolinguística e Aquisição da Linguagem, vinculado ao Departamento de Letras - PUC-Rio. Áreas de interesse: Psicolinguística, Processamento da Linguagem, Linguística Teórica, Rastreamento Ocular.

Ficha Catalográfica

Silva e Forster, Renê Alberto Moritz da

Aspectos do processamento de orações relativas: antecipação de referentes e integração de informação contextual / Renê Alberto Moritz da Silva e Forster ; orientadora: Letícia Maria Sicuro Corrêa. - 2013. 190 f. : il. ; $30 \mathrm{~cm}$

Tese (doutorado)-Pontifícia Universidade Católica do Rio de Janeiro, Departamento de Letras, 2013.

Inclui bibliografia

1. Letras - Teses. 2. Compreensão da linguagem. 3. Orações relativas. 4. Rastreamento ocular. 5. Incrementalidade. 6. Previsibilidade. I. Corrêa, Letícia Maria Sicuro. II. Pontifícia Universidade Católica do Rio de Janeiro. Departamento de Letras. III. Título. 


\section{Agradecimentos}

A Letícia Corrêa não só por sua disponibilidade em partilhar seu conhecimento, por seu suporte intelectual, mas acima de tudo por sua motivação, engajamento e entusiasmo, que são um exemplo e um incentivo para minha carreira e para minha atuação. Além disso, por sua incansável dedicação à frente do LAPAL, cujo suporte material foi essencial para a execução de todo o trabalho realizado.

A Eduardo Kenedy, Erica Rodrigues, Maria Luiza Cunha Lima e Marcus Maia, por seu tempo, disponibilidade e cuidado na leitura deste trabalho, e pelas sugestões feitas à redação final e a trabalhos futuros.

A Jacqueline Longchamps, Mercedes Marcilese e Tatiana Bagetti pelas trocas de experiências, pelo apoio na realização de tarefas e pela convivência. Em geral, a todos os companheiros do LAPAL, que formam um ambiente de compartilhamento e solidariedade, onde partilhamos uma vivência acadêmica, mas também nossos anseios e incertezas.

A Erica Rodrigues e Marina Augusto, por me ajudarem enquanto professoras, e por, além disso, terem patricipado profundamente do meu processo de formação.

A Francisca Ferreira de Oliveira, Chiquinha, pelos lembretes, pelo cuidado, mas, principalmente, pela paciência e pelo carinho no tratamento dos assuntos burocráticos que envolveram este trabalho. De forma mais geral, a todos os funcionários e professores do Departamento de Letras e da PUC-Rio, que, algumas vezes anonimamente, contribuem com seu tempo, trabalho e esforço para a realização de muitos trabalhos como este.

A Ricardo Joseh Lima por ter me acompanhado em meus primeiros passos na carreira acadêmica, por seu suporte logístico na execução de um dos experimentos, e pelo exemplo de dedicação e compromisso com a carreira docente e com seus alunos. 
A Antônio João Carvalho Ribeiro, por todo o apoio para a realização do experimento final deste trabalho, sem o qual sua conclusão não teria sido possível.

A CAPES, FAPERJ e PUC-Rio pelos auxílios concedidos.

A Clara Villarinho, que de todas as formas possíveis me ajudou e participou do processo de construção desta tese e de minha experiência profissional. Acima de tudo por seu apoio emocional, pelas conversas, experiências, alegrias, frustrações e por ter me proibido de desistir.

A Márcia, Esmeralda, Bárbara, Horácio e Rosa, por de formas diferentes também terem feito parte da minha trajetória profissional e, por mais que isso, terem feito parte da construção do que sou.

A meus amigos em geral, em especial aos que fizeram parte do percurso desse trabalho, Aline Fernanda, Arthur Caser, Diogo Oliveira, João Vitor, Paula Toledo e Rodrigo Carvalho, pelas mais que fundamentais horas de não trabalho. 


\section{Resumo}

Forster, Renê Alberto Moritz da Silva e; Corrêa, Letícia M. Sicuro. Aspectos do processamento de orações relativas: antecipação de referentes e integração de informação contextual. Rio de Janeiro, 2013. 190p. Tese de Doutorado - Departamento de Letras, Pontifícia Universidade Católica do Rio de Janeiro.

O presente estudo investiga o processamento incremental de orações relativas restritivas de objeto. Considera-se, em particular, o mapeamento antecipado do referente do DP complexo, por meio da integração incremental de informação contextual, durante o processamento da oração relativa, explorando-se a possibilidade de esse tipo de integração ser conciliado à concepção de um processador sintático autônomo. Esse tema é abordado em duas direções: (i) investigando-se o momento da integração de informação contextual e as condições em que poderia haver mapeamento antecipado de referentes de um DP complexo; e (ii) avaliando-se as vantagens computacionais de um processador autônomo (frente a modelos interativos) com vistas a propor procedimento de análise que permita compatibilizá-las com os resultados experimentais obtidos. Em razão de (i), foram conduzidos três experimentos de rastreamento ocular. Sentenças com um DP-sujeito complexo contendo relativas de objeto foram apresentadas concomitantemente (experimento 1) ou precedidas (experimento 2) de contextos discursivos e visuais que poderiam permitir a desambiguização da referência em diferentes segmentos da oração relativa. Os resultados, em consonância com a literatura, sugerem que estímulos verbais foram incrementalmente processados e mapeados em referentes visuais, de modo que a busca pelo referente do DP complexo parece ter emergido tão logo houvesse informação distintiva disponível. O experimento 3 teve por objetivo investigar em que medida o mapeamento antecipado ocorreria também em estímulos temporariamente ambíguos (entre uma leitura completiva ou relativa restritiva), apresentados verbalmente em entonação natural, e precedidos por informação contextual que poderia favorecer uma análise restritiva. Ao contrário de resultados anteriores, contudo, o direcionamento contextual não pareceu suplantar a aplicação de uma análise compatível com o princípio de aposição mínima. Em 
função de (ii), o modelo de computação online de Corrêa e Augusto (2007) e seus desdobramentos em Augusto, Corrêa e Forster (2012) foram explorados, incorporando-se unidades de processamento correspondentes ao conceito minimalista de fase, de forma a permitir a transferência gradual de material já parcialmente processado aos sistemas de interface com vistas a possibilitar a integração incremental de informação contextual. Propõe-se, adicionalmente, que um mecanismo de pré-ativação de relações temáticas, baseado em informação contextual, poderia ser capaz de caracterizar o mapeamento antecipado do referente de um DP complexo.

\section{Palavras-chave}

Compreensão da linguagem; orações relativas; rastreamento ocular; incrementalidade; previsibilidade. 


\section{Abstract}

Forster, Renê Alberto Moritz da Silva e; Corrêa, Letícia M. Sicuro (Advisor). Relative clause processing: incremental referential mapping and integration of contextual information. Rio de Janeiro, 2013. 190p. Doctoral Thesis - Departamento de Letras, Pontifícia Universidade Católica do Rio de Janeiro.

This study investigates the incremental processing of restrictive object relative clauses. The anticipation of the referent of the complex DP, as contextual information is integrated during the analysis of relative clause, is particularly considered and the possibility is explored of this sort of incremental processing being reconciled with an autonomous parser. The argument is conducted twoway: (i) by characterizing the moment in time at which the information provided by the complex DP is integrated with background information, and the conditions that allow for the anticipation of the referent of a complex DP; (ii) by considering the computational advantages of an autonomous parser (vis a vis interactive models), and possible means of reconciling the experimental results obtained. As for (i), three experiments were conducted in the visual world paradigm. Sentences with a complex DP subject containing a restrictive object relative clause were presented either concomitantly to a visually supported discourse context (Experiment 1) or preceded by it (Experiment 2). The visual context was manipulated in such a way as to enable the integration of the information provided by the complex DP and the discourse context to take place at different sentence segments. The results confirmed previously reported findings suggesting that sentences are incrementally interpreted and mapped onto the external world, and that the referent of the complex DP is search for as soon as possible. Experiment 3 was intended to verify the extent to which such an anticipation would take place in temporally ambiguous sentences (complement sentences or relative clauses), presented in normal intonation and preceded by contexts that would bias for the parsing of restrictive relative clauses. Unlike previous findings, however, the biasing context did not override Minimal Attachment. As for (ii), the on-line model of sentence computation in Corrêa \& Augusto (2007) and its expansion in Augusto, Corrêa \& Forster (2012) were further developed. The minimalist 
concept phase with a partially analyzed material being transferred to the interfaces, when adapted to left-right on-line computation, enables a partially analyzed complex DP to be minimally interpreted and integrated with background information. Additionally, the pre-activation of thematic relations on the basis of discourse/contextual information was proposed as a means of accounting for the anticipation of the referent of complex DP as the subject of the relative clause is analyzed.

\section{Keywords}

Language comprehension; object relative clauses; eye-tracking; incrementability; predibility. 


\section{Sumário}

1. Introdução 12

2. Pressupostos Teóricos 18

3. O processamento sintático e a compreensão de relativas 28

3.1. Aspectos da arquitetura do processador sintático 31

3.1.1. Modularidade 32

3.1.2. Incrementalidade $\quad 37$

$\begin{array}{ll}\text { 3.1.3. Serialidade } & 40\end{array}$

3.2. Autonomia vs. interatividade no processamento sintático 41

3.2.1. Preferências estruturais no processamento: argumentos para um processador autônomo 42

3.2.2. Integração incremental e antecipação: evidências para um processador sintático não especializado? 50

3.3. Antecipação, integração e custo no processamento de orações relativas

4. Experimentos com rastreamento do olhar 77

$\begin{array}{ll}\text { 4.1. O rastreamento ocular na pesquisa cognitiva } & 77\end{array}$

4.1.1. Parâmetros para o rastreamento ocular: sacadas e fixações 77

4.1.2. Movimentos oculares e cognição 80

4.2. EXPERIMENTO 1

4.2.1. Método 91

4.2.2. Resultados 98

4.2.3. Discussão 102

4.3. EXPERIMENTO 2

$\begin{array}{ll}\text { 4.3.1. Método } & 106\end{array}$

$\begin{array}{ll}\text { 4.3.2. Resultados } & 108\end{array}$

4.3.3. Discussão 112

4.4. EXPERIMENTO $3 \quad 116$

4.4.1. Método 119 
4.4.2. Resultados 123

4.4.3. Discussão 130

5. Uma proposta para a compreensão de relativas 134

5.1. Acesso a informação não estrutural no curso do processamento sintático 135

5.2. Processos interpretativos no curso do processamento sintático 140

5.3. Mapeamento de referentes no curso do processamento sintático 147

5.4. Circunstancialidade da emergência de processos antecipatórios no curso do processamento

6. Considerações Finais

7. Referências bibliográficas

Apêndice A: Estímulos experimentais dos experimentos 1 e 2

Apêndice B: Estímulos experimentais do experimento 3 


\section{Introdução}

As orações relativas constituíram um dos principais objetos de investigação da Psicolinguística ao longo de sua história. Por sua natureza estrutural complexa, que resulta de uma configuração de dependência descontínua, este tipo de oração tem sido foco de pesquisas que investigam aspectos diversos do processo de compreensão da linguagem. Resultados comportamentais obtidos a partir da compreensão desse tipo de estrutura têm sido utilizados como forma de ratificar ou refutar modelos de processamento.

Este trabalho integra esse campo de discussão investigando a antecipação de referentes e o processo de integração de informação contextual na compreensão de relativas restritivas com vistas a averiguar em que medida resultados que sugerem o mapeamento imediato de um DP complexo contendo uma relativa em um referente seriam compatíveis com um modelo de processamento em que se assume a autonomia do processador sintático $^{1}$, tal como um modelo de computação on-line que integre aspectos da Teoria Gerativa em sua vertente minimalista (Chomsky 1995, 1999). Este trabalho faz parte de uma linha de investigação em desenvolvimento no Laboratório de Psicolinguística e Aquisição da Linguagem (LAPAL - PUC/RJ) que busca conciliar processador e gramática, abordando questões de natureza teórica, como as relativas ao custo de processamento, e aplicada, como as relativas aos déficits de linguagem.

A evolução das técnicas de pesquisa com a crescente acessibilidade de tecnologias como as de rastreamento ocular e mapeamento cerebral tem permitido um monitoramento preciso do processamento on-line de sentenças. Com isso, tem sido possível detectar efeitos da influência de informações discursivas e contextuais em momentos iniciais do processamento de sentenças, assim como efeitos de antecipação do mapeamento de uma expressão linguística em um referente (Hagoort e Berkum, 2007; Altmann e Kamide, 1999). Resultados dessa

\footnotetext{
${ }^{1}$ Entende-se, por um processador autônomo ou modular, um mecanismo de análise sintática que conduz suas operações independentemente de informação não estrutural, como, por exemplo, de natureza semântica ou discursiva (Cf. seção 3.1).
} 
natureza têm sido, em geral, interpretados sob a ótica de uma tradição que busca defender um processamento sintático não especializado (Marslen-Wilson e Tyler, 1991). Neste trabalho, buscamos verificar em que medida um parser autônomo pode ser compatível com evidências dessa natureza, caso incorpore algum mecanismo que permita a integração de informações sintáticas a informações não estruturais durante momentos intermediários do processamento de um enunciado linguístico.

No âmbito da Teoria Linguística, vem sendo apontado que, durante o curso de uma derivação sintática, informações analisadas e linearizadas pela sintaxe seriam enviadas do sistema computacional em direção às interfaces com os sistemas de desempenho (Chomsky, 1998; Uriagereka; 1999), nomeadamente a interface com os sistemas conceituais-intencionais (Forma Lógica, FL) ${ }^{2}$ e com os sistemas sensório-motores (Forma Fonética, FF). Esse conceito de fases sintáticas (Chomsky, 1998), caso integrado a um modelo de processamento on-line, pode possibilitar que um processador sintático modular seja compatível com o acesso à informação extrassintática, durante estágios intermediários do parsing. O presente trabalho procura fazer essa articulação a partir da proposta de Corrêa e Augusto (2006, 2007), que concilia modelos de competência e de desempenho, adaptando os passos de uma derivação minimalista a um Modelo Integrado da Computação Online (Doravante, MINC).

Busca-se analisar, especificamente, como este modelo pode vir a dar conta do parsing de orações relativas restritivas. Já foi relatado que a compreensão deste tipo estrutura, normalmente associada a um alto custo de processamento (Wanner e Maratsos, 1978; King e Just, 1991; King e Kutas, 1995; Gibson et al., 2005), pode ser facilitada por contextos discursivos específicos (Grodner, Gibson e Watson, 2005; van Berkum, Brown e Hagoort, 1999). Há também relatos de que, em relativas de objeto, propriedades semânticas como animacidade (Mak, Vonk e Schriefers, 2002, 2006; Traxler, Morris e Seely, 2002), e discursivas, como o grau de acessibilidade discursiva (Warren e Gibson, 2005) do DP-sujeito da relativa podem ser refletidas no custo de processamento.

\footnotetext{
${ }^{2}$ Note-se que, a partir da concepção de fases, a ideia de LF como uma representação interna veio a ser questionada: "...the final internal level LF is eliminated, if at various stages of computation there are Transfer operations: one hands the SO already constructed to the phonological component, which maps it to the SM interface ("Spell-Out"); the other hands SO to the semantic component, which maps it to the C-I interface..." (Chomsky, 2005).
} 
Diante disso, as relativas podem fornecer alguns insights sobre a integração incremental de informações extrassintáticas à medida que o parsing transcorre. Ainda que o conceito de fase, tal como apresentado por Chomsky, esteja vinculado a CP e vP, algumas propostas preliminares no âmbito da Teoria Linguística (Sevenonius, 2004; Carnie e Barrs, 2006) têm assinalado que DPs poderiam ser vistos como fases sintáticas. Uma das possibilidades que pretendemos investigar é a de que o acesso a informação extrassintática relativa a DPs no curso do parsing possa ser compreendido a partir da proposta de um modelo integrado no qual DPs possam ser considerados como uma unidade de processamento similar a uma fase em modelos de competência, de forma que possam estar acessíveis aos sistemas de interface tão logo recebam algum tipo de estruturação sintática.

Em resumo, este trabalho tem os seguintes objetivos. Em primeiro lugar, o de verificar em que medida um modelo integrado, que explicite formalmente a maneira pela qual o conhecimento gramatical é utilizado no processamento, tal qual o MINC, pode ser capaz de descrever a compreensão on-line de orações relativas restritivas de objeto, conforme já sugerido em Corrêa, Augusto, Longchamps e Forster (2012). Pretende-se investigar como uma proposta dessa natureza poderia ser compatibilizada com efeitos de integração de informação extrassintática e efeitos de antecipação durante a análise do parser. Outro objetivo, ainda, é o de estabelecer um contraste entre propostas de processamento sintático autônomo e de processamento interativo, no sentido de explicitar as vantagens e desvantagens de cada tipo de modelo na arquitetura da mente humana e, diante de argumentos que apontem para a vantagem de um processador autônomo, considera-se em que medida as vantagens de modelos interativos no que concerne a processos antecipatórios, podem ser incorporadas por aquele. Nesse percurso, pretendemos delinear as previsões de algumas abordagens para o processamento de orações relativas, tratando de questões como as que dizem respeito à integração incremental de informação contextual discursiva e visual. Acolhendo a proposta subjacente ao MINC, de que é possível conciliar princípios da abordagem minimalista com um modelo de compreensão, nossa hipótese de trabalho é a de que a noção de fases, e, em especial, a ideia de que o DP seria uma fase, pode ser assumida como uma ferramenta capaz de compatibilizar um 
processador sintático autônomo com as evidências de acesso a informações extrassintáticas em estágios intermediários do processamento.

Considerando que uma das questões imperativas na articulação do conceito de fases com um modelo de processamento reside em detectar, precisamente, em quais momentos poderia haver envio de informação para as interfaces (em outros termos, quais seriam os agrupamentos sintagmáticos passíveis de serem integrados a informação não estrutural no fluxo da análise de uma oração), foram realizados dois experimentos de rastreamento ocular, que visaram a investigar em que medida poderia haver acesso a informação discursiva e contextual durante o processamento on-line de sentenças contendo orações relativas de objeto e em que medida esse acesso poderia possibilitar o mapeamento antecipado de DPs em referentes antes do fechamento da oração em análise. Nesses experimentos, sentenças contendo orações relativas restritivas de objeto, como "O garoto [que o cacique puxou _ _ vai passear de navio", foram oralmente apresentadas frente a informações contextuais visuais que permitiriam desambiguizar a referência em diferentes segmentos da relativa, com o objetivo de averiguar se informação contextual poderia ser utilizada durante o processamento on-line da relativa e, em caso positivo, precisamente em que momento poderia haver essa integração. Considerou-se que o mapeamento antecipado do DP complexo contendo a relativa restritiva em um referente apresentado visualmente, realizado com base em informação potencialmente distintiva do DP encaixado (eg. cacique), mesmo antes da disponibilidade de informação essencial para o preenchimento do gap da relativa (ie. a informação relativa ao verbo), poderia ser uma evidência a favor da hipótese de que DPs poderiam ser assumidos como unidades de processamento. Nesse contexto, entende-se antecipação como a capacidade do processador de predizer propriedades de elementos linguísticos subsequentes com base em informação corrente ou, em outros termos, a capacidade do processador de construir uma representação hipotética da forma futura de uma representação com base em informação corrente. Com base nesse processo, pode se tornar possível o mapeamento antecipado de um referente, entendido aqui como a busca por um referente para um DP no contexto de enunciação (no caso, um estímulo visual) a partir da interpretação de traços formais de defininitude, pessoa e gênero, por exemplo, mesmo antes, mesmo antes que toda a informação linguística relevante para a individuação desse referente esteja disponível. Considera-se que tal 
mapeamento poderia ser observado pelo direcionamento da atenção visual a esse estímulo visual, fenômeno potencialmente relacionado ao direcionamento do olhar.

Em um terceiro experimento de rastreamento ocular, investigou-se a natureza de uma possível influência de informação não estrutural na resolução da ambiguidade temporária entre completivas e relativas restritivas com o objetivo de verificar se informação contextual diretiva poderia influenciar a análise inicial do processador sintático. Foram contrastadas relativas ("Um marujo falou [pra garota que o pirata puxou__[duas mentiras]") e completivas ("Um marujo falou [pra garota][que o pirata puxou quatro barris]"), ambíguas até a altura do último DP, apresentadas em prosódia natural diante de informação contextual potencialmente favorável a uma leitura restritiva (ie. contextos com dois referentes possíveis). Nessa conjuntura, hipóteses que defendem o uso imediato de informação contextual poderiam prever a emergência de um comportamento indicativo de uma leitura restritiva, favorecido por informação contextual, em ambos os tipos de sentença testados (Altmann e Steedman, 1988; van Berkum, Hagoort e Brown, 2000). Por outro lado, a hipótese de processamento em dois estágios poderia prever um comportamento diferenciado para os dois tipos de estrutura, favorecido pela possível incorporação prioritária de informação de mais baixo nível, acústica de natureza prosódica, com possíveis evidências de uma leitura restritiva, no caso das relativas, e de uma leitura não restritiva no caso das completivas (Fodor, 2002a, 2002b). Além disso, hipóteses de processamento autônomo poderiam também prever um comportamento indicativo do uso de princípios estruturais de resolução de ambiguidade (Christianson et al., 2001; Ferreira et al., 2001). Por meio desse experimento, buscou-se analisar a natureza do processo de integração de informação não estrutural no curso da análise sintática. Com base nos resultados, pretende-se apresentar uma proposta que seja capaz de conciliar os princípios de atuação de um processador autônomo com possíveis evidências de integração de informação extrassintática no curso da análise estrutural de relativas restritivas de objeto.

No capítulo a seguir, apresentamos nossos pressupostos teóricos, descrevendo, em especial, o Modelo Integrado da Computação Online, a partir do qual pretendemos esboçar a proposta de um mecanismo para o parsing de orações relativas. No capítulo 3, apresentamos evidências e propostas que, por um lado, 
defendem a prioridade de informações sintáticas e, por outro lado, sugerem a interatividade na condução do processo de análise sintática. São tratadas também questões relativas ao estabelecimento de relações do tipo filler-gap, além de questões que dizem respeito ao custo de processamento e à integração de informação contextual no processamento de orações relativas. No capítulo seguinte, são apresentados os experimentos que investigaram o processamento de orações relativas restritivas de objeto. No capítulo 5 , com base nos resultados obtidos, argumenta-se a favor de uma proposta autônoma para a compreensão de relativas, considerando como o pressuposto da autonomia do processador sintático poderia conciliado com a ocorrência de processos integrativos e preditivos incrementais. Por fim, são apresentadas as considerações finais desse trabalho. 


\section{2 \\ Pressupostos Teóricos}

Desenvolvimentos recentes no âmbito da Teoria Linguística vêm possibilitando que se cogite certa aproximação entre a Psicolinguística e a teoria sintática, permitindo que se abordem questões relativas ao processamento à luz do modelo de conhecimento linguístico. Aproximações nesse sentido já haviam sido feitas no contexto dos primeiros modelos da Teoria Gerativa (Chomsky, 1957, 1965), como foi o caso da Teoria da Complexidade Derivacional (Cf. Fodor, Bever e Garrett, 1974). Contudo, a ideia central dessa proposta, a de que o custo de processamento refletiria o número de transformações requeridas para gerar uma determinada estrutura de superfície a partir de uma estrutura profunda, mostrou-se incompatível com evidências experimentais (Fodor, Bever e Garrett, 1974). No início da década de 1980, uma nova reaproximação entre os dois campos foi assinalada pela Teoria da Regência e Ligação (Chomsky, 1981), a partir da qual a ideia de regras derivacionais específicas para cada tipo de estrutura cede lugar a uma nova arquitetura de gramática. A concepção de movimento é um exemplo dessa mudança: passa-se a conceber a existência de elementos movidos de uma posição canônica e relacionados a uma representação da posição original do constituinte deslocado, de forma que, no processamento, a tarefa do ouvinte passa a ser relacionar o elemento movido a seu vestígio e não mais aplicar regras a uma estrutura de superfície para recuperar uma estrutura profunda (Cf. Ferreira, 2005). Mais recentemente, o minimalismo (Chomsky, 1995), ao postular que a arquitetura do conhecimento linguístico internalizado obedece a restrições impostas pelos sistemas de interface, avançou na possibilidade de conciliação entre modelos de competência e de desempenho ${ }^{3}$. Em função dessa nova perspectiva, algumas propostas no âmbito da psicolinguística vêm explorando a concepção minimalista de língua e também algumas das

\footnotetext{
${ }^{3}$ Para um panorama da evolução das relações entre propostas teóricas relacionadas à competência e relacionadas ao desempenho, veja-se Altmann (2006), Corrêa (2008) e Kess (1992).
} 
propriedades da computação linguística concebida nessa perspectiva (Fong, 2005; Weinberg, 1999; Phillips, 1996; 2003).

Características comuns às várias versões do modelo minimalista, tais como sua engenharia de natureza derivacional e as condições de economia e localidade (manifestas em princípios como o last resort e greed) ${ }^{4}$ oferecem possibilidades que poderiam ser exploradas para conceber algoritmos de um parser minimalista (Weinberg, 1999). Incursões nessa direção sugeriram, por exemplo, que preferências na resolução de ambiguidades poderiam ser relacionadas a condições de economia de natureza gramatical (Phillips, 1996) e que a adaptação do mecanismo de concordância por meio da relação sonda-alvo a procedimentos de parsing poderia explicar preferências detectadas no processamento de relativas em línguas SOV (Fong, 2005). Mesmo numa perspectiva conexionista ${ }^{5}$, argumentouse que dificuldades de processamento poderiam ser previstas pela simulação de um parser minimalista (Gerth e Graben, 2009).

Embora o arcabouço minimalista possa facilitar a aproximação entre a teoria linguística e modelos de processamento, algumas críticas foram endereçadas à possibilidade de reconciliação entre a teoria linguística e propostas para a compreensão online de sentenças. Uma das mais contundentes diz respeito à direcionalidade da derivação minimalista, que têm início a partir do elemento estrutural mais baixo de uma árvore, ou seja, procede da direita para a esquerda, o que contraria o sentido natural do fluxo da fala (Ferreira, 2005; Fong, 2005; Phillips, 1996; Cf. Corrêa, 2008 para a apresentação do problema numa perspectiva conciliatória). Outros entraves a esta aproximação estariam relacionados ao mecanismo de spell-out, que restringiria a possibilidade de reanálise por remover elementos necessários à reestruturação de uma sentença durante o curso de uma derivação e também à metodologia de obtenção de dados geralmente empregada no âmbito das propostas de base gerativa, essencialmente restrita a intuições linguísticas e julgamentos de gramaticalidade (Ferreira, 2005).

Neste trabalho, consideramos a articulação entre teoria linguística e processamento a partir da perspectiva oferecida pela proposta do Modelo

\footnotetext{
${ }^{4}$ Weinberg (1999) apresenta para esses princípios as seguintes definições. Last Resort: Operações não se aplicam a não ser que sejam requeridas para satisfazer uma restrição. Um número mínimo de operações é aplicado para satisfazer uma restrição. Greed: Uma operação não pode ser aplicada para permitir a satisfação das propriedades de outro elemento. Beneficiar outros elementos não é permitido (tradução livre).

${ }^{5}$ Para uma descrição da proposta conexionista, veja-se a seção 3.2.2.
} 
Integrado da Computação Online (Corrêa e Augusto, 2006, 2007), que busca adaptar o modelo de conhecimento linguístico proposto no âmbito do minimalismo a procedimentos de parsing e formulação sintática (codificação gramatical; cf. Levelt, 1999), levando em conta aspectos como a direcionalidade da computação online e fatores relativos a custo de processamento, além de incorporar desenvolvimentos no sentido de alinhar a incrementalidade do processamento em tempo real à noção de múltiplos spell-outs (Augusto, Corrêa e Forster, 2012; Uriagereka; 1999; Cf. seção 5.1).

Neste capítulo, em primeiro lugar, apresentamos em linhas gerais a proposta minimalista, particularmente no que diz respeito ao conceito de língua e a caracterização dos traços formais. Em seguida, apresentamos as propostas do MINC com base em Corrêa e Augusto (2006, 2007). Nesse percurso, buscaremos explorar algumas propriedades desse modelo que podem possibilitar a formulação de um procedimento de parsing para as relativas no PB, a ser apresentado no capítulo 5 .

No programa minimalista (PM), Chomsky $(1995,2007)$ passa a considerar o papel das interfaces da língua (FF e FL) com os chamados sistemas de desempenho na arquitetura das línguas humanas. O PM adota a hipótese de que a língua teria um design ótimo em relação às interfaces com os sistemas articulatório-perceptual e conceitual-intencional. O sistema computacional que atua sobre os itens do léxico na computação/derivação de uma expressão linguística é entendido, no contexto do programa minimalista, como faculdade de linguagem em sentido estrito (Hauser, Chomsky e Fitch, 2002). Esse é definido como um conjunto de operações formais universais, ao passo que os itens lexicais são caracterizados como matrizes de traços de natureza semântica, fonológica ou formal.

Os traços formais dizem respeito às propriedades gramaticais dos itens lexicais e o sistema computacional atuará em função destes últimos. Traços formais podem ser interpretáveis (no sentido de que podem ser lidos nas interfaces) ou não interpretáveis (i.e., traços que são apenas instrumentais à condução da computação sintática). Os traços formais codificam as distinções gramaticais relevantes para as línguas humanas em geral e para línguas em particular. Na medida em que o sistema computacional é assumido como sendo de caráter universal, os traços formais seriam responsáveis pela variedade das línguas 
no que se refere a aspectos gramaticais. A importância desses traços no modelo minimalista reside no fato de que serão os elementos que orientarão a condução das operações do sistema computacional. O sistema computacional atua, assim, com base exclusivamente em informação de natureza formal, de modo que o PM mantém o pressuposto da autonomia da sintaxe.

O ponto de partida para a operação do sistema computacional é um arranjo inicial de elementos do léxico ou Numeração. Do ponto de vista de um sistema formal, este arranjo é constituído aleatoriamente. O sistema computacional opera sobre os itens da Numeração por meio de quatro operações: Select, que seleciona os itens da Numeração a serem computados; Merge, que concatena itens em função de suas propriedades gramaticais, Agree; que estabelece o pareamento entre traços formais interpretáveis e não interpretáveis da mesma natureza, com a valoração destes (Chomsky, 1999) e Move (ou Merge interno), que desloca constituintes posicionados em uma estrutura sintática para posição correspondente a sua disposição linear. Uma vez montada uma estrutura sintática, derivacionalmente, os elementos terminais da mesma passam pelo chamado spellout, que consiste no envio de representações resultantes da atuação do sistema computacional às interfaces (FL e FF).

As representações enviadas a FL e FF estão sujeitas ao chamado Princípio da Interpretabilidade Plena (PIP), o qual determina que apenas traços legíveis nas interfaces podem ser enviados a FF e FL. Em função do PIP, os traços formais não interpretáveis, uma vez utilizados na computação, serão eliminados (Chomsky, 1995; ou valorados, Cf. Chomsky, 1999), garantindo, desse modo, que as expressões linguísticas geradas sejam compatíveis com o aparato processador humano.

O Princípio da Interpretabilidade Plena (PIP) é um dos aspectos do minimalismo que pode ser assumido como um ponto de articulação possível com modelos de processamento. Em termos de um modelo psicolinguístico, o PIP poderia ser traduzido pela necessidade de que todas as informações necessárias para o parsing estejam na sequência de itens lexicais apresentados como input, e de que a Numeração inicial seja constituída em função de uma intenção de fala e mensagem (entendida como sendo de natureza proposicional). Outro aspecto do minimalismo que facilita que se tome uma derivação sintática como referência para um modelo de computação em tempo real reside no fato de Merge combinar, 
incrementalmente, dois elementos de cada vez e no fato de a Numeração poder ser constituída por subarranjos ${ }^{6}$.

Partindo de convergências dessa natureza, Corrêa e Augusto (2006; 2007) propõem o Modelo Integrado da Computação Online, sugerindo uma aproximação entre o processador e a gramática, entendida num sentido minimalista. Nesse modelo, os passos de uma computação conduzida em tempo real são concebidos independentemente das condições de produção e de compreensão, sendo, contudo, adaptáveis às condições específicas de cada tipo de processamento ${ }^{7}$.

No caso da produção de enunciados linguísticos, considera-se no MINC que o arranjo inicial (ou subarranjo) de que parte a computação é resultado do acesso lexical (ao léxico mental) guiado por uma intenção de fala e uma mensagem. Assim sendo, diferentemente da Numeração aleatoriamente constituída quando se concebe uma derivação linguística em termos virtuais (como em um modelo de língua), o equivalente no MINC é motivado. Do ponto de vista da compreensão de enunciados, o passo inicial para a operação do parser resulta da segmentação de elementos do léxico apresentados em sequência (na interface fônica) e percebidos/mantidos na memória de trabalho em chunks (possivelmente unidades sintática/prosódicas). O caráter estritamente bottom-up da derivação linguística vem a ser problematizado no MINC, que assume uma arquitetura mista, parte bottom-up e parte top-down.

Informação de natureza intencional (pertinente à referência) direciona a criação de árvores de cima para baixo, a partir de elementos funcionais C, T e D (recuperados do arranjo inicial) e tomados como projeções máximas CP, TP e DP. A esses esqueletos sintáticos gerados em espaços derivacionais paralelos (um esqueleto que parte de Cmax ou CP, o qual incorpora Tmax ou TP, e esqueletos que partem de Dmax ou DP) são acoplados elementos de categorias lexicais, como Nome, Verbo, etc., que, por sua vez, direcionam a criação de árvores de

\footnotetext{
${ }^{6}$ A proposta, introduzida no minimalismo (Chomsky, 1995), de que o sistema computacional parte de uma Numeração, isto é, de um subconjunto delimitado de elementos do léxico a serem considerados como input para geração de uma sequência é, no que diz respeito ao processamento, particularmente útil à produção, uma vez que, na compreensão, o conjunto de lexicais a serem submetidos ao processamento é delimitado pelo fluxo da fala/leitura.

${ }^{7}$ Diferentemente de outras propostas de base estrutural (Ferreira et al., 2002; Frazier e Fodor, 1978; Gorrell, 1995; Weinberg, 1999), Corrêa e Augusto (2006; 2007) propõem uma caracterização de computação on-line comum à produção e à compreensão, mas que se adapta às condições de cada tipo de processo, em especial, partindo de formas diferentes de conceber o acesso lexical em cada um deles.
} 
maneira bottom-up, em função da estrutura argumental vinculada a esses predicadores.

Um recurso formal utilizado no MINC para dar conta do modo pelo qual uma derivação minimalista poderia ser adaptada a modelos de formulação e parsing é a distinção entre cópias simultâneas e cópias sequenciadas. Aquelas dizem respeito aos movimentos relacionados à fixação dos parâmetros pertinentes à ordem canônica da língua, enquanto estas dizem respeito aos movimentos motivados por demandas discursivas. O primeiro tipo não envolveria custos computacionais, pois, nessas estruturas, o que é descrito como movimento sintático no minimalismo passa a ser entendido como a inserção de cópias simultâneas, isto é, o elemento seria inserido simultaneamente com sua cópia na posição inicial e na de destino. Este é o tipo de cópia que se aplica ao sujeito de uma oração declarativa simples (inserido simultaneamente em Spec-TP e SpecvP), uma construção de ordem canônica. As cópias do segundo tipo acontecem em orações tais como passivas e interrogativas, de ordem não canônica, nas quais são geradas cópias sequenciadas. No caso do parsing de uma interrogativa QU- de objeto, por exemplo, o DP QU- é inserido em CP assim que chega para a análise do parser, no entanto, ele terá de ser reinserido na posição onde será interpretado semanticamente como complemento do verbo. Esta reinserção produziria uma cópia intermediária para ocupar tal posição e, além disso, o DP QU- teria de ser mantido, até a inserção de sua cópia, na memória de trabalho para que pudesse ser novamente ativado para gerar uma cópia a ser inserida na posição de complemento do verbo, o que ocasionaria o custo associado a este tipo de sentença.

Para ilustrar a natureza da arquitetura mista e da distinção entre os tipos de cópias considerados no MINC, recupera-se, a partir de Augusto e Corrêa (2007), o procedimento de análise de uma interrogativa. $\mathrm{Na}$ derivação de uma interrogativa QU- de objeto, por exemplo, a identificação da força ilocucionária da sentença promoveria a derivação top-down de um CP com a previsão de uma posição de especificador (que será preenchida pelo DP QU- identificado no início da sequência) e de um nó TP. O DP QU-, uma vez que não pode ainda ter seus requerimentos temáticos e de caso preenchidos, será mantido ativo na memória de trabalho à espera de um predicador que possa valorá-los (Figura 1). Em seguida, será construído, em um espaço derivacional paralelo, um DP (que futuramente 
será inserido na posição de sujeito da oração), considerando a identificação do núcleo funcional $\mathrm{D}$ e do núcleo lexical $\mathrm{N}$, que serão acoplados em um DP. Uma vez identificado um verbo flexionado, serão ativados os traços de T (a presença de EPP, neste elemento, irá sinalizar a necessidade do preenchimento de Spec-TP, a ser realizado adiante). A construção bottom-up de vP e VP se dará em função do acesso lexical disparado pelo verbo, que permitirá a identificação dos traços formais de $\mathrm{v}$ e $\mathrm{V}$. Uma vez que essa estrutura, relativa ao complexo verbal, for encaixada à árvore gerada a partir de $\mathrm{CP}$, na posição de complemento de $\mathrm{T}$, acontecerá também o acoplamento, a Spec-TP, do DP pleno gerado em espaço derivacional paralelo (o que permitirá a verificação da correspondência entre os traços interpretáveis em $\mathrm{D}$ e os traços não interpretáveis em T), enquanto uma cópia deste será simultaneamente encaixada a Spec-vP. Dados os requerimentos de V, o DP mantido ativo na memória de trabalho será então recuperado, gerando uma cópia intermediária a ser inserida na posição de complemento de V (Figura 2).

Figura 1 - Geração top-down de CP e acoplamento de DP QU- (Fonte: Corrêa e Augusto, 2007)

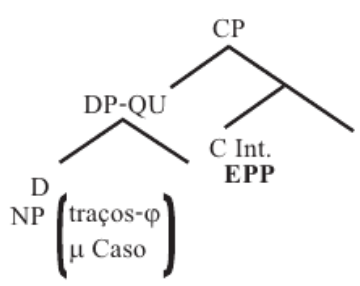

MEMÓRIA

DP-QU

Figura 2 - Acoplamento de cópia sequenciada do DP QU- em V (Fonte: Corrêa e Augusto, 2007)

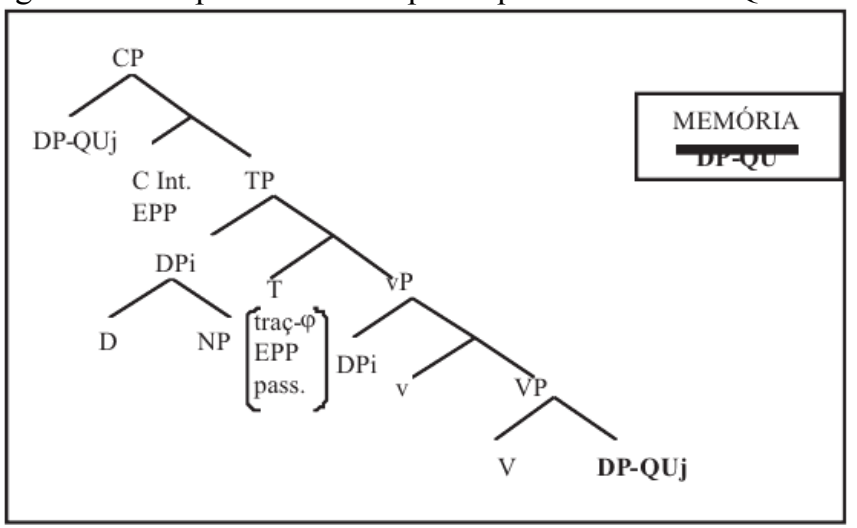

Algumas asserções do modelo apresentado são de particular interesse para a pesquisa proposta aqui. Uma delas é o fato de o MINC oferecer a possibilidade de se distinguirem diferentes medidas de custo computacional, por meio de formas 
distintas de lidar com movimentos sintáticos. Nesse sentido, o maior custo de processamento de orações relativas, quando comparadas com sentenças de ordem canônica, poderia ser capturado pelo custo associado a movimentos deflagrados por demandas discursivas. A diferença de custo entre relativas com foco no de sujeito e relativas com foco no objeto (Wanner e Maratsos, 1978; King e Just, 1991; King e Kutas, 1995), por sua vez, vem sendo acomodada pelo MINC com base no Princípio da Minimalidade Relativizada Estendido ${ }^{8}$ (Friedmann, Belletti e Rizzi, 2010; Cf. Correa \& Augusto, 2011). Esta análise pode ser também compatibilizada com algumas hipóteses que dão conta da assimetria entre relativas de sujeito e de objeto, como a hipótese da similaridade (Gordon, Hendrick e Johnson, 2001, 2004), segundo a qual a similaridade de certos tipos de traços entre o DP relativizado e o DP-sujeito da relativa, em relativas de objeto, provocaria interferências na memória de trabalho, gerando custo de processamento. O caráter preditivo deste MINC, que permite, por exemplo, num procedimento de parsing, antever a ocorrência de um TP a partir da derivação de um CP pode também vir a ser explorado na computação online de orações relativas no que diz respeito, por exemplo, à configuração da relação entre fillers e gaps.

A conciliação na noção de fases (Chomsky, 2005) com o MINC poderá permitir, conforme buscaremos desenvolver no capítulo 5, uma abordagem para fenômenos relativos à antecipação de referentes no curso do processamento de uma sequência. O conceito de fases (Chomsky, 2000; 2005), no âmbito do modelo minimalista, dá conta de que, em certos momentos de uma derivação sintática concebida nessa perspectiva, porções de informação seriam enviadas às interfaces, de forma que o módulo sintático não retivesse a derivação de toda uma oração para depois enviá-la aos sistemas de interface (como assumido nos primeiros modelos minimalistas). A partir dessa noção, é configurado o acesso cíclico ao léxico (organizado em subarranjos) e o envio também cíclico de informação às interfaces. Comumente, dois tipos de camadas sintáticas são tomadas por fases,

\footnotetext{
${ }^{8}$ Segundo o Princípio da Minimalidade Relativizada (Rizzi, 1990), relações sintáticas tenderiam a ser realizadas considerando a relação mais local possível, de forma que elementos intervenientes da mesma natureza de um elemento movido poderiam interferir no estabelecimento de relações entre esse elemento e seu predicador. Friedmann, Belletti e Rizzi (2010) estendem esse princípio com base em resultados obtidos com relativas e interrogativas de objeto em crianças falantes de hebraico. A dificuldade das crianças nessas estruturas com deslocamento do objeto poderia ser entendida como resultante da aplicação do Princípio da Minimalidade Relativizada Estendido, ocasionada pela interferência de um DP pleno entre o verbo e seu objeto deslocado.
} 
sob a motivação de comportarem complexos argumentais completos ou por seu conteúdo proposicional: CP (responsável por receber complementizadores, elementos QU- ou informação a respeito da força ilocucionária) e vP (a camada mais alta do complexo verbal e que guarda informações concernentes a causatividade do verbo, além de traços relacionados à concordância). No momento em que uma derivação sintática atinge um destes dois pontos, a informação analisada seria enviada, por meio de spell-out, para as interfaces, que poderiam, então, operar com base neste material. De acordo com a Condição de Impenetrabilidade das Fases (Chomsky, 2005), uma vez que esta transferência é feita, a informação sintática no interior da fase torna-se opaca e indisponível para operações futuras, a não ser pela borda $(e d g e) d a$ fase, que consiste na posição à extrema esquerda do constituinte movido. Uma consequência da opacidade das fases é a de que um elemento interno a elas, para se mover, deve ser atraído antes de spell-out.

Articular o conceito de fases com um modelo de processamento envolve dois passos. Em primeiro lugar, encontrar evidências comportamentais a respeito de que unidade poderia ser tomada como uma fase em um modelo psicolinguístico e, em segundo, desenvolver um ferramental teórico capaz de acomodar esta noção a um modelo de parsing. No que concerne a este último ponto, um dos problemas que se impõem é o de como pelo menos parte da informação de uma fase já enviada às interfaces poderia ainda se manter disponível para operações futuras, algo fundamental, por exemplo, para a adoção do mecanismo de cópias sequenciadas, já que a inserção da segunda cópia só poderia ocorrer caso a informação relativa ao elemento a ser copiado se mantivesse ainda disponível para a computação. Considerando evidências psicolinguísticas que sugerem o mapeamento incremental de DPs em referentes visuais (Eberhardet al., 1995; Kamide et al., 2003) e propostas recentes, no âmbito da teoria linguística, que têm apontado a possibilidade de que DPs sejam assumidos como fases (Chomsky 2005; Carnie e Barss, 2006; Svenonius 2004) ${ }^{9}$, no que diz respeito ao primeiro

\footnotetext{
${ }^{9}$ Svenonius (2004), com o intuito de banir movimentos de elementos A' para posições A, propõe que DPs poderiam ser entendidos como fases, considerando estruturas de línguas como o tagalog e o islandês, além de uma possível identidade entre projeções oracionais e nominais. Carnie e Barss (2006), por sua vez, sinalizam que a noção de fases, se restrita a vPs e CPs, poderia gerar inadequadamente, em LF, a ininterpretabilidade de certas estruturas. Chomsky (2005), citando o trabalho de Svenonius e também o de Hiraiwa (2005), menciona a possibilidade de que DPs possam ser assumidos como fases, sem, contudo desenvolver a proposta.
} 
passo, avaliaremos, no capítulo 4, a hipótese de que DPs possam ser considerados como fases, testando em que medida o referente visualmente apresentado de um DP complexo contendo uma relativa de objeto pode ser antecipadamente mapeado a partir de informação contextual visual e discursiva que permita a desambiguização da referência antes que informação relativa ao verbo esteja disponível. Em vistas de que menores unidades de processamento encapsulado poderiam permitir o envio mais rápido e mais frequente de informações do parser aos sistemas interpretativos, a possibilidade de que DPs sejam assumidos como fases pode se mostrar promissora para a operacionalização de um modelo psicolinguístico que permita a integração de informação contextual em momentos intermediários da análise sintática. Em relação ao segundo passo, apresentaremos, no capítulo 5, uma proposta de articulação da noção de fases com o modelo proposto por Corrêa e Augusto (2006; 2007), considerando, especificamente, a análise de DPs contendo relativas de objeto.

No capítulo a seguir, será apresentada uma discussão a respeito da arquitetura do parser, com o objetivo de delinear o enquadramento teórico da proposta que iremos adotar. Serão discutidas também algumas evidências que, ora favorecendo propostas de base estrutural que adotam princípios determinísticos de análise, ora favorecendo abordagens de natureza interativa, vêm fomentando a discussão a respeito da natureza do processador linguístico. No que diz respeito, especificamente, ao processamento de relativas, serão abordadas questões relacionadas ao preenchimento do gap e ao custo de processamento nas relativas. 


\section{3}

\section{O processamento sintático e a compreensão de relativas}

Entre a recepção do sinal acústico e a interpretação final de uma sentença, as informações linguísticas são submetidas a uma série de procedimentos de análise. No decorrer desse processo, entram em jogo várias fontes de conhecimento: desde os conhecimentos mais concretos, como os que dizem respeito às propriedades do som da fala, aos mais abstratos, como aqueles de natureza conceitual. Existem, entretanto, controvérsias a respeito da possibilidade de interferência de informação proveniente de níveis mais altos de processamento (como informação de ordem discursiva e semântica) na condução de operações de nível mais baixo (como fonológicas e sintáticas).

No que diz respeito à condução da análise sintática, por um lado, há os que defendem que, nos momentos iniciais da análise de uma sequência, apenas informação de natureza sintática seria considerada. Informação de natureza interpretativa, como informação semântica, discursiva e contextual só seria considerada a partir do momento em que o parser já houvesse estabelecido uma estruturação hierárquica dos itens lexicais. Em geral, esta é a hipótese assumida pelas teorias de base estrutural. Os modelos mais influentes dessa linha podem ser classificados como modelos determinísticos ${ }^{10}$ (Kimball, 1973; Frazier, 1979; 1987; Frazier e Fodor, 1978; Frazier e Rayner, 1982), na medida em que buscam analisar sequências atribuindo, a princípio, somente uma descrição estrutural (independentemente da existência de ambiguidade), tida como a melhor em função de sua possível adequação às limitações de processamento. Grande parte da motivação para a elaboração destes modelos parte do chamado efeito labirinto (garden-path effect), que se dá quando uma sentença possui uma ambiguidade

\footnotetext{
${ }^{10} \mathrm{O}$ termo determinístico parece ser empregado em diferentes sentidos na literatura. Por exemplo, Townsend e Bever (2001) entendem por determinístico o parser que não permite reanálise. Nesse sentido, podem ser englobados modelos como a teoria da descrição (Marcus et al., 1983) e o modelo de comprometimento mínimo (Barton e Berwick, 1985; Weinberg, 1993). Por esse ângulo, o parsing na Teoria do Labirinto, por exemplo, não seria determinístico. Já Pearlmutter e Mendelsohn (1999) e Gibson e Pearlmutter (2000) entendem o termo determinístico no sentido de um parser que opta por uma dentre as opções de estruturação concorrentes em caso de ambiguidade. No presente trabalho, o termo é utilizado nesse último sentido.
} 
temporária que permite duas interpretações estruturais diferentes, como em (1). Nesse exemplo", antes que se perceba o verbo "fugir" no final da sentença, o termo "suspeita" pode ser interpretado tanto como o presente do indicativo do verbo "suspeitar" (ou seja, a "mãe" tem a suspeita de que alguém tenha assassinado seu fillho) ou, então, como particípio do mesmo verbo (isto é, a "mãe" está sob suspeita de ter assassinado seu filho). Entretanto, a forma "foge" desambiguiza a sentença, deixando claro que a única leitura possível seria a participial. Defensores de modelos determinísticos argumentam que, nesses casos, o parser, regido por princípios de economia e simplicidade, optaria por uma dentre as análises possíveis, como no caso de (1), no qual há a tendência de se analisar o item ambíguo como um verbo, devido ao princípio da aposição mínima (Frazier, 1987). Daí o termo determinístico, herdado da teoria dos automata ${ }^{12}$, que faz referência ao fato de o parser buscar determinar uma análise potencialmente definitiva em um momento intermediário da sentença, descartando inicialmente outras opções possíveis. Caso a análise escolhida pelo parser se mostre incompatível com o desenrolar da sentença pela presença de um elemento que impinja uma análise diferente da adotada pelo parser, haveria, então, a necessidade de reanalisar a estrutura.

(1) Mãe suspeita do assassinato do filho foge.

Diferentemente dos modelos determinísticos, há uma linha na qual se defende que o processador ${ }^{13}$ consideraria, desde os momentos iniciais da análise de uma sentença, informações de diferentes tipos, incluindo informação proveniente dos chamados níveis interpretativos, como é o caso, por exemplo, das teorias baseadas em restrições ${ }^{14}$ (MacDonald, Pearlmutter e Seidenberg, 1994; Trueswell e Tanenhaus, 1994; Stevenson, 1994; Spivey e Tanenhaus 1998; Cf.

\footnotetext{
${ }^{11}$ Extraído de Maia (2001).

${ }^{12}$ Cf. MARCUS, 1978. A theory of syntactic recognition for natural language, p. 9-13.

${ }^{13} \mathrm{O}$ termo processador é utilizado neste trabalho, de forma geral, em um sentido amplo, genérico, que diz respeito ao aparato responsável pelo processamento de informação linguística de qualquer natureza. O termo parser, por sua vez, é utilizado em um sentido mais específico e já consolidado na literatura, e, nesses termos, diz respeito ao processamento de informação de natureza sintática. Uma vez que teorias de natureza interativa, comumente, não consideram a existência de um parser, o termo processador será usado nos contextos em que se faz referência a propostas desta natureza, mesmo nos contextos nos quais se discute especificamente a condução do processamento sintático. ${ }^{14}$ Tradução de constrain-based models, seguindo Corrêa (2011). Maia (2001), por sua vez, traduz por modelos de "satisfação de condições".
} 
McRae e Matsuki, 2012). Em abordagens dessa natureza, informações como as que dizem respeito ao contexto discursivo são acessadas para definir as prioridades de interpretação já na análise sintática inicial de uma sentença. Em geral, modelos dessa linha postulam que o processador não se comprometeria em definitivo com nenhuma análise particular. Caso haja mais de uma possibilidade de análise, o processador as manteria em paralelo, ranqueando cada uma delas por meio da atribuição de pesos diferentes, de forma a conduzir as escolhas sintáticas com base na representação mais bem ranqueada.

Em resumo, enquanto modelos determinísticos propõem que a análise sintática inicial de uma sequência aconteceria com base em informação de natureza sintática (que irá ser responsável pela escolha de uma determinada análise, caso haja a possibilidade de a sentença contemplar mais de uma estrutura), modelos de tradição interativa, de forma geral, irão prever que informações de diferentes tipos e níveis são aplicáveis para determinar a análise sintática inicial de uma sentença.

Com o intuito de discutir o processamento autônomo, especialmente, sob a perspectiva de resultados que indicam a integração incremental de informação não estrutural, apresentaremos, neste capítulo, por um lado, algumas evidências que vieram a sugerir a prioridade de informação estrutural na condução da análise sintática, e, por outro lado, alguns resultados que poderiam indicar interferência de informação de natureza conceitual durante o processamento sintático. Enquadramos essas evidências no contexto da discussão entre modelos autônomos e interativos.

Em primeiro lugar, apresentaremos alguns conceitos centrais na concepção de modelos de processamento, conceitos esses que vêm dando origem a hipóteses das quais partem os trabalhos que descreveremos e que permitirão também situar teoricamente a proposta que desenvolveremos. Nesse momento, serão abordados aspectos tais como a incrementalidade, a serialidade e a modularidade do processador.

Na seção seguinte, são apresentadas algumas evidências que motivaram a constituição de abordagens que reivindicam a autonomia do processador sintático, em especial, a proposta da Teoria do Labirinto (Frazier, 1979) e seus desenvolvimentos subsequentes, cujas previsões e pressupostos são 
frequentemente tomados como referência para discussões acerca da possível interatividade do processamento.

$\mathrm{Na}$ seção três, a partir da perspectiva das teorias baseadas em restrições, apresentaremos uma série de evidências que vêm sendo tomadas como indicativas da rápida emergência de processos integrativos e que motivarão o desenvolvimento dos experimentos deste trabalho.

Por fim, a quarta seção irá deter-se na compreensão de orações relativas, com especial atenção a resultados que têm demonstrado o caráter preditivo do processamento de orações dessa natureza. A partir da trajetória desse capítulo, consideraremos algumas hipóteses a respeito do processamento de relativas, que serão investigadas no capítulo 4.

\section{1.}

\section{Aspectos da arquitetura do processador sintático}

Um dos pontos mais controversos na discussão a respeito da arquitetura do processador linguístico está na questão da autonomia. De forma breve, é possível definir as abordagens chamadas de autônomas como aquelas nas quais se defende a existência de um processador sintático dedicado, que, durante certa etapa do processamento, trabalha exclusivamente com informação de natureza estrutural, enquanto as abordagens interativas seriam aquelas em que todas as fontes de informação relevantes poderiam ser utilizadas nos estágios iniciais do processamento. O posicionamento em relação a essa questão está no cerne do debate entre modelos de natureza determinística e modelos baseados em restrições ${ }^{15}$. Enquanto aqueles vêm acumulando resultados sugerindo autonomia do processador sintático, estes buscam contraevidências, em especial, argumentando que certas decisões no curso do processamento sintático seriam determinadas por informações não estruturais.

\footnotetext{
${ }^{15}$ Observe-se, contudo, que teorias baseadas em restrições podem comportar certa forma de modularidade (Cf. Jackendoff, 2002) e que modelos determinísticos podem não estar totalmente comprometidos com pressupostos relacionados à modularidade (Cf. Frazier, 1987).
} 


\subsection{1. Modularidade}

Essa discussão acerca da autonomia do processador está vinculada à questão da modularidade, que se consolidou a partir do trabalho de Fodor (1983). A defesa da modularidade avolumou o corpo de argumentos a favor de um parser autônomo e, desde então, vem orientando a tradição que defende um processamento sintático modular. Assumindo a influência de trabalhos tão diversos quanto o de Franz J. Gall, no século $\mathrm{XIX}^{16}$, e as primeiras formulações da Teoria Gerativa de Chomsky (1965), Fodor (1983) veio a propor a ideia de módulos mentais: sistemas perceptuais autônomos de input, cada qual responsável por um processo psicológico específico. Os sistemas modulares ${ }^{17}$ seriam responsáveis por habilidades pouco complexas, relacionadas à interpretação dos sinais neurais derivados dos estímulos físicos que constituem as informações de entrada (input) para o sistema cognitivo. Um processador central, não modular, seria responsável por integrar informações de diferentes módulos e ficaria a cargo de habilidades cognitivas complexas (como, por exemplo, o raciocínio analógico) ${ }^{18}$.

Fodor (1983) caracteriza o que seria um módulo por uma série de propriedades inter-relacionadas. Como um todo, essas propriedades ressaltam o caráter automático do funcionamento de um processo modular. O encapsulamento informacional seria, para Fodor, a propriedade mais importante de um sistema modular. Por encapsulamento, entende-se que um módulo não está sujeito à interferência direta de módulos de outros domínios ou do sistema cognitivo

\footnotetext{
${ }^{16}$ Franz Joseph Gall (1758-1828) considerava que a mente poderia se compartimentada em diferentes faculdades mentais, cada uma delas passível de ser associada a estruturas neurais específicas. As ideias de Gall deram origem à frenologia, disciplina que se tornou muito popular no século XIX. Entretanto, a tentativa de correlacionar certas habilidades a depressões e elevações da caixa craniana, prática mais característica da frenologia, a levou a cair em descrédito. Apesar disso, o raciocínio central da Gall, o de ver a mente como um agrupamento de diferentes faculdades associáveis a regiões neurais específicas, veio a ser retomado, evidentemente sob uma nova roupagem, no século XX.

${ }^{17}$ A despeito da discussão a respeito modularidade de certos processos cognitivos, parece haver, no caso particular da cognição linguística, certo consenso pelo menos em relação à chamada modularidade representacional, segundo a qual diferentes fontes de conhecimento - como, por exemplo, de ordem fonológica ou sintática - seriam representadas de forma distinta (Cf. Pickering, Clifton e Crocker, 2000). Evidências de que propriedades semânticas, sintáticas e fonológicas podem ser ativadas independentemente em experimentos de priming (Branigan, Pickering, Liversedge, Stewart e Urbach, 1995; Snider e Runner, 2010) poderiam ser entendidos como um argumento em prol da modularidade representacional.

${ }^{18}$ Fodor (1983) faz essa distinção sob os termos faculdades horizontais e faculdades verticais, em referência, consecutivamente, aos processos psicológicos modulares e não modulares.
} 
central. Essa propriedade garante, em grande parte, a rapidez da atuação de um módulo, que, ao lidar exclusivamente com informação de uma dada natureza, economiza recursos cognitivos. Uma segunda propriedade, intimamente relacionada ao encapsulamento, é a especificidade de domínio, que diz respeito aos tipos de informação de entrada que um sistema cognitivo processa. Um sistema modular operaria somente diante de um tipo de estímulo específico, sendo, assim, um mecanismo especializado. Ao mesmo tempo em que as informações do sistema cognitivo central não seriam consideradas durante a operação de um módulo, o sistema cognitivo central também teria, de acordo com Fodor (1983), acesso limitado às operações internas de um módulo. Assim, uma outra propriedade de um sistema modular seria a acessibilidade limitada, que significa que as representações intermediárias de um módulo, geradas antes do output, são inacessíveis à consciência. A língua, ou melhor, certos níveis de análise linguística poderiam ser tomados como exemplo nesse sentido, já que as operações relacionadas aos níveis mais baixos de análise (eg. fonológicas, sintáticas) dificilmente atingem algum nível de consciência.

Fodor (1983) apresenta algumas evidências a partir das quais procura embasar sua hipótese, dentre elas, faz-se referência a estudos nos quais se detectou que, em tarefas de reconhecimento de figuras, os participantes poderiam alcançar escores de 70\% com um tempo de exposição de $125 \mathrm{~ms}$ ou de $96 \%$ em 167 ms. De acordo com Fodor, esta velocidade refletiria algo próximo do limite da transmissão do sinal neural, um indício de que a visão, enquanto sistema modular, reagiria de maneira rápida e automática a estímulos.

Evidências da neuropsicologia também foram tomadas como favoráveis à teoria da modularidade. Nesse sentido, por exemplo, pesquisas que fazem recurso ao mapeamento cerebral sugeriram a lateralização da língua no hemisfério esquerdo (e.g., Binder et al. 1997), o que poderia atestar a especialização neuronal e, por conseguinte, a relativa independência física do sistema. Outra classe de evidências foi provida pelo estudo das afasias (Cf. Grodzinsky, 1990, Forster, 2008 e Villarinho, 2008 para uma revisão), que sugeria que a língua poderia ser seletivamente afetada. Lesões na região do lobo frontal, especificamente na região conhecida como área de Broca (localizada no giro frontal inferior), foram associadas a distúrbios de fala marcadamente sintáticos (Friedmann e Grodzinsky, 1997), enquanto lesões na área de Wernicke (Caramazza e Zurif, 1976), localizada 
no lobo temporal, foram relacionadas a distúrbios marcadamente semânticos. Mais recentemente, contudo, a função de regiões relacionadas a habilidades linguísticas tem se mostrado possivelmente mais abrangente. A área de Broca, por exemplo, vem sendo relacionada a outras habilidades, indo de funções cognitivas mais gerais (como a percepção de ações (Cf. Rizzolatti, Fogassi e Gallese, 2001)), a funções mais refinadas (como movimento sintático (Grodzinsky,1990), o processamento fonológico (Burton, 2001), a memória de trabalho verbal (Caplan et al., 2000), Cf. Grodzinsky e Santi, 2008 e Shalon e Poeppel, 2008, para uma revisão), passando pela sintaxe musical (Maess, Koelsch, Gunter e Friederici, 2001) e pela imitação (Heiser, Iacoboni, Maeda, Marcus e Mazziotta, 2003; Cf. Elsabbagh e Karmiloff-Smith, 2004).

A visão modularista de Fodor se enquadra na linha que veio a ser chamada de modularidade modesta (modest modularity) em função de considerar a existência de processos não modulares. Há também os proponentes da chamada modularidade massiva (massive modularity), segundo os quais todas as faculdades psicológicas poderiam ser vistas como modulares (Pinker, 1997; Samuels, 1998; Sperber, 1994) ${ }^{19}$. Nessa perspectiva, Carruthers (2006) apresenta uma distinção interessante entre encapsulamento em escopo estrito (narrow-scope encapsulation) e encapsulamento em escopo amplo (wide-scope encapsulation). O primeiro diz respeito ao encapsulamento tal qual considerado por Fodor. O sistema modular em escopo estrito não permite qualquer contato de informação de seu domínio com informações de outra natureza durante todo o processamento. $\mathrm{Na}$ proposta de modularidade defendida por Carruthers, os sistemas modulares exibiriam um encapsulamento em escopo amplo, no qual uma porção limitada de informações de outra natureza pode ser considerada durante momentos intermediários do processamento. Para Carruthers, o essencial de um sistema modular não é que ele seja totalmente encapsulado, no sentido defendido por Fodor, mas sim que seja frugal (do termo homófono em inglês), no sentido de que ele seja simples nas suas operações e nas informações que consulta, tendo acesso apenas a pequenas porções de informação. A frugalidade de um sistema modular, para Carruthers (2006), pode ser derivada tanto de um encapsulamento semelhante ao proposto por Fodor ou mesmo por encapsulamento de escopo amplo.

\footnotetext{
${ }^{19}$ Para algumas considerações a respeito da questão da incrementalidade no caso mais particular dos processos relacionados a produção de sentenças, veja-se Ferreira (2000).
} 
Além das propostas que advogam uma reformulação do conceito de modularidade, há também aquelas que se opõe completamente a esta noção. Prinz (2006), por exemplo, argumenta contra a modularidade recorrendo a fenômenos já difundidos na literatura, tais como a reconstrução fonológica e o efeito MacGurk ${ }^{20}$, além de relativizar supostas evidências em favor da modularidade, como no caso da ilusão das setas de Müller-Lyer ${ }^{21}$. Na visão de Prinz (2006), poderia haver uma vantagem de informações perceptuais, quando há conflito entre crença e percepção, mas isso não significaria que crenças não pudessem influenciar a percepção. No domínio do processamento de sentenças, um dos argumentos em desfavor à teoria da modularidade adveio de resultados que sugeriam o rápido mapeamento de sentença no modelo de discurso corrente (Marslen-Wilson e Tyler, 1991, dentre outros; Cf. seção 3.2).

Argumentos contrários à teoria da modularidade, entretanto, também se mostraram sujeitos a interpretações alternativas. O efeito McGurk já foi também considerado como uma evidência de uma percepção fonética encapsulada. Nesse sentido, argumentou-se que a percepção fonética não seria especificamente motora ou visual (Liberman e Mattingly, 1985), mas que o módulo responsável por esse processamento seria independente de modalidade. De acordo com essa perspectiva, a relação necessária entre gestos e articulação fonética seria levada em conta por um módulo dedicado ao processamento de informação fonética, de forma que a informação visual fosse também considerada como um tipo de informação específica a esse módulo. Quanto à reconstrução fonológica, foi proposto que um procedimento de análise pela síntese (Halle e Stevens, 1963) poderia dar conta desse fenômeno sem a necessidade de acesso a informações de níveis superiores. Durante a percepção da fala, a representação da sequência em análise seria usada para gerar comandos motores como se fossem destinados à

\footnotetext{
${ }^{20}$ O efeito MacGurk (MacGurk e McDonald, 1976) consiste em uma ilusão perceptual que demonstraria a integração entre informações de natureza visual e informações de natureza linguística. $\mathrm{Na}$ visão dos oponentes da teoria da modularidade, essa ilusão denunciaria a ausência de encapsulamento informacional, ao menos no que diz respeito à percepção fonológica.

${ }^{21}$ A ilusão das setas de Müller-Lyer (Cf. Fodor, 1983) resulta da percepção enganosa de que duas setas têm tamanhos diferentes quando na verdade ambas têm o mesmo comprimento. De acordo com Fodor, isso poderia ser um indício de encapsulamento, na medida em que a ilusão persiste mesmo depois de se adquirir a consciência de que ambas as setas teriam a mesma extensão. Há reportes de que esta ilusão poderia estar sujeita a variações socioculturais. Certas populações do deserto do Kalahari, por exemplo, parecem ser completamente imunes a essa ilusão (McCauley e Henrich, 2006). Entretanto, além das setas de Müller-Lyer, há outros fenômenos visuais que parecem permanentes, como a ilusão da face côncava (hollow-face illusion), no qual se percebe como convexa uma mascara côncava (Bruce, Green e Georgeson, 2003).
} 
articulação. A articulação seria inibida, mas a representação dos comandos motores seria sintetizada com a representação de entrada. Nesse processo, possíveis lacunas derivadas da percepção do sinal acústico poderiam ser recuperadas antes que a representação de saída fosse gerada (Halle e Stevens, 1963; Bever e Poeppel, 2010). Da mesma maneira, as evidências a respeito da integração de informação contextual podem estar sujeitas a interpretações alternativas, conforme buscaremos defender.

Assumindo o processamento modular como hipótese de trabalho, a presente pesquisa tem, dentre seus objetivos, o de prover evidências experimentais complementares para a sustentação dessa concepção de processamento. Assumimos, ainda, dois argumentos centrais para a defesa de uma abordagem modular para a cognição linguística.

Em primeiro lugar, tem-se o argumento da computational tractability ${ }^{22}$, relacionado ao argumento da pobreza de estímulo concebido numa perspectiva gerativista de aquisição da linguagem (Chomsky, 1965) e também ao chamado problema da explosão combinatória (combinatorial explosion). Esse argumento diz respeito ao fato de que as inferências possíveis a partir do input de dados de natureza linguística poderiam ser potencialmente ilimitadas caso os sistemas de análise não fossem restringidos em sua arquitetura (Barrett e Kurzban, 2006). Mecanismos especializados de processamento, restringindo o conjunto de informação analisada, por sua vez, poderiam limitar consideravelmente os recursos computacionais e o tempo necessários para gerar uma determinada representação, e, em função disso, de um ponto de vista evolutivo, poderiam até mesmo ser favorecidos pelo processo de seleção natural (Newcombe, Ratliff, Shallcross e Twyman, 2009). De forma semelhante, a existência de operações universais disparadas por propriedades formais de representações linguísticas, conforme postulado em uma concepção minimalista de língua, e, além disso, uma concepção hierárquica e ascendente de processamento, parecem constituir-se como as formas mais viáveis de conceber a possibilidade de que estímulos linguísticos derivem representações compartilhadas entre falantes, diante das multiplicidade de informações que poderiam interferir em um processamento não

\footnotetext{
${ }^{22} \mathrm{Na}$ ausência de uma tradução adequada, é usado aqui o termo original em inglês.
} 
direcionado, de forma a gerar representações semânticas idiossincráticas a partir de um mesmo sinal acústico.

Um segundo argumento, de natureza epistemológica, em favor dessa proposta reside em seu valor enquanto uma hipótese científica. Fodor (2000) observa que quanto mais holística a natureza de um processo cognitivo, mais difícil será estudá-la. Processos não computacionais não se sujeitam a uma modelagem precisa e dificultam também a investigação neurocientífica, na medida em que são pouco localizáveis. Por motivos como esses, Fodor (1983) afirma que, provavelmente, os limites da Teoria da Modularidade serão também os limites da nossa compreensão a respeito dos processos cognitivos. McClamrock (2003) ressalta ainda que metodologia de "dividir e conquistar" subjacente à Teoria da Modularidade é uma esperança de que venhamos aos poucos a compreender funções cognitivas complexas. Assim, tomar como hipótese o tratamento modular e computacional de certos processos cognitivos parece ser uma das perspectivas mais promissoras para o desenvolvimento da ciência cognitiva.

\subsection{2. \\ Incrementalidade}

Enquanto a autonomia do parser motiva ainda um intenso debate, a questão da incrementalidade na arquitetura do processador é, em certo sentido, menos controversa. Em sentido estrito, incremental seria um processador que analisa os itens lexicais de uma sentença assim que os recebe, o que quer dizer que os itens de uma sequência não são armazenados isoladamente para que sejam estruturados apenas ao final de uma oração (Cf. Gorrell, 1999) ${ }^{23}$. Entendida dessa forma, a incrementalidade parece ser uma propriedade comum a modelos de processamento de diferentes tradições, a ponto de poder ser assumida, conforme defendem Pickering, Clifton Jr. e Crocker (2000), como uma restrição a mecanismos e arquiteturas da compreensão da linguagem. Uma evidência elementar de processamento incremental na compreensão da linguagem é, por

\footnotetext{
${ }^{23}$ Além de uma definição operacional de incrementalidade, Gorrel (1999) ressalta ainda a importância desta propriedade para a economia de recursos no processamento: "we structure the words as they are perceived rather than store them as a list that is later combined when there is a pause in the input. Incremental structuring has the clear benefit of keeping short-term memory burdens to a minimum" (Gorrell, 1999, p. 748).
} 
exemplo, o fenômeno do garden-path, que pode sugerir a integração sintática incremental de um item lexical. Diante de uma ambiguidade temporária, a análise incremental de um elemento ambíguo poderia conduzir o falante ao caminho do labirinto $^{24}$, o que, em uma análise não incremental, poderia ser evitado, uma vez que estruturação do elemento ambíguo pudesse aguardar a análise do elemento desambiguizador.

O sentido estrito de incrementalidade, contudo, circula ao lado de definições um tanto diversas:

Psychological theories of natural language processing have usually assumed that the sentence processor resolves local syntactic ambiguities by selecting a single analysis on the basis of structural criteria such as Frazier's (1978) "minimal attachment" [...] An alternative hypothesis exists, however: If sentences are understood incrementally, more or less word-by-word $[\ldots]$, then syntactic processing can in principle exploit the fact that interpretations are available, using them "interactively" to select among alternative syntactic analyses on the basis of their plausibility with respect to the context. (Altmann e Steedman, 1988, p. 191)

Implícita nesse trecho de Altmann e Steedman (1988) está uma ideia de incrementalidade que engloba não só quando o input é processado, mas também a natureza da informação utilizada na análise. O processamento incremental, neste contexto, está associado ao uso de informações semânticas e contextuais na análise sintática inicial, uma concepção que se apoia, como veremos na próxima seção, em evidências como as que sugerem, por exemplo, que informação discursiva poderia influenciar a análise inicial de segmentos que contêm ambiguidades temporárias. Esta é uma das questões que contornam a discussão entre modelos de natureza determinística e modelos interativos. Em ambos os casos, tem-se um processamento incremental, mas os modelos interativos permitirão que informação de nível superior seja considerada desde os primeiros instantes do processamento.

Neste trabalho, embora o uso de informação extraestrutural para a condução do processamento sintático inicial venha a ser problematizado, assumiremos, com base em evidências experimentais (Cf. seção 3.2), que os itens lexicais são incrementalmente estruturados com base em informação sintática. Além dessa análise rápida do input, buscaremos também avaliar em que medida o output do

\footnotetext{
${ }^{24}$ A chegada a um "labirinto", contudo, só poderá alcançar a consciência de um falante caso o mecanismo de análise incremental gere uma representação que venha a se mostrar incompatível com o input.
} 
processador sintático poderia ser considerado incremental. A esse respeito, é necessário diferenciar ao menos duas formas de incrementalidade, que, tomando por empréstimo os termos de Hildebrandt, Eikmeyer, Rickheit e Weiß (1999 apud Guhe, 2007), podem ser chamadas de massiva e moderada. A primeira noção aplica-se a um processador que não só analisa um input imediatamente, mas também produz outputs assim que possível, em contraste com a segunda, na qual as representações intermediárias são armazenadas durante algum período. Essa distinção também pode ser capturada pelo princípio de Wundt, proposto por Levelt (1989), e por sua versão estendida, formulada por Guhe (2007):

\section{Princípio de Wundt ${ }^{25}$ :}

Each processing component will be triggered into activity by a minimal amount of its characteristic input. (Levelt, 1989, p. 26)

\section{Princípio de Wundt estendido:}

Each processing component will be triggered into activity by a minimal amount of its characteristic input and produces characteristic output as soon as minimal amount of output is available. (Guhe, 2007, p. 70)

Resultados como os de Kamide, Altmann e Haywood (2003), por exemplo, parecem favorecer a hipótese de que a compreensão seria massivamente incremental. Neste estudo, estímulos auditivos, como "The man will ride the motorbike" registraram, no segmento relacionado ao verbo principal (ie., "ride"), mais olhares em direção àquelas ilustrações relacionadas às restrições selecionais do verbo e também mais frequentemente associadas ao tipo de agente apresentado (como, p. ex., a figura de uma moto) do que em direção a ilustrações não relacionadas ou ao verbo (p. ex., uma caneca de cerveja), ou ao agente (p. ex., um carrossel). Isso poderia sugerir que, no momento em que se ouve o verbo, o indivíduo já seria capaz de mapear o estímulo linguístico em um referente visual, um indicativo de que o processador linguístico poderia ter gerado outputs para os sistemas cognitivos responsáveis, por exemplo, pela programação dos movimentos oculares.

Além de gerar outputs incrementalmente, esse tipo de resultado sugere que o processador gera previsões a respeito de material linguístico que ainda estaria por vir, ou seja, contempla um mecanismo de antecipação. Um mecanismo dessa natureza poderia prover uma resposta rápida para a necessidade de

\footnotetext{
${ }^{25}$ Em referência a W. Wundt (1900 apud Levelt 1996).
} 
estabelecimento da referência a partir da percepção de enunciados fala. Poderia também ajudar o parser a lidar com estruturas potencialmente custosas, como as que envolvem dependências de longa distância. Em particular, o processamento de orações relativas restritivas poderia ser beneficiado por um mecanismo dessa natureza. Se o processador for capaz de antecipar a ocorrência de uma relativa com base em um input indicativo desse tipo de estrutura, como um DP seguido de um marcador relativo e se, além disso, informação interpretativa puder ser antecipada na presença de informação contextual desambiguizadora, poderia haver uma redução no custo de processamento por meio de uma estratégia heurística para a atribuição de papéis temáticos (Cf. capítulo 5). Os experimentos reportados no capítulo 4 buscarão justamente avaliar a possibilidade de antecipação no processamento de relativas.

\subsection{3.}

\section{Serialidade}

Uma outra questão a ser levada em conta em relação à natureza de um modelo de processamento está na oposição entre arquiteturas paralelas e seriais. Atualmente, os modelos paralelos mais influentes são os modelos baseados em restrições. Neles, a diferentes descrições estruturais, são atribuídos diferentes pesos de acordo com a adequabilidade de cada uma destas análises a restrições como frequência, plausibilidade e prosódia, dentre outras. Em um modelo de natureza serial, por outro lado, entende-se que a passagem de um nível de análise a outro, como a passagem do nível sintático para o nível semântico, se dê em estágios. Assim, haveria um estágio no qual são consideradas exclusivamente informações estruturais, por exemplo. Uma vez que esta análise tenha sido realizada, o output resultante é encaminhado para um nível posterior, serialmente. Entretanto, como ressalta Levelt (1989), com base em Fry (1969) e Garrett (1976), não é necessário que haja o processamento exaustivo de toda a informação de um processador para que o próximo possa entrar em ação. Um processador pode encaminhar a outros fragmentos já analisados do material sob processamento. Assim, cada processador trabalha com informações específicas ao seu domínio, mas os processadores operam em paralelo, de maneira incremental. A partir dessa última concepção de serialidade, buscaremos defender, analisando o parsing das orações relativas, um nível autônomo de computação sintática, 
operacionalizando uma arquitetura ascendente e hierárquica de processamento, que, contudo, permite que informação de níveis superiores sejam paralelamente processadas com base em outputs do sistema de computação sintática.

Nessa proposta, partindo de um processador autônomo e serial e considerando a noção de fases sintáticas, sugerimos que fragmentos de material sintaticamente analisado poderão ser integrados a informação não estrutural durante o curso de processamento da oração. Isso permitirá, assim, que a informação sintática seja incrementalmente integrada a informações não estruturais. Nas próximas seções, apresentaremos algumas evidências que indiciam a necessidade de que esse tipo de incrementalidade deva ser considerado em modelos de compreensão da linguagem.

\section{2.}

\section{Autonomia vs. interatividade no processamento sintático}

Independentemente do tipo de abordagem para o processamento da linguagem, uma propriedade a ser considerada quando se propõem mecanismos de compreensão de sentenças é a de que o fluxo da fala impõe ao processador a limitação de que o input tenha de ser processado linearmente. Como consequência direta desse pressuposto, tem-se que frequentemente um item que chega ao processador sintático terá mais de uma possibilidade de análise. Embora haja modelos nos quais a análise é adiada (pela construção de estruturas subespecificadas ou por recurso a buffers de memória associados a um mecanismo de look-ahead (Marcus et al., 1983; Barton e Berwick, 1985; Weinberg, 1993; Gorrell; 1995), as abordagens estritamente incrementais de processamento, com as quais buscaremos dialogar, em geral, dão conta desse problema por meio, basicamente, de dois mecanismos diferentes. A solução dessa ambiguidade, segundo as abordagens determinísticas, está na proposta de que o parser escolheria, a princípio, uma dentre as possíveis opções de análise (uma análise default), considerando encapsuladamente propriedades estruturais. Por outro lado, abordagens interativas, argumentam, em geral, pelo o uso de informação contextual na resolução de ambiguidades.

$\mathrm{Na}$ seção a seguir apresentaremos os argumentos e os desenvolvimentos de propostas do primeiro tipo, ressaltando as revisões pelas quais modelos dessa linha estiveram sujeitos ao longo de sua trajetória e que ressaltaram a necessidade 
de que os pressupostos de encapsulamento e autonomia fossem revistos, principalmente no que diz respeito à extensão dos constituintes que podem ser tratados de maneira completamente encapsulada.

Em seguida, serão apresentadas as evidências que motivaram a investigação proposta neste trabalho, ie., evidências de antecipação e integração incremental de informação não estrutural contextualizadas no âmbito da proposta interativa das teorias baseadas em restrições, que negariam a possibilidade de um processamento sintático encapsulado sugerindo a influência de informação dessa natureza na análise sintática inicial.

\subsection{1. \\ Preferências estruturais no processamento: argumentos para um processador autônomo}

Conforme veremos nesta seção, a abordagem estrutural de natureza determinística foi concebida e vem se desenvolvendo com base no argumento central de que o processador sintático autônomo, limitado pelas condições de processamento e atuando de maneira incremental, recorre a estratégias de base estrutural fundamentadas em princípios de economia para estabelecer a estruturação inicial de sequências, argumento esse, essencialmente derivado de evidências que indicariam preferências na resolução de expressões ambíguas no inglês. O desenvolvimento da literatura psicolinguística, contudo, veio a sugerir que a aplicabilidade de estratégias dessa natureza parece ser limitada por fatores como informações concernentes ao contexto, à plausibilidade ou mesmo à especificidade de outras línguas. A manutenção da hipótese determinística, ou mais amplamente, a manutenção da hipótese de um processador autônomo vem sendo viabilizada, diante de evidência a princípio contraditória, com base em, essencialmente, dois argumentos ou em dois princípios de reformulação de modelos dessa natureza. Em primeiro lugar, o argumento de que unidades de processamento exclusivamente encapsulado poderiam ser reformuladas, de forma que o processador poderia gerar representações semi-estruturadas. Um segundo argumento seria o de que resultados contradizendo a atuação de princípios estruturais e, por consequência o argumento indutivo central desses modelos, poderiam ser explicados por recurso à atuação de outros níveis de processamento, como a prosódia ou os níveis interpretativos, em momentos anteriores ou 
posteriores ao processamento sintático. Esses argumentos, investigados experimentalmente no capítulo 4, traçam o caminho que buscaremos percorrer na adaptação da proposta de Corrêa e Augusto $(2006$; 2007) para o processamento incremental de orações relativas e serão apresentados nesta seção com foco nos desenvolvimentos da chamada Teoria do Labirinto (Frazier, 1979; Frazier e Fodor, 1978; Frazier e Rayner, 1982; Frazier 1987).

Uma das abordagens pioneiras na tradição determinística vem do clássico trabalho de Kimball (1973). O autor propõe um mecanismo procedimental de parsing que busca explicar fatores como a complexidade de sentenças com base em princípios exclusivamente estruturais, um traço essencial desse trabalho que irá influenciar propostas subsequentes para o processador sintático. Baseando-se em algumas estratégias de parsing aplicadas em linguagens de programação, Kimball propõe alguns princípios que seriam responsáveis por determinar a aceitabilidade das sentenças, tratando as dificuldades de processamento "em termos da configuração superficial ${ }^{26}$ da árvore sintática". Ao todo, Kimball propõe sete princípios responsáveis pelo parsing de estruturas de superfície. Dentre os princípios que tiveram influência no desenvolvimento de modelos posteriores, está o da associação à direita, que determina que os símbolos terminais associam-se otimamente ao nó terminal mais baixo. Este princípio explicaria efeitos de recência, em frases como "Joe figured that Susan wanted to take the cat out" e "The girl took the job that was attractive", nas quais os falantes tendem a associar "out" a "take" e "attractive" a "job" (e não a "figured" e a "girl", respectivamente). Um outro princípio proposto por Kimball é o do fechamento, segundo o qual, um constituinte é fechado assim que possível, a não ser que o próximo constituinte seja um constituinte imediato do nó sendo construído. Este princípio, associado ao princípio da estrutura fixa, que define ser custoso reorganizar um constituinte fechado, sugere uma explicação para os casos em que ocorrem garden-paths.

A ideia central do trabalho de Kimball é a de que a demanda por uma análise rápida de sequências linguísticas pode ser satisfeita a partir de alguns princípios que atuam sobre informações estruturais. Essa concepção de parser

\footnotetext{
26 "Superficial", neste caso, se refere à estrutura de superfície (em oposição à estrutura profunda), nos termos propostos no Modelo Padrão (Chomsky, 1965) em vigor quando a hipótese de Kimball foi elaborada.
} 
revela o caráter mais essencial da proposta de um processador sintático autônomo, que é a capacidade de fornecer uma descrição sintática para uma expressão com base em informação de natureza categorial e hierárquica, dando conta, a partir disso, de fatores relacionados ao desempenho psicolinguístico, tais como o custo de processamento e preferências de aposição em casos de ambiguidade.

Esta também é a ideia central de outra proposta, a da chamada Teoria do Labirinto, uma teoria serial e modular, que foi sendo elaborada em uma série de trabalhos publicados por Lyn Frazier e colaboradores (Frazier, 1979; Frazier e Fodor, 1978; Frazier e Rayner, 1982; Frazier 1987). Entretanto, com a Teoria do Labirinto, Frazier procura uma proposta mais sintética, na qual, essencialmente, apenas duas estratégias universais seriam capazes de reger as escolhas do parser. Estes dois princípios ficaram conhecidos em português por Fechamento Tardio, do inglês Late Closure, e Aposição Mínima, do inglês Minimal Attachment ${ }^{27}$. Estas duas estratégias teriam a capacidade de explicar a geração de garden-paths em algumas sentenças e também algumas preferências de leitura identificadas no inglês ${ }^{28}$.

Apesar de a Teoria do Labirinto advogar um parser autônomo, foi percebida, já em seus primeiros desenvolvimentos, a necessidade de que informação de natureza estrutural pudesse ser correlacionada à informação não estrutural em momentos intermediários do parsing. Rayner, Carlson e Frazier (1983), procurando por uma explicação que desse conta de como o conhecimento de mundo poderia ter algum efeito sobre a análise corrente do parser e de como o processador sintático poderia descobrir uma alternativa de análise mesmo quando a análise corrente é procedente (em termos gramaticais), sugeriram a existência de um processador temático, que atuaria paralelamente ao parser. De acordo com essa proposta, dentre as grades temáticas associadas à entrada lexical de um

\footnotetext{
${ }^{27}$ Conforme a definção de Frazier (1987): "Minimal attachment: Do not postulate any potentially unnecessary nodes. Late Closure: If grammatically permissible, attach new items into the clause or phrase currently being processed (i.e., the phrase or clause postulated most recently)" (Frazier, 1987 , p. 562).

${ }^{28}$ Por exemplo, a escolha pela aposição do PP ao verbo ao invés da aposição ao objeto direto numa sentença como "John hit the gril [рр with a book]" (resultando na interpretação de John usou um livro para atingir a garota) pode ser entendida como uma consequência da Aposição Mínima, já que a aposição ao NP exigiria a criação de um novo nó. Já na sequencia "Since Jay jogs a mile seems like a short distance to him", a preferência pela leitura na qual "a mile" é interpretado como objeto de "jog" seria determinada pela estratégia de Fechamento Tardio, que daria prioridade a manter o NP encaixado no constituinte em processamento, ou seja, VP. Para ambiguidades e garden-paths característicos do português, veja-se a relação apresentada por Maia (2001).
} 
núcleo, o processador temático escolheria a mais adequada, em função do discurso e conhecimento de mundo. Caso a análise do parsing seja condizente com a grade temática escolhida pelo processador temático, a sentença é processada mais rapidamente, caso não seja coerente, o processador temático alerta o parser da necessidade de revisão da estrutura (Cf. Frazier, 1987b; Rayner e Pollatsek, 1989). Como assinalado em Frazier (1987), este seria um ponto no qual a Teoria do Garden-Path se distanciaria do conceito de modularidade, tal qual proposto por Fodor (1983).

Em versões mais recentes, a Teoria do Labirinto incorporou uma abertura um pouco maior para a utilização de informação não estrutural no curso da análise sintática, em grande parte em função do trabalho de Cuetos e Mitchell (1988), que, no espanhol, detectou que, na aposição de relativas ambíguas como "Alguém atirou no empregado da atriz que estava na varanda", haveria uma preferência pela aposição alta da relativa, contrariando o que seria previsto pela estratégia de fechamento tardio. Resultados dessa natureza (Cf. Hemforth, Konieczny e Scheepers, 2000; Michell, Cuetos, Zagar, 1990 ${ }^{29}$ motivaram a elaboração da Teoria Construal (Frazier e Clifton Jr., 1996), que introduziu a distinção entre relações primárias e relações não primárias como uma ferramenta para possibilitar essa conciliação. As relações primárias seriam definidas em termos daquelas consideradas mais essenciais à gramaticalidade de uma sentença, mais especificamente, as relações entre verbo e seus argumentos. As relações não primárias seriam definidas, por sua vez, em termos daquelas que dizem respeito aos adjuntos, como, de acordo com Frazier e Clifton Jr. (1996), seria o caso da relação subjacente à aposição de orações relativas. No caso das relações primárias, as informações de natureza sintática e o princípio de Aposição Mínima seriam aplicados pelo parser de maneira determinística, ao passo que, em se tratando das relações não primárias, haveria a atuação do princípio Construal ${ }^{30}$, possibilitando a influência de informação não estrutural na condução da análise sintática. Com isso, conhecimentos de diferentes níveis, como, por exemplo, os que dizem

\footnotetext{
${ }^{29}$ Aspectos mais específicos da discussão acerca da ambiguidade na aposição de orações relativas, que transcendem a discussão dos processos integrativos focados neste trabalho, podem ser encontrados em Hemforth, Konieczny, Schepers e Strube (1998); Gibson, Pearlmutter, CansecoGonzalez e Hickok's (1996); e Maia, Fernández, Costa e Lourenço-Gomes (2007).

${ }^{30}$ Nos termos de Frazier e Clifton Jr. (1996, p. 152), o princípio Construal poderia ser definido nos seguintes termos: "(a) Associate XP into the current processing domain [the extended XP $(\mathrm{XP}=\mathrm{Xmax})$ dominating the last theta assigner $(\mathrm{X})]$, and (b) Try to interpret $\mathrm{XP}$ within that domain using non structural interpretive principles along with structural well-formedness principles".
} 
respeito à referência ou plausibilidade, podem vir a atuar na resolução de problemas estruturais. Tendo que a relativa é um modificador nominal, configurando, portanto, uma relação não primária, o parser estabeleceria uma relação subespecificada entre a relativa e a projeção máxima estendida do último atribuidor theta $^{31}$. Caso haja mais de um local possível de associação, o parser faria sua escolha levando em conta princípios interpretativos ${ }^{32}$. O movimento da Teoria do Labirinto em direção a Teoria Construal destaca o papel das relativas na construção de modelos de processamento e evidencia a dificuldade do tratamento de grandes unidades de processamento de maneira encapsulada com a possibilidade, aberta pelo princípio Construal, de que, em relações não primárias, haja a influência de informação de natureza não estrutural.

Ainda no que concerne às preferências de encaixamento em relativas ambíguas, uma fonte de informação que poderia auxiliar na condução de um parsing encapsulado está na prosódia, conforme sugere a Hipótese da Prosódia Implícita (Fodor, 2002a, 2002b), segundo a qual fronteiras prosódicas poderiam subsidiar as decisões do parser, na medida em que sinalizariam fronteiras entre constituintes. Fodor (2002a) aponta, por exemplo, que o comprimento de uma oração relativa influenciaria as preferências de aposição, de forma que, em relativas curtas, que costumam não vir acompanhadas de fronteiras prosódicas separando-as da matriz, haveria uma preferência pela aposição baixa, ao passo que em relativas longas, que costumam vir antecedidas por uma fronteira prosódica, haveria uma preferência pela aposição alta. Pela proposta de Fodor (2002b), preferências de aposição como as observadas em estudos como o de Cuetos e Mitchell (1988) poderiam estar relacionadas a fatores de natureza prosódica, mesmo em se tratando de estudos que investigam a leitura silenciosa, pois em contextos de leitura haveria a projeção de uma prosódia default. Fodor (2002a) nota que a prosódia poderia até mesmo ser encarada como uma espécie de Preliminary Phrase Packager em analogia com a proposta inicial do Sausage

\footnotetext{
${ }^{31}$ No caso de "Someone shot the servant of the actress who was in the balcony", o ultimo atribuidor theta é o DP servant, já que a preposição "of", nesse caso uma preposição funcional, não instancia um novo domínio temático. Assim, ambos os DPs estariam disponíveis para receber a relativa. Note-se que em "Someone was looking at the servant with the actress who was on the balcony", o caso é diferente, já que o último atribuidor theta é a preposição lexical "with". Dessa maneira, apenas o DP "actress" encontra-se disponível para ser associado à relativa. Estudos como o de Gilboy et al. (1995) parecem confirmar esta previsão.

${ }^{32} \mathrm{Em}$ sua forma atual, a teoria Construal não especifica qual o momento exato em que ocorreria o processamento de relações não primárias (Cf. Papadopoulou, 2006).
} 
Machine (Frazier \& Fodor 1978). Embora Maia et al. (2007) considerem, a partir de dados de relativas ambíguas do português, a possibilidade de que efeitos de influência prosódica surjam apenas em uma etapa pós-sintática, a ideia de que a existência de certas fronteiras prosódicas poderiam sinalizar relações entre constituintes é compatível com resultados obtidos em outras línguas, conforme sugerem os casos mencionados por Fodor (2002a, 2002b), e pode ser instrumental para a operação de um parser modular, na medida em que a informação de natureza prosódica poderia auxiliar na análise de constituintes ambíguos, assumindo a existência de uma interface entre a prosódia e a sintaxe.

Outro argumento em favor de estratégias estruturais, como o fechamento tardio, vem de evidências que sugerem a persistência de análises derivadas deste tipo de mecanismo em respostas obtidas no processamento offline. Na leitura de sentenças como "While Mary bathed the baby played in the crib", foi detectado que falantes do inglês tendiam a responder afirmativamente a uma pergunta como "Did Mary bath the baby?" (Christianson et al., 2001; Ferreira et al., 2001), embora essa interpretação derivasse do estabelecimento de uma dependência local incoerente com a estrutura global da sentença. Em um estudo posterior (Patson et al. 2006), mesmo com o adiamento do tempo de resposta para evitar a possibilidade de que representações sintáticas recentes (possivelmente originadas a partir de uma leitura de fechamento tardio) influenciassem o comportamento dos participantes, a tendência de respostas afirmativas se manteve. No português brasileiro, resultados semelhantes são reportados por Ribeiro (2008). Em sentenças não ambíguas como "The dog was bitten by the man", foi observado um número expressivo de respostas incorretas (Ferreira, 2003), sugerindo, possivelmente, a atuação de uma estratégia heurística de assinalar, ao primeiro DP, o papel de agente da oração (Bever 1970; Townsend \& Bever 2001). Com base em resultados dessa natureza, Ferreira et al. (2001) propuseram que o processador sintático, confrontado com ambiguidades e diante das pressões de tempo para o processamento, atuaria com base em princípios heurísticos, gerando, nos termos dos autores, representações good-enough, cuja reanálise seria implementada apenas como último recurso. Ferreira e Patson (2007) argumentam ainda, com base em pesquisas sobre a tomada de decisões (Gigerenzer et al. 1999; Gigerenzer e Selten 2001), que estratégias heurísticas baseadas em um set limitado de informação, considerando a limitação de recursos e tempo no 
processamento linguístico, seriam biologicamente mais plausíveis do que uma análise na qual múltiplas representações são mantidas e o processador tem acesso livre a informação de diversas naturezas, o que poderia significar assumir uma racionalidade irrestrita (unbounded rationality) ${ }^{33}$. Assim, resultados dessa natureza ressaltariam a atuação de heurísticas estruturais simples, tais quais as defendidas no âmbito da Teoria do Labirinto (Ferreira e Patson, 2007).

Neste trabalho, buscaremos confrontar hipóteses derivadas de alguns princípios estruturais de processamento com algumas das advogadas por propostas interativas, apresentadas a seguir. Como foi possível observar na trajetória traçada nesta seção, a noção de um parser determinístico e autônomo se desenvolveu à medida que a necessidade de se lidar com informação de natureza não estrutural no curso da análise sintática se impôs por evidências experimentais. Os desenvolvimentos da Teoria do Labirinto sugerem que uma noção de encapsulamento tal qual a subjacente a propostas como a de Kimbal (1973) deveria ser revista. Nesse sentido, mecanismos como o processador temático paralelo e o princípio Construal buscaram ressaltar a influência de informação extrassintática no resultado final gerado a partir da estruturação estabelecida pelo componente sintático. Por sua vez, a Hipótese da Prosódia Implícita veio a relativizar resultados contraditórios a estratégias estruturais incorporando mecanismos de segmentação prosódica a serem considerados pelo parser. Contudo, a integração incremental de informação contextual durante o curso do processamento de relações argumentais (conforme sugerido, por exemplo, por evidências que indicariam a antecipação do mapeamento de referentes com base em informação de verbos apresentados diante de contextos visuais restritivos (Altmann e Kamide, 1999; 2007) ${ }^{34}$ ) parece não ser contemplada mesmo por

\footnotetext{
${ }^{33}$ Nas palavras de Gigerenzer e Selten (2001), “... models of bounded rationality describe how a judgment or decision is reached (that is, the heuristic processes or proximal mechanisms) rather than merely the outcome of the decision, ant they describe the class of environments in which these heuristics will succeed or fail. These models dispense with the fiction of optimization, which in many real-world situations demands unrealistic assumptions about the knowledge, time, attention and other resources available to humans". De acordo com os autores, de forma geral, modelos de racionalidade restrita (bounded rationality) seriam caracterizados por três princípios: regras simples de busca, regras simples de interrupção da busca e regras simples de tomada de decisão. Note-se, contudo, que grande parte da pesquisa no campo de tomada de decisões originase a partir de resultados da tomada consciente de decisão, o que limita a analogia entre processos dessa natureza e os processos decisórios implementados na compreensão da linguagem.

${ }^{34}$ Note-se que, embora o princípio Construal possa ser suficiente para dar conta da possibilidade de integração de informação contextual na aposição de relativas, este não parece ter a intenção de acomodar fenômenos relativos à emergência de processos integrativos no interior de orações
} 
evoluções da Teoria do Labirinto, como o princípio Construal. Por outro lado, trabalhos como o de Ferreira e colaboradores (Christianson et al.2001; Ferreira, 2003; Ferreira et al., 2001; Ferreira e Patson, 2007) parecem sugerir que princípios estruturais poderiam não só ser implementados, mas também preservados, mesmo após a atuação do componente sintático, na ausência de informação contextual desambiguizadora. Conforme apresentado no capítulo 1 , nossa proposta nesse trabalho é a de conciliar essas duas classes de evidências. Para tal, investigaremos, por meios de dois experimentos, o quanto a previsibilidade do argumento interno do verbo encaixado (característica de estruturas relativas quando apresentadas em contextos informativos) poderia indiciar a atuação de processos antecipatórios e integrativos, com o objetivo principal de avaliar em que medida informação interpretativa de DPs, por sua previsibilidade diante de informação contextual, poderia ser incrementalmente disponibilizada. Com base nessa investigação, pretendemos discutir a extensão de constituintes tratados encapsuladamente pelo parser. Em outro experimento, buscaremos analisar a integração de informação não estrutural no estabelecimento inicial de fronteiras sintáticas. Nesse experimento, serão apresentadas relativas e completivas temporariamente ambíguas na presença de informação contextual, com o objetivo de avaliar em que medida a análise inicial do processador poderia ser determinada pelo contexto (Brown, van Berkum e Hagoort, 2000; Grodner, Gibson e Watson, 2005; Hagoort e Berkum, 2007; van Berkum, Brown e Hagoort, 1999) ou guiada por informação de mais baixo nível, como informação relativa à segmentação prosódica. Com base nos resultados, buscaremos argumentar em favor da possibilidade de conciliação de evidências a princípio contraditórias no âmbito de um modelo que incorpore aspectos da concepção minimalista de língua (Corrêa e Augusto, 2006; 2007; Cf. capítulo 2).

Retornaremos ainda à Teoria do Labirinto para abordar o posicionamento desta quanto à questão do preenchimento do gap no processamento de orações contendo relativas, abordando, em particular, evidências que sugerem a atuação preditiva do parser no estabelecimento da relação filler-gap. Antes, contudo,

relativas durante o processamento on-line, tais quais os que buscaremos investigar por meio dos dois primeiros experimentos reportados no capítulo 4. Tal princípio parece, tampouco, possibilitar o estabelecimento de um marco temporal para a ocorrência de processos integrativos na aposição de orações dessa natureza - problema que investigaremos no terceiro experimento reportado -, uma vez que, em sua forma atual, a teoria Construal não especifica o momento exato em que ocorreria o processamento de relações não primárias (Cf. Papadopoulou, 2006). 
apresentaremos, na próxima seção, trabalhos que vieram a questionar a possibilidade de um processador sintático em dois estágios, defendendo uma perspectiva de natureza não modular com base em evidências que poderiam sugerir a interferência de informação não estrutural no curso do processamento sintático.

\subsection{2. \\ Integração incremental e antecipação: evidências para um processador sintático não especializado?}

Um dos pressupostos de modelos de processamento sintático autônomo é o de que a primeira análise do parser não levaria em conta conhecimento de background ou informações interpretativas de maneira geral, uma consequência do encapsulamento informacional. Contudo, a ideia de um processador encapsulado veio a ser fortemente questionada.

$\mathrm{Na}$ literatura sobre o processamento de sentenças, um dos principais argumentos contra esta concepção tem advindo de pesquisas nas quais se aborda a influência de informação de natureza contextual, seja ela de natureza discursiva ou visual, no processamento. Nessa direção, conforme apresentaremos nesta seção, algumas evidências que têm sido apresentadas como um desafio à hipótese da autonomia, como, por exemplo, as que indicam que item lexical semanticamente incongruente com o contexto pode ser imediatamente detectado (Nieuwland e Van Berkum, 2006), as que sugerem a detecção imediata de itens lexicais sintaticamente incoerentes com o modelo de discurso corrente (van Berkum, Hagoort e Brown, 2000) ou as que sugerem a antecipação de itens lexicais com base em informação de natureza não estrutural durante o curso do processamento (Altmann e Kamide, 1999; 2007).

De maneira geral, evidências dessa natureza parecem sinalizar a atuação de processos integrativos e antecipatórios durante a estruturação sintática de uma sequência. Dado o pressuposto de que informações de natureza interpretativa, como as que dizem respeito ao contexto discursivo, seriam ilegíveis para o processador sintático autônomo, a incrementalidade na integração de informação dessa natureza é tomada como fruto de um processamento linguístico em estágio 
único $^{35}$, no qual informação de qualquer natureza seria continua e incrementalmente avaliada. $\mathrm{O}$ argumento de que processos antecipatórios implicariam a ausência de um processamento sintático especializado segue a mesma linha de raciocínio. A antecipação pode ser entendida como uma expectativa do processador por um determinado material linguístico gerada a partir do processamento de material precedente. Assim, processos antecipatórios estão relacionados à incrementalidade (ou, nos termos de Kamide (2008), seriam uma forma radical de incrementalidade), uma vez que a antecipação supõe que o processador seja capaz de incorporar o material linguístico corrente e, com base em informação da representação em construção, predizer propriedades de itens subsequentes. Processos antecipatórios são entendidos como um argumento em desfavor de um processamento em dois estágios, nos casos em que as propriedades previstas ou a partir das quais se faz uma previsão envolvem conhecimento de natureza não estrutural ou nos casos em que a emergência desta previsão se dá no âmbito de uma unidade de processamento cuja análise estaria sob domínio do processador sintático.

Nesta seção, apresentaremos alguns trabalhos que se inserem nesta discussão e que vêm sendo conduzidos, em especial, por proponentes de modelos interativos de parser, tais como os modelos baseados em restrições. Nosso objetivo nesta apresentação será traçar um panorama das hipóteses e estratégias experimentais avaliadas em investigações que visam a detectar a natureza da interação entre informações contextuais e o processamento online de sentenças. A partir disso, com foco no propósito específico deste trabalho, ie., o processamento de orações contendo relativas, serão delimitadas algumas hipóteses e estratégias para a investigação experimental a ser desenvolvida. Contextualizando a discussão, apresentamos, em primeiro lugar aspectos da proposta das teorias baseadas em restrições.

A proposta interativa de algumas dessas teorias, como por exemplo a de MacDonald, Pearlmutter e Seidenberg (1994), tem sua arquitetura fortemente inspirada em modelos de natureza conexionista. Em analogia ao funcionamento do sistema neuronal, os modelos conexionistas (Cottrell, 1985; Rumelhart e Mc

\footnotetext{
${ }^{35}$ Um processador em estágio único (one-stage model) não prevê um estágio especializado de processamento sintático (Trueswell e Tanenhaus, 1991; MacDonald et al., 1994), enquanto um processador em dois estágios (two-stage model) se baseia na existência de uma etapa específica para o processamento de informações estruturais (Frazier, 1995).
} 
Clelland, 1986; Small, Cottrell e Shastri, 1982; Stevenson e Merlo, 1997) são baseados em computações de ordem numérica. O processamento se dá por meio de unidades simples de processamento que, a exemplo dos neurônios, são ativadas ou inibidas por unidades vizinhas (Cf. Onnis, Christiansen e Chater, 2008). Redes dessa natureza seriam capazes de aprender a processar determinado tipo de dado mediante a exposição contínua a inputs. A despeito do conflito entre propostas conexionistas e simbólicas (Fodor e Pylyshyn, 1988; Pinker e Prince, 1988), essas perspectivas não são, necessariamente, mutuamente excludentes, uma vez que modelos simbólicos podem ser implementados em redes de natureza conexionista (Ford et al., 1982; McClelland e Kawamoto, 1986; Miyata, Smolensky e Legendre, 1993; Small, Cottrell e Shastri, 1982). A oposição entre essas duas propostas não se dá, assim, ao nível da implementação, mas nas operações que cada tipo de sistema supõe para atingir resultados. Ao contrário do que acontece em modelos simbólicos, o conhecimento em redes neurais estritamente conexionistas não precisa ser explicitamente representado na forma de regras, podendo ser derivado de um padrão de atividade implementado pelos nós interconectados, de forma que diferentes níveis de análise de um modelo simbólico podem ser aglutinados em um sistema homogêneo (Rumelhart e Mc Clelland, 1986). Críticas a esse tipo de abordagem ativeram-se, em especial, à capacidade de generalização (ou à sistematicidade) desses modelos que, em não incorporando representações abstratas, seriam incapazes de generalizar o conhecimento utilizado para interpretar uma sequência como "Bob loves Mary" para uma outra estruturalmente equivalente, como "Mary loves Bob" (Fodor e Pylyshyn, 1988). Além disso, apesar dessas redes demonstrarem capacidade de aprendizado, considera-se que o treinamento programado ao qual são submetidas é essencialmente diferente das condições de aprendizado de uma língua natural (Pinker e Prince, 1988; Pinker, 1999). Aspectos da abordagem conexionista, como o processamento homogêneo, ie. sem níveis de análise delimitados, e a ausência de regras de processamento explícitas são comumente associados às teorias baseadas em restrições, como o modelo lexicalista de MacDonald et al. (1994) ${ }^{36}$ (Cf. Jackendoff, 2007).

\footnotetext{
${ }^{36}$ Segundo os autores, a proposta deles é neutra em relação à implementação em uma rede conexionista ou em outro tipo de rede. A despeito disso, para "propósitos descritivos", os autores
} 
Em suas diversas versões (MacDonald, Pearlmutter e Seidenberg, 1994; Trueswell \& Tanenhaus, 1994; Stevenson, 1994; Spivey e Tanenhaus 1998), as teorias baseadas em restrições comungam algumas propostas centrais (McRae e Matsuki, 2012). Em primeiro lugar, nessas abordagens, defende-se ser possível acessar, simultaneamente, várias fontes de restrições, ou níveis de informação, como as de natureza probabilística, lexical, sintática, pragmática, prosódica, conceitual, discursiva e espacial do ambiente intra ou extra oracional. Tais restrições podem ser violadas ou competir entre si. Em segundo, considera-se que tais informações tornam-se disponíveis com o mínimo delay possível e são prontamente acessadas pelo processador tão logo disponíveis. As múltiplas representações construídas com base nas informações de um dado input são ativadas em paralelo e ranqueadas probabilisticamente.

Essa é a essência da proposta das teorias baseadas em restrições, que, em um matiz lexicalista, são traduzidas no trabalho de MacDonald, Pearlmutter e Seidenberg (1994). Essa proposta se sustenta na defesa de um léxico altamente rico que inclui informações semânticas, fonológicas e estruturais, estas últimas essenciais para a operacionalização de um sistema de compreensão em estágio único, prescindindo de um estágio exclusivo para computação sintática. Muito embora estejam em claro contraponto com modelos autônomos, como o de Frazier (1979), MacDonald, Pearlmutter e Seidenberg (1994) salientam que a ausência de um parser independente responsável pela construção da estrutura frasal não deve ser confundida com a inexistência de representações ou restrições sintáticas.

$\mathrm{Na}$ abordagem em questão, o léxico inclui informações a respeito de subcategorização, estrutura argumental, tempo, finitude, voz, número, pessoa, gênero, estruturas X-barra, além de informações de natureza probabilística. Os itens lexicais, assim definidos, são submetidos a um processador que incorpora dois mecanismos importantes das teorias baseadas em restrições: a ativação em cadeia e o ranqueamento de descrições por meio da atribuição de pesos. Dessa maneira, o reconhecimento de um item lexical irá disparar a ativação em cadeia de todos os traços possivelmente associados ao item. A ativação de determinado traço de um item lexical resultará do peso atribuído a restrições de natureza semântica, sintática ou ainda contextual. O peso de cada uma destas restrições é, 
em grande parte, consequência de fatores associados à frequência, ajustada em termos de uso. A ativação de um traço excita a ativação de traços associados, numa reação em cadeia. A ativação de associações é determinada pela probabilidade de coocorrência. Nos termos da hipótese de MacDonald, Pearlmutter e Seidenberg (1994), a descrição sintática de uma sentença seria atribuída localmente na interação entre itens lexicais. De acordo com o modelo proposto, a descrição sintática de uma sentença será uma função do pareamento de estruturas $X^{\prime}$ e argumentais mais ativadas pelos itens lexicais de uma sequência.

We have suggested that the arena for syntactic processing is the lexicon, in that syntactic structure is build through links between individual lexical items. This approach retains the idea that syntactic structure is computed during comprehension but abandons the parser, a modular, special-purpose processor that combines knowledge of grammar with special purpose algorithms such as minimal attachment. (MacDonald, Pearlmutter e Seidenberg, 1994)

Embora nem todos os modelos na linha das teorias baseadas em restrições assumam totalmente a interatividade do processador (Jackendoff, 2002; 2007; Cf. capítulo 5), argumenta-se, no contexto de alguns desses modelos, que o acesso a múltiplas fontes de restrições seria a forma mais adequada de permitir que informação contextual seja prontamente acessada, de forma a derivar previsões a respeito da forma do input que chegará ao processador (Hale, 2001; Levy, 2008). Nesse sentido, um dos argumentos dos defensores de modelos como o de MacDonald, Pearlmutter e Seidenberg (1994) é o de que preferências de recência estrutural, que serviram de base para a atuação de princípios estruturais como o fechamento tardio, poderiam ser revertidas por contextos diretivos, ou seja, argumenta-se que informação extrassentencial poderia suprimir preferências relacionadas à recência estrutural.

Nesse contexto, Altmann et al. (1998) reportam que, inseridas em um contexto como (2), sentenças que favoreciam a aposição alta de um adjunto, como "She'll implement the plan she proposed to the committee next week, they hope" eram lidas mais rapidamente e registravam menos movimentos regressivos do que sentenças análogas, mas que, pela configuração das marcações de tempo, favoreceriam a aposição baixa, como "She'll implement the plan she proposed to the committee last week, they hope". Restrições de natureza contextual, em 
especial o princípio da Parcimônia ${ }^{37}$ (Crain e Steedman, 1985), entrariam em jogo para determinar as preferências de aposição em uma dada sentença. Altmann et al. (1998) defendem, em consonância com a perspectiva das teorias baseadas em restrições, que estes dados poderiam ser interpretados como resultantes da atuação de restrições de natureza estatística (derivadas de uma possível correlação probabilística entre determinados contextos e determinadas estruturas), que seriam implementadas incrementalmente durante o processo de compreensão.

\section{(2) Contexto favorecendo aposição alta}

Last week Fiona presented a new funding plan to her church comittee. The other committee members wonder when Fiona will implement the plan she proposed.

Outro argumento contra o encapsulamento informacional é o de que o processamento autônomo dependeria, empiricamente, de quando o contexto seria usado na resolução de ambiguidades. Assim, evidências de que informações contextuais seriam consideradas durante os primeiros momentos do processamento sintático poderiam sugerir que o mapeamento de uma estrutura em um modelo de discurso seria rápido e, portanto, restringiria a possibilidade de existência de um estágio específico para a computação sintática. Buscando resultados nessa direção, em um dos experimentos reportados no clássico trabalho de Marslen-Wilson e Tyler (1991), sintagmas ambíguos do inglês, como visiting relatives, eram apresentados inseridos em contextos que poderiam desambiguizar a leitura: ora precedidos por contextos que induziam uma leitura gerundiva, ora por contextos que induziam a uma leitura adjetiva.

\section{(3) Contexto induzindo leitura gerundiva}

If you want a cheap holiday, visiting relatives...

\footnotetext{
${ }^{37}$ De acordo com o princípio da Parcimônia, diante de ambiguidade, a análise que implica um menor número de pressuposições (derivadas de um dado contexto) contrariadas deve ser favorecida. Há ainda uma instância específica desse princípio, o princípio da falência referencial (referential failure principle), de acordo com o qual uma sequência ambígua deverá ser interpretada como um modificador restritivo caso um DP não seja capaz, por si só, de discriminar um referente único (Altmann, 1987). Esses princípios foram propostos no contexto da Teoria Interativa Incremental (Altmann e Steedman, 1988), que comunga com modelos baseados em restrições a ideia de que a análise inicial de uma sequência deve incorporar conhecimento não sintático, a qual buscaremos discutir ao longo deste trabalho.
} 


\section{(4) Contexto induzindo leitura adjetiva}

If you have a spare bedroom, visiting relatives...

Em ambos os casos, as sentenças eram seguidas por uma forma verbal congruente ou incongruente com a leitura induzida pelo contexto. Tomando (3) como exemplo, is seria a forma verbal apresentada na condição congruente (já que a leitura gerundiva formaria um sintagma sujeito com traço singular) e are seria a forma verbal apresentada na condição incongruente ${ }^{38}$. Em (4), o inverso aconteceria, i.e., are seria congruente (tendo que, na leitura adjetiva, visiting seria tomado como um modificador adjetivo do substantivo relatives, cujo traço de plural iria requerer um verbo também no plural). De acordo com os resultados, os tempos de resposta (em uma tarefa de leitura em voz alta), para os alvos congruentes com o modelo de discurso, foram significativamente menores do que os tempos de reposta apresentados para os alvos incongruentes, indicando que efeitos de integração de informação contextual poderiam ser detectados bem cedo no processamento da sentença. Contudo, Marslen-Wilson e Tyler (1991) reconhecem que, por conta da técnica experimental, esse tipo de resultado não pode ser encarado como uma evidência definitiva contra o encapsulamento, uma vez que não seria possível eliminar a possibilidade de que tenha havido um processamento sintático encapsulado antes mesmo que os efeitos reportados pudessem ser captados.

Atualmente, com o refinamento e a acessibilidade de técnicas experimentais como o rastreamento ocular e a eletroencefalografia, a discussão a respeito dos níveis de informação empregados durante o processamento online ganha uma nova dimensão, a partir da possibilidade de captar repostas em intervalos de milissegundos e, possivelmente, em momentos mais iniciais do processamento.

No que diz respeito à técnica de potenciais evocados, defensores de modelos interativos vêm lançando mão de técnicas de mapeamento cerebral como uma maneira de monitorar mais precisamente as respostas dos participantes no curso do processamento. Nessa perspectiva, Hagoort e Berkum (2007) apresentam resultados que evidenciariam que a integração de informações discursivas poderia acontecer em momentos iniciais do processamento. As principais evidências vêm

\footnotetext{
${ }^{38}$ Note-se que a condição traz uma forma verbal incongruente com o modelo de discurso, mas que, independente dessa incongruência, poderia ser gramatical.
} 
de estudos com potenciais evocados nos quais é identificada a ocorrência de ondas N400. Em um destes resultados (Berkum et al., 2003), foram apresentadas sentenças incoerentes com o contexto discursivo, como, por exemplo, "Jane told the brother that he was exceptionally slow", em um contexto no qual havia sido dito que o irmão de Jane teria sido rápido. Quando comparadas com sentenças contendo violações semânticas no domínio de uma sentença, o padrão elétrico detectado mostrou-se bastante similar, sendo caracterizado pela ocorrência de ondas N400 com início entre 150 e 200 ms (Figura 3). Segundo os autores, esses resultados demonstrariam que efeitos de integração de informação discursiva podem surgir a partir de $150 \mathrm{~ms}$, em contraponto a estudos anteriores, nos quais se defendia que este tipo de informação seria armazenada na memória para recuperação, gerando efeitos apenas a partir de 300-400 ms, pelo menos (Ericsson \& Kintsch 1995; Kintsch 1998).

Figura 3 - Efeitos N400 disparados por anomalias semânticas e contextuais
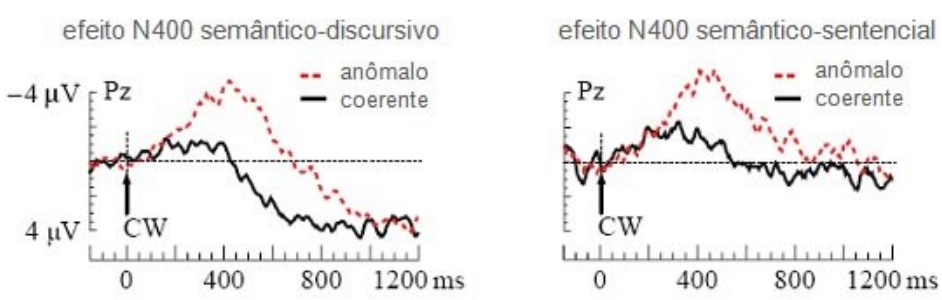

Em um experimento posterior, Nieuwland e Van Berkum (2006) apresentaram gravações de narrativas em duas condições:

A woman saw a dancing peanut who had a big smile on his face. The peanut was singing about a girl he had just met. And judging from the song, the peanut was totally crazy about her. The woman thought it was really cute to see the peanut singing and dancing like that. The peanut was salted/in love, and by the sound of it, this was definitively mutual. He was seeing a little almond. (Nieuwland e Van Berkum, 2006)

Numa condição, havia uma informação semanticamente incoerente em um nível sentencial (in love), mas coerente com o discurso; em outra, uma informação semântica coerente (salted), mas incoerente com o discurso. De acordo com os resultados, a condição discursivamente anômala provocou uma onda N400 maior do que a condição semanticamente anômala (Figura 4). 
Figura 4 - Efeitos N400 reportados em Nieuwland \& Van Berkum (2006).

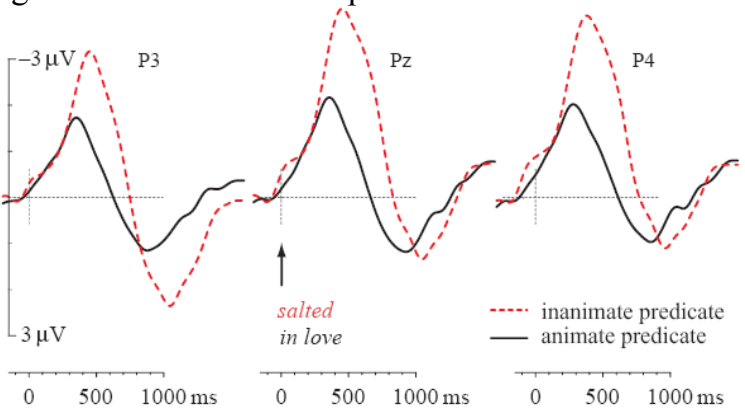

Investigando a análise inicial de sentenças ambíguas, van Berkum, Brown e Hagoort (1999) reportam um experimento indicando que informação contextual poderia ser considerada em momentos iniciais do processamento de sequências do holandês. Sentenças como (5) e (6), que possuem uma ambiguidade em dat (que, seguindo um nome de gênero neutro, pode ser analisado como um relativo ou complementizador) foram apresentadas em contextos como (7) e (8). Aquele favoreceria uma leitura de completiva, enquanto este uma leitura de relativa.

Considerando resultados indicando que o abandono de uma análise sintática inicial em favor de outra eliciava um onda do tipo P600/SPS, os autores monitoraram a atividade neural dos participantes numa tarefa de Apresentação Visual Serial e lançaram mão da hipótese de que, se contexto discursivo influencia o processador na resolução de ambiguidades, quando (5) fosse apresentada após o contexto (8) deveria haver a emissão deste tipo de onda na palavra desambiguizadora (ie., er), bem como no caso de (6) no contexto (7). Os resultados reportados mostraram-se compatíveis com essa hipótese.

(5)

David vertelde het meisje dat er visite kwam

David told the girl NEU $_{\text {tham }}$ there would be some visitors

(6)

David vertelde het meisje dat had zitten bellen op te hagen

David told the girl NEU $_{\text {the }}$ ReL(NEU) $_{\text {had }}$ been phoning to hang up

Contexto com 1 referente :

David had de jongen en het meisje gezegd nun kamer voor de lunch op te ruimen. Maar de jongen had de hele ochtend liggen slapen, en het meisje had voortdurend zitten bellen. (David had told the boy and the girl to clean up their room before 
lunch time. But the boy had stayed in bed all morning, and the girl had been on the phone all the time.)

\section{Contexto com 2 referentes:}

David had de twee meisjes gezegd nun kamer voor de lunch op te ruimen. Maar het ene meisje had de hele ochtend liggen slapen, en het andere had voortdurend zitten bellen. (David had told the two girls to clean up their room before lunch time. But one of the girls had stayed in bed all morning, and the other had been on the phone all the time.)

Neste estudo, foram testadas também sentenças como (9), que também têm uma leitura de completiva como (5), mas que não poderiam ser analisadas como relativas na presença de dat, uma vez que vrouw, pertencente ao gênero comum, demandaria o pronome die, também comum, no caso de uma relativa. Neste tipo de sentença, foi detectada a presença de P600/SPS entre 400 e $500 \mathrm{~ms}$ depois de dat quando antecedida por um contexto de dois referentes. Este resultado seria, segundo van Berkum, Hagoort e Brown (2000), bem prematuro e, portanto, capaz de revelar a influência de informação discursiva na análise sintática inicial. Mesmo diante de uma evidência de natureza formal, o gênero, o processador pareceu considerar, pelo menos momentaneamente, a análise favorecida pelo discurso, já que o padrão P600 foi detectado ainda em dat.

Em um trabalho posterior, para evitar a interferência de estratégias conscientes de compreensão em razão do longo período de apresentação dos segmentos das sentenças testadas (600 ms) na versão escrita, Brown, van Berkum e Hagoort (2000) reaplicam o experimento do trabalho de 1999, mas, dessa vez, apresentando os estímulos críticos oralmente em prosódia neutra, obtendo, contudo, resultados semelhantes aos da tarefa de Apresentação Visual Serial.

David vertelde de vrouw dat er visite kwam.

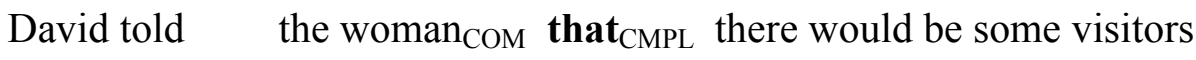

Brysbaert e Mitchell (2000) questionaram os resultados de van Berkum, Brown e Hagoort (1999), sugerindo, por exemplo, que a informação de gênero do pronome relativo, em certos casos, poderia ser ignorada no holandês. A partir da análise de questionários foi observado que, mesmo no processamento offline, 
leitores associaram pronomes relativos a um nome de gênero incompatível em mais de 20\% dos estímulos (Brysbaert e Mitchell, 1996; Mitchell et al., 2000). Contestando a hipótese de que o contexto poderia induzir a análise inicial da sentença, Brysbaert e Mitchell (2000), na linha de um modelo good-enough como o de Ferreira e Henderson (1999), defendem que parte das informações sintáticas poderia ser ignorada na construção de representações iniciais. Brysbaert e Mitchell (2000) sugerem ainda uma interpretação alternativa para os resultados de van Berkum, Brown e Hagoort, levantando a possibilidade de os resultados terem emergido não em função do parser assumir informação discursiva em sua análise inicial, mas em função de uma reanálise, o que seria condizente com a possibilidade de um processamento sintático encapsulado. Brysbaert e Mitchell (2000) questionam, ainda, a interpretação do padrão P600/SPS, que, caso fosse interpretado como um indicador da forma como os participantes atualizam seus modelos de discurso (Coulson et al., 1998), poderia ser relacionado a processos pós-sintáticos, relativos à etapa de reanálise.

Em anuência a uma das críticas apresentadas, van Berkum, Hagoort e Brown (2000), da mesma forma que Marslen-Wilson e Tyler (1991), reconhecem que, pela falta de um conhecimento preciso a respeito do curso temporal dos eventos sintáticos, só é possível considerar que os resultados reportados reflitam uma sintaxe não encapsulada caso se assuma que um processamento sintático modular não haveria ocorrido antes da detecção dos efeitos reportados. Em contrapartida, endereçam uma crítica frequente aos mecanismos estruturais de resolução de ambiguidade:

First of all, why would the parser ignore potentially useful context information in favor of a syntax-based heuristic if the system can bring context information to bear on parsing so quickly... (Berkum, Hagoort e Brown, 2000)

A respeito dessa crítica deve-se notar, contudo, que embora heurísticas de natureza estrutural para a resolução de ambiguidades estejam sujeitas a gerar resultados incongruentes com o input, também a integração incremental de informação contextual pode levar a uma análise improcedente de sentenças ambíguas, como deixam supor os próprios resultados reportados em Berkum, Hagoort e Brown (2000). O mecanismo de resolução por recurso ao contexto pode também ser considerado um procedimento heurístico, uma vez que é 
implementado sem o benefício do recurso à informação desambiguizadora definitiva, podendo gerar, assim como os mecanismos estruturais, resoluções improcedentes, sendo, contudo, mais custoso que estes últimos.

Investigando também os mecanismos de resolução de ambiguidades diante de informação contextual a partir da técnica de potenciais evocados, outro estudo apresentou contraevidências à hipótese de processamento em estágio único (Vos e Friederici, 2003). Indivíduos classificados de acordo com seu desempenho numa avaliação da memória de trabalho foram apresentados a relativas e completivas temporariamente ambíguas do alemão encabeçadas por um DP-objeto e antecedidas por informação contextual diretiva ou neutra. Nos indivíduos com maior capacidade de memória de trabalho, um padrão do tipo P600 foi detectado, à altura do elemento desambiguizador, em ambos os tipos de contexto apresentados (um indicativo provável de que estes indivíduos inicialmente interpretariam o DP inicial da sentença como sujeito, de acordo com a leitura preferencial deste tipo de estrutura), enquanto em indivíduos com baixa capacidade de memória não houve emergência deste tipo de padrão (o que poderia estar associado a uma incapacidade de realizar a reanálise, pelas limitações da memória de trabalho). Contudo, resultados obtidos em perguntas de compreensão dos estímulos revelaram que os sujeitos com menor capacidade de memória registravam uma melhora em seu desempenho nas condições nas quais informação contextual diretiva era apresentada, sugerindo que se beneficiariam de informação discursiva no processamento offline. Nas medidas obtidas durante o processamento online, não foram detectados efeitos de informação contextual na análise inicial, contradizendo a previsão de processadores interativos.

Em um dos experimentos que reportaremos neste trabalho, buscaremos avançar na compreensão de processos integrativos na compreensão de relativas, investigando também o papel de informação contextual no processamento dessas sentenças por meio da técnica de rastreamento ocular. Embora seja limitada à investigação de estímulos linguísticos que possam ser associados a uma representação visual ${ }^{39}$, essa técnica tem a vantagem, em comparação a técnicas de mapeamento cerebral, de revelar com maior transparência a ocorrência de

\footnotetext{
${ }^{39}$ Essa limitação é particularmente aplicável ao visual world paradigm, no qual movimento ocular dos participantes é rastreado enquanto estes manipulam objetos ou observam ilustrações a partir de um comando ou estímulo linguístico. Neste paradigma, os estímulos linguísticos devem ser construídos de forma que possam ser associados a ilustrações ou objetos apresentados visualmente.
} 
processos referenciais (mas veja-se a seção 4.1) e, por esse motivo, vem sendo amplamente empregada na literatura psicolinguística (Ferreira e Tanenhaus, 2007, Kamide, 2008; Maia, 2008; Hartsuiker, Huetigg e Olivers, 2011; Trueswell et al., 1999), especialmente na investigação de processos integrativos e antecipatórios, possibilitando, além disso, a detecção de dificuldades de processamento e de preferências estruturais em estímulos escritos (Demberg e Keller, 2008; Altmann et al., 1998).

No que diz respeito à investigação da influência de informação contextual na compreensão, Trueswell \& Tanenhaus (1992), por exemplo, detectaram, na leitura, que uma frase ambígua, como "The student spotted by the proctor..." (na qual, em geral, existe uma tendência de interpretar spotted como um verbo da oração principal), pode ter uma leitura de relativa induzida por um contexto que faça menção a um evento futuro, como, por exemplo, “...tomorrow... a proctor will notice one of the students cheating", em conformidade com alguns dos resultados com potenciais evocados já apresentados nesta seção. Sugerindo que, além de informação contextual discursiva, também informação de natureza visual poderia ser rapidamente acessada e integrada, são reportados resultados indicando que a ambiguidade no processamento online de sentenças contendo PPs temporariamente ambíguos quanto ao local de aposição ("Put the apple on the towel in the cup") poderia ser mais facilmente resolvida diante de contextos visuais informativos (Tanenhaus et al., 1995; Trueswell et al., 1999).

No que diz respeito à ocorrência de processos antecipatórios, argumentouse, em uma série de estudos (Altmann e Kamide, 1999; 2007; Kamide et al., 2003; Kamide, 2008), que movimentos oculares poderiam indicar, além de integração de informação discursiva, a antecipação de material linguístico não apresentado. No influente estudo de Altamann e Kamide (1999), por exemplo, foi observado que em uma sentença como "The boy will eat the cake", os participantes dirigiam seu olhar à ilustração de um bolo (em um set com outras ilustrações concorrentes) já a partir do segmento relacionado ao verbo da sequência. Mesmo quando, em uma outra condição, o pretenso alvo era retirado de cena antes da apresentação do estímulo linguístico, os olhos continuavam a se mover na direção que o bolo ocupava anteriormente. Em Altman e Kamide (2007), os experimentos reportados buscaram investigar o impacto da marcação temporal no direcionamento do olhar. No primeiro experimento, os autores confrontam sentenças como 'The man will 
drink the beer' e 'The man has drunk the wine', apresentando aos participantes figuras como a Figura 5, na qual há um copo vazio, suposto alvo do verbo no passado, e um copo cheio, pretensamente, alvo da sentença com o verbo no futuro.

Figura 5 - Estímulo visual apresentado em Altmann e Kamide (2007)

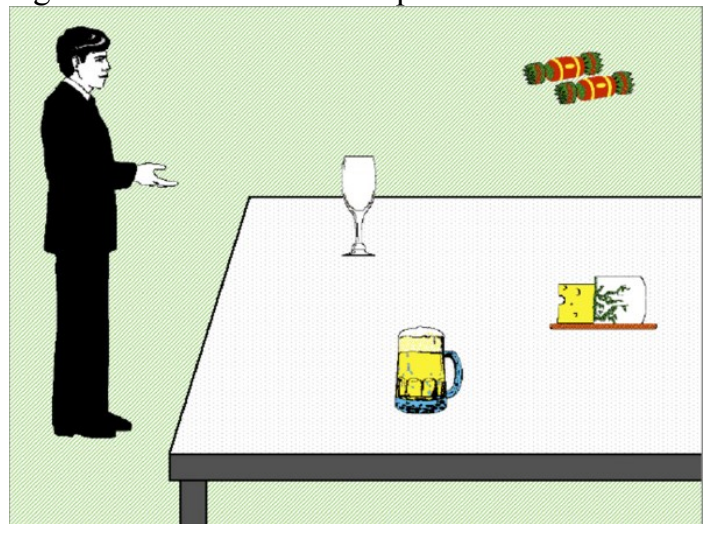

Segundo os resultados, os participantes tendiam a olhar mais frequentemente para o copo vazio (e para objetos análogos em outros estímulos) na condição envolvendo frases como 'The man has drunk the wine', ainda que, na condição com o verbo no futuro, o alvo hipotético não tenha contabilizado um número significativamente maior de olhares. Num segundo experimento, acrescentou-se às frases a expressão "all of”, procurando facilitar a associação entre a condição de futuro com o copo cheio. Com essa reformulação, tanto na condição de futuro, quanto na de passado, os participantes tornaram-se propensos a olhar mais para os possíveis alvos no início da expressão referencial. ${ }^{40}$

De maneira geral, esses resultados, como outros apresentados até aqui, vêm sugerindo a integração incremental de informação contextual e a ocorrência de

\footnotetext{
${ }^{40} \mathrm{O}$ trabalho de Altmann e Kamide (2007) é especialmente direcionado a demonstrar a relação entre atenção visual e processamento linguístico. Em relação a essa questão, os autores confirmaram a ideia de que o olhar tende a antecipar a entidade que deverá ser referida no desenrolar de uma sentença. Segundo os autores, o comportamento observado poderia ser explicado por uma interseção entre as propriedades da representação conceitual disparada pelos objetos representados por meio da figura e a representação conceitual disparada pelo estímulo linguístico, de forma que, mesmo que a sentença não esteja literalmente representada na ilustração, os olhos seriam capazes de antecipar o alvo potencial da ação. Essa interseção conceitual parece ser compatível, segundo Altmann e Kamide, com resultados anteriores (Huettig e Altmann, 2005) no qual foi notado que uma palavra como piano, por exemplo, pode conduzir o olhar para a imagem de um trompete (num set contendo outras imagens). Os resultados também estão, em certa medida, na mesma direção assinalada pelos defensores da 'situated vision', que propõem que a visão serviria como um tipo de 'memória externa' (e.g., Ballard, Hayhoe, Pook \& Rao, 1997; O'Regan, 1992). Em especial, ressalta-se a possibilidade de que essa antecipação refletira mudanças no estado atencional do sistema cognitivo.
} 
processos antecipatórios com base em informação não estrutural. Nos experimentos reportados no capítulo 4, recorremos a algumas das estratégias experimentais apresentadas nessa seção, como a manipulação de informação contextual visual e discursiva, com o objetivo de testar, no processamento de orações contendo relativas de objeto, ao menos duas hipóteses relacionadas à discussão que apresentamos: a de que informação contextual visual informativa pode ser associada à antecipação do mapeamento de sentenças em referentes visuais e a de que informação contextual diretiva pode interferir na análise sintática inicial de sentenças contendo orações relativas (e completivas) temporariamente ambíguas.

Com base nos resultados, pretendemos questionar a interpretação de evidências relacionadas a processos integrativos e antecipatórios como argumentos favoráveis a um processador em estágio único. Buscaremos discutir a proposta de que a transferência gradual, a partir do componente sintático, de informações aos domínios interpretativos poderia permitir a associação incremental entre informação de natureza sintática e informação interpretativa, mantendo, contudo, o princípio da autonomia do processador sintático. Considerando essa proposta, argumentaremos, conforme o fazem Clifton e Duffy (2001) numa ampla revisão sobre a integração incremental de informação contextual, que, embora evidências como as que apresentamos nesta seção possam indicar que a análise inicial seria influenciada pelo discurso, também podem sugerir, simplesmente, que o discurso facilitaria uma determinada análise (ou favoreceria um processo de reanálise) e, além disso, que, embora o apoio de um contexto discursivo possa reduzir efeitos de garden-path, esses não são eliminados completamente.

\section{3.}

\section{Antecipação, integração e custo no processamento de orações relativas}

Nesta seção, apresentamos o debate acerca de alguns aspectos relacionados ao processamento de sentenças contendo orações relativas. Em vista de nossos objetivos neste trabalho e dando continuidade à discussão apresentada na seção anterior, abordaremos, em especial, evidências que tratam de processos integrativos e preditivos no processamento desse tipo de sentença. Nessa 
trajetória, serão abordadas questões que dizem respeito à relação filler-gap, ao custo de processamento desse tipo de estrutura e ao papel dos DPs associados ao verbo encaixado.

No que diz respeito à questão da antecipação no estabelecimento da relação filler-gap, um dos resultados sugerindo que o processador atuaria preditivamente vem do trabalho de Stowe (1986). Comparando a leitura automonitorada de sentenças como (10) e (11), foi detectado que, à altura do pronome "us", o tempo de leitura se tornava maior em se tratando de orações completivas com um elemento WH- deslocado (11).

(10) My brother wanted to know if Ruth will bring us home to Mom at Christmas.

(11) My brother wanted to know who Ruth will bring us home to at Christmas.

$\mathrm{O}$ que foi chamado de efeito de gap preenchido (filled gap effect) foi entendido, na perspectiva de um parser de base estrutural, como resultante da busca ativa do parser pelo gap (Frazier \& Clifton, 1989; Frazier e Flores d'Arcais, 1989). Em função do filler, o parser prediria que um gap deveria ser encontrado em seguida ao verbo "bring", uma previsão que seria frustrada pela presença do pronome $u s$. Essa previsão, segundo a proposta da "estratégia ativa de busca do gap" ${ }^{\prime 1}$, seria realizada com base em informação de natureza estritamente estrutural.

\section{Active Filler Strategy}

When a filler has been identified, rank the option of assigning it to a gap above all other options. (Frazier \& Clifton, 1989, p. 95)

Boland et al. (1995), entretanto, apresentaram evidências sugerindo que este tipo de previsão levaria em conta informação a respeito da plausibilidade da relação entre o filler e um verbo. Procurando negar a existência de um processador sintático autônomo, foram apresentadas evidências que sugerem a influência de propriedades temáticas do verbo na procura por uma posição para o filler. Nesse sentido, argumentou-se que o efeito do gap preenchido poderia desaparecer em sentenças nas quais o filler é um complemento implausível do verbo. Investigando interrogativas como (12) e (13), numa tarefa de stop-making-

\footnotetext{
${ }^{41}$ Tradução livre de Active Filler Strategy.
} 
sense palavra-por-palavra, foi detectado que participantes tendiam a dizer que a sentença parava de fazer sentido ao ler "machine guns" no caso de (13). Esse resultado seria decorrente do fato de "machine guns" ser um Tema implausível em (13) (mas não em (12)). A implausibilidade, entretanto, só poderia ser detectada, de acordo com Boland et al. (1995), caso o processador já houvesse, no momento em que encontra o verbo, deliver, atribuído à preschool nursery, o papel de recipiente/alvo.

(12) Which military base did Hank deliver the machine guns to _ last week?

(13) Which preschool nursery did Hank deliver the machine guns to _ last week?

Esses resultados poderiam indicar que os participantes fariam um uso incremental da informação temática do verbo, considerando a plausibilidade de uma relação. Na interpretação de Boland et al. (1995), esses resultados poderiam ser tomados como evidencia de que, duas análises diferentes poderiam ser computadas ao longo do processamento e que a informação a respeito de plausibilidade seria utilizada na avaliação da adequabilidade de cada uma delas durante o curso do processamento, em acordo com a hipótese das teorias baseadas em restrições. Cabe notar, entretanto, a possibilidade de que, pela natureza da tarefa, tenha sido possível a interferência de uma reflexão consciente dos participantes a respeito das estruturas.

Evidências similares na compreensão de relativas, contudo, foram observadas também com a técnica de rastreamento ocular (Pickering \& Traxler, 1998). Notou-se que, em sentenças como (14), o tempo de first-pass reading em "several of the" era maior do que em (15). Esse resultado poderia sugerir que o processador haveria antecipado uma relação entre o núcleo da relativa e o verbo em (14), mas não em (15), já que só no primeiro caso foi verificado um efeito de gap preenchido. Ao encontrar "several of the", seguindo o verbo, haveria uma quebra de expectativa apenas em (14), mas não em (15), possivelmente, pela implausibilidade de "movies" ser tomado como complemento de "remind". De acordo com Pickering e Traxler (2001), para que o estabelecimento deste tipo de relação fosse possível, pelo menos alguma informação de natureza não estrutural deveria ser computada incrementalmente durante a análise da sentença, de forma que o processador só buscaria estabelecer uma relação filler-gap caso uma 
checagem de traços de natureza semântica determinasse a compatibilidade entre o filler e o verbo.

(14) That's the child that Mark reminded several of the women to watch this evening.

(15) That's the movie that Mark reminded several of the women to watch this evening.

Contrariando, em parte, esses resultados, em um estudo posterior de rastreamento ocular, estímulos semelhantes contendo verbos intransitivos (The party that the student arrived promptly for _ at the fraternity house was late in getting started) foram contrastados com estímulos contendo verbos opcionalmente transitivos (The gadget that the manager called occasionally about_after the accident still didn't work). Detectou-se que, no caso dos verbos transitivos, a incompatibilidade entre os DPs que precediam o verbo ocasionava dificuldade de leitura à altura do advérbio ou do verbo que o precedia, o que não ocorria no caso dos verbos rigorosamente intransitivos, sugerindo que a informação de subcategorização do verbo seria considerada prioritariamente no processamento (Staub, 2007). Resultados obtidos por Omaki et al. (2010) - apresentados na sequência desta seção -, contudo, parecem ir em uma direção contrária.

Além da possibilidade de integração online de informação temática, outra questão que vem sendo investigada, conforme apresentado na seção anterior, diz respeito à integração de informação de natureza discursiva (van Berkum, Brown e Hagoort, 1999; van Berkum, Hagoort e Brown, 2000; Hagoort e van Berkum, 2007). Em uma investigação sobre a compreensão de relativas, contextos discursivos foram manipulados com o objetivo de verificar em que medida informação contextual prévia influenciaria a interpretação de relativas restritivas e não restritivas e em que medida poderiam ser verificadas alterações no custo de processamento (Grodner, Gibson e Watson, 2005). Considerando que relativas restritivas implicam na existência de um set de referência a partir do qual o modificador relativo 'escolhe' um elemento por meio de uma característica expressa na oração encaixada e considerando que relativas não restritivas fornecem apenas informação adicional não restritiva concernente a um DP (não implicando, assim, um set de contraste), Grodner, Gibson e Watson (2005) 
investigaram a hipótese de que informação contextual discursiva convergente facilitaria a leitura de orações dessa natureza. Em uma tarefa de leitura automonitorada de palavra-por-palavra, foram apresentadas restritivas e não restritivas em contextos nulos (i.e., sem contexto) e com contextos de amparo ((16) e (17)). Os resultados apresentaram um efeito principal de contexto e também uma interação entre contexto e tipo de relativa. Analisando os segmentos relativos ao sujeito e ao verbo da relativa, verificou-se que o contexto nulo desfavoreceu a leitura das restritivas, quando comparadas às não restritivas. Por outro lado, o contexto de apoio, gerou diferenças significativas entre os dois tipos de relativas favorecendo as restritivas. De acordo com os autores, os resultados indicariam que o modelo de discurso poderia induzir escolhas da sintaxe.

\section{(16) Relativa restritiva}

A vicious guard dog bit a postman on the leg and another postman on the arm. The postman that the dog bit on the leg needed seventeen stiches and had a permanent scar from the injury.

\section{(17) Relativa não restritiva}

A vicious guard dog bit a postman and a garbage man.

The postman, who the dog bit on the leg, needed seventeen stiches and had a permanent scar from de injury.

Efeitos de integração de informação contextual também foram detectados na resolução da ambiguidade de aposição em orações relativas (Rohde, Levy e Kehler, 2011). Em um tarefa de leitura automonitorada, foram apresentadas sentenças contendo orações relativas ambíguas quanto ao ponto de aposição, como "John detests/babysits the children of the musician who is/are generally arrogant". Em sentenças como essa, foram contrastados os efeitos do tipo de verbo empregado na oração principal. Na condição de "causalidade implícita", o verbo empregado tendia a gerar a expectativa de uma explicação subsequente (eg., detests), enquanto que, na condição de "causalidade não implícita", não haveria essa expectativa. Explorando a possibilidade de orações relativas atuarem, no contexto extraoracional, como um elemento explicativo e também a tendência de que a explicação implicada por verbos como "detest" seja apresentada no objeto, 
analisou-se o contraste entre os tipos de verbo principal apresentados e as preferências de aposição. De acordo com os autores, a preferência pela aposição baixa, comum no inglês, foi reduzida na condição de causalidade implícita, conforme detectado pelos tempos de leitura à altura do advérbio, o que, segundo eles, poderia ser resultante da atuação das expectativas discursivas no mecanismo de resolução de ambiguidades.

Também investigando o papel de informação contextual, mais especificamente, informação contextual de natureza visual, no processamento de sentenças contendo relativas, Eberhard et al. (1995) relatam um experimento no qual os participantes foram apresentados a um conjunto de miniaturas de cartas de baralho, concomitantemente a instruções como "Put the five of hearts that is below the eight of clubs above the three of diamonds", que continham relativas de sujeito. Em uma sentença como essa, a desambiguização da referência poderia ser possível, de acordo com o conjunto de cartas apresentado visualmente, em um, dentre três segmentos considerados (eg., below, eight ou clubs). Latências para o objeto alvo indicaram um efeito significativo do ponto de desambiguização, sugerindo que o mapeamento referencial ocorreria incrementalmente, assim que informação distintiva se apresenta.

Evidências dessa natureza sugerem tanto a atuação preditiva do processador como o acesso a informação não estrutural durante o curso do processamento. Contudo, informações de natureza gramatical parecem restringir a possibilidade de processos antecipatórios. Além de resultados que indicam que a plausibilidade da relação entre um filler e o verbo pode interferir na atuação de processos preditivos possivelmente empregados pelo processador, mais recentemente, foram reportados resultados que sugerem que fatores estruturais estão envolvidos nesse mecanismo. De acordo com Wagers e Philips (2009), a existência de ilhas sintáticas parece desencorajar o processador a se engajar em uma busca ativa pelo gap, como na sentença abaixo (18). O fato de não haver uma procura por um gap derivaria de um parser que atua de acordo com conhecimento gramatical.

(18) *Which babysitter did the revelation that the toddler tormented frighten her mother? 
Wagers e Philips (2009) apresentam três experimentos que investigaram estruturas de relativas com VPs coordenados e estruturas com parasitic gap. A leitura automonitorada de sentenças como (19) e (20) demonstrou que, na versão implausível da sentença com VPs coordenados, a leitura era mais lenta na região do segundo verbo.

(19) VPs coordenados

Plausível: The adhesive coating that the talented engineer designed for his

boss and methodically sprayed the special test surfaces with _ in his new laboratory could make the company lots of money.

Implausível: The computer program that the talented engineer designed _ for his boss and methodically sprayed the special test surfaces with in his new laboratory could make the company lots of money.

\section{(20) Parasitic gap}

Plausível: The adhesive coating that the talented engineer from the high-tech aerospace firm methodically sprayed the special test surfaces with in his new laboratory could make the company lots of money.

Implausível: The computer program that the talented engineer from the high-tech aerospace firm methodically sprayed the special test surfaces with in his new laboratory could make the company lots of money.

A diminuição na velocidade de leitura poderia sugerir a atuação de um mecanismo de busca ativa pelo gap, que, contudo, poderia ser impactado pela incompatibilidade entre verbo e o filler. Por outro lado, a assimetria entre as versões plausíveis e implausíveis não foi observada no caso dos parasitic gaps. Wagers e Philips (2009) sugerem que a taxa de velocidade não seria diminuída na versão implausível pela inoperatividade do mecanismo de busca ativa pelo gap. Assim, ao passo que no caso do VP coordenado o parser se engajou numa busca ativa pelo gap, no caso das sentenças com parasitic gap o mesmo não ocorreria, o que poderia sugerir que o parser, guiado por conhecimento gramatical, procura um segundo gap apenas quando este é obrigatório (VPs coordenados), mas não quando ele é opcional (adjuntos com parastic gap). 
Os autores interpretam esses resultados defendendo a ideia de um principlebased parsing, segundo o qual se entende que o efeito de gap preenchido seria resultante de uma pressão para que requerimentos gramaticais sejam satisfeitos. Nessa perspectiva, o objetivo do parser ao atuar preditivamente, antecipando a existência de gaps, seria o de licenciar a estrutura e satisfazer requerimentos gramaticais.

$\mathrm{Na}$ mesma linha de investigação, Omaki et al. (no prelo) compararam sentenças relativas com verbos encaixados transitivos e intransitivos em versões com e sem ilhas sintáticas, como nos exemplos abaixo. A versão transitiva da relativa, em (23), ao contrario da versão intransitiva em, (21), possui um verbo que tem o núcleo da relativa como complemento implausível. Comparando o tempo de leitura dos verbos relativos das sentenças, verificou-se que as primeiras fixações e a duração do olhar foram maiores, durante o verbo encaixado, nas versões sem ilha - (21) e (23) - do que nas versões com ilha - (22) e (24). Seguindo o raciocínio de Wagers e Philips (2009), nas versões com ilha o parser não se engajaria na busca ativa pelo gap em função de restrições gramaticais. $\mathrm{Na}$ versão transitiva sem ilha, (23), o estranhamento seria provocado pela incompatibilidade entre o núcleo da relativa e o verbo que seria responsável pela atribuição do papel temático. Entretanto, o resultado de maior interesse, segundo Omaki et al. (no prelo), reside no fato de ser possível detectar dificuldades de processamento também na condição intransitiva sem ilha, (21), já que o estranhamento parece ter sido provocado pelo fato de que, no contexto de uma relativa, o parser parece ter previsto a ocorrência de um verbo transitivo, ou seja, levando em conta a configuração estrutural que sugere uma oração realtiva, o parser poderia ter antecipado a ocorrência de um verbo que pudesse tomar o núcleo da relativa como complemento. Assim, Omaki et al. (no prelo) propõem que o processador atua preditivamente, construindo representações antes mesmo que haja evidência bottom-up suficiente, até mesmo antes que a informação de subcategorização fornecida pelo verbo possa ser acessada. Dados do japonês parecem também apontar para uma conclusão semelhante (Aoshima et al. 2004).

\section{(21) Intransitiva sem ilha}

The airport that the ambassador departed rapidly from during the unrest was closed to most traffic. 


\section{(22) Intransitiva com ilha}

The airport that the ambassador who departed rapidly had visited during the unrest was closed to most traffic.

\section{(23) Transitiva (implausível), sem ilha}

The airport that the ambassador left rapidly for during the unrest was closed to most traffic.

\section{(24) Transitiva (implausível), com ilha}

The airport that the ambassador who left rapidly had visited during the unrest was closed to most traffic.

Resultados como os de Omaki et al. (no prelo) e de Wagers e Philips (2009), quando comparados a outras evidências e abordagens apresentadas ao longo desta seção e no curso deste trabalho, consumam uma das principais controvérsias presentes na literatura sobre o processamento de sentenças e, mais especificamente, também na literatura sobre a compreensão de relativas. Se por um lado, processos integrativos e antecipatórios com base em informações interpretativas parecem emergir ao longo da análise sintática, por outro lado, restrições de natureza estrutural parecem estabelecer restrições para a atuação de mecanismos dessa natureza. Neste trabalho, exploramos três características das orações relativas de objeto, com o objetivo de integrar essa discussão: (i) a relação entre relativas e informação contextual; (ii) a possibilidade de desambiguização da referência de relativas antes do preenchimento do gap; (iii) e a ambiguidade temporária entre relativas e completivas. Como notado por Grodner, Gibson e Watson (2005), por se constituir como um modificador, as relativas implicam na existência de um set de referência, no qual dois referentes representados por um mesmo DP serão distinguidos por meio de uma propriedade expressa na relativa. Neste trabalho, exploraremos experimentalmente esta competição entre entidades no processamento referencial envolvido em relativas, recorrendo à técnica de rastreamento ocular com o objetivo verificar em que medida a manipulação de informação contextual influencia o momento de desambiguização da referência. 
Contudo, diferentemente do trabalho de Eberhard et al. (1995), no qual uma estratégia semelhante foi empregada, avaliaremos a compreensão de relativas de objeto, uma vez que estas últimas podem permitir que a desambiguização da referência se dê mesmo antes da disponibilidade de informação verbal (Cf. seção 4.2). Nesse sentido, pretendemos não apenas investigar a natureza da interação entre informação contextual, mas também em que medida a informação relativa a DPs pode, independentemente de informação verbal, atuar em processos antecipatórios e integrativos, considerando a hipótese (defendida em trabalhos que apresentaremos a seguir) de que informação discursiva e interpretativa concernente a esses constituintes poderia ser acessada (e influenciar o processamento) no curso da análise de relativas. Exploraremos também a ambiguidade introduzida pelo marcador relativo, mas diferentemente de experimentos apresentados neste trabalho (Grodner, Gibson e Watson, 2005; Rohde, Levy e Kehler, 2011; van Berkum, Brown e Hagoort, 1999; van Berkum, Hagoort e Brown, 2000), buscaremos avaliar a influencia de informação contextual no processamento online de relativas por meio da técnica de rastreamento ocular, uma vez que, na presença de referentes visualmente apresentados, essa técnica permite verificar mais transparentemente (do que técnicas envolvendo tempos de resposta ou mapeamento cerebral) a ocorrência de processos referenciais e, consequentemente, de processos integrativos.

Conforme já mencionado, uma das motivações para os experimentos que investigarão o papel dos DPs no curso do processamento de relativas de objeto vem pesquisas que sugeriram efeitos de informação de natureza interpretativa associada aos DPs da relativa, como a animacidade e a acessibilidade discursiva, durante o processamento online deste tipo de oração.

Nessa direção, pesquisas têm mostrado que a já amplamente documentada assimetria de custo entre relativas de sujeito e objeto (no inglês: Sheldon, 1974; Wanner e Maratsos, 1978; Gibson et al., 2005; no alemão: Mecklinger et al. 1995; no holandês: Frazier, 1987; Mak, Vonk, e Schriefers, 2002; no português: Corrêa, 1995a; Costa, Lobo e Silva, 2011; no francês: Cohen e Mehler, 1996; ERPs: King e Kutas, 1995; fMRI: Caplan et al., 2002) pode ser influenciada pela natureza dos DPs envolvidos na relativa, que podem ampliar ou reduzir o custo de processamento. Mak, Vonk \& Schriefers (2002, 2006), por exemplo, sugerem que, no holandês, a animacidade do DP poderia interagir com fatores estruturais 
na determinação do custo de processamento de orações relativas. Os autores reportam que, quando o sujeito de uma relativa é animado e seu objeto inanimado, não há maior dificuldade no processamento de relativas de objeto do que no processamento de relativas de sujeito. Quando os dois DPs envolvidos na relativa são inanimados, há uma preferência pela relativa de sujeito, enquanto relativas de objeto parecem conduzir a um processo de reanálise. O custo e as preferências de leitura relacionadas às relativas, na visão de Mak, Vonk \& Schriefers (2002, 2006), seriam assim derivadas de uma estratégia de parsing na qual seriam computados continuamente fatores estruturais e semânticos, em uma abordagem compatível com teorias baseadas em restrições. Por outro lado, Traxler, Morris e Seely (2002), reportando resultados similares, no inglês, consideram que resultados dessa natureza poderiam ser explicados por um processo de reanálise. Em princípio, o parser atuaria sob uma estratégia de natureza estrutural, considerando o sujeito da oração matriz como o sujeito da relativa. Quando confrontado com uma relativa de objeto, o parser teria que recorrer à reanálise. Somente então, informação a respeito da animacidade seria considerada e poderia facilitar ou dificultar o processo de reanálise ${ }^{42}$.

Além de propriedades semânticas como a animacidade, aspectos referenciais e discursivos de DPs em relativas poderiam se mostrar relevantes para o custo de processamento. Warren e Gibson (2002; 2005) observaram que a manipulação de diferentes tipos de DP no interior das relativas poderia ocasionar alterações nas medidas de custo. Em um experimento de leitura automonitorada, à altura do verbo da relativa, sentenças do tipo (25) seriam lidas mais lentamente que sentenças do tipo (26), que, por sua vez, seriam lidas mais lentamente do que sentenças do tipo (27).

(25) It was the lawyer who the businessman

(26) It was the lawyer who Dan

(27) It was the lawyer who we avoided at the party. avoided at the party. avoided at the party.

\footnotetext{
42 No que diz respeito ao processamento de relativas de objeto por parte de crianças, sugeriu-se que o número de DPs animados (independentemente de estarem na relativa ou na oração principal) poderia influenciar o processamento (Corrêa, 1995), o que foi explicado em termos de uma avaliação prévia de possíveis relações semânticas a partir de busca lexical em tarefas de manipulação de objetos.
} 
Considerando a Syntactic Prediction Locality Theory (Gibson, 1998, 2000), na qual se faz uma diferenciação entre custo de integração (entendido como o custo de integração de itens à estrutura sintática em construção, calculado com base no número de novos referentes discursivos introduzidos desde que o filler é detectado até o seu encaixamento) e custo de memória (entendido como relacionado à manutenção de elementos na memória para integração posterior), Warren e Gibson (2005) interpretam seus resultados com base em uma escala de acessibilidade discursiva. Nesse contexto, pronomes de primeira pessoa seriam uma espécie de referentes default do discurso e, estariam, assim, mais disponíveis no modelo de discurso, o que diminuiria seu custo de integração. Nomes próprios estariam um pouco menos acessíveis, enquanto DPs completos definidos, como em (25), por outro lado, exigiriam a integração de um novo referente no discurso, aumentando o custo de processamento. Nessa perspectiva, em contraponto a propostas de processamento sintático autônomo, a referência seria, então, processada no curso da análise sintática e, quanto mais recursos da memória de trabalho direcionados para o processamento referencial, menos recursos estariam disponíveis para manter representações sintáticas, de forma que estas enfraqueceriam, tornando o processamento mais custoso.

Gordon e colegas (Gordon, Hendrick, e Johnson, 2001; 2004; Gordon, Hendrick, Johnson e Lee, 2006), contudo, sugerem que os dados apresentados por Warren e Gibson (2005) poderiam estar sujeitos a uma interpretação alternativa. Nessa proposta, o maior custo de (25), por exemplo, em relação a outras versões da sentença, poderia ser explicado pela similaridade de traços entre o DP núcleo da relativa e o DP sujeito. Em relativas de objeto, na medida em que a memória de trabalho mantém a representação do núcleo da relativa ativa ao mesmo tempo em que é obrigada a processar o sujeito da relativa, a existência de traços comuns aos DPs críticos poderia provocar interferência na memória de trabalho, contribuindo para dificultar o processamento. A manutenção de dois DPs não integrados e similares na memória provocaria interferências na manutenção e na recuperação destes. Evidências para esta proposta advém de resultados experimentais de leitura automonitorada e de rastreamento ocular, nos quais a similaridade dos DPs envolvidos nas relativas de objeto (o DP relativizado e o DP sujeito da relativa) foi manipulado (Gordon, Hendrick, e Johnson, 2001; 2004; Gordon, Hendrick, Johnson e Lee, 2006). Além disso, resultados encontrados pelo grupo de Gibson e 
seus colaboradores sugerem que a acessibilidade referencial dos DPs de uma relativa poderia não ser compatível com resultados obtidos em experimentos mais recentes (Fedorenko, Piantadosi e Gibson, 2012; Cf. capítulo 5). 


\section{4 \\ Experimentos com rastreamento do olhar}

As duas últimas décadas têm assistido a um crescente interesse pela metodologia do rastreamento ocular na investigação do processamento da linguagem. Este interesse parece advir de algumas características desse tipo de técnica que a tornam de grande valia para a pesquisa cognitiva. Nessa técnica, o controle consciente do participante sobre o comportamento que está sendo tomado como variável dependente (os movimentos oculares) é infrequente, já que tal comportamento é, em grande parte, involuntário. O rastreamento ocular proporciona também, ao experimentador, um monitoramento contínuo do sujeito com uma latência potencialmente bem pequena entre o estímulo e a resposta.

Este capítulo apresentará três experimentos que recorreram à técnica de rastreamento ocular para investigar o processamento de orações relativas de objeto. A próxima seção traz uma introdução a essa técnica, contemplando uma breve descrição dos movimentos oculares e, em seguida, apresentam-se questões relativas à interpretação dos movimentos oculares como indicativos de processamento cognitivo em geral e psicolinguístico em particular. Nas seções seguintes, os dois experimentos conduzidos com essa técnica serão relatados.

\section{1.}

\section{0 rastreamento ocular na pesquisa cognitiva}

\subsection{1.}

Parâmetros para o rastreamento ocular: sacadas e fixações

No que concerne ao uso da técnica de rastreamento ocular na investigação psicolinguística, dois são os parâmetros de maior interesse: as sacadas e as fixações ${ }^{43}$. As sacadas são movimentos balísticos, voluntários ou reflexivos, que ocorrem, tipicamente, entre 3 e 4 vezes por segundo e duram entre 10 e 100 milissegundos (Richardson e Spivey, 2004; Martinez-Conde, Macknik e Hubel,

\footnotetext{
${ }^{43}$ Para outros tipos de movimentos oculares, ver Duchowsky (2007, cap. 4).
} 
2004). Durante as sacadas, a visão é praticamente suprimida, retornando somente quando os olhos voltam a repousar (Martinez-Conde, Macknik e Hubel, 2004). O papel funcional deste tipo de movimento é permitir o direcionamento e movimentação apropriada de um pequeno ponto da retina, conhecido por fóvea, região na qual as imagens podem ser captadas com maior acuidade. A visão foveal abrange por volta de $3^{\circ}$ de diâmetro, o que corresponde mais ou menos ao dedo polegar à distância de um braço. Um pouco ao redor da fóvea, a região parafoveal, ainda possui uma resolução relativamente alta e abrange um diâmetro aproximado de $5^{\circ}$. A latência de uma sacada, que compreende o tempo relativo ao processamento de um estímulo até o início da resposta motora, passando pela programação do movimento motor a partir das coordenadas espaciais relativas ao ponto de aterrissagem da sacada, dura em média cerca de $200 \mathrm{~ms}$ (Matin, Shao \& Boff, 1983; Cf. Findlay and Walker, 2011), podendo variar de $100 \mathrm{~ms}$ a até 1000 ms (Cf. Glichrist, 2011; Altmann \& Kamide, 2004).

Figura 6 - Diagrama do olho (Adaptado de: National Eye Institute, National Institutes of Health)

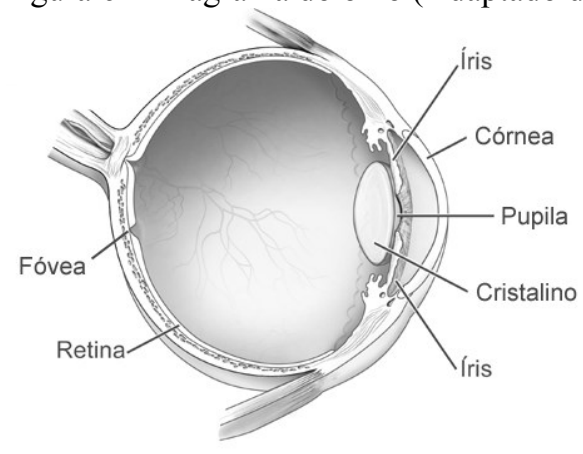

Figura 7 - Acuidade visual em relação à fóvea (Adaptado de: Rayner e Castelhano, 2007)

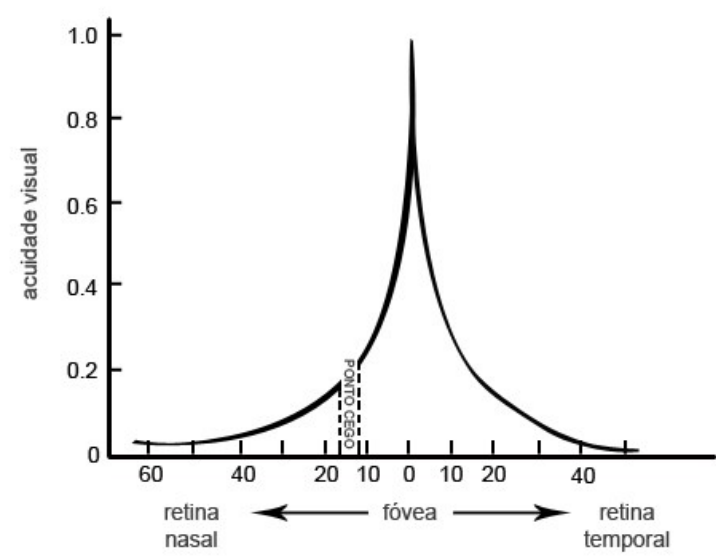

graus a partir da fóvea 
Entre as sacadas, ocorrem as fixações, que são períodos parcialmente estacionários. Em geral, as fixações duram entre 200-300 ms (Richardson, Dale e Spivey, 2007), mas pode haver variação de acordo com o tipo de tarefa na qual o sujeito está engajado, como mostra a Tabela 1. Durante as fixações, ocorrem ainda pequenos movimentos imperceptíveis que mantêm a percepção visual, evitando a adaptação neural e o consequente esvanecimento da visão (Martinez-Conde, Macknik e Hubel, 2004).

Tabela 1 - Características dos movimentos oculares na leitura, percepção de cena e busca visual. (Adaptado de: Rayner \& Castelhano, 2007)

\begin{tabular}{ccc}
\hline Tarefa & Duração média da fixação $(\mathrm{ms})$ & Extensão média da sacada \\
\hline $\begin{array}{c}\text { Leitura } \\
\text { silenciosa } \\
\text { Leitura em voz } \\
\text { alta } \\
\begin{array}{c}\text { Percepção de } \\
\text { cena }\end{array}\end{array}$ & $225-250$ & $8-9$ caracteres \\
Busca visual & & \\
Busca & $275-325$ & 6 - caracteres \\
\hline
\end{tabular}

Nas fixações, a informação visual é analisada com foco na região foveal, aproveitando o nível de resolução disponível na área correspondente a ela. As fixações estão naturalmente relacionadas ao foco de atenção visual (Findlay, 2004), ainda que nem toda a atenção esteja concentrada nesta área, como será visto na seção seguinte. Diante das limitações de resolução na região além da fóvea e também das limitações do sistema cognitivo, que não nos permite processar todo o campo visual ao mesmo tempo, a fixação irá possibilitar a seleção de uma determinada porção do estímulo visual para o processamento. A visão periférica, durante as fixações, permitirá a seleção do alvo para a sacada conseguinte (Irwin, 2004).

\footnotetext{
${ }^{44}$ Tradução de "scene perception". De acordo com Henderson e Hollingworth (1999), uma cena pode ser definida como uma imagem semanticamente coerente, em escala baseada nas proporções humanas, englobando um fundo e ainda objetos discretos. Entretanto, segundo Henderson e Ferreira (2004), a literatura registra o uso deste termo relacionado a outros contextos, como, por exemplo, em referência a conjuntos de objetos dispostos de maneira arbitrária.

${ }^{45}$ Tradução de "visual search". Uma tarefa de busca visual consiste, em geral, na busca consciente de um objeto-alvo, definido por algum tipo de instrução, no contexto de um conjunto delimitado de objetos semelhantes ou não.
} 


\subsection{2. \\ Movimentos oculares e cognição}

As pesquisas que fazem recurso ao rastreamento ocular são baseadas na pressuposição de que os movimentos oculares são reflexos do estado cognitivo de um indivíduo em um determinado momento e, por isso, poderiam nos dizer como e quando certas informações são processadas. Pressupõe-se que, ao direcionar o olhar para um determinado ponto, o sujeito direciona também sua atenção visual a este com vistas a processar informações nele contidas ou relacionadas.

A atenção visual pode ser atraída, por um lado, por propriedades intrínsecas de um estímulo visual, i.e., propriedades relacionadas à forma, tais como cor, brilho, contraste, simetria, complexidade, dentre outras. Essas propriedades, mais concretas e ligadas a processos mais básicos da cognição, costumam ser designadas como propriedades bottom-up. Por outro lado, a atenção visual pode ser atraída por propriedades de natureza interpretativa e conceitual, que costumam receber o nome de propriedades top-down. Ao ser exposto a uma cena, por exemplo, de acordo com Henderson e Ferreira (2004), o sujeito pode ter seus movimentos oculares influenciados por fontes de conhecimento tais como: o conhecimento episódico de curta duração, que diria respeito a uma cena especifica em um momento específico do tempo (por exemplo, o conhecimento de que se acabou de colocar chaves do carro em um determinado lugar); o conhecimento episódico de longa duração, que codifica uma informação potencialmente estável (não momentânea), mas não generalizável nem necessariamente compartilhada, a respeito de uma cena específica (por exemplo, alguém saber que sua cafeteira está sempre ao lado direito de sua pia); o conhecimento de um esquema de cena, que seria um conhecimento genérico acerca de propriedades comuns a certos tipos de cena (por exemplo, saber que placas informando nomes de ruas costumam ser encontradas em cruzamentos); e, por fim, o conhecimento acerca de tarefas, um conhecimento genérico sobre o que fazer diante de certos tipos de tarefas (como saber que mudar de pista em uma estrada requer que se olhe pelo espelho retrovisor).

Muitas pesquisas e modelos no âmbito da percepção visual focam seus esforços na investigação de propriedades bottom-up, como por exemplo, a abordagem que busca desenvolver mapas de saliência, detectando as propriedades 
mais proeminentes de certos estímulos visuais, com o objetivo de derivar previsões a respeito da distribuição de fixações em uma cena (Itti \& Koch, 2000; 2001). Henderson e Ferreira (2004), entretanto, destacam que propriedades intrínsecas do estímulo visual não são suficientes para prever os padrões de movimentação ocular e que fatores top-down, como os apresentados acima, interagem com fatores bottom-up para gerar os padrões de movimentação ocular.

Outra questão que concerne à atenção espácio-visual, diz respeito à maneira pela qual a atenção pode ser dirigida. Sabe-se que a atenção visual pode ser patente ou latentemente direcionada. Ou seja, podemos alocar nossa atenção em um objeto orientando nosso olhar a ele, caso em que se tem a atenção patente (overt attention), ou podemos fazê-lo de maneira menos evidente, alocando recursos cognitivos em um ponto sem que seja necessário dirigir nosso olhar a ele, caso em que se tem a atenção latente (covert attention).

De acordo com Irwin (2004), problemas relacionados a essa dissociação podem dificultar a interpretação de medidas relativas à fixação do olhar. Apresentando uma série de trabalhos que investigaram a relação entre as fixações oculares e o processamento cognitivo, Irwin argumenta que quatro problemas devem ser levados em conta pela psicolinguística. Em primeiro lugar, o processamento cognitivo pode envolver áreas além do ponto de fixação. Um dos estudos que apontam nesta direção é o de Edwards \& Goolkasian (1974). Eles desenvolveram um experimento que consistia de quatro tarefas: detecção de um ponto de luz, reconhecimento de formas, identificação de letras e categorização de palavras de três letras. Cada uma das tarefas deveria ser desempenhada em níveis diferentes de distância da fóvea. De acordo com os resultados, a $10^{\circ}$ do centro da fixação, todas as tarefas puderam ser desempenhadas; a $15^{\circ}$ e $25^{\circ}$, detecção, reconhecimento e identificação ainda podiam ser realizadas. Isto significa que há extração de informação no campo visual periférico, além da fóvea.

O segundo problema notado por Irwin aponta especificamente para a possibilidade de que o locus do processamento cognitivo (atenção visual) possa estar dissociado do local de fixação. Deubel \& Schneider (1996) elaboraram um experimento no qual os participantes deveriam reportar a forma de um caractere para o qual eles deveriam, sob instrução, direcionar o olhar, mas que, a princípio, encontrava-se fora de um ponto determinado para a fixação. Assim que sinalizava-se aos participantes que eles deveriam realizar uma sacada na direção 
indicada, o caractere-alvo desaparecia antes que houvesse tempo para que os olhos o alcançassem ${ }^{46}$. Ainda assim, os participantes puderam determinar a forma do objeto quando ele encontrava-se no local preciso para onde eles haviam sido instruídos a direcionar sua sacada. Esse resultado parece indicar que, antes mesmo de deixar o ponto inicial de fixação, os sujeitos já estavam dirigindo sua atenção, i.e. os seus recursos cognitivos, ao local-alvo da sacada, podendo, dessa forma, determinar a natureza do caractere-alvo.

O terceiro problema elencado por Irwin, talvez de menor importância para a pesquisa psicolinguística tal como feita atualmente, diz respeito à possibilidade de o controle dos movimentos oculares poder estar fora do controle cognitivo, como atestado por alguns trabalhos que demonstram que sacadas podem ser atraídas, reflexivamente, por aparições repentinas de alguns estímulos (Theeuwes, Kramer, Hahn e Irwin, 1998). Entretanto, como assinala o próprio Irwin, este tipo de evidência só se apresenta como um problema para pesquisas nas quais se trabalha com cenas dinâmicas.

Um problema adicional para a interpretação de medidas relacionadas à fixação ocular, por fim, diz respeito às circunstâncias nas quais poderia ocorrer processamento de informação durante os movimentos sacádicos. Irwin remete a alguns trabalhos nos quais se mostrou que processos de reconhecimento e identificação podem ocorrer durante movimentos sacádicos. Há evidências (Irwin, 1998), por exemplo, de que, em tarefas experimentais, a demanda por movimentos sacádicos mais longos, em comparação com movimentos mais curtos, pode favorecer a identificação de palavras escritas previamente apresentadas, sugerindo que o tempo adicional inerente à sacada mais longa pode compreender processamento de informação lexical.

Em resumo, o trabalho de Irwin (2004) indica que medidas relativas à fixação devem ser tomadas com cautela, pois ainda que fixações estejam relacionadas a processos atencionais, o local e a duração das fixações, em certas circunstâncias, pode não coincidir exatamente com o locus e com a duração do processamento cognitivo. Diante disto, Irwin assinala que comparações de duração de fixações entre condições podem ser mais informativas do que os

\footnotetext{
${ }^{46} \mathrm{O}$ caractere permanecia disponível por apenas $120 \mathrm{~ms}$ depois que os sujeitos eram instruídos a iniciar a sacada, enquanto a latência média das sacadas era de $225 \mathrm{~ms}$.
} 
valores considerados em si mesmos. Nesse sentido, Irwin parece ter a mesma posição de Hayhoe (2004).

Although the mere presence of gaze at a particular location in the visual field does not reveal the variety of brain computations that might be operating at that moment, the experimental context within which the fixation occurs often provides critical information that allows powerful inferences. (Hayhoe, 2004, p. 267)

Um outro problema que poderia dificultar a interpretação de resultados de rastreamento ocular reside no argumento de que a configuração dos estímulos visuais apresentados em muitos estudos que relacionam movimentos oculares e compreensão da linguagem poderia facilitar o desenvolvimento de estratégias de resposta. Por exemplo, ao ver elementos dispostos tal como representados na Figura 8, o participante poderia imaginar que a presença de duas maças seria indicativa de que a instrução da tarefa focaria, necessariamente em uma delas e, assim, até prever o tipo de instrução.

Figura 8 - Exemplo de estímulo visual usado por Spivey et al. (2000)

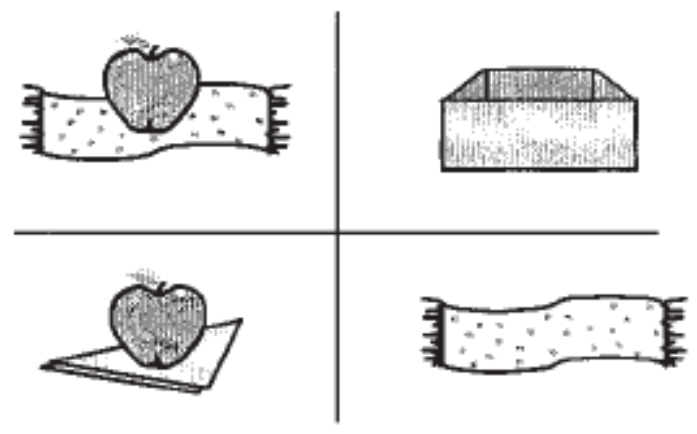

No entanto, Tanenhaus et al. (2000) contra-argumentam, afirmando que os movimentos oculares durante a compreensão da linguagem já se mostraram sujeitos a fatores que não poderiam estar envolvidos em estratégias, como, por exemplo, a frequência lexical. Por exemplo, numa tarefa na qual foi apresentado aos participantes um conjunto de objetos designados por palavras com semelhanças fonéticas (e.g., "bed”, "bench”, "bell"), constatou-se que o objeto nomeado pela palavra de maior frequência (no caso, "bed") tendia a registrar mais fixações a partir do onset da palavra que nomeava outro objeto (por exemplo, bench), a partir de uma instrução do tipo "Pick up the bench" (Dahan, Magnuson e Tanenhaus, 2001). Esse tipo de resultado parece indicar que a busca pelo 
referente correto está sujeita a uma competição análoga a que supostamente se dá durante o acesso lexical.

Para Tanenhaus et al. (2000), no domínio de pesquisas sobre o acesso lexical, o uso da metodologia de rastreamento ocular pode tirar proveito da existência de modelos suficientemente explícitos em suas previsões a respeito do curso da ativação lexical. Por exemplo, um modelo de acesso como o conhecido por TRACE (McClelland \& Elman, 1986), por fazer previsões quantitativas sobre o curso de ativação de elementos lexicais concorrentes, permite gerar, em tarefas experimentais, previsões quantitativas a respeito da probabilidade de fixação de um determinado objeto em função da forma do substantivo que o nomeia e da forma de possíveis nomes concorrentes dado um arranjo de objetos variados (Allopena, Magnunson \& Tanenhaus, 1998; Tanenhaus et al., 2000). Com isso, a hipótese de que os padrões de fixação disparados pelo reconhecimento de uma palavra refletiriam um modelo hipotético de acesso lexical pode ser testada com base em previsões bem definidas.

No que concerne ao processamento de sentenças, entretanto, a formulação de uma hipótese que relacione os padrões de movimentação ocular e o processamento linguístico com vistas a gerar previsões precisas a respeito do desempenho dos sujeitos em tarefas experimentais ainda depende, como também defendem Tanenhaus et al. (2000), do desenvolvimento de modelos de processamento mais explícitos.

Em resumo, esta seção apresentou alguns aspectos da relação entre os movimentos oculares e os processos cognitivos. Como foi visto, a ideia central por trás da possibilidade de tomar sacadas e fixações como indicativas do processamento cognitivo ou, mais especificamente, do processamento linguístico, advém de uma possível associação entre a atenção e olhar. A atenção espáciovisual pode ser atraída tanto por fatores interpretativos e conceituais (top-down), quanto por propriedades mais concretas, ligadas à forma (bottom-up) e pode se manifestar tanto patente (overt attention) como latentemente (covert attention). A possibilidade da dissociação entre a atenção visual e o ponto de fixação, que configura a atenção latente, impõe algumas dificuldades à interpretação da localização e da duração das fixações como variáveis dependentes, já que, nem sempre, o objeto atendido ou em processamento encontra-se na área da visão foveal. Soma-se a isso, a possibilidade de haver processamento cognitivo durante 
as sacadas. Fatores dessa natureza limitam a interpretação de fixações como indicadores precisos do processamento cognitivo, de modo que a duração das fixações não pode ser equiparada à duração de processos cognitivos, assim como a localização das fixações não pode ser considerada sempre e rigorosamente como locus do processamento cognitivo. Apesar de dificuldades dessa natureza, a técnica de rastreamento vem se mostrando produtiva na medida em que vem sendo capaz de corroborar resultados obtidos a partir de outras técnicas e também na medida em que os resultados apresentados mostram-se congruentes com hipóteses derivadas de modelos teóricos.

Nas seções seguintes, serão apresentados três experimentos que utilizaram a técnica de rastreamento ocular e que investigaram a incrementalidade no processamento on-line de orações relativas restritivas de objeto. No primeiro deles, o qual chamaremos de experimento 1 , sentenças contendo orações relativas de objeto foram apresentadas na presença ${ }^{47}$ de ilustrações relacionadas à informação trazida pela relativa, com o intuito de verificar em que medida o tipo de desenho apresentado poderia interferir no processamento destas sentenças e, consequentemente, nos padrões de movimentação ocular dos participantes. No segundo experimento, chamado de experimento 2 , informações de natureza linguística e visual envolvidas na interpretação das sentenças contendo orações relativas eram apresentadas anteriormente à apresentação destas. Nesse caso, o intuito era o de verificar se os resultados do primeiro experimento poderiam ser reproduzidos caso não houvesse informação visual imediatamente disponível, isto é, quando uma informação de backgroud tivesse que ser recuperada da memória. O experimento 3 investigou o papel de informação contextual na análise da ambiguidade de orações relativas restritivas de objeto.

\section{2.}

\section{EXPERIMENTO 1}

A interpretação de DPs contendo orações relativas restritivas baseia-se numa relação de modificação na qual a oração relativa (OR) irá modificar o DP no qual está encaixada. Esse DP é, por sua vez, representado no interior da OR por um gap $(\Delta)$, um elemento foneticamente nulo que remete ao DP modificado. No

\footnotetext{
${ }^{47} \mathrm{Na}$ verdade, como será descrito a seguir, os estímulos visuais eram apresentados ligeiramente antes dos estímulos auditivos.
} 
caso específico de DPs contendo relativas de objeto, este gap atuará como argumento interno do verbo da OR. Sua compreensão depende, assim, do estabelecimento de uma relação entre o gap e o DP que se encontra na margem externa da relativa. A partir do estabelecimento dessa relação, as posições argumentais do verbo poderiam ser preenchidas. Em princípio, isso significa que, no curso da compreensão de uma relativa de objeto, o parser só poderia definir uma interpretação a partir do momento em que o verbo fosse encontrado, permitindo, desta maneira, a identificação de suas posições argumentais (em outros termos, a satisfação de seus requerimentos sintáticos), o estabelecimento da relação entre o gap e o DP que encabeça a relativa e, por conseguinte, o fechamento do DP. A partir daí, a referência do DP complexo poderia ser estabelecida.

(1) [DP A garota [oR que [DP o bombeiro] pegou $\Delta]$ ] vai comprar um brinquedo

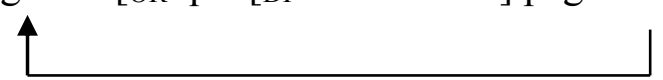

Em razão de suas propriedades semânticas, relativas restritivas supõem a existência de um set de referência no qual duas ou mais entidades contrastam nos termos de alguma das informações trazidas pela OR. Por exemplo, no caso de uma sentença como (1), está implícita a existência de um set de referência no qual existe mais de uma garota, sendo que somente uma delas pode ser associada às informações trazidas pela relativa, ou seja, "o bombeiro pegou" apenas uma dentre as garotas do set e o fato desta informação associar-se a apenas uma das entidades faz com que a referência desta sentença possa ser estabelecida com sucesso.

No caso das relativas de objeto, a propriedade que permite a distinção entre a entidade referida na OR e as outras entidades do set de referência é apresentada antes da satisfação dos requerimentos sintáticos do verbo, isto é, antes de o gap poder ser encontrado. Por exemplo, caso a sentença "A garota que o bombeiro pegou vai comprar um brinquedo" fosse apresentada diante de um contexto visual semelhante ao da Figura 9, haveria informação suficiente para que a referência da OR fosse estabelecida já no sujeito da relativa, considerando que somente uma das garotas pode ser associada a uma ação na qual está presente um bombeiro. Por outro lado, caso a mesma sentença fosse apresentada em um contexto visual 
semelhante ao apresentado na Figura 10, haveria informação suficiente para que a referência fosse estabelecida a partir do onset do verbo encaixado. Nesse contexto, as duas garotas são associadas a bombeiros, portanto, não há informação suficiente para que as duas sejam distinguidas pelo sujeito da relativa, contudo, apenas uma garota é paciente da ação de pegar descrita na relativa. Esse fato traz à tona a possibilidade de que, no processamento on-line, a referência de um DP complexo possa ser estabelecida antes mesmo do fechamento do DP, a despeito da necessidade da satisfação dos requerimentos sintáticos do verbo encaixado.

Figura 9 - Exemplo de contexto visual para a sentença (1)

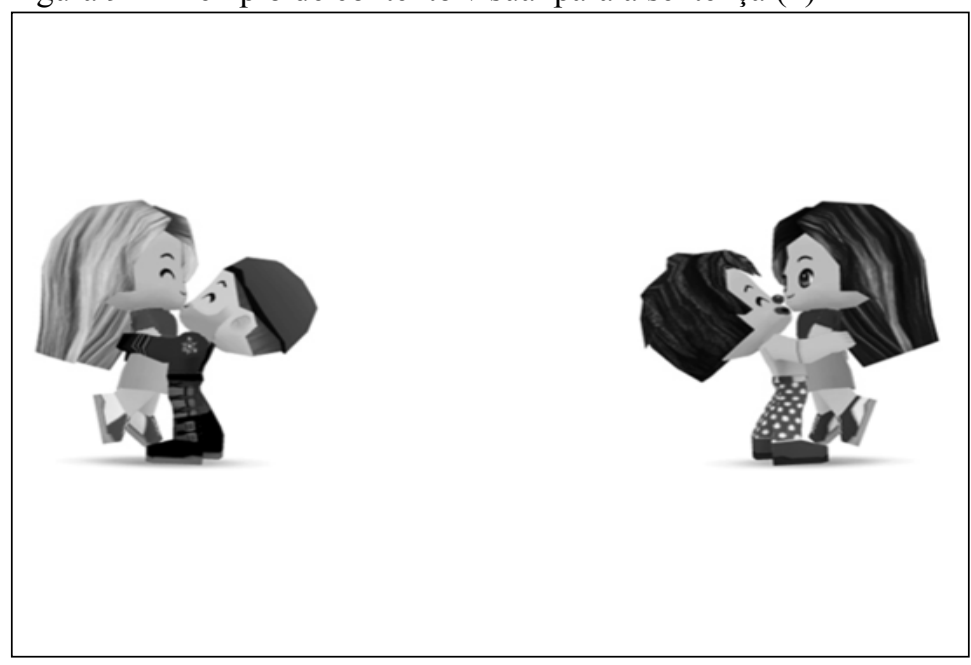

Figura 10 - Exemplo de contexto visual para a sentença (1)

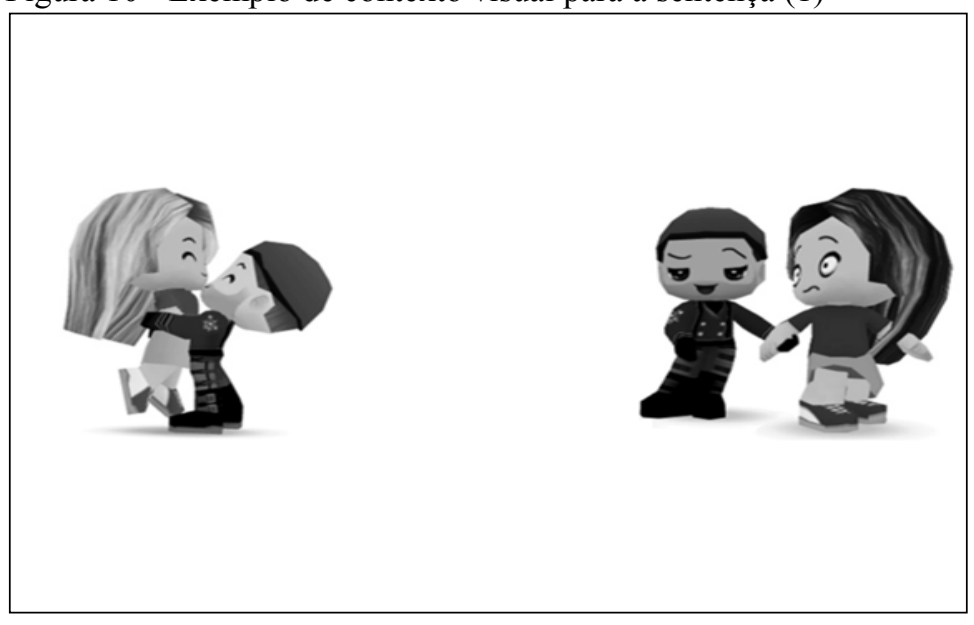

O experimento 1 (assim como o experimento 2) teve o intuito de avaliar esta possibilidade. O objetivo deste experimento foi o de investigar em que momento do processamento on-line é possível identificar ou antecipar o referente de um DP 
que contém uma oração relativa restritiva de objeto frente à disponibilidade de informação contextual de natureza visual.

A tarefa dos participantes era a de responder uma interrogativa QU- como (2), a qual os participantes deveriam responder levando em conta a informação trazida, anteriormente, por uma sentença contendo uma relativa de objeto (3). Este experimento, entretanto, não considerou como variável dependente a resposta a essas interrogativas, mas sim, os movimentos oculares registrados durante a apresentação da sentença contendo uma relativa.

(2) Quem vai comprar um brinquedo?

Ao mesmo tempo em que ouviam os estímulos experimentais (3), i.e. enunciados com um DP-sujeito contendo uma relativa de objeto, os participantes podiam ver duas ilustrações, uma das quais, a ilustração-alvo, correspondia à informação transmitida por meio da relativa. Fazendo recurso à técnica de rastreamento ocular, considerou-se que o momento em que o participante direcionasse seu olhar para a ilustração-alvo poderia ser tomado como o momento de identificação do referente.

(3) A garota que o bombeiro pegou vai comprar um brinquedo.

$\mathrm{Na}$ eventual identificação do referente antes mesmo da possibilidade de preenchimento do gap contido na oração relativa, os resultados desse experimento poderiam ser integrados ao corpo de evidências a favor de um processamento incremental na compreensão de sentenças, indicando que informações de natureza visual podem ser levadas em conta durante o processamento on-line.

Para determinar em que ponto do processamento das relativas a identificação do referente seria possível, as sentenças experimentais foram apresentadas em quatro condições diferentes, determinadas pelo tipo de contexto visual oferecido concomitantemente a essas sentenças. Em todas as condições, o contexto visual era constituído por duas ilustrações (posicionadas horizontalmente em cada uma das metades de uma tela de computador) que representavam uma ação na qual estavam envolvidos um agente e um paciente. Enquanto a ilustraçãoalvo correspondia ao evento descrito pelo estímulo experimental, a ilustração 
concorrente diferia daquela em algum aspecto, podendo ser ele: (condição (A)) o sexo do paciente representado; (condição (B)) o tipo de agente; (condição (C)) o tipo de agente e a natureza da ação; (condição (D)) somente a natureza da ação (Figura 11). Desta forma, estes elementos distintivos (ED), constituíram-se como a variável independente deste experimento. Como variáveis dependentes, foram consideradas o número de rodadas (trials) com fixação na figura-alvo e a duração total das fixações.

A contagem do número e da duração das fixações na ilustração-alvo durante a apresentação da sentença experimental foi feita em função de 3 segmentos: S1, correspondente à porção inicial da sentença, que se inicia com o determinante do DP-sujeito da matriz e se estende até o determinante do DP-sujeito da relativa; S2, correspondente ao $\mathrm{N}$ sujeito da relativa; e $\mathrm{S} 3$, com início no verbo da relativa e englobando todo o restante da sentença. Conforme apresentado na seção 4.1, as fixações tendem a revelar o foco de atenção visual em um dado momento do tempo, podendo indicar que o estímulo visual fixado está relacionado ao estado corrente de processamento do sistema cognitivo. O que se quis avaliar com a contagem das rodadas (trials) com fixação no alvo por segmento, conforme realizado em estudos anteriores (Kamide et al. 2003; Knoeferle et al., 2004; Tanenhaus et al., 1995), foi a variação da probabilidade de a atenção visual estar direcionada ao objeto crítico num dado intervalo de tempo em função das variáveis independentes (uma medida, em sua finalidade, semelhante ao que Henderson e Ferreira (2004) chamam de probabilidade de entrada da região), enquanto que, com a duração total das fixações, que pode ser tomada como um indicador da carga de recursos de processamento relacionada a um estímulo, se quis avaliar o quanto a alocação de recursos de processamento cognitivo poderia variar em função das diferentes possibilidades de mapeamento do referente em cada uma das condições.

A garota que o bombeiro pegou vai comprar um brinquedo. 
Figura 11 - Elementos distintivos e condições experimentais
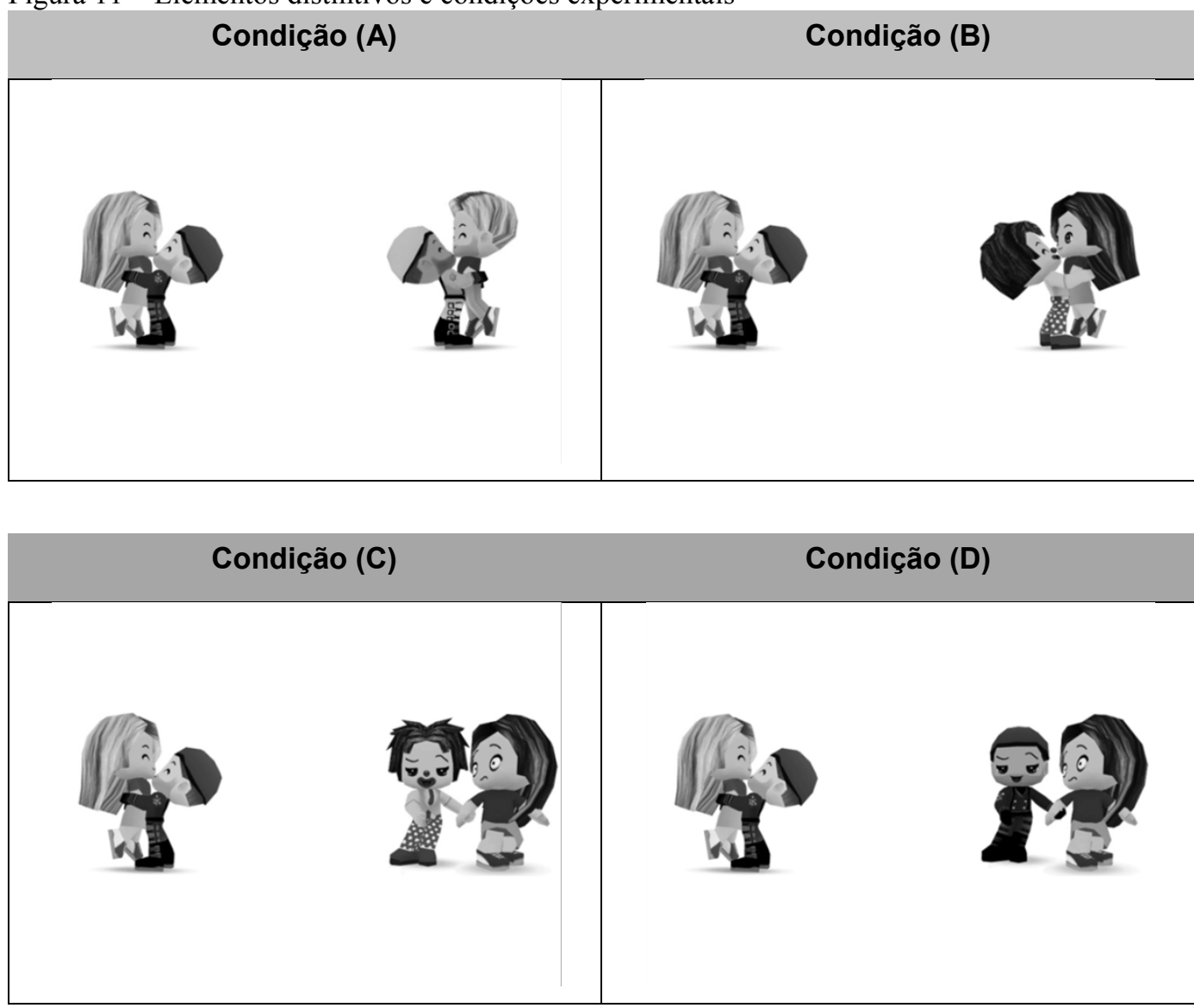

Partindo da hipótese de que o contexto visual poderia influenciar na identificação do referente, na medida em que permitiria, em conjunto com a sentença experimental, a distinção da ilustração alvo por meio do ED e considerando que, desta maneira, cada uma das condições tornaria a identificação do referente possível em diferentes momentos da relativa, previu-se que: (i) no segmento 1 (S1), deveria ser registrada uma média maior de rodadas (trials) com fixação na figura-alvo e de durações totais de fixação na condição (A), já que nesta condição o contexto visual trazia, nas duas ilustrações apresentadas, pacientes de diferentes sexos, o que poderia permitir que a ilustração-alvo fosse detectada no momento em que a marcação de gênero do DP-sujeito da matriz, e.g. "A garota ...", fosse identificada; (ii) em S2, eram esperadas mais e mais longas fixações nas condições (B) e (C), já que estas, por trazerem como ED diferentes tipos de agentes, poderiam restringir a referência à ilustração alvo na apresentação deste segmento, correspondente ao sujeito da relativa; (iii) por fim, em S3, todas as condições deveriam exibir um número alto de rodadas (trials) com fixação na figura-alvo, assim como longas durações totais, já que, neste ponto, a condição 
(D) passaria a permitir a identificação do referente, enquanto as outras condições restantes já haveriam permitido esta identificação em pontos anteriores da sentença.

\subsection{1.}

\section{Método}

\section{Participantes}

O experimento 1 contou com a colaboração de 20 voluntários gratificados, todos alunos da Pontifícia Universidade Católica do Rio de Janeiro (PUC-Rio). Em agradecimento pela realização do experimento, os participantes poderiam receber uma quantia de $\mathrm{R} \$ 5$ ou créditos de carga horária complementar. A média de idade dos participantes é de 25,6 anos. O grupo era composto por 5 homens e 15 mulheres. Por problemas técnicos relacionados ao equipamento de rastreamento, 23 participantes foram descartados, considerando a soma de participantes obtida nos dois experimentos de rastreamento.

\section{Material}

Para este experimento, foram construídas 8 sentenças experimentais (4 a 11). Tanto a oração matriz quanto a oração relativa tiveram sua extensão controlada em termos do número de sílabas. Os verbos e os sujeitos das relativas eram iniciados, ambos, por consoantes plosivas, que facilitariam a identificação das fronteiras entre os segmentos S1, S2 e S3 no momento da análise, feita com o auxílio de um oscilograma. Os verbos das relativas eram todos agentivos e transitivos diretos. Os nomes envolvidos na relativa continham, todos, três sílabas. Todos os verbos encaixados continham duas sílabas. Foram escolhidos nomes de três sílabas, pois, por sua extensão, permitiriam monitorar por mais tempo o posicionamento do olhar durante a audição de cada um dos segmentos, facilitando, assim, a análise dos dados. A quantidade de sílabas dos verbos foi menor, pois não foi possível encontrar verbos de três sílabas que, além de atenderem todos os critérios, fossem passíveis de ilustração. Além destas 8 relativas, mais duas outras foram construídas, em padrões menos rigorosos, para servir à etapa de pré-teste. 
(4) A garota que o pirata puxou vai passear no parque.

(5) A garota que o professor pulou vai ganhar um presente.

(6) A garota que o bombeiro pegou vai comprar um brinquedo

(7) A garota que o padeiro beijou vai morar no Nordeste.

(8) O garoto que o cacique puxou vai passear de navio.

(9) O garoto que o palhaço pegou vai ganhar uma surpresa.

(10) $\mathrm{O}$ garoto que o goleiro beijou vai comprar um boneco.

(11)O garoto que o pedreiro pulou vai morar em Curitiba.

Todas as sentenças experimentais foram apresentadas em todas as condições. Entretanto, para que o mesmo participante não fosse exposto à mesma relativa mais de uma vez, foram criadas quatro listas. Cada uma delas trazia uma determinada relativa em uma condição diferente. As quatro listas criadas continham um total de oito estímulos experimentais, resultantes da apresentação de dois estímulos em cada condição. A ordem da apresentação das sentenças experimentais em cada uma das listas foi aleatória ${ }^{48}$.

Foram criados, ao todo, 21 slides para este experimento, 5 dos quais foram utilizados no pré-teste. Cada rodada (trial) do experimento compreendia a apresentação de 2 slides.

O primeiro slide trazia a ilustração de dois personagens apresentados um em cada lado horizontal do slide (ver Fig. 12, p. 97). Estes personagens poderiam ser ou dois meninos, ou duas meninas, ou um menino e uma menina. Para evitar que um dos personagens pudesse chamar mais atenção do que o outro, eles eram ilustrados da maneira mais semelhante o possível. No caso de slides que continham personagens do mesmo sexo, a diferença entre os dois (que permitiria sua identificação) era determinada pela cor da roupa, pela cor dos olhos e por uma pequena diferença na tonalidade da pele. Em slides com personagens de sexos diferentes, a menina diferenciava-se do menino por ter cabelos compridos e vestir saias, enquanto o menino trazia cabelos curtos e vestia calças. As meninas poderiam ter os cabelos loiros ou morenos, assim como os meninos. As roupas destes personagens poderiam ser pintadas nas cores: branca, preta, verde ou azul. As calças (ou saias) eram sempre da mesma cor das camisas, sendo as camisas

\footnotetext{
${ }^{48} \mathrm{O}$ presente experimento não contou com a presença de distratores uma vez que havia sido concebido inicialmente como um experimento piloto.
} 
numa tonalidade mais escura e as calças numa tonalidade mais clara. $\mathrm{O}$ número de ocorrência das cores de vestuário e das personagens loiras e morenas foi contrabalançada entre e intra listas. Estas características também foram contrabalançadas em relação à posição da tela em que apareceriam (direita ou esquerda).

O segundo slide trazia duas ilustrações que representavam, cada, uma ação envolvendo um agente e um paciente. Os personagens-pacientes eram os mesmos apresentados no slide 1 e permaneciam no mesmo lado da tela em que haviam sido apresentados anteriormente. Em razão da natureza das sentenças experimentais e dos nomes escolhidos como sujeitos da oração relativa, os personagens-agentes eram construídos de tal forma que pudessem ser identificados por uma vestimenta que correspondesse nitidamente a uma profissão. Foram criados oito personagens-agentes: um bombeiro, um pedreiro, um palhaço, um cacique, um professor, um goleiro, um padeiro e um pirata. Os traços com os quais os personagens foram desenhados eram semelhantes. Entretanto, as diferenças entre cores, acessórios e vestimentas foram mais acentuadas do que no caso dos personagens-pacientes, já que, para tornar cada uma das profissões identificáveis, os personagens deveriam estar adequadamente trajados de acordo com os estereótipos de cada profissão em questão. Cada um destes personagens era usado apenas uma vez em cada sessão do experimento. A depender de cada condição, este segundo slide poderia trazer ilustrações apresentando ou dois personagens-agentes de profissões diferentes, ou então dois de mesma profissão. Neste último caso, os personagens agentes poderiam ser diferenciados pela cor de suas vestimentas e por uma ligeira diferença na tonalidade de suas peles. A posição da ilustração tomada como alvo em cada rodada (trial) do experimento foi contrabalançada entre e intra listas.

Quanto aos 5 slides utilizados durante o pré-teste, o primeiro trazia uma tarefa de nomeação (ver "Procedimento"), enquanto os outros quatro compunham duas rodadas (trials) de treinamento com pares de slides semelhantes aos experimentais. Entretanto, os personagens-agentes e as ações ilustradas nestes slides eram diferentes dos apresentados nos slides experimentais. 
Aparato

O experimento 1 foi realizado em uma cabine anti-acústica nas dependências do Laboratório de Processamento e Aquisição da Linguagem (LAPAL). Foram utilizados dois notebooks da marca Hewlett-Packard (HP) com sistema operacional Windows XP e monitores de 15". Um destes computadores disparava os experimentos para o participante, enquanto o outro coletava os dados fornecidos por um eye-tracker, fazendo o registro de um vídeo de cada sessão, além de permitir que o experimentador monitorasse o comportamento do participante.

O eye-tracker utilizado foi um TM2, um eye-tracker de mesa (tablemounted) fabricado pela EyeTech Digital Systems. O equipamento tem $1^{\mathrm{o}} \mathrm{de}$ acurácia, registra as imagens a 55fps, permitindo até $25 \times 16 \times 19 \mathrm{~cm} \mathrm{de}$ movimentação da cabeça. Este equipamento era administrado pelo software Quick Glance, que realizava a calibração de cada um dos participantes e registrava seus movimentos oculares durante a sessão. Foram utilizados também duas caixas de som, um microfone e um mouse especialmente preparado para que se pudesse comandar, ao mesmo tempo, tanto o notebook do participante quanto o notebook do experimentador.

Para a apresentação dos estímulos foi utilizado o programa Power Point. Para cada uma das listas do experimento, foi criado um arquivo diferente para ser rodado neste programa, que apresentava tanto os estímulos auditivos quanto os visuais. Para a gravação dos estímulos auditivos e para a análise dos dados foi utilizado o software Soundforge. O software Snag-it permitiu a gravação de toda a atividade realizada na tela do computador que monitorava a realização do experimento, registrando assim, todo material auditivo e visual, além dos registros de movimentação ocular coletados, por meio do eye-tracker, com cada um dos participantes.

\section{Procedimento}

Antes da realização do experimento, cada um dos participantes era informado de que participaria de uma tarefa na qual deveria ouvir algumas sentenças e responder a algumas perguntas. Eram informados também de que estávamos coletando informações a respeito da movimentação de seu olhar e que, por isso, antes do experimento, deveriam realizar uma etapa de calibração. 
A calibração do equipamento era realizada, semi-automaticamente, por meio do software Quick Glance. Durante este procedimento, o participante deveria fixar seu olhar em 16 pontos diferentes da tela. Ao final, o software atribuía uma pontuação relacionada à qualidade da calibração. Caso a pontuação fosse insuficiente, o participante deveria fixar novamente seu olhar em alguns pontos determinados pelo software até que atingisse uma pontuação adequada.

Passada a etapa de calibração, os participantes eram instruídos a respeito de sua tarefa. Recebiam a informação de que veriam alguns slides contendo algumas ilustrações e que deveriam estar atentos aos desenhos e as frases para que, a cada rodada (trial), pudessem responder a uma pergunta. Em seguida, realizavam uma tarefa de nomeação para assegurar que todos os personagens utilizados como agentes poderiam ser corretamente diferenciados. Nesta etapa, todos os possíveis personagens-agentes apareciam, na parte superior da tela, rotulados com um número. Um nome correspondente a um dos personagens aparecia próximo ao centro da tela. $\mathrm{O}$ participante deveria, então, dizer o número que rotulava o personagem correspondente aquele nome. O nome então desaparecia e um outro nome, correspondente a outro personagem, aparecia. $\mathrm{O}$ procedimento era repetido até que todos os personagens fossem nomeados.

Para garantir que os participantes haviam entendido as instruções a respeito da tarefa experimental e que eram capazes de cumprir a tarefa, foram realizadas duas rodadas (trials) de pré-teste com estímulos diferentes dos estímulos experimentais. Em seguida, os participantes eram informados de que o experimento iria começar. Neste momento, o experimentador deixava os participantes sozinhos na cabine anti-acústica.

Cada rodada (trial) do experimento consistia na apresentação de dois slides. No primeiro deles, eram apresentadas duas ilustrações, dispostas horizontalmente, uma em cada lado de uma tela de computador (ver figura 12). Ambos os personagens são sempre candidatos possíveis a pacientes da ação que, em seguida, será apresentada na relativa. Esses personagens eram apresentados oralmente, por meio de uma gravação, em frases como 'Está é a garota de verde' ou 'Esta é a garota de azul'. Ao mesmo tempo em que a frase era apresentada, uma seta aparecia na tela apontando para o personagem em questão. O objetivo deste primeiro conjunto de estímulos era o de apresentar o traço que permitiria distinguir visualmente um personagem de outro, i.e. a cor da roupa. A 
apresentação deste slide levava cerca de 11 segundos, após os quais o próximo slide aparecia automaticamente.

O segundo slide apresentava a ilustração de duas ações (ver figura 12), sendo uma delas o referente alvo da relativa e a outra, uma ação que diferiria da primeira, como já foi dito, nos termos ou do sexo do paciente (e.g., um menino e uma menina), ou do tipo de agente (e.g., um bombeiro e um palhaço), ou do tipo de agente e de ação (e.g., um bombeiro pegando e um palhaço puxando), ou somente da ação (e.g., um bombeiro pegando e outro bombeiro puxando). Assim que este segundo slide era apresentado, havia um intervalo de cinco segundos no qual o participante poderia olhar livremente para as figuras, permitindo que ele identificasse os personagens e as ações representadas. Só em seguida, era apresentada a sentença experimental. Imediatamente antes da apresentação da relativa, um ponto vermelho aparecia no centro da tela, acompanhado da gravação de dois clicks, com o propósito de desviar o olhar do participante para um ponto equidistante das duas ilustrações. Imediatamente depois, a sentença experimental era apresentada. Após cerca de 4 segundos, era apresentada uma interrogativa QU- com a qual se questionava qual personagem havia realizado a ação discriminada pelo verbo da oração matriz da sentença experimental. A tarefa do participante era a de responder a esta pergunta de maneira que fosse possível identificar a personagem a que ele se referia, respondendo, por exemplo, "A menina de verde" ou então "A menina que o bombeiro pegou". A inserção desta interrogativa no experimento foi motivada por três fatores: fazer com que a identificação do referente fosse relevante para a tarefa que o participante deveria desempenhar; mascarar o objetivo do experimento e verificar se os participantes estavam atentos aos estímulos que lhes eram apresentados. Raramente os participantes responderam incorretamente a uma destas perguntas. Assim que os participantes respondiam à pergunta, o experimentador dava o comando para que os computadores disparassem a próxima rodada (trial). O participante poderia dispor de quanto tempo quisesse para responder a pergunta. 
Figura 12 - Sequência de estímulos do Experimento $1^{49}$

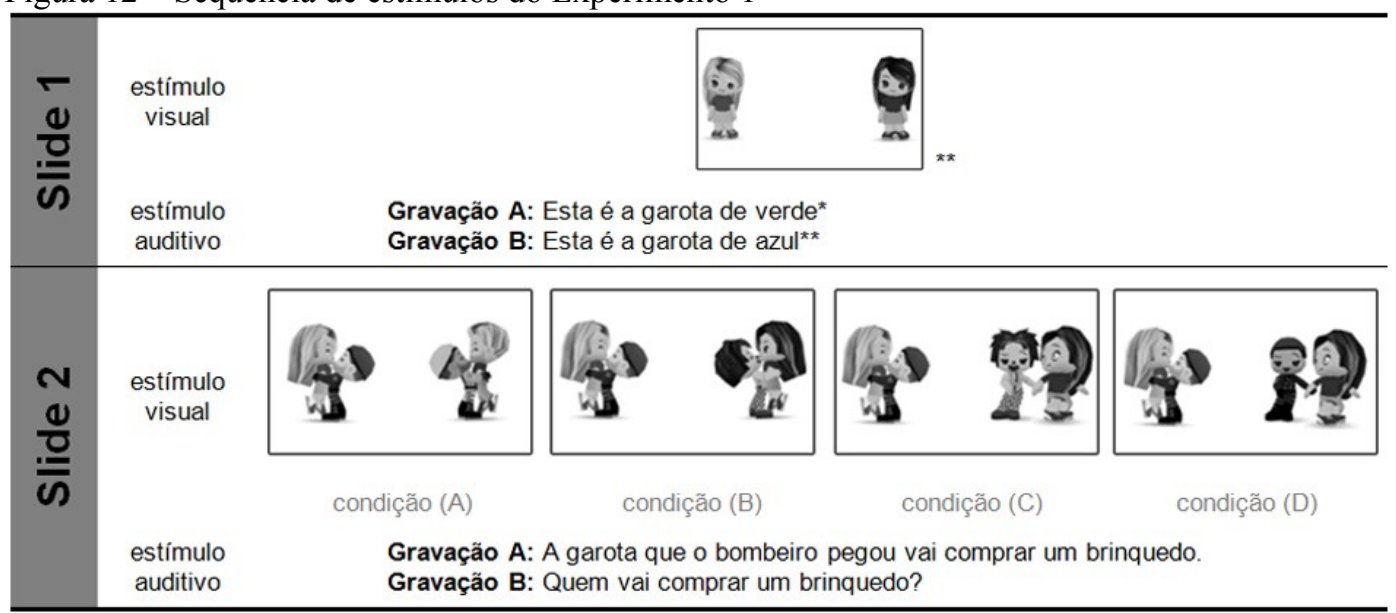

\section{Análise das medidas}

A performance dos participantes durante o experimento era gravada por meio do software Snag-it, que registrava toda a atividade de tela no notebook utilizado para monitorar a tarefa. Com isso, para cada participante, era gerado um arquivo em formato de vídeo (.avi) no qual se poderia ver o registro do posicionamento do olhar do participante (indicado pelas movimentações do cursor do mouse), o registro da imagem capturada pela câmera do eye-tracker, a apresentação dos estímulos tal qual vista pelo participante e a gravação dos estímulos auditivos apresentados ao participante, bem como as respostas fornecidas por ele a cada uma das perguntas.

Este vídeo era analisado com o apoio do programa Soundforge, que permitia que o arquivo de vídeo fosse analisado paralelamente a um oscilograma gerado a partir de todo áudio incluído no vídeo. Desta maneira, por meio da inspeção auditiva e visual e com o apoio do oscilograma, era possível determinar os momentos em que os participantes posicionavam seu olhar sobre a região correspondente à ilustração-alvo de cada rodada (trial). Em primeiro lugar, considerando as regiões nas quais a relativa foi dividida, verificava-se se havia ou não uma fixação na ilustração-alvo para cada uma destas regiões. Havendo uma fixação, a duração desta era então aferida. A inspeção visual do oscilograma era facilitada pela presença de plosivas no início dos pontos que marcavam as fronteiras entre os segmentos nos quais a sentença experimental foi dividida.

\footnotetext{
49 (*) Estímulos originalmente coloridos. (**) Estímulos relativos à condição (C).
} 


\subsection{2.}

\section{Resultados}

Os dados concernentes ao número de rodadas (trials) com fixação na figuraalvo foram submetidos a 3 ANOVAS, cada um deles relativo a um dos segmentos nos quais as sentenças experimentais foram divididas ( $\mathrm{S} 1$ : $\mathrm{F}(3,57)=2,21 \mathrm{p}=.09$; $\mathrm{S} 2: \mathrm{F}(3,57)=3,59 \mathrm{p}<.02 ; \mathrm{S} 3: \mathrm{F}(3,57)=0,322 \mathrm{p}<.9)$. O Gráfico (1), mostra a média de rodadas (trials) com fixação no alvo por condição no Segmento 1 (S1). Como é possível observar, em S1, houve mais rodadas (trials) com fixação na condição (A), na qual o núcleo da relativa desambiguiza a referência. Comparações pareadas mostraram que esta condição difere significativamente das condições (B) e (C) e que há uma diferença marginal entre (A) e (D). (Tabela 2).

Gráfico 1 - Média de rodadas (trials) com fixação na ilustração-alvo por condição no Segmento 1 (escore máximo: 2)

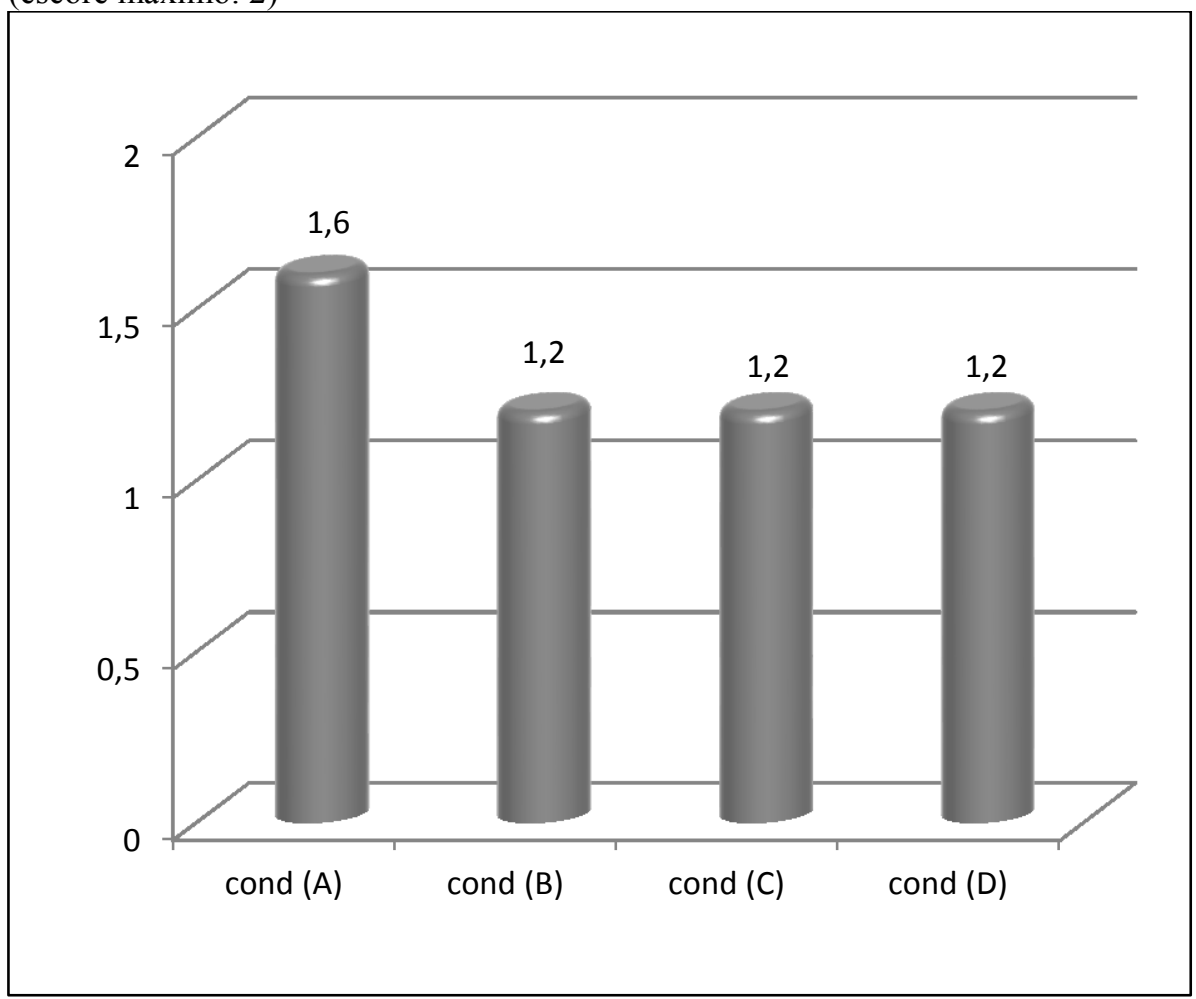


Gráfico 2 - Média de rodadas (trials) com fixação na ilustração-alvo por condição no Segmento 2 (escore máximo: 2)

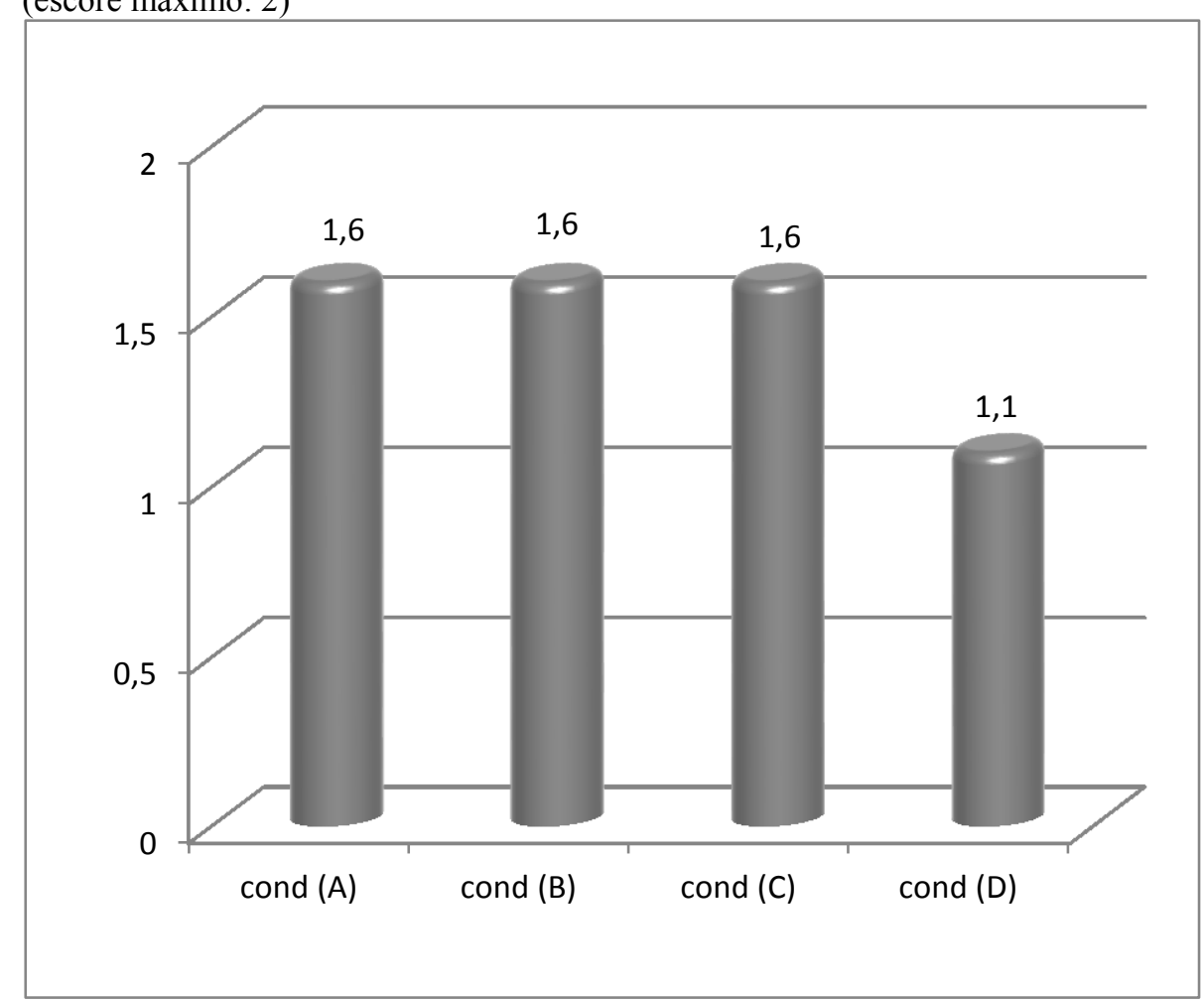

Gráfico 3 - Média de rodadas (trials) com fixação na ilustração-alvo por condição no Segmento 3 (escore máximo: 2)

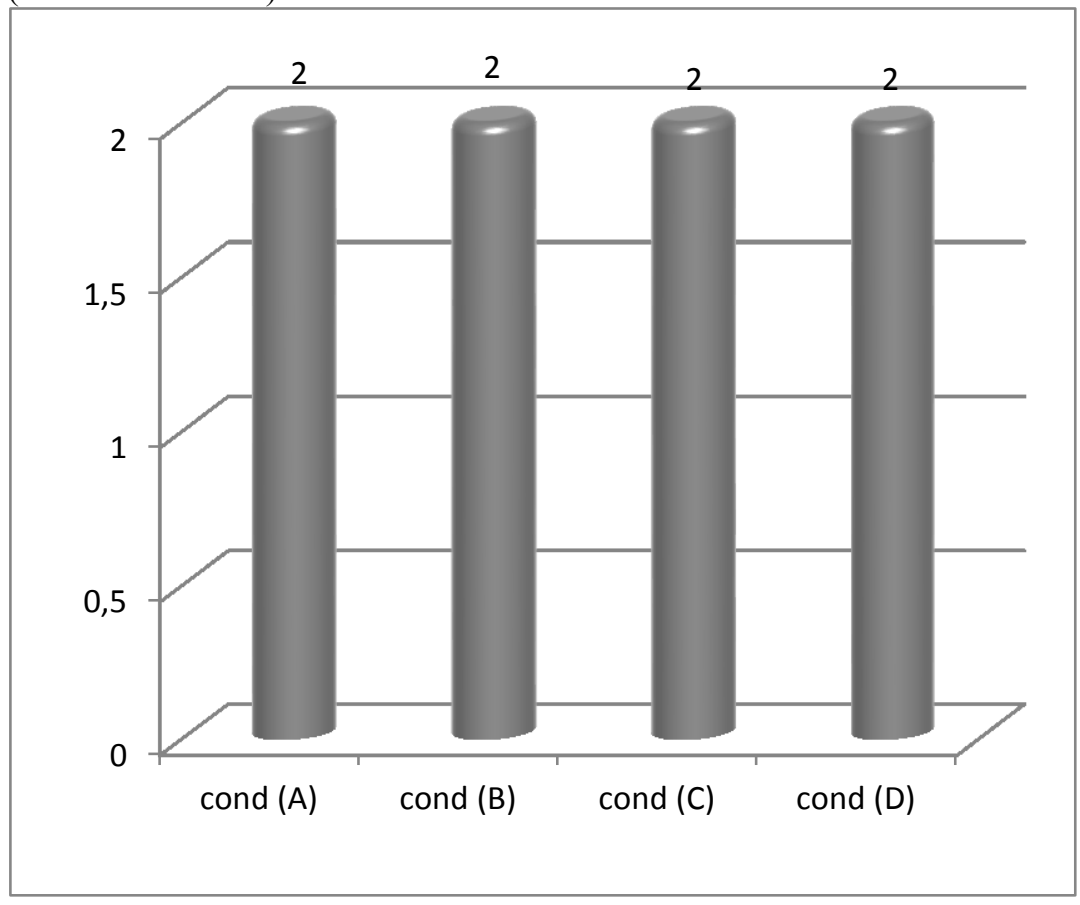


Em relação ao Segmento 2 (S2), houve mais rodadas (trials) com fixação na ilutração-alvo nas condições (A), (B) e (C) (Gráfico 2). Comparações pareadas revelaram que estas condições diferem significativamente da condição (D) (Tabela 2), à exceção de (A), cuja diferença entretanto mostrou-se muito próxima de ser signitivativa.

No Segmento 3 (S3), o número de rodadas (trials) com fixação na ilustração-alvo atingiu o score máximo em todas as quatro condições (Gráfico 3).

Tabela 2 - Comparações pareadas (teste $t$ ) entre condições por segmentos referentes ao número de rodadas (trials) com fixação na ilustração-alvo (os valores em negrito ressaltam as diferenças significativas).

S1 S2 S3

\begin{tabular}{llll}
\hline (A) $x$ (B) & $t(19)=2,37 p<.03$ & $t(19)=0,37 p<.80$ & $t(19)=0,00 p=1$ \\
(A) $x$ (C) & $t(19)=2,63 p<.02$ & $t(19)=0,33 p<.80$ & $t(19)=1,00 p<.40$ \\
(A) $\times$ (D) & $t(19)=2,03 p<.06$ & $t(19)=2,02 p<.06$ & $t(19)=0,00 p=1$ \\
(B) $\times$ (C) & $t(19)=0,00 p=1$ & $t(19)=0,00 p=1$ & $t(19)=1,00 p<.40$ \\
(B) $\times$ (D) & $t(19)=0,00 p=1$ & $t(19)=2,52 p<.03$ & $t(19)=0,00 p=1$ \\
(C) $\times$ (D) & $t(19)=0,00 p=1$ & $t(19)=2,24 p<.04$ & $t(19)=1,00 p<.40$
\end{tabular}

Os dados relativos à duração total das fixações exibiram um padrão semelhante aos obtidos com o número de rodadas (trials) com fixação no alvo (ANOVAs: S1: $\mathrm{F}(3,57)=2,89 \mathrm{p}<.05 ; \mathrm{S} 2$ : $\mathrm{F}(3,57)=3,42 \mathrm{p}<.03$; S3: $\mathrm{F}(3,57)=6,82$ p <.01.). Em S1 (Gráfico 4), ocorreram fixações mais longas na condição (A), que diferiu significativamente das outras condições (Tabela 3), levando em conta que (D) registrou uma diferença marginalmente significativa. Em S2 (Gráfico 5), ocorreram fixações mais longas em especial nas condições nas quais o sujeito da relativa se constituiu como elemento desambiguizador da referência, isto é, nas condições (B) e (C), que diferiram significativamente da condição (D) (Tabela 3). Em S3 (Gráfico 6), todas as condições registraram longas fixações, sendo que as condições (A) e (D) diferiram significativamente das condições (B) e (C) (Tabela $3)$. 
Gráfico 4 - Duração total das fixações (em milissegundos) na ilustração-alvo por condição no Segmento 1

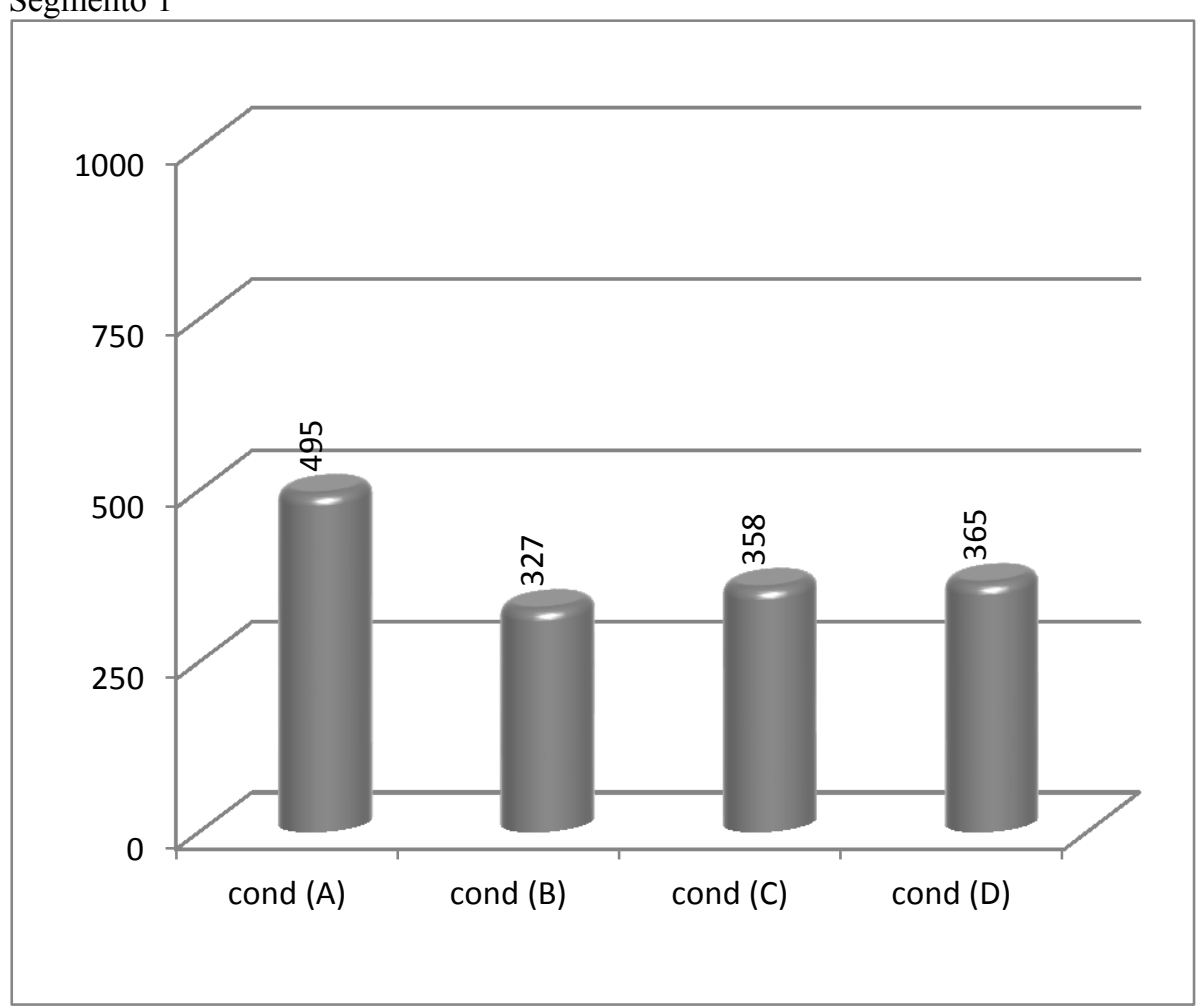

Gráfico 5 - Duração total das fixações (em ms.) na ilustração-alvo por condição no Segmento 2

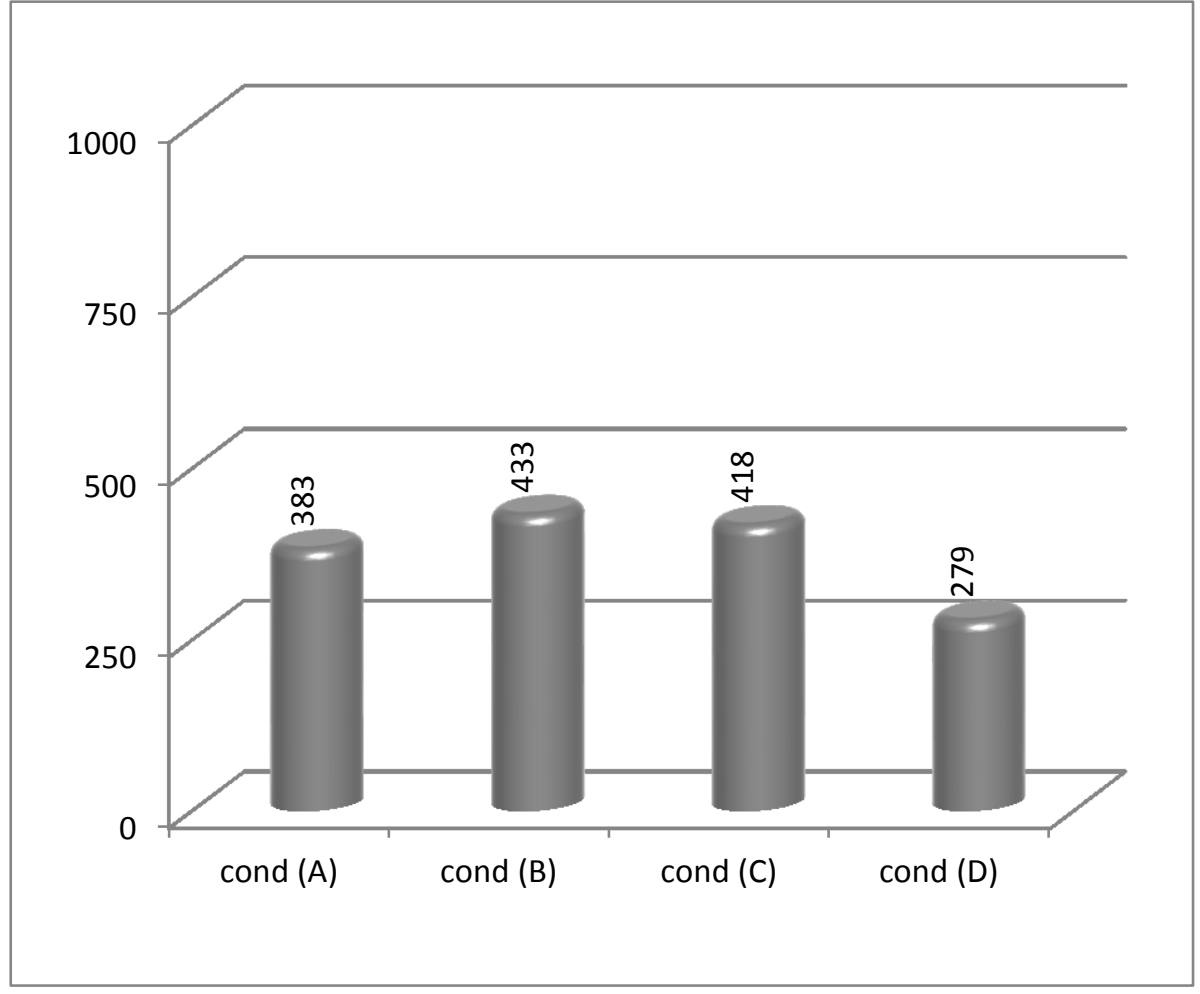


Gráfico 6 - Duração total das fixações (em ms.) na ilustração-alvo por condição no Segmento 3

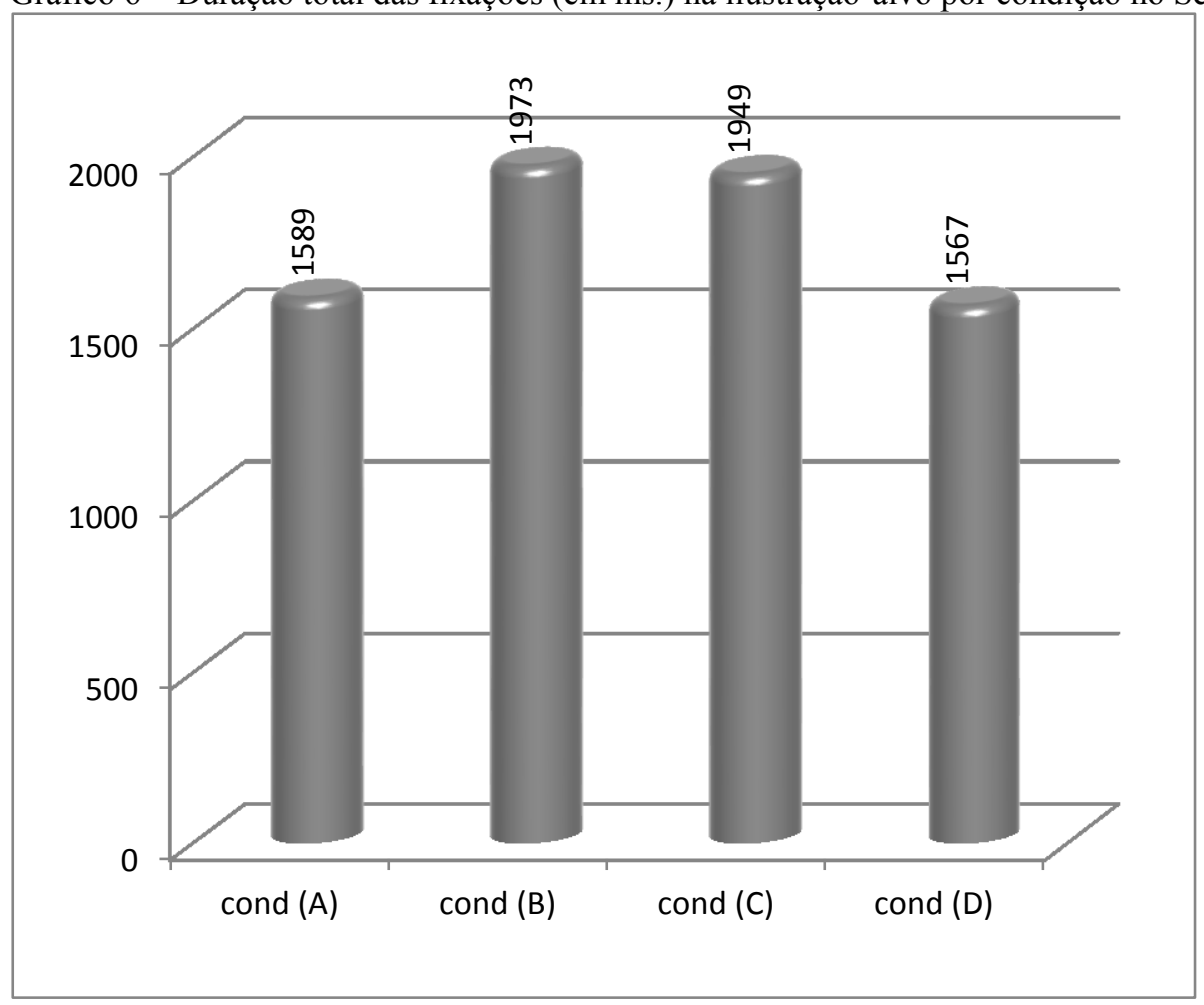

Tabela 3 - Comparações pareadas (teste $t$ ) entre condições por segmentos referentes à duração total das fixações na ilustração-alvo (os valores em negrito ressaltam as diferenças significativas)

S1

S2

S3
(A) $x$ (B) $\quad t(19)=2,99 p<.01$
$\mathrm{t}(19)=0,99 \mathrm{p}<.40$
$\mathrm{t}(19)=3,12 \mathrm{p}<.01$
(A) $x$ (C) $t(19)=2,69 p<.02$
$\mathrm{t}(19)=0,71 \mathrm{p}<.50$
$\mathrm{t}(19)=2,85 \mathrm{p}<.02$
(A) $x$ (D) $\quad t(19)=1,85 p=.08$
$\mathrm{t}(19)=1,75 \mathrm{p}<.10$
$\mathrm{t}(19)=0,15 p<.89$
(B) $x$ (C) $\quad t(19)=0,49 p<.70$
$t(19)=0,32 p<.76$
$\mathrm{t}(19)=0,32 \mathrm{p}<.76$
(B) $x$ (D) $\quad t(19)=0,62 p<.60$
$t(19)=3,17 p<.01$
$t(19)=3,37 p<.01$
(C) $\times$ (D) $\quad t(19)=0,12 p<1$
$t(19)=2,29 p<.04$
$t(19)=3,30 p<.01$

\subsection{3.}

\section{Discussão}

Em resumo, os resultados do Experimento 1 se mostraram condizentes com as previsões iniciais. Em relação a S1 (abaixo, o exemplo com a configuração dos segmentos é reapresentado), mais rodadas (trials) com fixação e fixações mais longas na ilustração-alvo foram registradas na condição (A), que, neste momento da sentença, seria a única dentre as condições a permitir a desambiguização da referência. Ainda que esta condição não tenha diferido significativamente da condição (D), seja em relação ao número rodadas (trials) com fixação no alvo, 
seja em relação à duração total das fixações, foi possível observar uma diferença marginal entre essas condições. Como é possível observar com auxílio da Figura (13), em função do contexto visual apresentado na condição (A), apenas a informação de gênero trazida no DP inicial da sentença, independentemente do conteúdo da relativa, seria suficiente para que a referência pudesse ser desambiguizada. Com isso, muito embora o resultado obtido na análise do S1 não diga respeito diretamente ao processamento da oração relativa, este resultado reafirma estudos que vêm indicando um rápido mapeamento entre sentenças e elementos do campo visual no processo de compreensão da linguagem.

$\underline{\text { A garota que o }}$ bombeiro pegou vai comprar um brinquedo.

S1
S3

Figura 13 - Exemplos de elementos distintivos e condições experimentais tomando como referência o estímulo "A garota que o bombeiro pegou vai comprar um brinquedo".
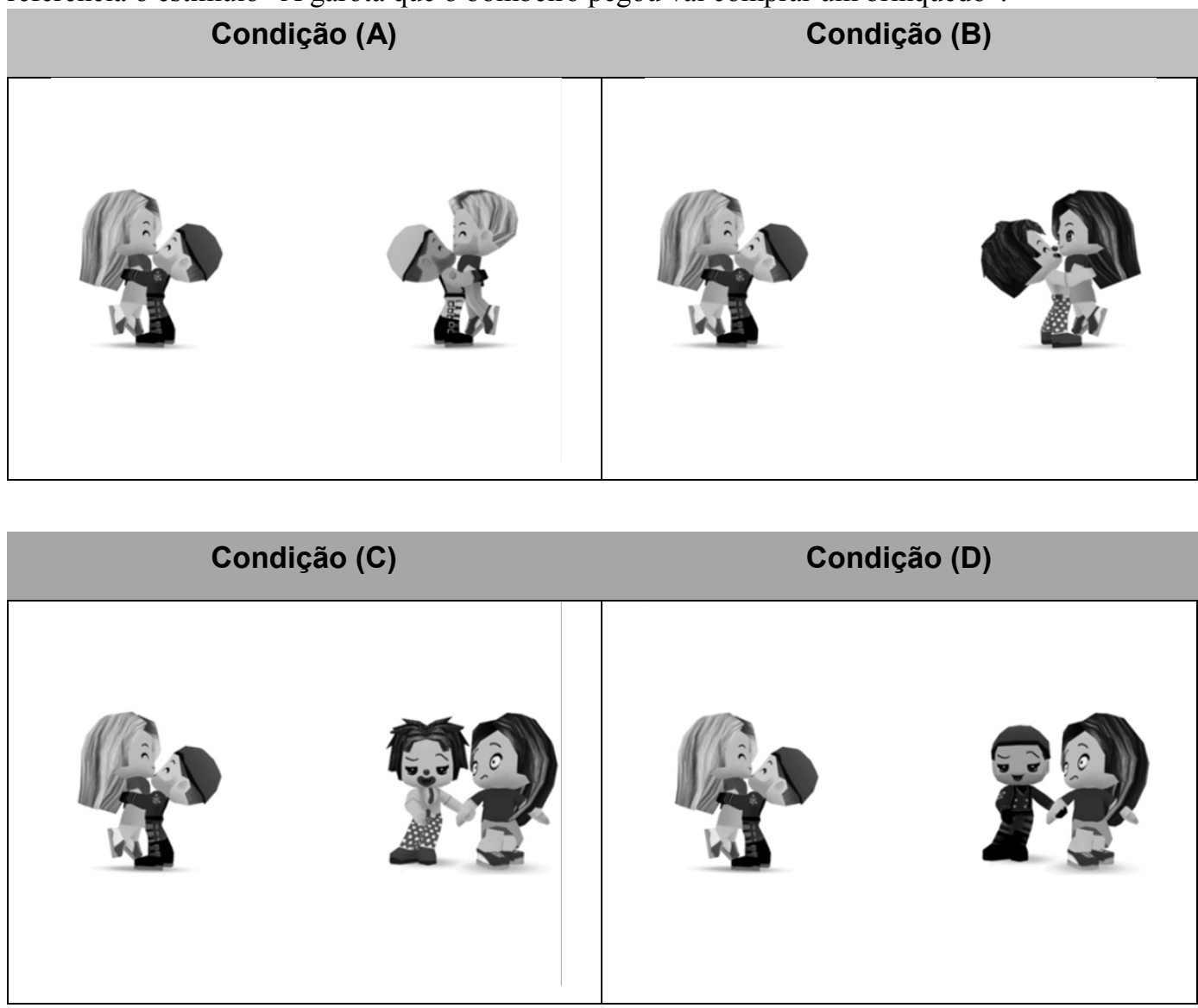

Em S2, novamente de acordo com as previsões, as condições (B) e (C), em ambas as variáveis dependentes observadas, registraram significativamente mais rodadas (trials) com fixação e fixações mais longas na ilustração-alvo, quando 
comparadas à condição (D). Considerando que (B) e (C) eram as condições nas quais o sujeito da relativa constituía-se como elemento distintivo, esse resultado pode ser tomado como uma indicação de um mapeamento antecipado do DPnúcleo da relativa, sugerindo um processamento altamente incremental e preditivo: a disponibilidade de um contexto visual distintivo proveu meios para que o referente visual da relativa pudesse ser antecipado, conforme indicado pelo alto número de rodadas (trials) com fixação na ilustração-alvo, ainda no segmento 2 , isto é, ainda antes que o gap da relativa pudesse ser alcançado.

Ainda no S2, a condição (A) mostrou um número maior rodadas (trials) com fixação na ilustração-alvo do que a condição (D), gerando uma diferença muito próxima da margem de significância (Tabela 3). A duração total das fixações também foi maior em (A) do que em (D), embora esta diferença não tenha sido significativa. A vantagem de (A) sobre (D) em termos do número de rodadas (trials) com fixação e duração de fixações provavelmente surge como consequência do fato de a condição (A), à altura do S2, já ter permitido a identificação do referente, como indicam os resultados observados no S1.

O S3, diferentemente dos outros segmentos, apresentou um grande número de rodadas (trials) com fixação na ilustração-alvo em todas as condições. Levando em conta que o S3 é o segmento no qual está contido o verbo da relativa, o alto número de rodadas (trials) com fixação pode ser entendido como um reflexo de um processo de integração sintática disparado pela identificação do gap. Pode ser entendido também como resultado de um processo de checagem do mapeamento ocorrido anteriormente, no caso das condições (A), (B) e (C) (na condição (D), não há antecipação e, portanto, não haveria necessidade de checagem). Contudo, em função do tamanho deste segmento, os resultados obtidos devem ser vistos com cautela, pois as fixações ocorridas neste trecho tornam-se sujeitas à influência de fatores diversos. O S3 também ocasionou longas fixações em todas as condições. As condições (A) e (D) se distinguiram de maneira significativa, das condições (B) e (C).

\section{3. \\ EXPERIMENTO 2}

O experimento 2 foi semelhante ao experimento 1, mas com algumas reformulações: na apresentação do slide 2, ao invés da sentença contendo uma 
oração relativa, eram apresentadas, no presente experimento, duas sentenças declarativas descrevendo cada uma das ilustrações deste slide (ver Figura 14, p. 107). A relativa seria apresentada somente em um terceiro slide concomitantemente com imagens ilustrando somente os pacientes da ação e não mais os personagens-agentes. As variáveis independentes (elementos distintivos) e dependentes (número de rodadas (trials) com fixação e duração total de fixações), entretanto, mantiveram-se as mesmas, assim como se manteve inalterada a configuração das condições.

As reformulações foram motivadas pelo fato de que, no experimento 1, havia a possibilidade de que, ao ouvir uma sentença experimental como "A garota que o bombeiro pegou vai comprar um brinquedo", o participante direcionasse seu olhar para a ilustração referida pela sentença no momento em que ouvia a palavra "bombeiro", por exemplo, não porque estivesse, de fato, antecipando o conteúdo do gap, mas simplesmente porque o processo de acesso lexical poderia ter direcionado a atenção do paciente à ilustração na qual estava sendo apresentado um bombeiro, i.e. a ilustração-alvo. Em função disso, os personagens-agentes deixaram, no presente experimento, de ser apresentados concomitantemente com a sentença experimental.

A ilustração que estabeleceria as relações entre as entidades referidas na oração relativa passou a ser apresentada antes da sentença experimental. Para que estas ilustrações e as informações não passassem ao largo da atenção dos participantes, elas vieram introduzidas por declarativas simples. Desta forma, o Experimento 2 permitirá avaliar não só a relação entre a informação visual e o processamento linguístico, mas também em que medida a informação contextual de natureza discursiva é integrada no processamento on-line de DPs complexos contendo relativas de objeto.

Note-se que, em função da arquitetura deste experimento, havia a necessidade de que os participantes recuperassem na memória as informações visuais e linguísticas apresentadas no slide 2 para interpretar adequadamente a sentença experimental apresentada no slide 3.

Caso tais informações pudessem ser adequada e rapidamente acessadas, previa-se que, o Experimento 2 deveria repetir os resultados obtidos no experimento 1, em resumo: mais rodadas (trials) com fixação e fixações mais longas na ilustração alvo, durante S1, na condição (A); durante S2, nas condições 
(B) e (C) e, durante S3, muitas rodadas (trials) com fixação e longas fixações em todas as condições.

\subsection{1.}

Método

\section{Participantes}

Foram voluntários deste experimento 20 alunos dos cursos de graduação em Letras da PUC-Rio e da Universidade do Estado do Rio de Janeiro. O grupo dividiu-se entre 4 homens e 16 mulheres, com média de idade de 24,5 anos. Como no experimento anterior, os alunos, em troca de sua participação, receberam uma gratificação. Ao todo, nos dois experimentos, 23 participantes foram descartados por dificuldades na calibração do equipamento ou por falhas no registro ocular durante a aplicação.

\section{Material}

Ao invés de 2 slides, o experimento 2 contava com 3 slides por rodada (trial), totalizando 31 slides, dos quais 24 compunham os estímulos experimentais. Como no experimento 1, o primeiro dos slides trazia a apresentação das duas personagens candidatas potenciais a pacientes da ação que viria a se constituir como verbo da oração relativa (ver Figura 14, p. 107). O segundo slide também manteve-se o mesmo no tocante aos estímulos visuais: duas ilustrações, uma alvo e outra concorrente, mostrando ações envolvendo um agente e os pacientes do slide 1. Os estímulos verbais, entretanto, no experimento 2, foram alterados. Eram apresentadas, em sequência, duas declarativas com estrutura sujeito-verbo-objeto. Cada uma destas frases fazia referência a cada uma das ilustrações do segundo slide, de forma que os estímulos verbais variavam, assim como variavam as ilustrações (Fig. 14). Os estímulos visuais do terceiro slide eram os mesmos apresentados no slide 1: os dois personagens que haviam sido pacientes da ação apresentada no slide 2. Como estímulos verbais, o slide 3 trazia as sentenças experimentais (4 a 11) seguidas das interrogativas QU-, ambas idênticas àquelas utilizadas no experimento 1 .

Dos 7 slides utilizados no pré-teste, um era dedicado a uma tarefa de nomeação, idêntica a do experimento 1, enquanto os outros 6 slides formavam duas rodadas (trials) de treinamento. 


\section{Aparato}

Este experimento contou com o mesmo aparato utilizado no experimento 1.

\section{Procedimento}

Os procedimentos relativos à calibração e ao treinamento dos participantes foram idênticos aos do experimento 1. Na apresentação dos estímulos experimentais, os participantes assistiam ao primeiro slide por cerca de 11 segundos, após os quais o segundo slide era automaticamente apresentado por cerca de 14 segundos. O terceiro slide também era automaticamente apresentado após o anterior. Antes da apresentação dos estímulos verbais, os participantes tinham 3 segundos para observar livremente as ilustrações. Um ponto vermelho aparecia então brevemente no centro da tela. Em seguida a sentença experimental era apresentada. Cerca de 3 segundos depois do fim da apresentação da sentença contendo a relativa de objeto, era apresentada a interrogativa QU- a qual o participante deveria responder. A partir deste momento o participante poderia dispor de quanto tempo desejasse para fornecer sua resposta, após a qual o experimentador disparava outra rodada (trial) do experimento.

Figura 14 - Sequência de estímulos do Experimento $2^{50}$

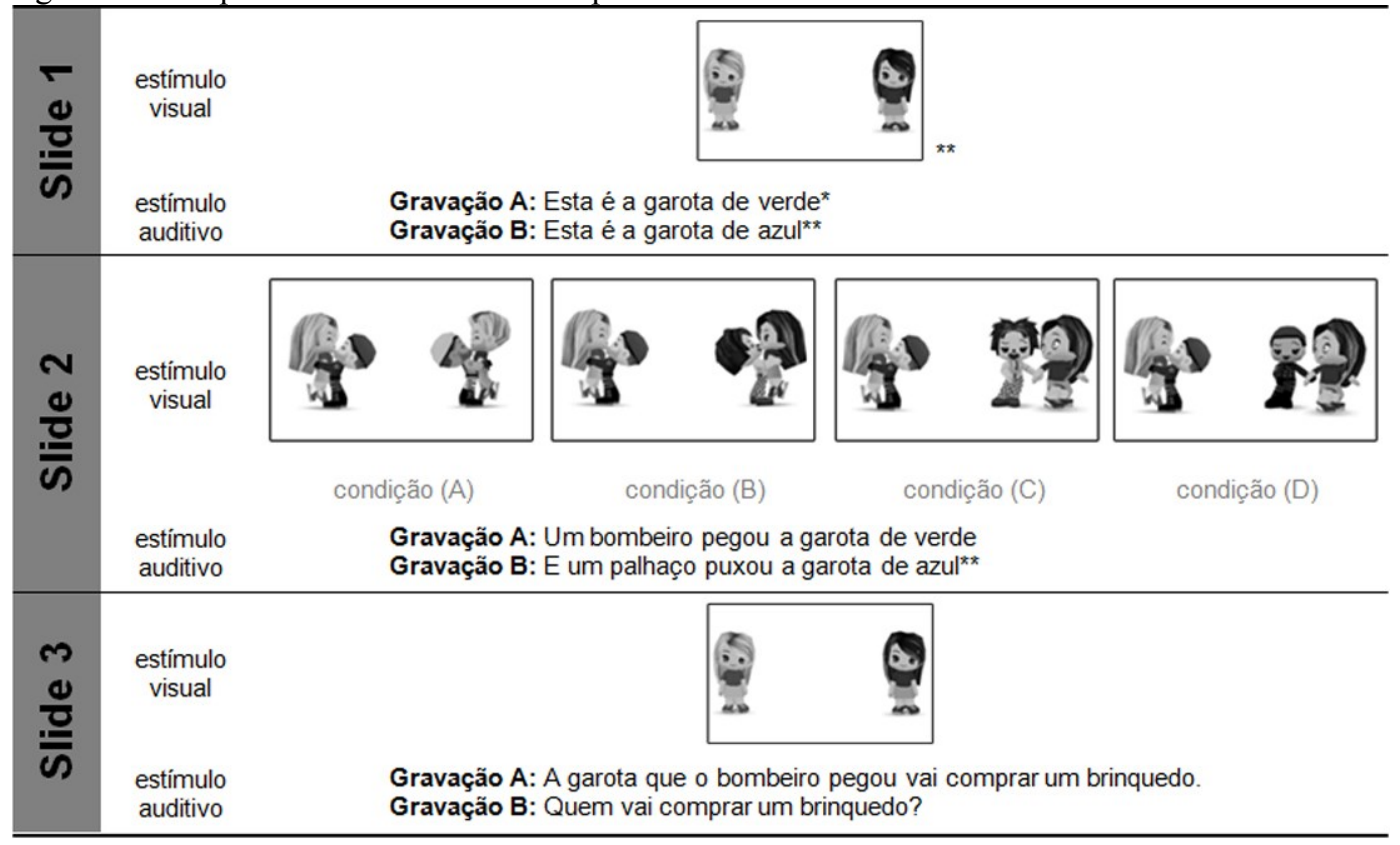

${ }^{50}(*)$ Estímulos originalmente coloridos. (**) Estímulos relativos à condição $(\mathrm{C})$. 


\subsection{2.}

\section{Resultados}

Os dados relativos ao número de rodadas (trials) com fixação no alvo foram submetidos a 3 ANOVAs, um para cada um dos segmentos considerados (S1: $\mathrm{F}(3,57)=3,14 \mathrm{p}<.04 ; \mathrm{S} 2: \mathrm{F}(3,57)=1,50 \mathrm{p}<.3 ; \mathrm{S} 3: \mathrm{F}(3,57)=1,76 \mathrm{p}<.1) . E m \mathrm{~S} 1$, a condição (A), neste experimento assim como no experimento 1, registrou um número maior rodadas (trials) com fixação na figura-alvo (Gráfico 7). Comparações pareadas (Tabela 4) revelaram que esta condição, na qual o núcleo da relativa desambiguizava a referência, diferiu significativamente das condições (C) e (D), diferindo também marginalmente da condição (B). Em S2 (Gráfico 8), as condições $(\mathrm{A}),(\mathrm{B})$ e $(\mathrm{C})$, nas quais a referência poderia ser resolvida antes do verbo encaixado, repetindo os resultados do Experimento 1, estiveram relacionadas a um maior número de rodadas (trials) com fixação na ilustraçãoalvo, quando comparadas à condição (D). Entretanto, o menor número de rodadas (trials) com fixação no alvo na condição (D) não foi suficientemente para configurar uma diferença significativa, à exceção de uma diferença marginal em relação às condições (A) e (B) (Tabela 4). Em S3 (Gráfico 9), todas as condições apresentaram um elevado número de rodadas (trials) com fixação no alvo, sem qualquer diferença significativa entre elas. 
Gráfico 7 - Média de rodadas (trials) com fixação na ilustração-alvo por condição no Segmento 1 (escore máximo 2)

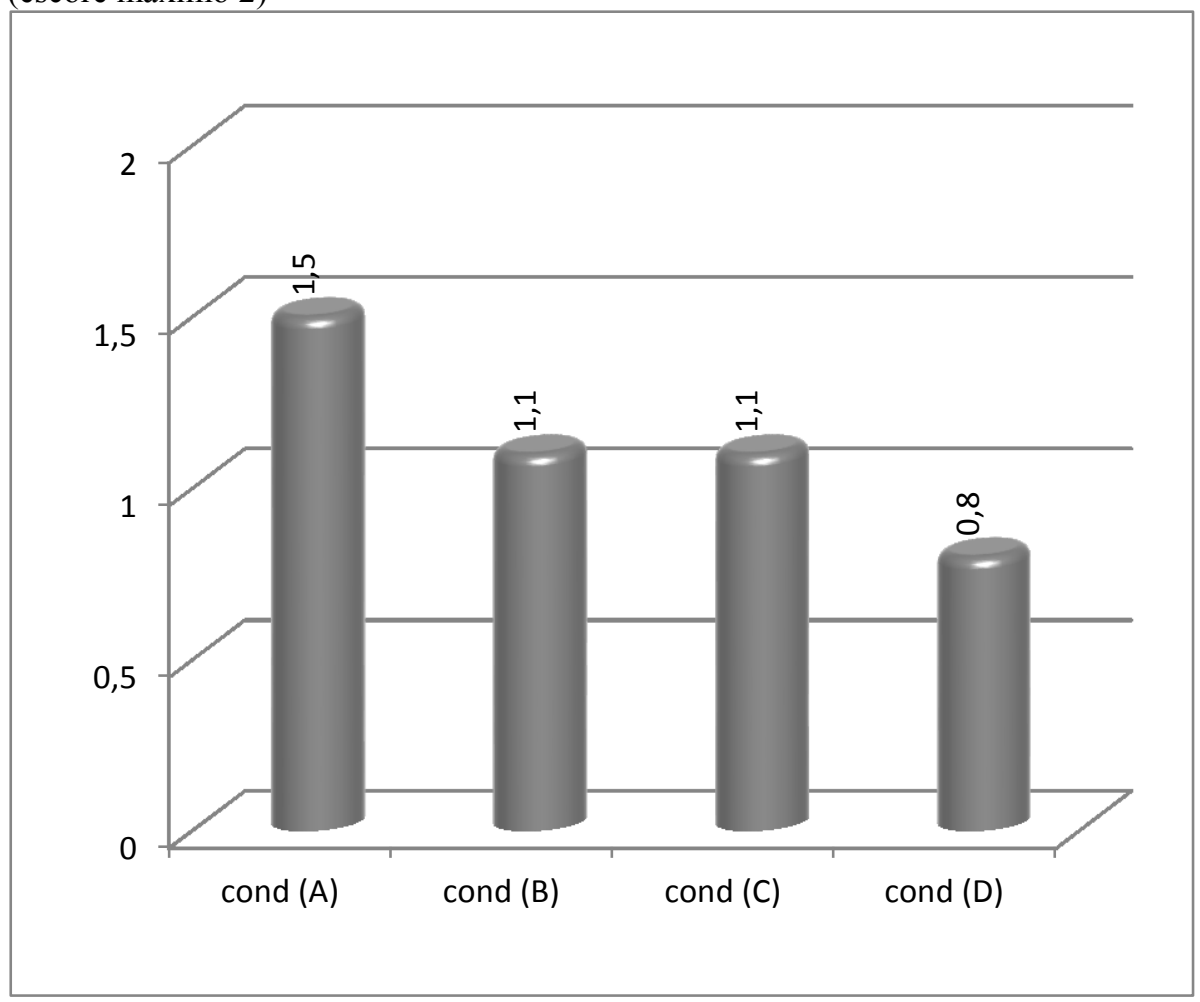

Gráfico 8 - Média de rodadas (trials) com fixação na ilustração-alvo por condição no Segmento 2 (escore máximo: 2)

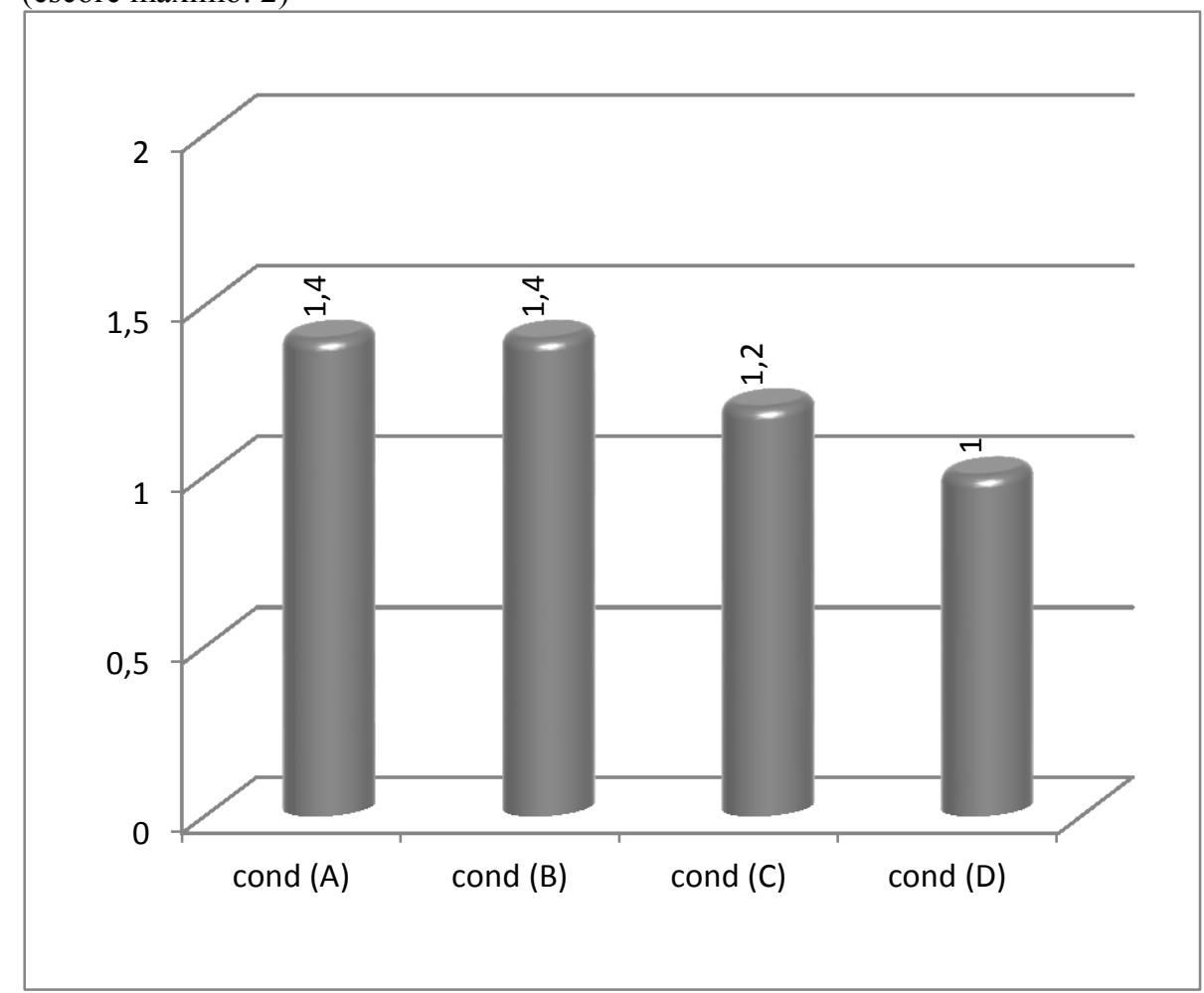


Gráfico 9 - Média de rodadas (trials) com fixação na ilustração-alvo por condição no Segmento 3 (escore máximo: 2)

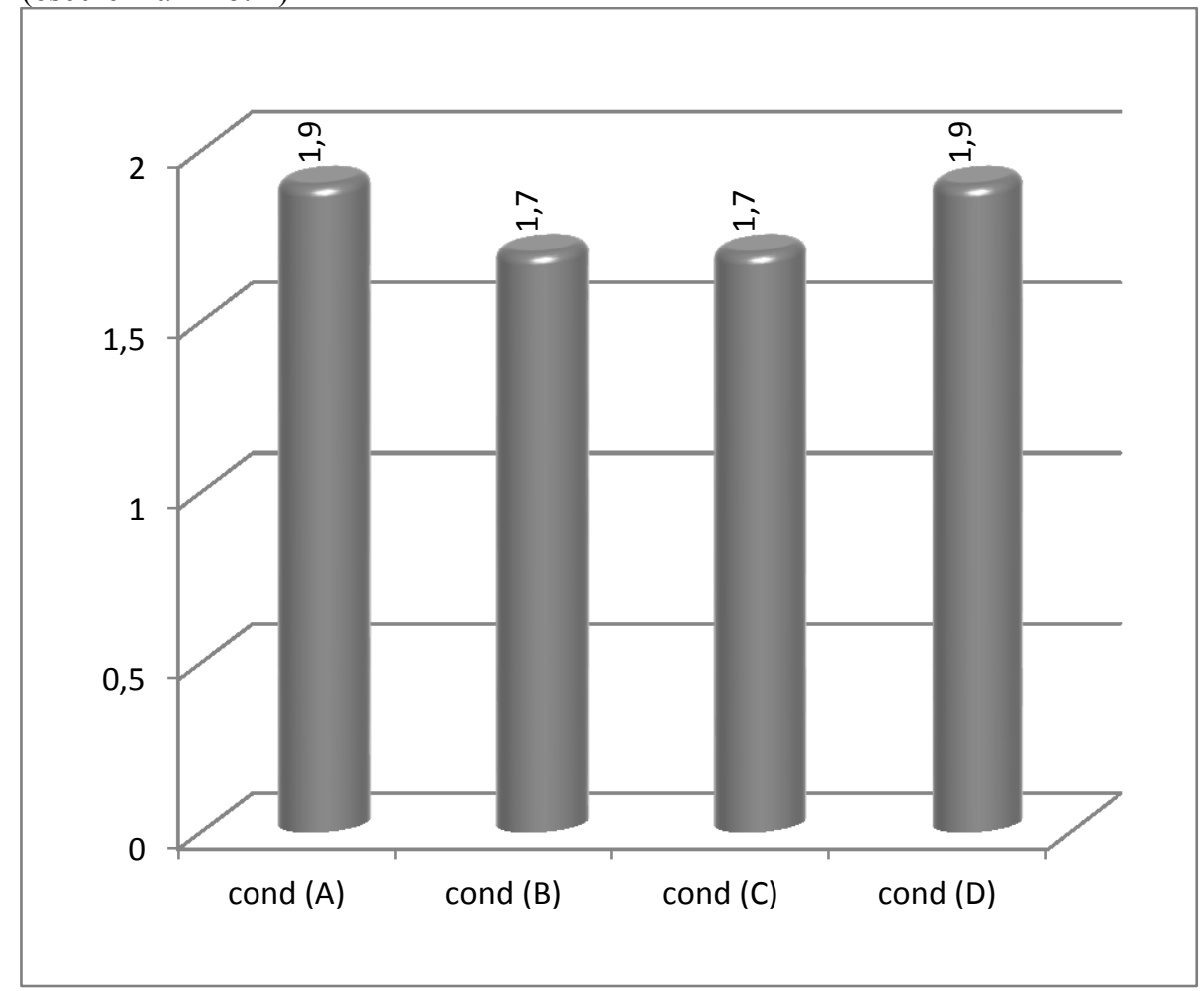

Tabela 4 - Comparações pareadas (teste $t$ ) entre condições por segmentos referentes à duração total das fixações na ilustração-alvo (os valores em negrito ressaltam as diferenças significativas)

S1 S2 S3
(A) $x$ (B) $t(19)=1,83 p<.09 \quad t(19)=0,22 p<.83$
$\mathrm{t}(19)=1,29 \mathrm{p}<.22$
(A) $x$ (C) $t(19)=2,27 p<.04$
$t(19)=0,89 p<.39$
$\mathrm{t}(19)=1,29 p<.22$
(A) $x$ (D) $t(19)=2,67 p<.02$
$\mathrm{t}(19)=1,79 p<.09$
$\mathrm{t}(19)=0,57 p<.58$
(B) $x$ (C) $\quad t(19)=0,00 p=1$
$t(19)=1,31 p<.20$
$t(19)=0,00 p=1$
(B) $x$ (D) $t(19)=1,31 p<.20$
$\mathrm{t}(19)=1,80 \mathrm{p}<.09$
$\mathrm{t}(19)=1,75 p<.10$
(C) $x$ (D) $\quad t(19)=0,96 p<.35$
$t(19)=0,68 p<.51$
$t(19)=1,75 p<.10$

Os dados relativos à duração total de fixações na ilustração-alvo também foram submetidos a três ANOVAs, um por segmento (ANOVAs: S1: $\mathrm{F}(3,57)=2,49 \mathrm{p}<.07 ; \mathrm{S} 2: \mathrm{F}(3,57)=2,56 \mathrm{p}<.07 ; \mathrm{S} 3: \mathrm{F}(3,57)=0,750 \mathrm{p}<.6)$. Em S1 (Gráfico 10), a condição (A), novamente, foi fixada durante uma extensão maior de tempo, ainda que só tenha diferido significativamente da condição (D) (Tabela 5). Em S2, as condições (A) e (B) estiveram associadas a fixações mais longas, diferindo significativamente da condição (D) (Tabela 5). Por fim, em S3 (Gráfico 12), todas as condições apresentaram longas durações, sem diferenças significativas entre elas. 
Gráfico 10 - Duração total das fixações na ilustração-alvo (em ms.) por condição no Segmento 1

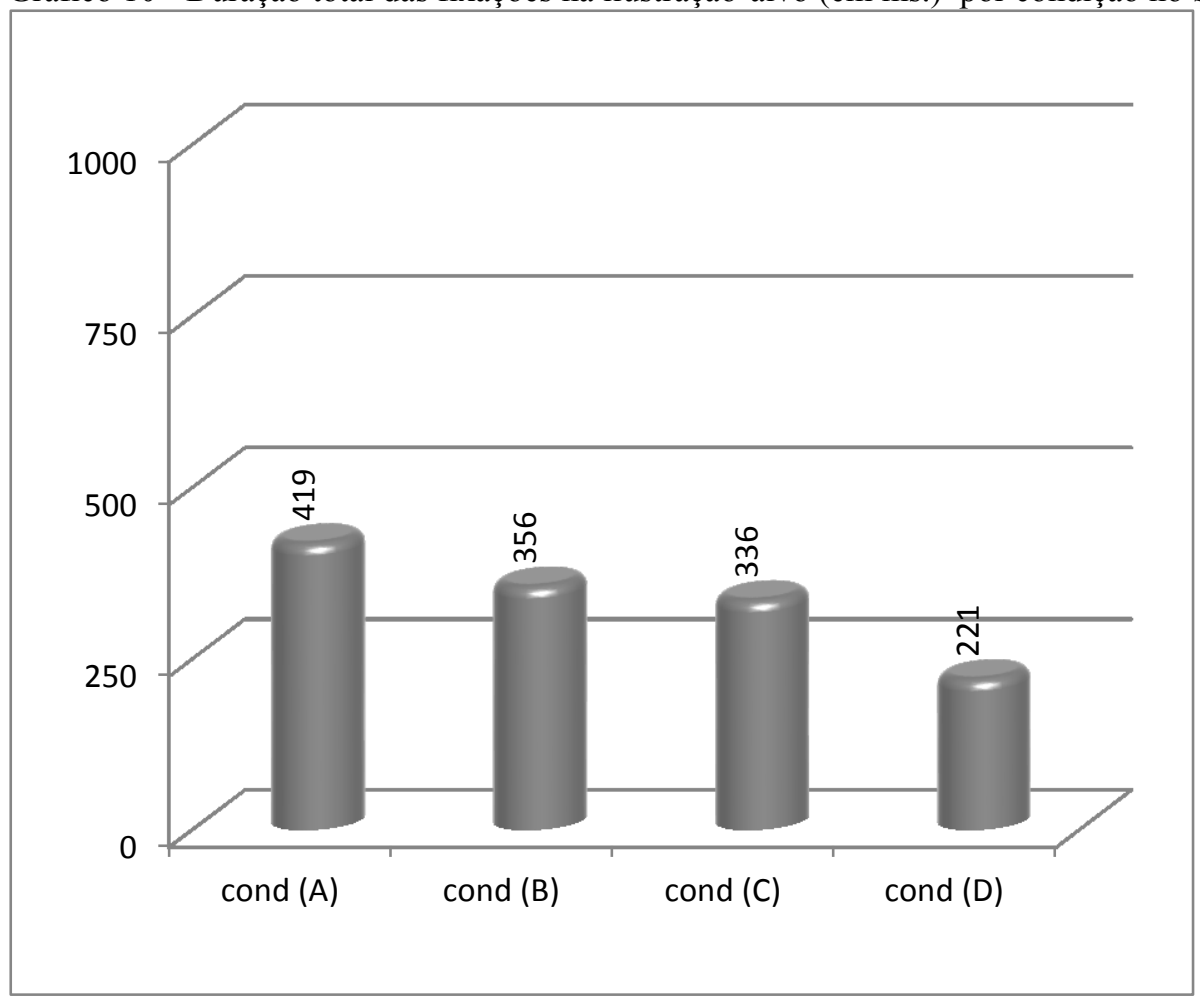

Gráfico 11 - Duração total das fixações (em ms.) na ilustração-alvo por condição no Segmento 2

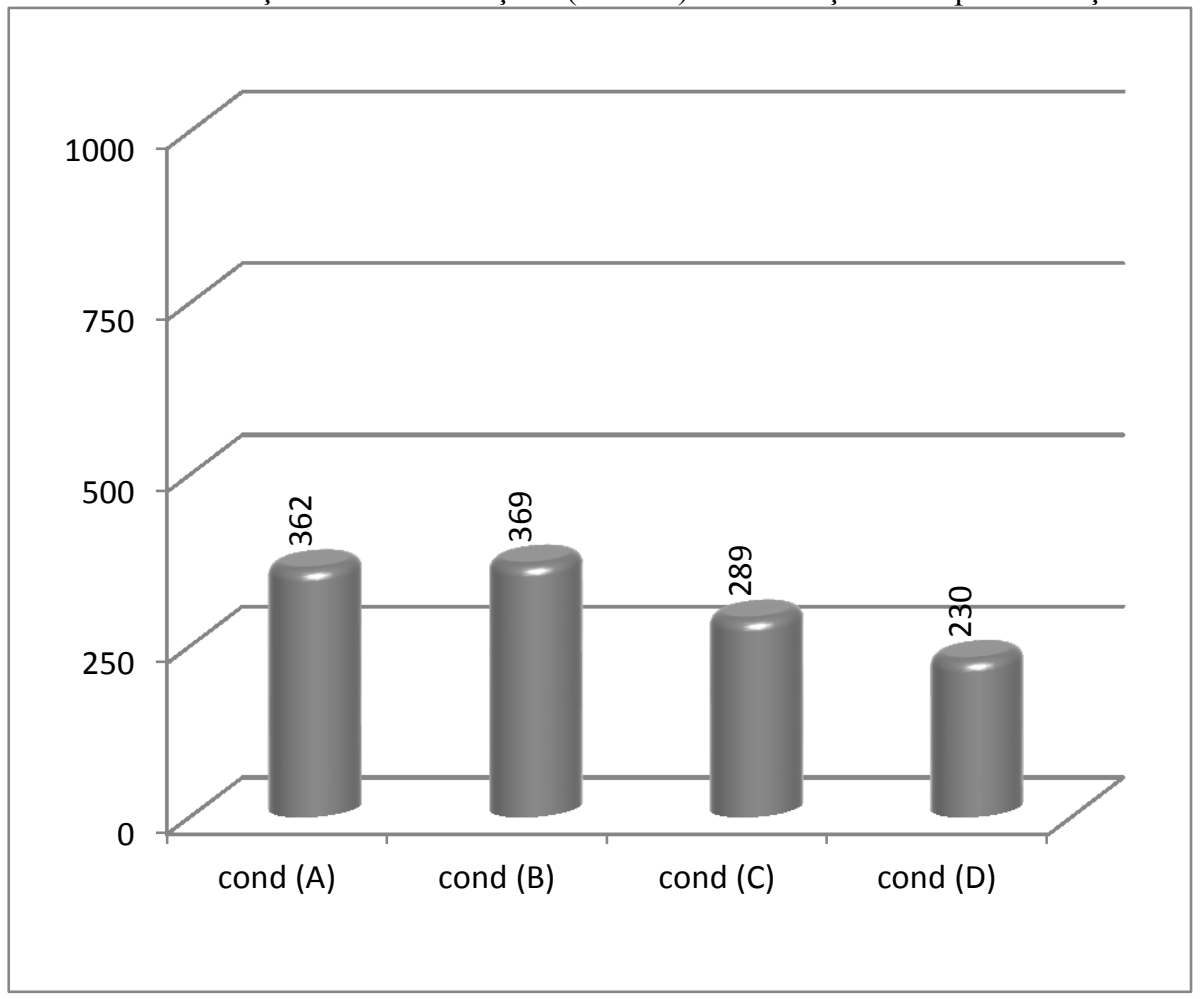


Gráfico 12 - Duração total das fixações (em ms.) na ilustração-alvo por condição no Segmento 3

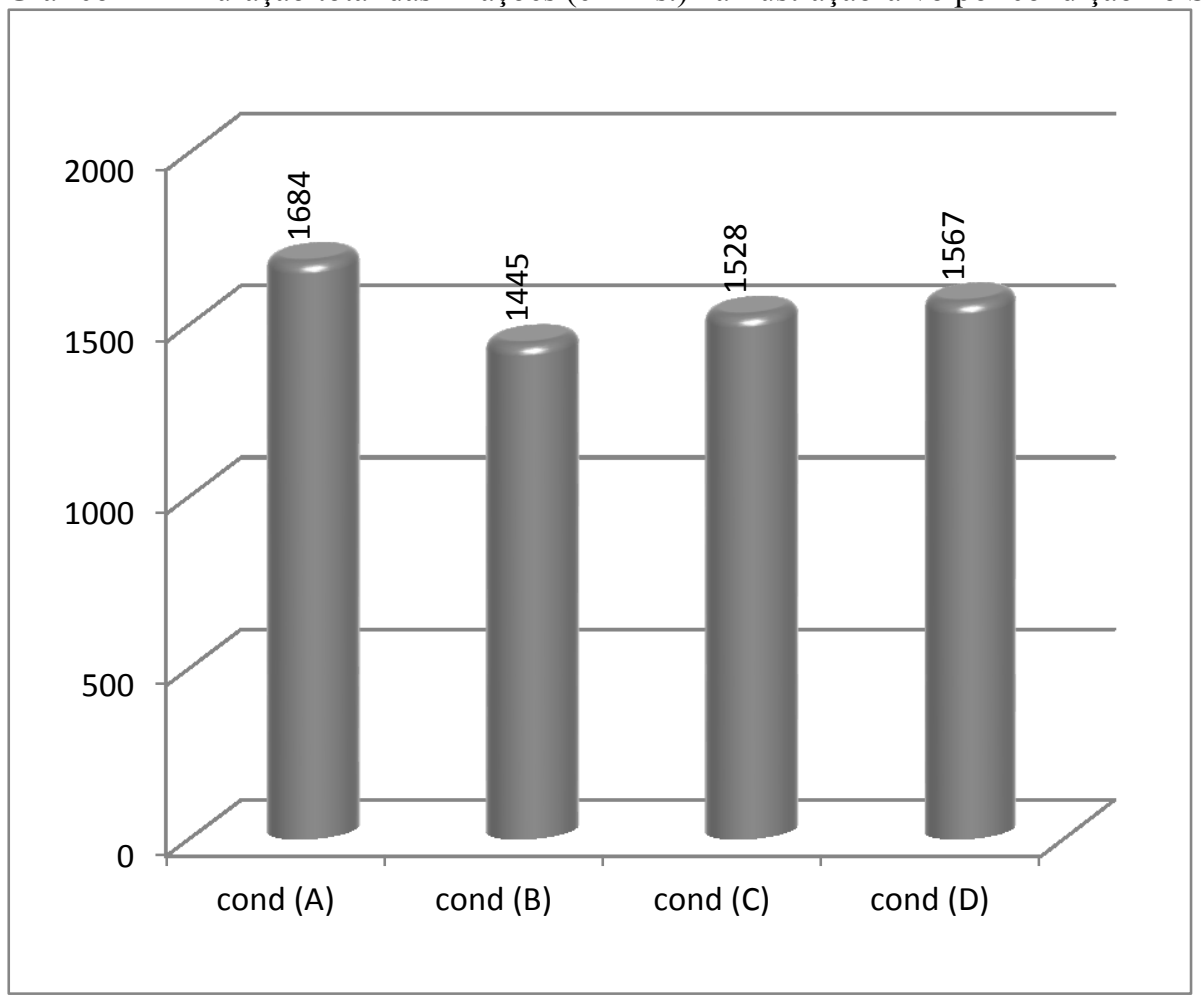

Tabela 5 - Comparações pareadas (teste de $t$ ) entre condições por segmentos referentes à duração total das fixações na ilustração-alvo (os valores em negrito ressaltam as diferenças significativas).

S1

S2

S3

\begin{tabular}{llll}
\hline (A) $x$ (B) & $t(19)=1,00 p<.34$ & $t(19)=0,11 p<.92$ & $t(19)=1,25 p<.23$ \\
(A) $x$ (C) & $t(19)=1,32 p<.21$ & $t(19)=1,22 p<.24$ & $t(19)=0,78 p<.45$ \\
(A) $x$ (D) & $t(19)=2,61 p<.02$ & $t(19)=2,63 p<.02$ & $t(19)=0,95 p<.36$ \\
(B) $x$ (C) & $t(19)=0,24 p<.82$ & $t(19)=1,46 p<.17$ & $t(19)=0,54 p<.60$ \\
(B) $x$ (D) & $t(19)=1,88 p<.08$ & $t(19)=2,39 p<.03$ & $t(19)=0,84 p<.42$ \\
(C) $\times$ (D) & $t(19)=1,33 p<.20$ & $t(19)=0,99 p<.34$ & $t(19)=0,27 p<.79$
\end{tabular}

\subsection{3.}

Discussão

Embora o Experimento 2 exigisse que o elemento desambiguizador da referência fosse recuperado da memória, os resultados obtidos foram, em termos gerais, semelhantes aos resultados do Experimento 1, no qual a informação distintiva era apresentada concomitantemente à sentença experimental. Desta forma, os resultados do Experimento 2 se mostraram consonantes também com as previsões iniciais. 
No segmento 1, em ambos os experimentos, foi possível observar uma vantagem no número de rodadas (trials) com fixação e na duração das fixações para a condição (A), na qual o sexo do paciente apresentava-se como elemento distintivo, permitindo, de acordo com as previsões iniciais, o mapeamento da sentença em um referente antes mesmo do DP relativo. Tanto no experimento 1 quanto no experimento 2, a condição (A) registrou um número maior de rodadas (trials) com fixação e também durações totais mais longas. Nem sempre, a diferença entre a condição (A) e as outras condições foi suficiente para se mostrar significativa, registrando uma diferença apenas marginal em relação à condição (D) no Experimento 1 e, no Experimento 2, uma diferença também marginal em relação à condição (B), para o número de rodadas (trials) com fixação. Ainda no Experimento 2, a duração total das fixações na condição (A) foi significativamente maior apenas em relação à condição (D). Contudo, a condição (A) esteve consistentemente associada a mais rodadas (trials) com fixação na figura-alvo e a fixações mais duradouras, de forma que, considerados em conjunto, os dados dos dois experimentos parecem prover evidências em favor de um mapeamento entre o DP-núcleo da relativa e seu referente, esteja ele visualmente presente, como no Experimento 1, ou esteja ele representado na memória. Como dito anteriormente, estes resultados sugerem um mecanismo que permita um mapeamento incremental de DPs.

No que diz respeito ao Segmento 2, as condições (A) e (B) se destacaram por estarem associadas a fixações mais longas e a um maior número de rodadas (trial) com fixação, o que não parece ser surpreendente, diante dos resultados do Experimento 1. A condição (A), à altura do S2, já haveria permitido o mapeamento do referente do DP inicial durante o S1, de forma que as fixações registradas no Segmento 2 poderiam, assim, ser entendidas como uma continuidade das fixações registradas no Segmento 1. A condição (B), por sua vez, permitiria a desambiguização da referencia, a partir de S2 (ver Figura 15, p. 115) e, deste modo, como esperado e repetindo os resultados obtidos no Experimento 1, registrou longas e numerosas rodadas (trials) com fixação. Este resultado, assim, provê indícios a favor da hipótese de um rápido mapeamento entre DPs e seus referentes. Note-se, entretanto, que no Experimento 2, diferentemente do Experimento 1, a condição (C) não se distinguiu significativamente da condição (D). Como é possível observar, tanto no que diz 
respeito ao número de rodadas (trials) com fixação ou à duração das fixações, a condição (C) ficou a meio caminho entre fixações registradas em (B) e as fixações registradas em (D). O menor número de rodadas (trials) com fixação em (C), quando comparada a (B), no experimento 2, não foi previsto a princípio, pois imaginava-se que, na medida em que houvesse a possibilidade de um mapeamento rápido entre a sentença e o contexto visual, isso implicaria que, em ambas as condições, deveria ser possível registrar movimentos oculares que indicassem a identificação do referente correto em S2. A possibilidade desse mapeamento seria uma consequência de tanto (B) quanto (C) permitirem a desambiguização da referência a partir da informação trazida pelo sujeito da relativa, na medida em que ambas apresentavam o agente como um elemento distintivo. Entretanto, o fato de a condição (C) trazer, além do agente, a ação como um elemento distintivo, parece ter influenciado o comportamento dos participantes no Experimento 2. Além disso, o fato de que os participantes, neste experimento, tivessem que recuperar a informação distintiva (apresentada no slide 2) da memória parece também ser um fator que contribui para a diferença entre (B) e (C), na medida em que esta diferença não se apresentou no experimento 1 , no qual o contexto visual era apresentado em conjunto com a sentença experimental. Assim, se a representação do contexto discursivo e/ou visual mantido na memória (seja a representação semântica verbal, seja a representação visual) apresenta mais de um elemento distintivo, parece haver a necessidade de que ambos sejam identificados na relativa para que possa haver um mapeamento efetivo da sentença que se desdobra em um referente visual. Ainda assim, a possibilidade de um mapeamento antecipado do DP complexo que contém a relativa em um referente visual, à altura do S2, parece encontrar evidências suficientes no conjunto dos dados. 
Figura 15 - Sequencia de estímulos do Experimento $2^{51}$

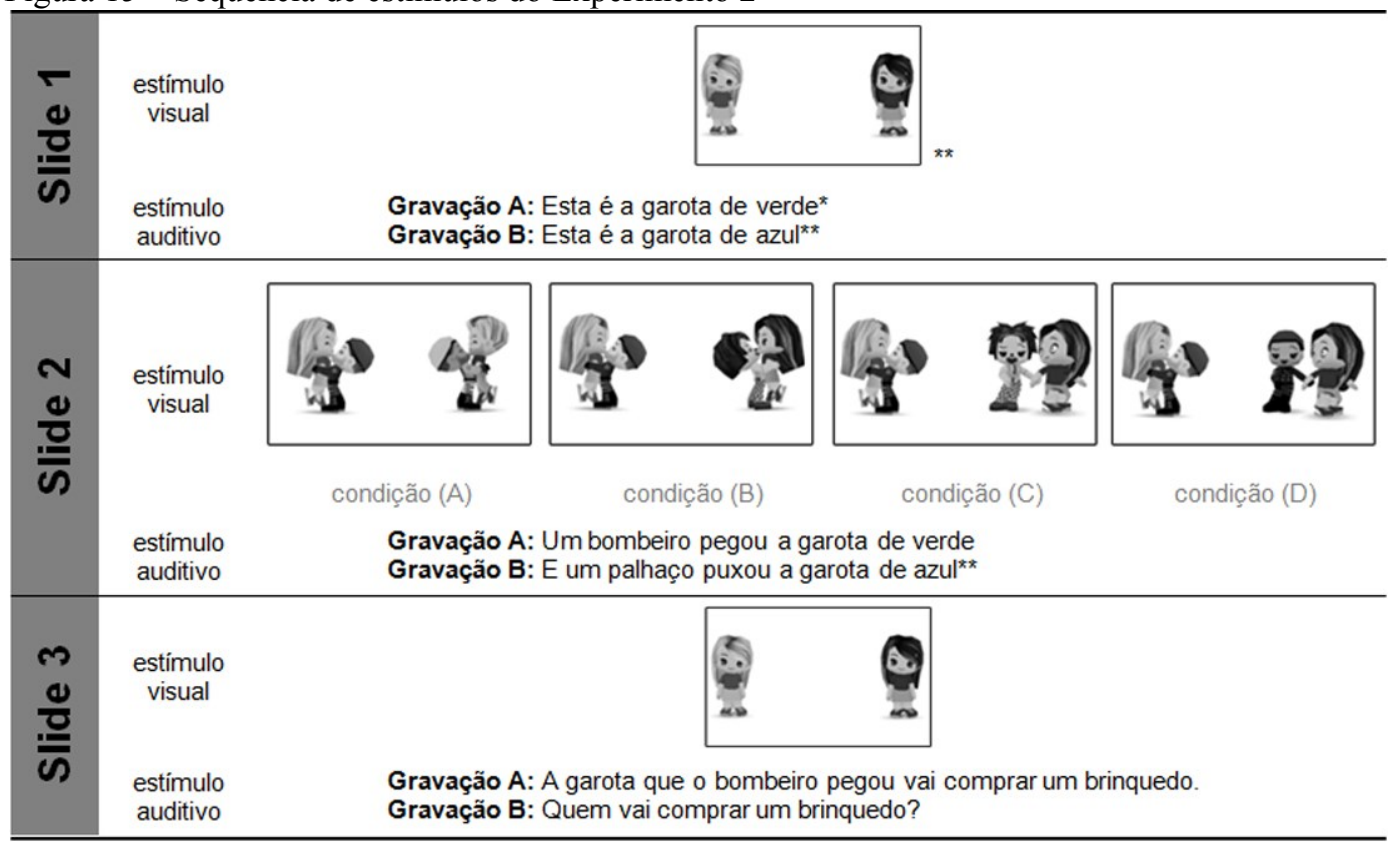

Em relação ao Segmento 3, neste experimento como no primeiro, foram observadas muitas rodadas (trials) com fixação no alvo e longas fixações em todas as condições. Como dito anteriormente, este resultado poderia ser tomado como um indicativo de processos integrativos no S3.

Em termos gerais, os resultados apresentados sugerem que há uma tendência de que os DPs sejam mapeados em possíveis referentes tão logo haja informação distintiva disponível. Na existência de um DP complexo e na disponibilidade de mais de um candidato à referência, a disponibilidade de informação distintiva dispara uma busca pelo referente do DP complexo, que tende a ser antecipadamente mapeado. Como permitiriam concluir os dados relativos ao número de rodadas (trials) com fixação no alvo e a duração total das fixações no Segmento 2, o DP sujeito da relativa, tende a ser mapeado em um referente mediante a disponibilidade de informação contextual visual, tendo em vista que se observou, neste caso, que as condições nas quais o contexto visual fornecia informação distintiva suficiente registraram mais e mais longas fixações. No Segmento 3, o alto número de rodadas (trials) com fixação na ilustração-alvo e as longas durações podem sugerir um processo de checagem da referência

\footnotetext{
${ }^{51}(*)$ Estímulos originalmente coloridos. (**) Estímulos relativos à condição (C).
} 
estabelecida anteriormente, além de um processo de integração sintática, no qual haveria o preenchimento do gap da relativa.

\section{4.}

\section{EXPERIMENTO 3}

$\mathrm{O}$ experimento 3 investigou a ambiguidade temporária entre relativas de objeto e completivas. Em certos contextos estruturais, como aqueles que envolvem verbos bitransitivos, a ambiguidade lexical do que pode criar uma ambiguidade estrutural temporária, permitindo que este elemento seja analisado como marcador relativo, que introduz uma oração relativa (12), ou como um complementizador, que introduz um argumento interno sentencial do verbo principal (13).

(12) Um sargento disse [para a garota que o bombeiro pegou]...

(13) Um sargento disse [para a garota][que o bombeiro pegou...]

Conforme apresentado no capítulo 3, tem-se argumentado, no contexto das teorias baseadas em restrições, que diante de ambiguidades dessa natureza, o processador poderia valer-se, incrementalmente, de informação de natureza contextual para resolver a ambiguidade em questão. Nesse sentido, foi detectado em experimentos com potenciais evocados (van Berkum, Brown e Hagoort, 1999; van Berkum, Hagoort e Brown, 2000) e de leitura automonitorada (Grodner, Gibson e Watson, 2005) que informação contextual precedente poderia facilitar a desambiguização. Com base nestes experimentos, argumentou-se que informação contextual discursiva a partir da qual se apresentavam, previamente, duas entidades representadas por um mesmo DP, criaria, em uma próxima ocorrência deste DP, uma expectativa de modificação que tenderia a facilitar uma leitura relativa.

Considerando os resultados dos experimentos 1 e 2 , no quais se verificou que informação contextual visual e discursiva poderia permitir a desambiguização da referência à altura do DP sujeito de uma relativa de objeto, nos casos em que este se constituía como uma informação desambiguizadora, o experimento buscou contrastar o efeito da presença de informação contextual, na qual se apresentam 
duas entidades que competem pela referência de um DP, diante da ambiguidade temporária do que (complementizador/marcador de relativas), levando em conta informação de natureza prosódica.

Diferentemente de experimentos anteriores nos quais estímulos auditivos foram apresentados em prosódia neutra (van Berkum, Hagoort e Brown, 2000), neste experimento, sentenças contendo relativas e completivas temporariamente ambíguas foram apresentadas em prosódia natural. Nesse sentido, buscou-se avaliar em que medida informação de baixo nível, como a de natureza prosódica, poderia guiar o parser, tornando irrelevante a informação contextual, no caso das completivas.

Com este objetivo, empregou-se a estratégia experimental utilizada nos experimentos 1 e 2 com o intuito de verificar em que medida contextos nos quais se apresentam dois candidatos à referência de um DP poderiam induzir a uma leitura inicial de relativa em completivas temporariamente ambíguas ou em que medida a informação prosódica poderia sinalizar a segmentação adequada da sentença, limitando a influência de informação interpretativa na análise inicial da ambiguidade. Neste experimento, foram consideradas as seguintes variáveis independentes:

- Elemento potencialmente desambiguizador dado o contexto (fator grupal):

○ DP agente

○ Verbo

- Informação prosódica compatível com a estrutura:

○ relativa

○ completiva

O cruzamento dessas variáveis resultou em quatro condições (Tabela 5). Assim como nos experimentos anteriores, a variável dependente considerada foi o número de rodadas (trials) com fixação no referente alvo por segmento ${ }^{52}$. No caso deste experimento, os segmentos considerados, tanto nas estruturas relativas, quanto completivas, foram o sujeito (S1) e o verbo da oração encaixada (S2).

\footnotetext{
${ }^{52}$ Neste experimento, não foi considerada a duração total das fixações como variável dependente, uma vez que os constituintes críticos, nas diferentes estruturas, tinham extensões diferentes.
} 
Um sargento disse para garota que o bombeiro pegou $\ldots$

S1 S2

Tabela 5 - Condições experimentais

\begin{tabular}{lcc}
\hline & \multicolumn{2}{c}{ Variável dependente } \\
& $\begin{array}{c}\text { Elemento potencialmente } \\
\text { desambiguizador }\end{array}$ & $\begin{array}{c}\text { Informação prosódica } \\
\text { compatível com a estrutura }\end{array}$ \\
\hline Condição 1 & DP agente & relativa \\
(C1) & DP agente & completiva \\
Condição 2 & & relativa \\
(C2) & verbo & \\
Condição 3 & & completiva \\
(C3) & verbo & \\
Condição 4 & & \\
(C4) & & \\
\hline
\end{tabular}

A partir das variáveis apresentadas, foram estabelecidas as seguintes previsões: (i) se a informação contextual predominar, independentemente da informação prosódica, é previsto um efeito principal da variável elemento potencialmente desambiguizador, à altura do Segmento 1, com mais olhares no alvo da relativa na condição $1(\mathrm{C} 1)$ e na condição $2(\mathrm{C} 2)$ quando comparadas à condição $3(\mathrm{C} 3)$ e à condição $4(\mathrm{C} 4)$; à altura do segmento 2 , não seriam esperadas diferenças significativas entre as condições, pois, nesse segmento, todas elas poderiam permitir o mapeamento antecipado do referente de uma relativa; (ii) se a informação prosódica predominar, independentemente da informação contextual à altura de $\mathrm{S} 1$, é esperado um número maior de rodadas (trials) com fixações no referente da relativa apenas na $\mathrm{C} 1$, quando comparada às outras condições, uma vez que a leitura relativa, requerida para o mapeamento antecipado, com base na informação contextual desambiguizadora, só seria possível, à altura do sujeito da encaixada, nesta condição; em S2, considerando a disponibilidade de informação desambiguizadora e a possibilidade de uma leitura relativa ser possível em $\mathrm{C} 3$, mais rodadas (trials) com fixação seriam esperadas nessa condição quando comparada a $\mathrm{C} 2$ e a C4; (iii) se informação estrutural predominar, independementemente de informação contextual e prosódica, a hipótese nula não pode ser rejeitada. Nesse caso, uma interpretação compatível 
com o princípio da aposição mínima poderia ser esperada para todas as sentenças, o que poderia ser verificado no tipo resposta à uma pergunta offline de compreensão com foco no objeto do verbo da principal.

Figura 16 - Sequência de estímulos experimentais no Experimento 3

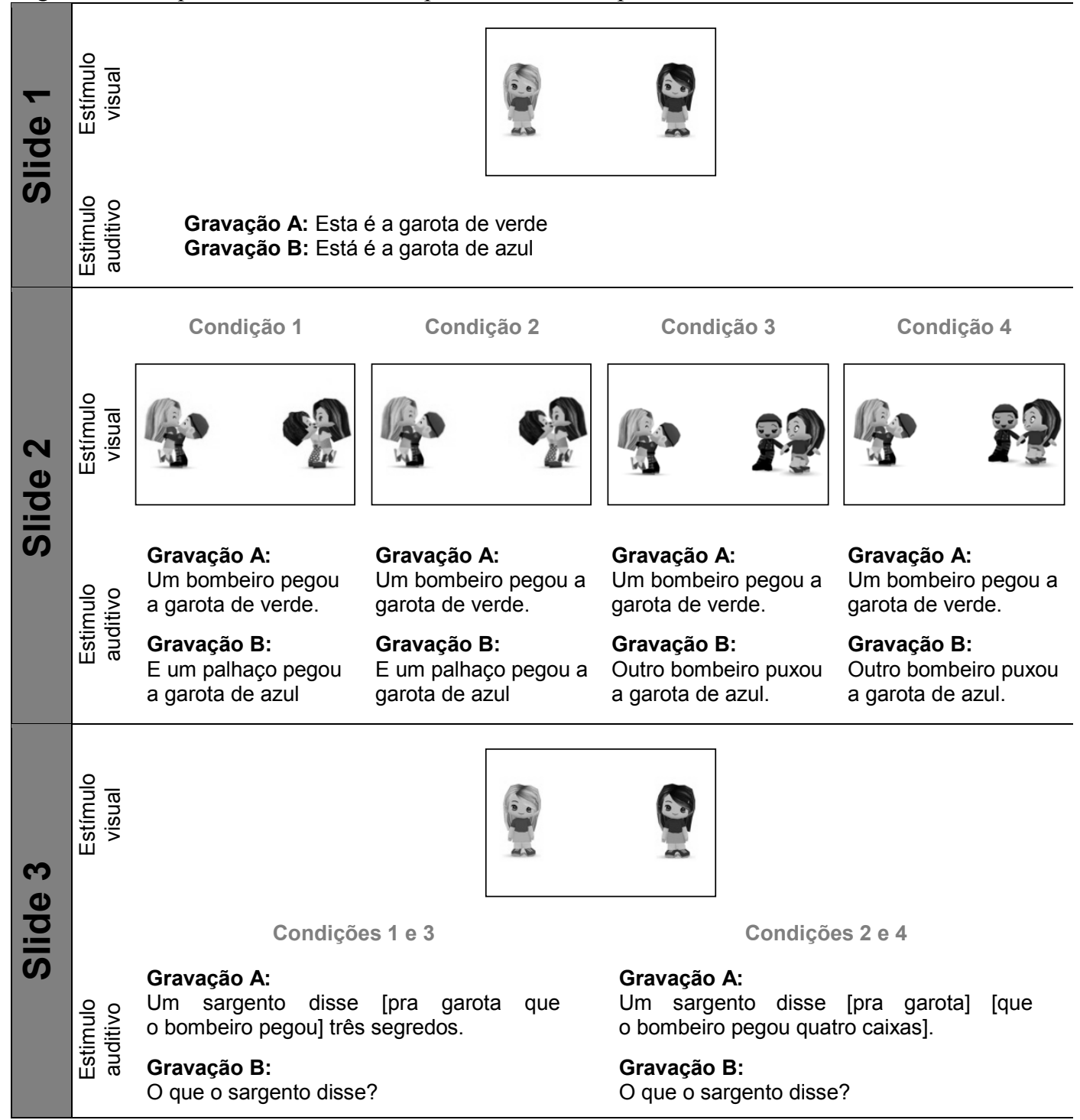

4.4.1.

Método

\section{Participantes}

Participaram deste experimento 47 voluntários gratificados, alunos da Universidade Estadual da Zona Oeste (UEZO). Em agradecimento pela realização do experimento, os participantes receberam uma gratificação de $R \$ 15,00$. O grupo era composto por 28 homens e 19 mulheres, com média de idade de 23 anos. Do total de participantes, 11 foram descartados da amostra, por erros do 
experimentador, por problemas técnicos em geral ou por falhas no rastreamento. Em particular, participantes cujo índice de validade dos dados calculado pelo equipamento tenha sido igual a 4 em rodadas (trials) experimentais foram excluídos da amostra ${ }^{53}$. Cada grupo experimental contou com um total de 18 participantes.

\section{Material}

Foram construídas, para este experimento, 16 sentenças experimentais, sendo 8 relativas (14 a 21$)$ e 8 completivas (22 a 29). Relativas e completivas distinguiam-se apenas pelo DP final que desambiguizava a sentença. Até à altura deste DP, a extensão dos estímulos foi controlada de acordo com o número de sílabas. Em especial, os segmentos considerados para análise, o sujeito e o verbo da encaixada, continham, em todos os estímulos, respectivamente, três e duas sílabas. A escolha dos verbos para a construção dos estímulos seguiu os critérios considerados nos dois primeiros experimentos. As sentenças experimentais foram distribuídas em duas listas distintas, de forma que sentenças relativas e completivas semelhantes (eg., 14 e 22) não fossem apresentadas a um mesmo participante. Na gravação dos estímulos auditivos, uma linguista treinada foi instruída a ler cada uma das sentenças em prosódia natural ${ }^{54}$.

Além das sentenças experimentais, foram construídos 24 distratores (p. ex, 30 e 31), que poderiam ter a estrutura de uma passiva ou de uma declarativa, nenhuma das quais contendo orações completivas ou relativas. Distratores foram apresentados em uma sequência narrativa semelhante à que antecedia os estímulos experimentais.

No que diz respeito aos estímulos visuais, ao todo, foram criados 105 slides para este experimento, sendo 7 deles utilizados na etapa de pré-teste (dentre eles, 1 em uma tarefa de nomeação), 32 nas rodas experimentais e os demais nos distratores. Cada rodada (trial) do experimento compreendia a apresentação de três slides, sendo o primeiro e o terceiro semelhantes aos utilizados no

\footnotetext{
${ }^{53} \mathrm{O}$ software responsável pela coleta de dados durante o experimento classifica cada frame de dado de acordo com um índice de validade que vai de 0 a 4 , sendo 0 a captação de ambos os olhos e 4 a captação de nenhum dos dois.

${ }^{54}$ Pela inspeção visual dos estímulos no oscilograma, verificou-se nas completivas, quando comparadas às relativas, o alongamento da sílaba tônica do nome que compõe o PP que complementa o verbo, um possível indicador de fronteira prosódica (Lourenço-Gomes, 2003; Finger e Zimmer, 2005).
} 
experimento 2. O segundo slide da sequência, embora também semelhante aos utilizados no experimento 1, apresentava como elementos distintivos apenas o agente (nas condições 1 e 2) ou a ação (nas condições 3 e 4) (ver Figura 16). Como nos experimentos anteriores, foram contrabalançadas as cores de vestuário e de cabelo das personagens, assim como foi contrabalançado o posicionamento (direta ou esquerda) do personagem alvo.

Em função dos requerimentos do software de apresentação dos estímulos, à exceção daqueles destinados ao pré-teste, cada um dos slides acrescidos dos áudios que lhes correspondiam foram convertidos, por meio do software Snag-it, em arquivos de vídeo no formato avi, gerando um total de 98 arquivos de vídeo, dentre os quais 16 continham sentenças experimentais. Os slides utilizados no préteste foram apresentados por meio do software Power Point.

A ordem de apresentação dos estímulos foi semialeatória. Relativas e completivas foram intercaladas. Entre cada estímulo experimental, havia um bloco com três distratores, distribuídos de forma a não envolver ações ou personagens agentes relacionados ao estímulo experimental seguinte.

(14) Um marujo falou [pra garota que o pirata puxou][duas mentiras].

(15) Um sargento disse [pra garota que o bombeiro pegou][três segredos].

(16) Um técnico falou [pro garoto que o goleiro beijou][duas fofocas].

(17) Um servente disse [pro garoto que o pedreiro pulou][três segredos].

(18) Um aluno disse [pra garota que o professor pulou][três segredos].

(19) Um feirante falou [pra garota que o padeiro beijou][duas fofocas].

(20) Um músico disse [pro garoto que o palhaço pegou][três segredos].

(21) Um médico falou [pro garoto que o cacique puxou][duas mentiras].

(22) Um marujo falou [pra garota][que o pirata puxou quatro barris].

(23) Um sargento disse [pra garota][que o bombeiro pegou quatro caixas].

(24) Um técnico falou [pro garoto][que o goleiro beijou duas meninas].

(25) Um servente disse [pro garoto][que o pedreiro pulou três barreiras].

(26) Um aluno disse [pra garota][que o professor pulou três barreiras].

(27) Um feirante falou [pra garota][que o padeiro beijou duas meninas].

(28) Um músico disse [pro garoto][que o palhaço pegou quatro caixas].

(29) Um médico falou [pro garoto][que o cacique puxou quatro barris]. 
(30) Um músico chamou a garota de azul para o concerto.

(31) Os garotos foram questionados pelo aluno sobre o exercício.

\section{Aparato}

No experimento 3, foi utilizado um computador portátil fabricado pela Apple com sistema operacional Windows rodando em uma partição do HD. Este computador hospedava o software Tobii Studio, responsável pela calibração, apresentação dos estímulos, coleta e análise parcial dos dados. O eye-tracker utilizado foi um Tobii TX120 com monitor embutido de 17", no qual eram apresentados os estímulos visuais. $\mathrm{O}$ equipamento tem $1^{\circ}$ de acurácia, registrando dados a, em média, $120 \mathrm{~Hz}$, permitindo até $30 \times 22 \times 30 \mathrm{~cm}$ de movimentação da cabeça. Foram utilizados também um headphone (para a apresentação dos estímulos auditivos), um microfone (para a captação de medidas da tarefa offline). Para a gravação e para a análise dos estímulos auditivos (com vistas ao estabelecimento dos segmentos considerados) foi utilizado o software Soundforge. A análise dos dados foi realizada em planilhas geradas pelo Tobii Studio para análise no Excel.

\section{Procedimento}

Os voluntários foram informados de que participariam de uma tarefa de compreensão na qual deveriam ouvir sentenças e responder a algumas perguntas. Eram notificados de que se tratava de um experimento de rastreamento ocular e que, para tanto, deveriam realizar uma tarefa de calibração. A calibração do equipamento era realizada, por meio do software TobiiStudio, no início e repetida no meio de cada sessão. Durante este procedimento, o participante deveria fixar seu olhar em 9 pontos diferentes da tela. Ao final, o software classificava o desempenho do participante, sugerindo a repetição do procedimento, em casos de uma calibração pobre. As instruções aos participantes, a tarefa de nomeação e a etapa de pré-testagem foram realizadas conforme os procedimentos descritos no experimento 1 .

Cada rodada (trial) experimental consistia da apresentação de três slides, sendo o procedimento de apresentação dois primeiros idêntico ao conduzido no experimento 2. No terceiro slide, era apresentada a sentença experimental, 
precedida pela apresentação de um ponto vermelho no centro da tela, acompanhado de um click sonoro. Após cerca de 3 segundos, era apresentada uma interrogativa QU-, a qual os participantes deveriam responder em 8 segundos, antes da apresentação da sequência de estímulos seguinte. A duração total de uma sessão experimental, incluindo os procedimentos de calibração e pré-teste, durava, em média, 40 minutos.

\section{Análise das medidas}

Em primeiro lugar, cada um dos arquivos de vídeo que continham estímulos experimentais foi analisado, com auxílio de um oscilograma gerado pelo software Soundforge, com vistas a estabelecer os marcos de tempo que delimitavam o início e o fim de cada segmento considerado para análise, ie., os segmentos relativos ao sujeito e ao verbo da oração encaixada.

A movimentação ocular dos participantes foi registrada, durante as sessões, pelo software Tobii Studio. Neste programa, definiam-se as áreas de interesse correspondentes a cada um dos estímulos experimentais, delimitadas pela borda externa de cada um dos personagens apresentados no slide 3. Considerando tais áreas de interesse, o programa gerava planilhas de dados relativos à movimentação ocular de cada participante, nas quais eram listadas as ocorrências de fixações nas áreas de interesse a cada amostra/frame captado pelo eye-tracker. Nestas planilhas, selecionavam-se, manualmente, os dados relativos aos conjuntos de frames correspondentes a cada um dos segmentos de análise (S1 e S2) para cada um dos vídeos que continham estímulos experimentais, com base nos marcos temporais detectados na análise do oscilograma. A partir dessa seleção, eram contabilizadas, também manualmente, as rodadas (trials) nas quais foram registradas fixações no referente da relativa. O processo de seleção de frames de dados e de contabilização das medidas foi checado por um segundo avaliador.

\subsection{2. \\ Resultados}

Os dados aferidos, obtidos em cada um dos dois segmentos de interesse neste experimento, S1 e S2, foram submetidos a duas ANOVAs (2x2), uma para cada segmento considerado. Em relação à análise do S1, não houve efeitos principais estatisticamente significativos (para a variável Elemento 
desambiguizador: $\mathrm{F}(1,34)=2,97, \mathrm{p}<.10$; para a variável Informação prosódica compatível com a estrutura: $F(1,34)=2,40, p<.13)$ nem foi significativo o efeito da interação entre as variáveis $(\mathrm{F}(1,34)=2,97, \mathrm{p}=.89)$. Também não foram encontradas diferenças estatisticamente significativas entre as condições, comparação realizada utilizando-se um teste-t. O gráfico 13 apresenta as médias de rodadas (trials) com fixação no referente da relativa por condição no S1. Assim, nesse segmento, não houve indicativo de que informação de natureza contextual pudesse induzir a uma análise relativa, gerando o mapeamento antecipado do referente da relativa nas condições 1 e 2 ou de que informação prosódica fosse considerada na análise inicial da ambiguidade, o que levaria a um número maior de fixações na condição 1 .

Gráfico 13 - Médias de rodadas (trials) com fixação no referente da relativa por elemento potencialmente desambiguizador no Segmento 1 (escore máximo: 4)

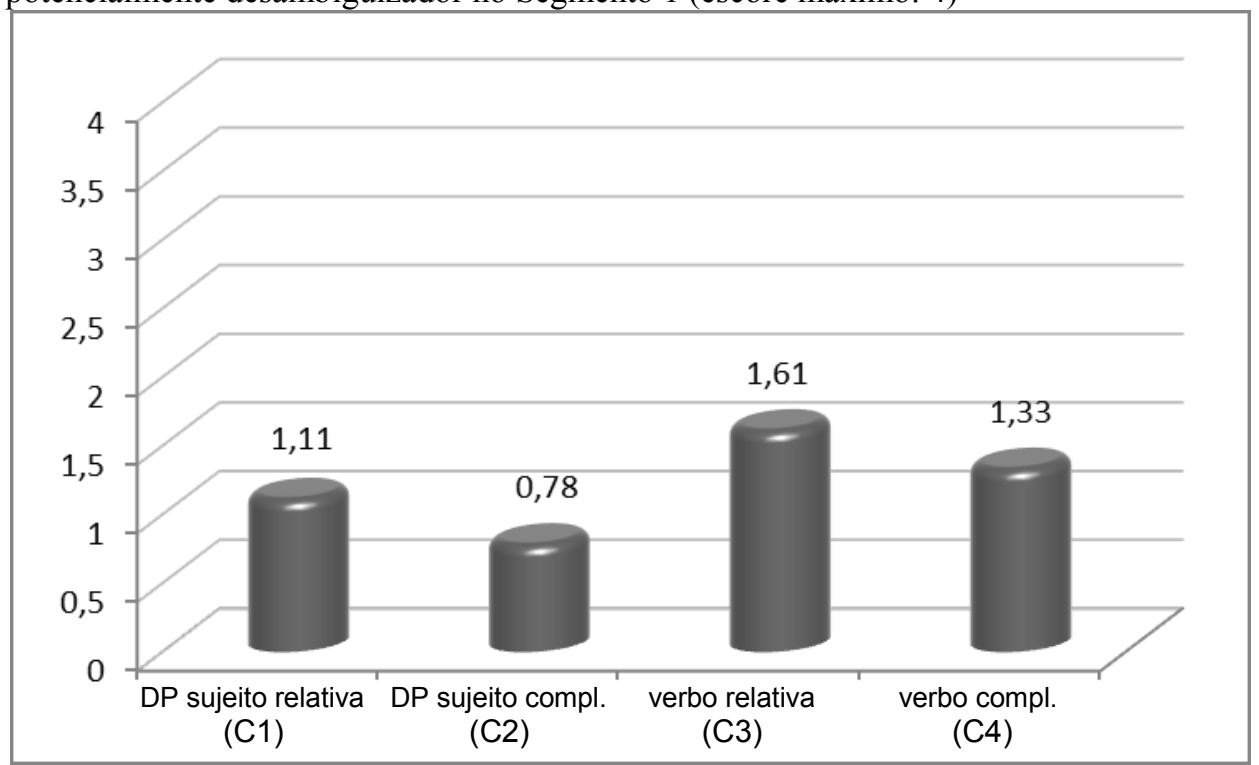

No gráfico 14, são apresentadas as médias de rodadas (trials) com fixação no referente da relativa por condição no S2. Embora tenha havido uma discreta vantagem no número de rodadas (trials) com fixação no referente da relativa na condição 3, a diferença entre essa condição e as condições com completivas não foi significativa. Neste segmento, também não foi verificada interação $\mathrm{F}(1,34)=3,46, \mathrm{p}=.56$ ) ou efeito principal entre as variáveis consideradas (para a variável Elemento desambiguizador: $\mathrm{F}(1,34)=2,39, \mathrm{p}<.13$; para a variável Informação prosódica compatível com a estrutura: $\mathrm{F}(1,34)=0,014, \mathrm{p}<.91)$, o que poderia indicar que, mesmo nas condições com estruturas relativas, os 
participantes permaneciam em um procedimento de busca por um possível referente.

Gráfico 14 - Médias de rodadas com fixação no referente da relativa por elemento potencialmente desambiguizador no Segmento 2 (escore máximo: 4)

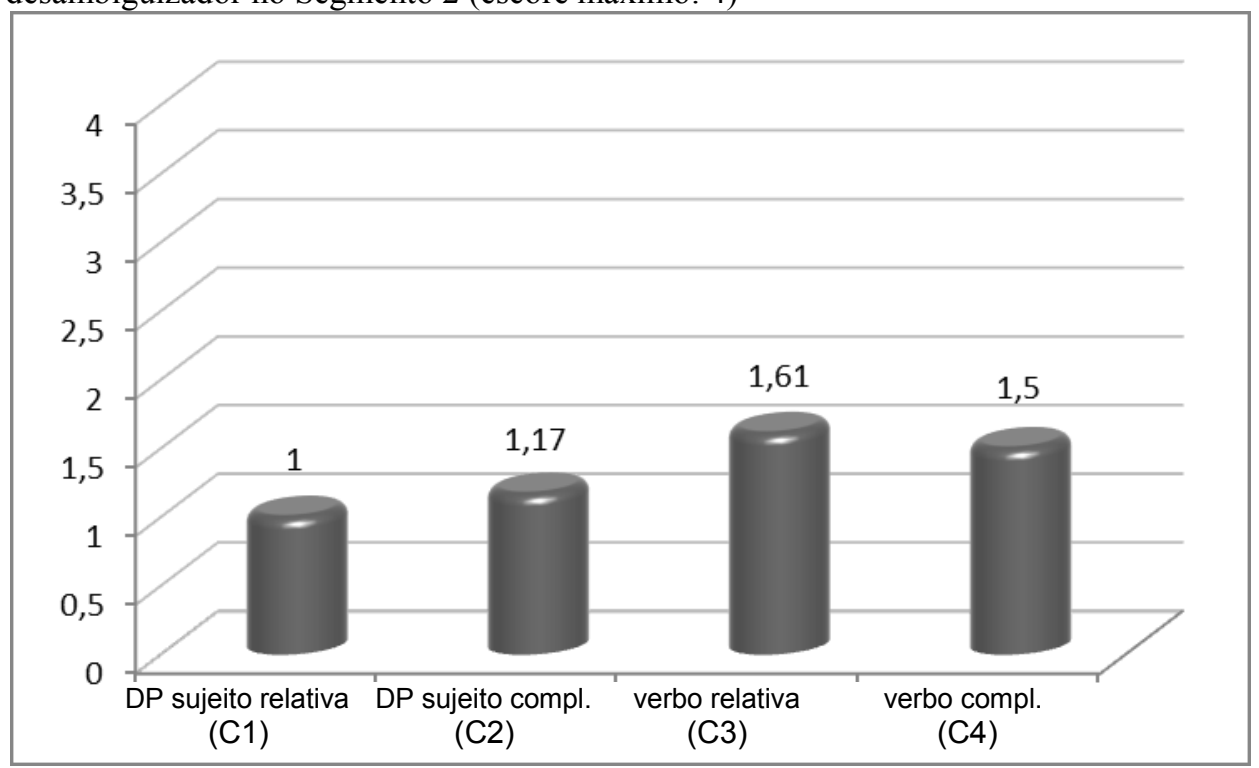

Como se observa, os resultados de um modo geral demonstram um baixo número de rodadas (trials) com fixação no referente da relativa, em todas as condições e em ambos os segmentos. Além disso, não foram encontradas diferenças significativas entre as condições com estruturas relativas e as condições com estruturas completivas, conforme seria esperado ao se assumir a hipótese de que a prosódia poderia ser considerada incrementalmente no curso da análise sintática inicial, de forma a permitir o mapeamento antecipado do referente da relativa.

Diante disso, foi considerada a possibilidade de a ausência de resultados esperados se dever a um efeito de spillover acarretado pelo tempo necessário à programação da sacada (Matin, Shao e Boff, 1983; Cf. Findlayand Walker, 2011). Dessa forma, foram realizadas duas novas ANOVAs $(2 \times 2)$, tomando-se uma distinta segmentação dos estímulos, na qual os segmentos 1 e 2 foram deslocados $200 \mathrm{~ms}$ adiante.

No gráfico 15, são apresentadas as medias de rodadas (trials) com fixação no referente da relativa em cada condição, no S1, considerando a compensação do tempo relativo à programação da sacada. Embora, novamente, tenha havido uma pequena vantagem das relativas em relação às completivas, não foram 
encontrados efeitos ou diferenças significativos (para a variável Elemento desambiguizador: $\mathrm{F}(1,34)=2,62, \mathrm{p}<.11$; para a variável Informação prosódica compatível com a estrutura: $\mathrm{F}(1,34)=0,75, \mathrm{p}<.39$; Interação: $\mathrm{F}(1,34)=0,015$, $\mathrm{p}<.90$ ).

Gráfico 15 - Médias de rodadas com fixação no referente da relativa por elemento potencialmente desambiguizador no Segmento 1 deslocado (escore máximo: 4)

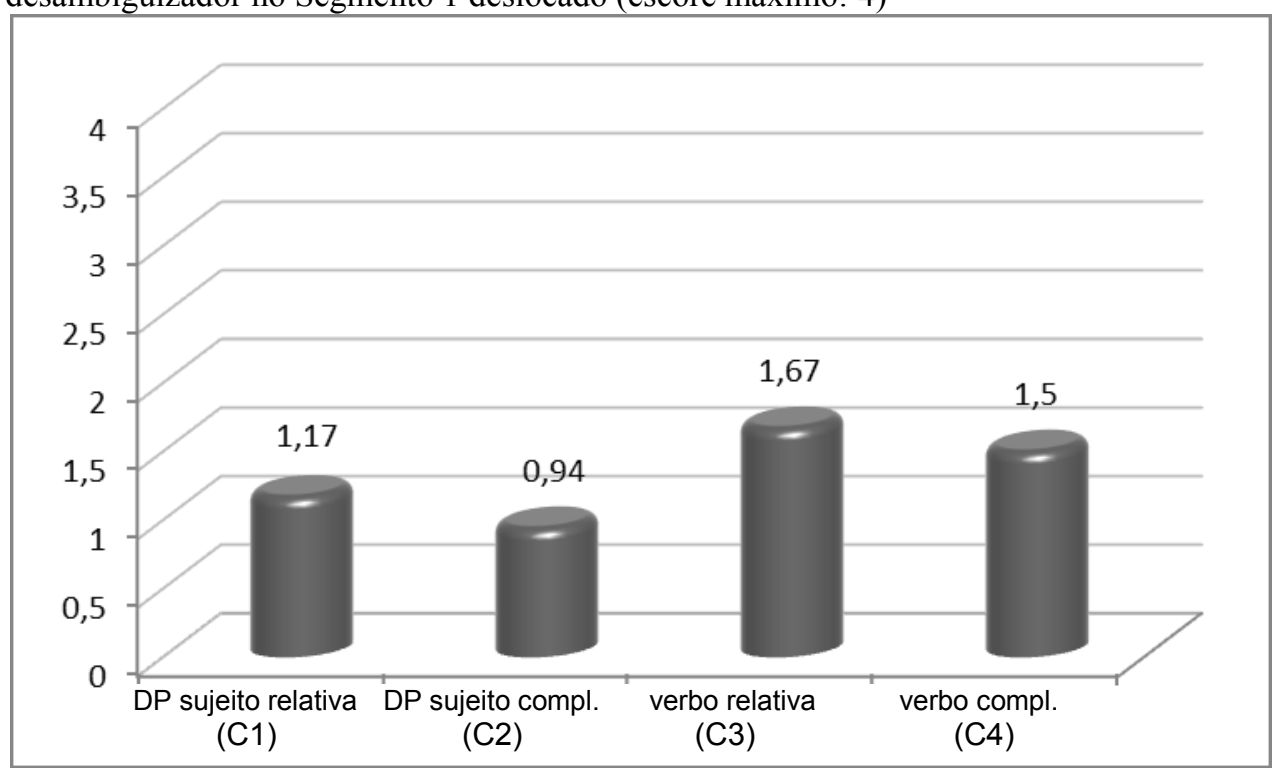

No que diz respeito ao S2 (Gráfico 16), nessa nova análise, também não foram obtidos efeitos nas comparações entre as variáveis (para a variável Elemento desambiguizador: $\mathrm{F}(1,34)=0,96, \mathrm{p}<.34$; para a variável Informação prosódica compatível com a estrutura: $\mathrm{F}(1,34)=2,19, \mathrm{p}<.15$; para a interação: $\mathrm{F}(1,34)=0,97, \mathrm{p}<.33)$. As comparações pareadas, contudo, revelaram uma tendência de mais rodadas (trials) com fixações na condição 3 quando comparada à condição $4(\mathrm{t}(17)=1,82 ; \mathrm{p}<.09)$. Este resultado poderia indicar que a informação verbal distintiva nesse segmento poderia ter permitido o mapeamento da sentença relativa em um referente, embora esse resultado não possa ser considerado conclusivo, uma vez que o deslocamento do segmento 2 para $200 \mathrm{~ms}$ adiante permite que parte do material relativo ao DP final, que desambiguiza a sentença seja englobado nesse segmento. 
Gráfico 16 - Médias de rodadas com fixação no referente da relativa por elemento potencialmente desambiguizador no Segmento 2 deslocado (escore máximo: 4)

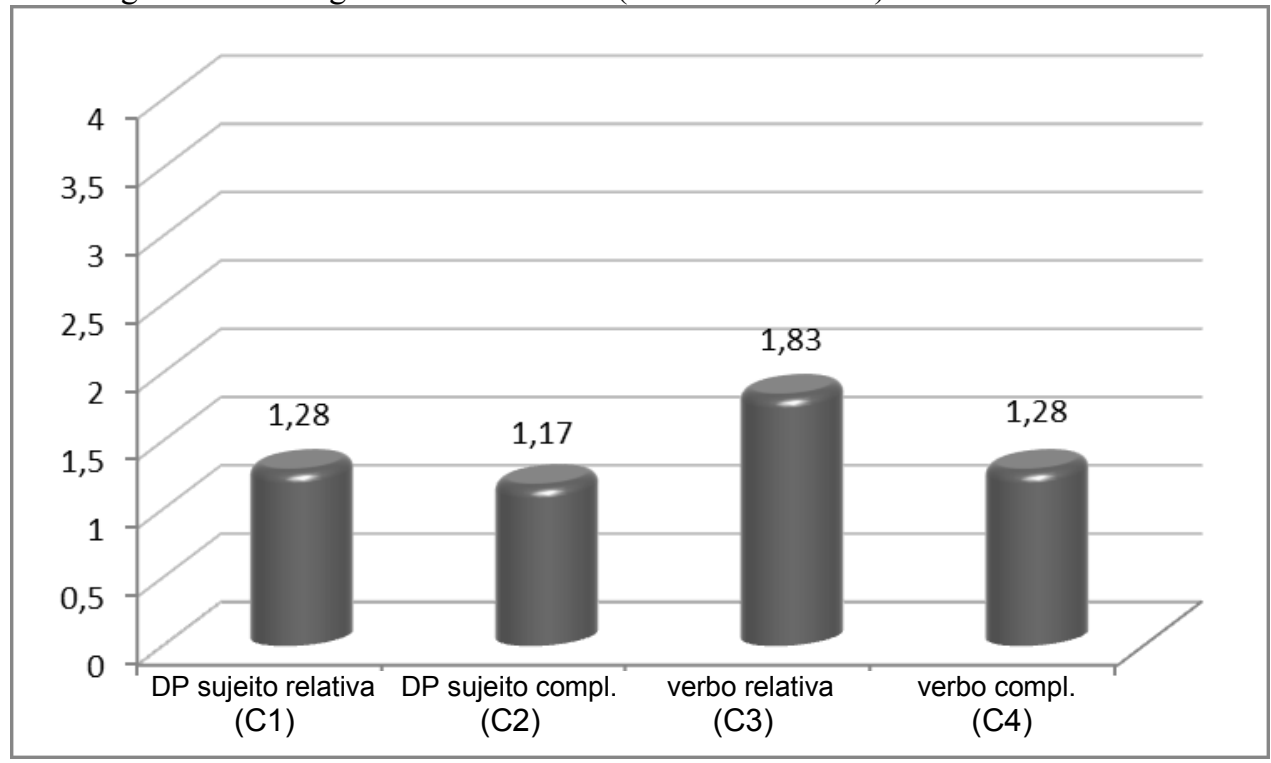

Apesar de uma ligeira diferença entre o número de rodadas (trials) com fixações no alvo em condições com estruturas relativas e em condições com estruturas completivas ter sido observada nesta última análise, em termos gerais, os resultados indicam um comportamento oculomotor aparentemente indiferenciado dos participantes diante dos estímulos visuais. Tal comportamento pode, entretanto, ser resultante da atuação de do princípio de aposição mínima, que seria relacionado à hipótese nula. A análise de aposição mínima parece ser corroborada pelo desempenho dos participantes na tarefa de compreensão offline. Essa análise foi adotada em 39,58\% das respostas offline a estímulos que continham orações relativas. Assim, por exemplo, diante de um estímulo experimental como em (32), alguns participantes forneciam respostas como "que o goleiro beijou duas fofocas". Como se observa, os participantes optaram por ignorar a coerência semântica da sentença, preservando uma possível análise inicial, na qual a ambiguidade temporária das relativas conduziria a uma leitura completiva.

Um técnico falou [pro garoto que o goleio beijou] [duas fofocas].

O que o técnico falou? 
Considerou-se, desse modo, que o princípio da aposição mínima, na medida em que implicava na análise de relativas como completivas, poderia ter limitado a possibilidade de mapeamento dos referentes no caso dessas sentenças. Desse modo, foi realizada uma terceira rodada de análises estatísticas, das quais foram excluídos os participantes que não responderam corretamente à pergunta de compreensão offline, em pelo menos duas das oito sentenças experimentais. Essa análise foi realizada considerando-se apenas os dados do Grupo 1, uma vez que o número de participantes do Grupo 2 que responderam corretamente à pergunta de compreensão foi insuficiente para se realizar uma análise estatisticamente confiável $^{55}$. A nova análise teve, assim, o intuito de avaliar se informação prosódica distintiva, possivelmente sinalizando ao parser a existência de fronteiras sintáticas, poderia permitir o mapeamento antecipado do referente nas relativas, o que poderia conduzir a uma diferença significativa entre as condições 1 e 2 , em favor da condição com estruturas relativas.

Para essa terceira análise, foram realizados testes-t, nos quais se compararam os números de rodadas (trials) com fixação no alvo nas condições com estrutura relativa e completiva, nos segmentos 1 e 2 . Os dois tipos de análise realizadas anteriormente, considerando-se os segmentos não deslocados (não avançados em $200 \mathrm{~ms}$ ) e os segmentos deslocados, foram feitas também neste caso.

No que concerne à análise dos segmentos não deslocados, não foram obtidas diferenças significativas entre as condições (no $\mathrm{S} 1: \mathrm{t}(10)=0,80, \mathrm{p}<.44$; no $\mathrm{S} 2$ : $\mathrm{t}(10)=0,89, \mathrm{p}<.39)$, embora tenha havido uma vantagem numérica das relativas em relação às completivas. Os gráficos 17 e 18 apresentam as médias de rodadas (trials) com fixação no referente da relativa no S1 e no S2, respectivamente.

\footnotetext{
55 No Grupo 1, o número de participantes que responderam corretamente à pergunta de compreensão foi de 11, enquanto no Grupo 2 foi de apenas 7.
} 
Gráfico 17 - Médias de rodadas com fixação no referente da relativa por elemento potencialmente desambiguizador no Segmento 1 não deslocado (escore máximo: 4) dos participantes do Grupo 1 com respostas off-line corretas

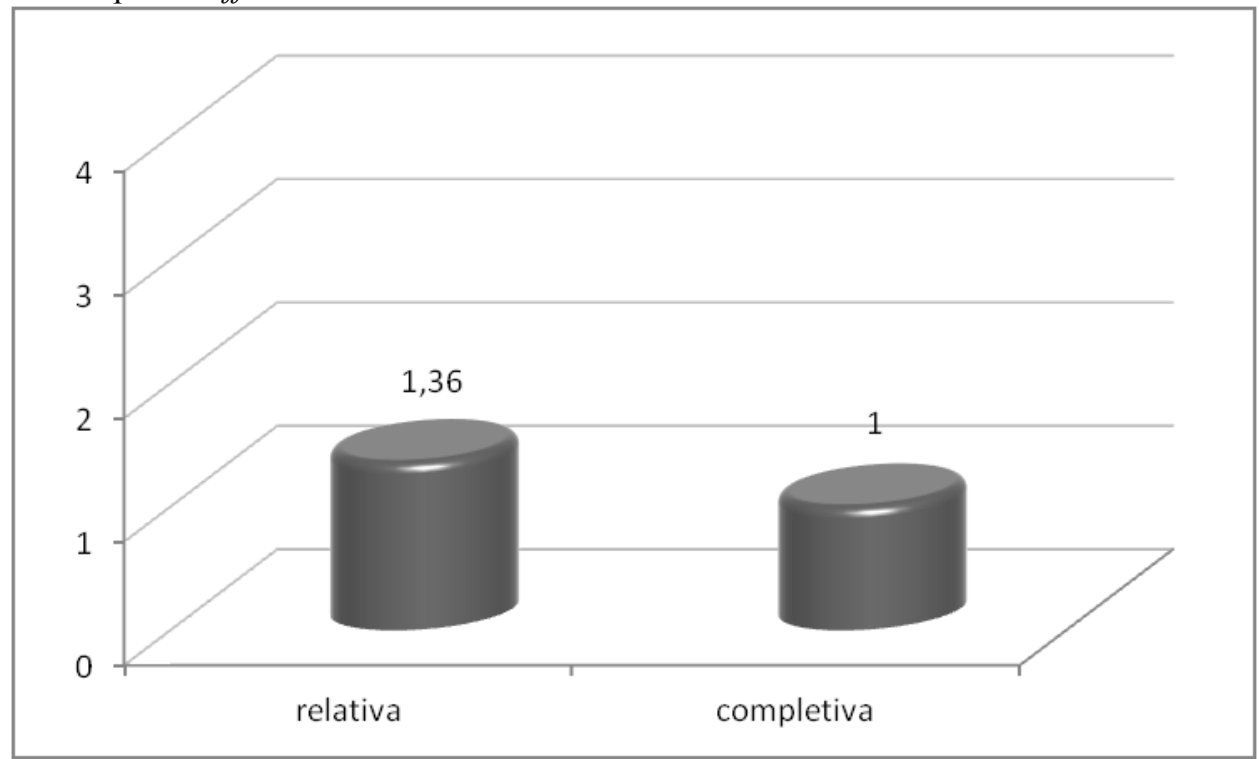

Gráfico 18 - Médias de rodadas com fixação no referente da relativa por tipo de estrutura no Segmento 2 não deslocado (escore máximo: 4) dos participantes do Grupo 1 com respostas off-line corretas

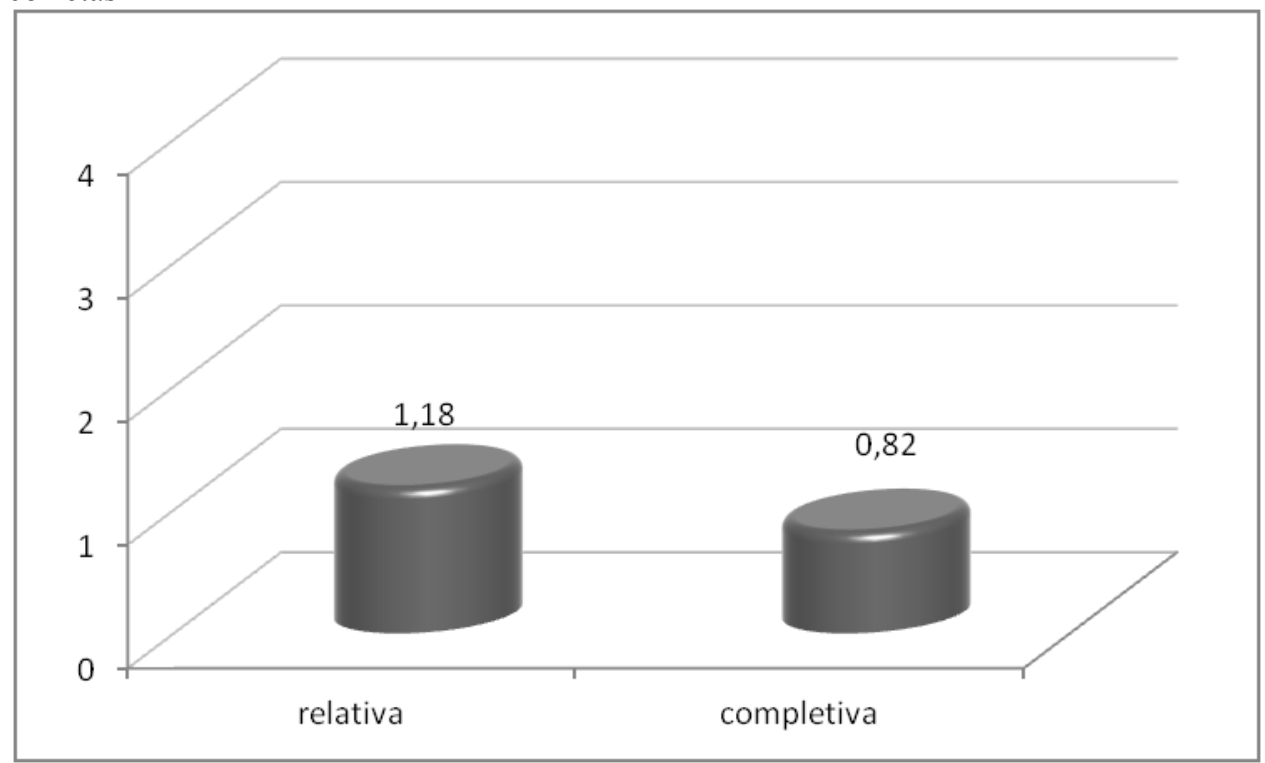

Similarmente, a análise dos dados relativos aos segmentos deslocados não revelou diferenças significativas entre as condições (no $\mathrm{S} 1$ : $\mathrm{t}(10)=1,49, \mathrm{p}<.17$; no S2: $\mathrm{t}(10)=0,21, \mathrm{p}<.84)$, embora, novamente, tenha sido detectado um maior número de rodadas (trials) com fixações no alvo da relativa na condição 1. Nos gráficos 19 e 20 são apresentadas as médias de rodadas (trials) com fixação obtidas pelos participantes. 
Gráfico 19 - Médias de rodadas com fixação no referente da relativa por tipo de estrutura no Segmento 1 deslocado (escore máximo: 4) dos participantes do Grupo 1 com respostas off-line corretas

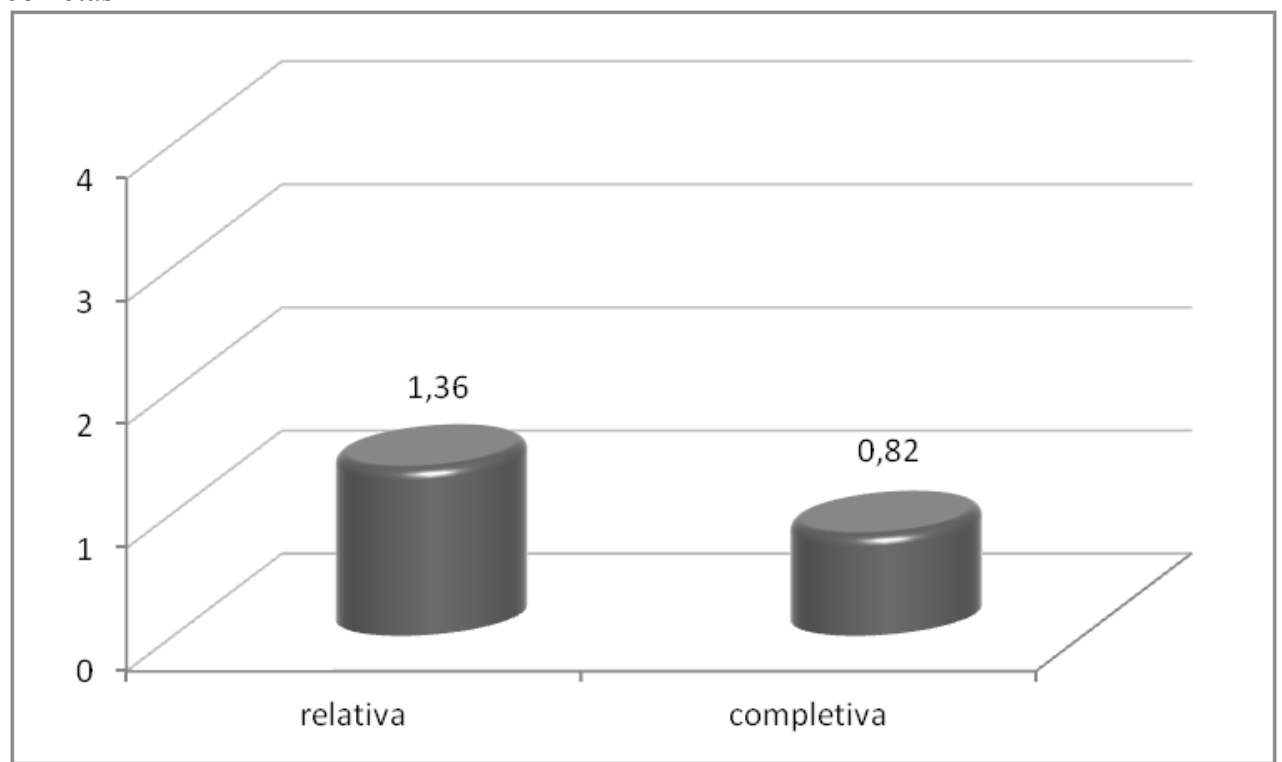

Gráfico 20 - Médias de rodadas com fixação no referente da relativa por tipo de estrutura no Segmento 2 deslocado (escore máximo: 4) dos participantes do Grupo 1 com respostas off-line corretas

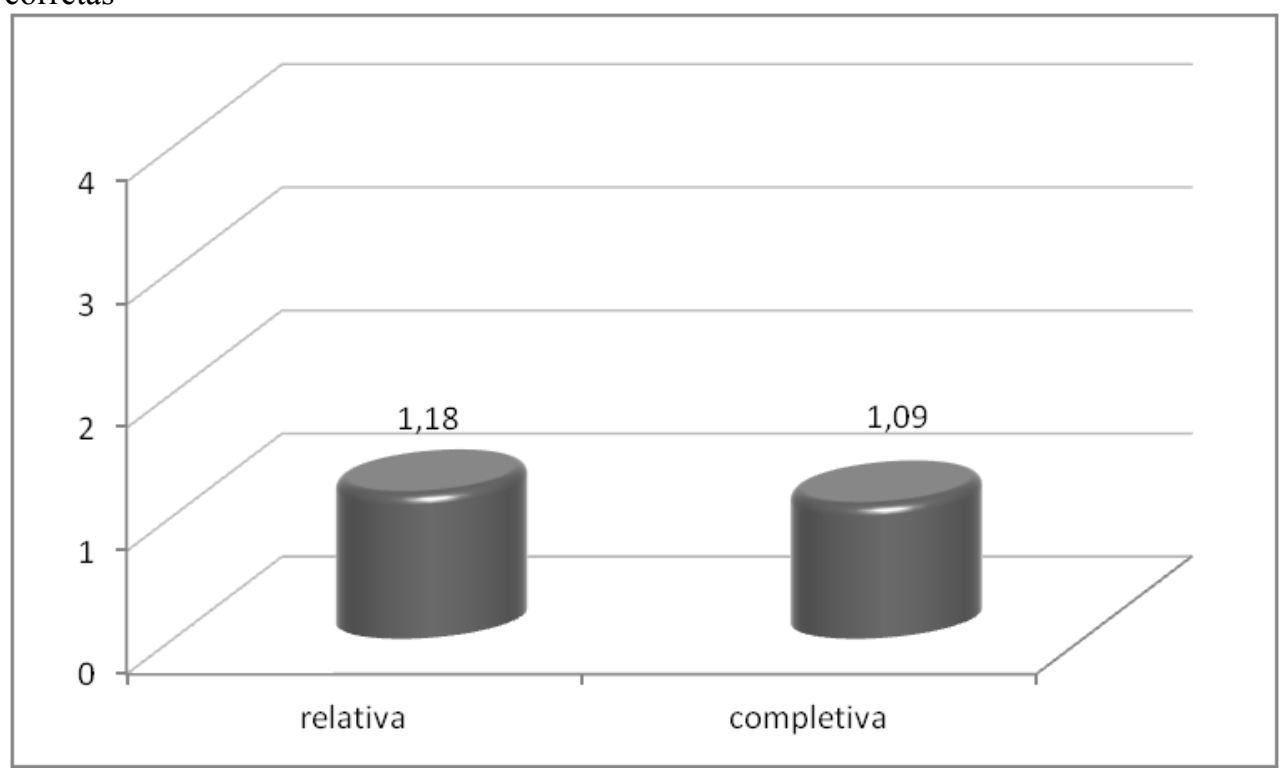

\subsection{3.}

\section{Discussão}

Diferentemente dos experimentos anteriores, nos quais se verificou que informação contextual visual e discursiva permitia a desambiguização da referência durante o processamento online de relativa, no presente experimento, este comportamento não se repetiu. Em particular, nas condições 1 e 4, (que traziam relativas que poderiam ser, diante da informação contextual apresentada, 
desambiguizadas, respectivamente no sujeito e no verbo da relativa) não se verificou um número de rodadas (trials) com fixação no alvo da relativa significativamente maior em comparação com outras condições, embora, numericamente, tenham registrado mais fixações.

Uma das razões para o comportamento observado neste experimento ter sido distinto daquele observado nos experimentos anteriores pode residir no conjunto de expectativas geradas nos contextos experimentais anteriores, em comparação com o contexto do presente experimento. Nos experimentos 1 e 2, foram apresentadas apenas sentenças contendo orações relativas, o que pode ter levado os participantes a criarem uma expectativa maior pela modificação dos DPs complexos contidos nas sentenças experimentais. Essa expectativa poderia derivar um maior grau de atenção dos participantes a possíveis propriedades distintivas dos elementos envolvidos nas sequências narrativas apresentadas nos experimentos em questão, de forma que o mapeamento antecipado do referente do DP complexo contendo a relativa de objeto, com base nessas propriedades, poderia ter sido facilitado. A expectativa por modificação do DP no processamento das sentenças experimentais também pode ter sido incrementada pelo fato de que a pergunta a qual os participantes deveriam responder como tarefa experimental (eg. “Quem o bombeiro pegou?”) ressaltava a necessidade de individuação de uma entidade. Por fim, o menor número de rodadas (trials) do experimento anterior pode também ter vindo a contribuir para que os participantes se mantivessem, ao longo da sessão experimental, mais atentos. No presente experimento, a variedade de estruturas apresentadas (que incluía, além das estruturas empregadas nas sentenças experimentais, aquelas utilizadas nos distratores), o maior número de rodadas (trials) e a natureza da interrogativa empregada na tarefa experimental (que não requeria a individuação de uma entidade) podem ter contribuído para a diminuição da expectativa de modificação. Além disso, têm-se, naturalmente, a ambiguidade estrutural dos estímulos experimentais empregados neste experimento, derivada das possibilidades de subcategorização do verbo principal e da ambiguidade lexical de que, contrapondo-se aos estímulos sem ambiguidades estruturais apresentados nos primeiros experimentos.

O baixo número de rodadas (trials) com fixações no referente alvo da relativa em todas as condições pareceu evidenciar, neste experimento, um 
procedimento de busca por um referente, que poderia ser caracterizado pela alternância constante entre os alvos de fixação, como fazem sugerir os resultados apresentados. Este comportamento, que resulta na não rejeição da hipótese nula, associado aos resultados obtidos na pergunta de compreensão offline, podem sugerir a possibilidade de que a análise inicial da ambiguidade temporária que constituía as sentenças apresentadas pode ter se dado com base em uma estratégia de aposição mínima, segundo previsto por abordagens de processamento em dois estágios (Cf. capítulo 3). A possível preservação dessa análise inicial e seu reflexo nas respostas offline, a despeito de sua incoerência semântica, é condizente com resultados apresentados por Ferreira e seu grupo de colaboradores (Christianson et al.2001; Ferreira et al.2001; Ferreira, 2003; Patson et al. 2006; Cf. capítulo 3), nos quais se verificou a preservação de análises como a de fechamento tardio em medidas offline.

Em relação às previsões consideradas, a partir dos resultados do experimento 3, não foi possível detectar evidências diretas de que o contexto pudesse influenciar a análise inicial da ambiguidade temporária entre completivas e relativas, uma vez que a previsão de um efeito principal da variável elemento potencialmente desambiguizador não foi verificada. Da mesma forma, não foram verificadas evidências condizentes com a hipótese de que informação prosódica poderia direcionar a análise inicial, uma vez que não foram obtidos resultados conclusivos, embora tenha havido, no Segmento 2 (na análise com compensação para o tempo de programação da sacada), nas condições cujo o verbo poderia desambiguizar a referência, uma tendência de um maior número de rodadas (trials) com fixação no alvo da relativa, na condição de estrutura relativa, quando comparada à condição de estrutura completiva, o que poderia sinalizar que informação verbal distintiva poderia conduzir ao mapeamento do referente, com base em informação contextual e prosódica. De maneira geral, contudo, informação de natureza prosódica pareceu não permitir o direcionamento da análise inicial, o que condiz com resultados obtidos por Maia et al. (2007), de acordo com os quais esse nível de informação pareceu ser usado, no português, em uma etapa pós-sintática ${ }^{56}$.

\footnotetext{
${ }^{56}$ No estudo em questão, com o objetivo de testar previsões da Hipótese da Prosódia Implícita, os autores manipularam o comprimento de orações relativas. Embora esta manipulação não tenha
} 
Em resumo, a comparação deste experimento com os experimentos 1 e 2 parece sugerir que, embora a antecipação de referentes de DPs complexos contendo relativas de objeto seja possível em situações nas quais há uma grande expectativa de individuação de um referente por meio da detecção de um traço distintivo, esta mesma possibilidade pode ser restringida em situações mais heteróclitas, que envolvem, por exemplo, a necessidade de resolução de uma ambiguidade. Nesses casos, conforme indica o comportamento offline dos participantes, há a possibilidade de atuação de um mecanismo de base estrutural para a resolução da ambiguidade. No próximo capítulo tentaremos conciliar essas duas direções observadas nos diferentes experimentos realizados nessa pesquisa. 


\section{5 \\ Uma proposta para a compreensão de relativas}

Estabelecer previsões a partir de estímulos sensoriais parece ser uma propriedade comum a vários domínios da cognição humana. Esta capacidade poderia permitir a redução do tempo de percepção, a economia de recursos cognitivos, além de oferecer a possibilidade de reações rápidas e a habilidade de lidar com estímulos ruidosos ou ambíguos (Bubic, Cramom e Schubotz, 2010; Kveraga, Ghuman e Bar, 2007). A percepção visual, por exemplo, parece ser facilitada por pistas contextuais. Cenas de um ambiente familiar, como uma cozinha, por exemplo, tendem a proporcionar um reconhecimento mais rápido de objetos coerentes com este tipo de ambiente - como pães - do que de objetos incoerentes - como instrumentos musicais (Palmer, 1975 apud Bar, 2004).

Na compreensão da linguagem, já os modelos pioneiros de processamento, diante da ambiguidade e da linearidade do estímulo linguístico, anteviram a necessidade de que a estruturação do estímulo pudesse ser atribuída preditivamente, mesmo sem que toda a informação lexical crucial estivesse disponível para o processador. O princípio do fechamento de Kimball (1973), por exemplo, de acordo com o qual um constituinte seria fechado assim que possível (a não ser que o próximo constituinte seja um constituinte imediato do nó sendo construído), resulta em um procedimento no qual o processador associa uma estrutura a uma sequência, embora uma possível ambiguidade não possa ser, ainda, definitivamente resolvida. Outros princípios de natureza determinística, como o fechamento tardio e a aposição mínima (Frazier, 1987) também atuariam no sentido de estabelecer preditivamente, a partir de conhecimento estrutural, relações sintáticas em condições de incerteza, ou seja, na ausência de informação bottom-up necessária.

A despeito disso, evidências de processos antecipatórios na compreensão têm sido apontadas como contra-argumentos a modelos de natureza determinística ou, mais amplamente, a modelos de natureza modular. Resultados sugerindo a emergência de expectativas linguísticas relacionadas a informação contextual 
discursiva e visual (Cf. seção 3.2.2), de acordo com esta perspectiva, seriam indicativos de um processamento não especializado, que estabeleceria previsões a partir de informação não-estrutural, diferentemente dos processadores modulares.

No presente estudo, os resultados obtidos nos experimentos 1 e 2 indicam a possibilidade de que um DP complexo contendo uma relativa de objeto possa ser mapeado em um referente no curso do processamento, caso haja informação distintiva suficiente, até mesmo antes que o ouvinte tenha acesso à informação do verbo, que permitirá associar o núcleo da relativa a um gap. Por outro lado, os resultados do terceiro experimento foram incompatíveis com a possibilidade de um mapeamento antecipado de referentes e, além disso, sugeriram a preservação de uma possível análise de aposição mínima remanescente da primeira passagem do parser. Neste capítulo, será apresentada a proposta de um mecanismo de processamento para a compreensão de relativas que busca acomodar estes resultados na perspectiva de um parser autônomo que, por meio do envio paulatino de informação aos sistemas de interface, pode possibilitar a ocorrência de processos interpretativos de natureza preditiva.

Considerando resultados como os dos experimentos 1 e 2 como indicativos de acesso a informação não estrutural durante o processamento sintático, buscando manter, contudo, a hipótese de um processamento sintático especializado, a primeira questão que se apresenta é : como um processador sintático especializado poderia dar conta da recuperação de informações não estruturais durante a construção de uma representação sintática? Se, além de explicar a recuperação de informação não estrutural, a hipótese de processamento modular for compatibilizada com a possibilidade de que processos interpretativos sejam acionados em momentos intermediários do processamento sintático, permitindo, por exemplo, o mapeamento de referentes, uma segunda pergunta que se impõe é: como poderia haver uma interpretação, mesmo que temporária, de fragmentos da sequência ainda em análise?

\section{1.}

\section{Acesso a informação não estrutural no curso do processamento sintático}

Para responder à primeira questão, devemos considerar, em primeiro lugar, que o acesso a informação discursiva, por exemplo, durante o processamento 
sintático, não parece ser um argumento necessariamente contrário à existência de um processador estrutural especializado, mas sim contra um processamento serial exaustivo (no qual a atividade de um processador de um nível $\mathrm{X}$ seria condicionada ao esgotamento da atividade de um processador anterior) associado a longas unidades de análise, como, por exemplo, orações inteiras. Um processador dessa natureza, naturalmente, impediria a possibilidade de acesso a qualquer informação que não àquela de natureza estrutural durante um longo intervalo. Como assinala Levelt (1989; Cf. capítulo 3), contudo, o processamento serial não deve ser, necessariamente, entendido nesses termos, pois não é incompatível com a ideia de processamento paralelo, que permitiria a atuação de diferentes tipos de processadores em um mesmo momento. Em vista disso, o acesso a informação não estrutural durante o processamento sintático poderia ser explicado por meio do envio de fragmentos da representação em construção à interface conceitual intencional durante estágios intermediários do parsing, permitindo que estas informações funcionem como um gatilho para a recuperação de informação não estrutural.

Uma noção do âmbito da teoria linguística que proporciona a operacionalização de um mecanismo com esta função é o conceito de fases (Chomsky, 2005). Sob a motivação conceitual de economizar recursos do sistema computacional com o envio periódico de material às interfaces, CPs e vPs foram inicialmente concebidos como fases, dentre outros razões, pela motivação também conceitual de comportarem, respectivamente, complexos sentenciais e temáticos completos. Em desenvolvimentos mais recentes, também os DPs passaram a ser considerados como fases (Svenonius, 2004; Chomsky, 2005; Hiraiwa, 2005).

Incorporado a um processador sintático encapsulado (Cf. seção 3.1), que constrói representações independentemente de informação discursiva e que, além disso, é incapaz de lidar com informação de natureza não estrutural, o conceito de fases poderia permitir a transferência de pequenas porções de informação parcialmente analisadas aos sistemas interpretativos durante estágios intermediários do parsing. O processador, assim, não aguardaria a construção da representação completa de uma sequência para que, então, fosse enviada aos sistemas interpretativos, mas enviaria porções semi-hierarquizadas à interface conceitual-intencional, que trabalharia paralelamente. A transferência incremental, da esquerda para a direita, de informação à interface conceitual intencional 
permitiria que os traços semânticos, inativos durante o processamento sintático, pudessem ser ativados, habilitando a operação dos sistemas interpretativos, que poderiam recuperar informação semântica e discursiva, atualizar o modelo de discurso e atuar no processo de referenciação, entendido como o mapeamento das unidades em análise em entidades do mundo real (ou em entidades projetadas internamente a partir do mundo real, Cf. Jackendoff, 2002) e do universo de discurso. No âmbito do MINC (Corrêa e Augusto, 2006, 2007; Cf. cap. 2), esta incorporação foi proposta em Augusto, Corrêa e Forster (2012) e retomada em Corrêa, Augusto, Longchamps e Forster (2012).

Considerando especificamente a computação, no parsing, de um DPcomplexo contendo uma relativa de objeto, parte-se de uma sequência de itens lexicais mantidos em arranjos ou subarranjos em uma janela de processamento. Assumindo uma arquitetura mista, parte top-down e parte bottom-up, o núcleo funcional D promoveria a derivação top-down de um DP ao qual seria acoplado um Nome e um $\mathrm{CP}$, considerando a previsão de que o DP seria modificado por uma relativa. O pronome relativo sinaliza que o head noun tem de ser mantido ativo na memória de trabalho (Cf. modelo HOLD (Corrêa, 1995b)). A manutenção desse elemento na memória pode ser considerada como uma fonte potencial de custo. A derivação procede com um segundo núcleo funcional D promovendo a derivação top-down de um DP em um espaço derivacional paralelo (Figura 17, quadro 2). O verbo flexionado permitirá a identificação dos traços de $\mathrm{T}$ (que sinalizarão a necessidade de preenchimento de SpecTP); de v (que irá requerer um argumento externo); e de $\mathrm{V}$ (que sinalizará o requerimento de um argumento interno). A partir de $\mathrm{V}$ dá-se a derivação bottom-up de uma estrutura cuja projeção máxima é vP (Figura 17, quadro 3) e que será acoplada a TP. O DP construído em um espaço derivacional paralelo é então inserido simultaneamente em SpecTP e SpecvP (Figura 17, quadro 4). Pela configuração estrutural que implica em uma relação de concordância, os traços interpretáveis em DP serão confrontados com os traços não interpretáveis em $\mathrm{T}$. $\mathrm{O}$ requerimento de um argumento interno para $\mathrm{V}$ será satisfeito por uma cópia do pronome relativo mantido ativo na memória de trabalho (Figura 17, quadro 4). 
Figura 17 - Relativa de objeto em um Modelo Integrado da Computação Online

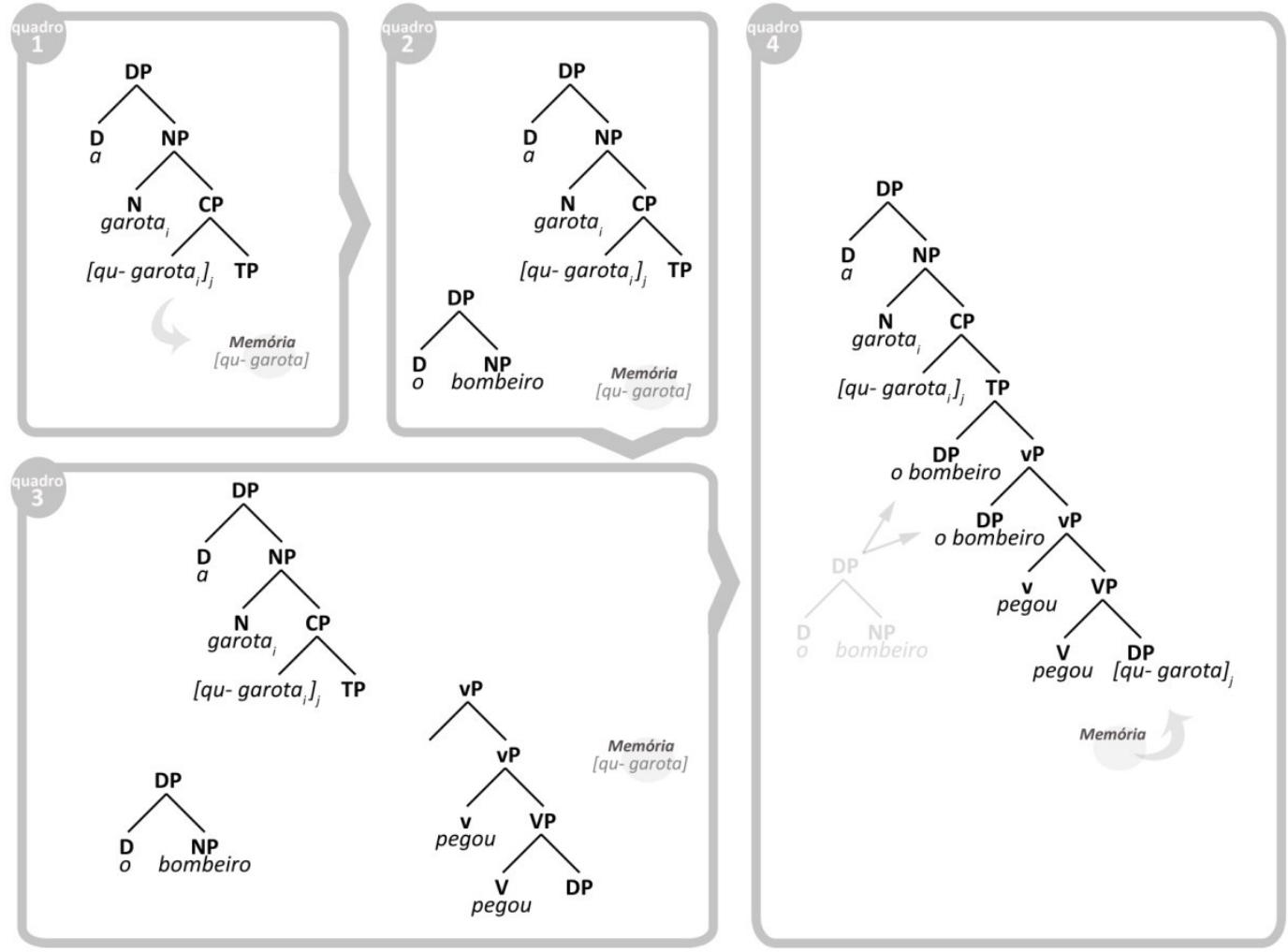

A incorporação da noção de fases a essa proposta (adaptada a um processamento da esquerda para a direita), permite operacionalizar a transferência incremental de informação à interface com os sistemas conceituais-intencionais. Tomando-se como exemplo a oração relativa exemplificada na Figura 17, considera-se, nesse modelo, que, após a identificação do determinante, $a$, e a derivação top-down do DP, seu núcleo D, por se constituir como borda da fase, sofre Transfer $^{57}$ e tem seus traços interpretados na interface semântica, o que possibilitaria o início da busca por seu referente. Caso a informação de gênero (no caso, feminino) constitua-se como distintiva, o referente relacionado a esse D poderia ser antecipadamente mapeado. No caso da relativa exemplificada, o NP que compõe o núcleo da relativa sofreria Transfer juntamente com o pronome relativo que, visto que tal complementizador é a borda da segunda fase da estrutura, constituída pelo $\mathrm{CP}$ da relativa, o que indicaria a existência de mais de um possível referente para o DP, que será determinado apenas a partir de informação adicional. Desse modo, é criada uma cópia do pronome relativo

\footnotetext{
${ }^{57}$ Transfer designa uma operação na derivação sintática similar ao que vinha sendo denominado Spell-out em momentos anteriores da teoria. Transfer ocorre após a derivação de cada objeto sintático que compõe uma fase. Considerando-se os propósitos da discussão apresentada, não serão feitas maiores distinções entre Transfer e Spell-out, sendo os termos tomados de forma intercambiável. Para uma discussão mais detalhada acerca dessas noções, ver Grohmann (2009).
} 
indexado ao NP garota, que é mantida ativa na memória de trabalho até que o gap seja encontrado. Este complementizador também deflagra a derivação topdown dos núcleos funcionais da relativa, conforme explicitado acima. A introdução, no parsing, do D seguinte, $o$, sujeito da relativa, impede que o gap seja identificado nessa posição, e leva a que a busca por seu referente seja iniciada, por sua transferência para a interface. O NP bombeiro, no âmbito da fase que constitui esse DP, poderia permitir a antecipação do mapeamento de um referente, caso se constitua como informação distintiva.

A partir do processamento do verbo pegou, o DP em questão, derivado paralelamente, é concatenado à estrutura central da relativa, simultaneamente em SpecTP e SpecvP, atendendo ao requerimento de um argumento externo. Com o requerimento de um argumento interno, o gap é, assim, identificado na posição de objeto do verbo da relativa e a cópia do pronome relativo, mantida na memória, é inserida. O DP complexo tem, então, sua interpretação fechada. Na Figura 18, são indicadas as localizações das fases e bordas de fase.

Figura 18 - Caracterização das fases e bordas de fases em uma relativa de objeto

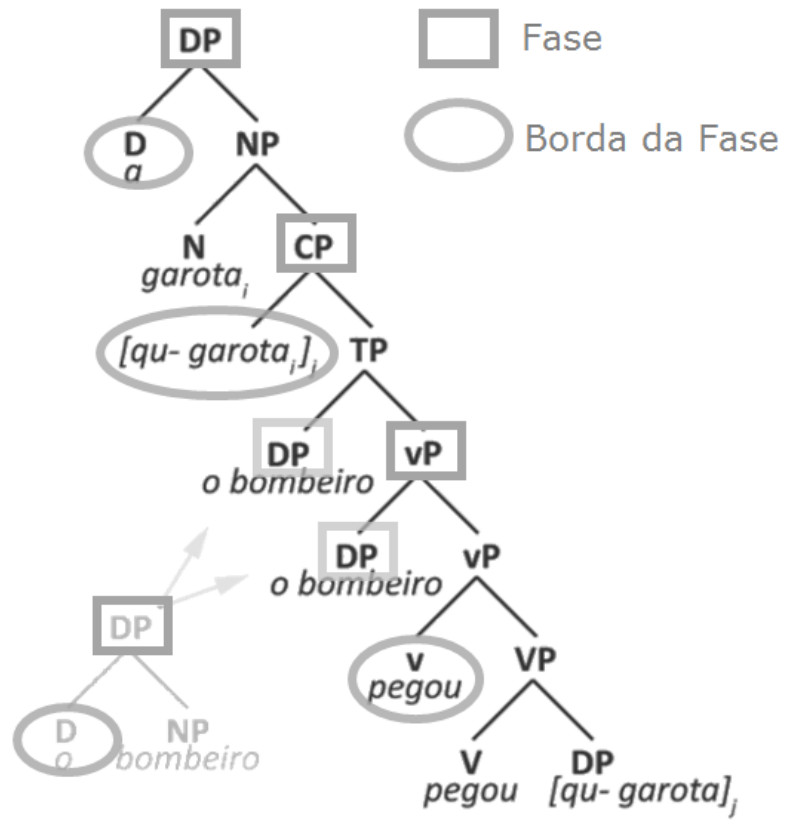




\section{2. Processos interpretativos no curso do processamento sintático}

O mecanismo de transferência gradual de informações à interface conceitual intencional, contudo, não é capaz, por si só, de explicar o processo de antecipação, tal qual detectado, por exemplo, nos experimentos 1 e 2. No momento da análise do DP bombeiro, em (1), por exemplo, não há ainda informação estrutural suficiente para que os sistemas interpretativos possam associar um papel temático a este DP ou ao DP núcleo da relativa. Neste ponto, retomamos a segunda questão inicialmente apresentada, a de como seria possível uma interpretação da informação enviada, uma vez que ela se encontra apenas parcialmente estruturada.

(1) A garota que o bombeiro pegou...

Uma possível solução para este problema, em consonância com propostas anteriores nas quais se defendia o processamento paralelo de informação temática (Rayner, Carlson e Frazier, 1983; Cf. seção 3.2.1), poderia estar na pré-ativação paralela de papéis temáticos nos sistemas interpretativos a partir das unidades parcialmente estruturadas envidas pelo componente sintático e com base no resultado do processamento de material precedente. Considerando, por exemplo, o DP bombeiro na sentença 1, seria possível que, fazendo parte do modelo de discurso corrente, o papel temático de agente atribuído anteriormente a uma ocorrência deste item no contexto discursivo, seria pré-ativado nos sistemas interpretativos quando estes recebessem o material transferido pelo componente computacional. Este mecanismo de pré-ativação atuaria com base na possível identidade entre o DP em processamento e uma representação daquele recuperado do modelo de discurso, tendo como gatilho a interpretação do traço de definitude do DP em processamento, que indicaria a possível necessidade de retomada de informação discursiva. Nestes termos, a pré-ativação de informação temática poderia ser entendida como um processo de antecipação da atribuição de papel temático por parte dos sistemas interpretativos, a partir do resultado do processamento prévio a despeito da indisponibilidade de informação verbal. Como consequência, o processamento do verbo poderia ser facilitado caso a 
informação temática no precedente fosse convergente com os papéis temáticos relacionados ao verbo em processamento.

Conforme reporta Lau (2009), a existência de um mecanismo de préativação é sugerida por vários resultados experimentais com potenciais evocados nos quais a expectativa por material futuro parece afetar o estado corrente do processador. Van Berkum et al. (2005), por exemplo, compararam, no holandês, sentenças como (2b) e (2c), seguindo um preâmbulo como (2a). Enquanto (2b) trazia um nome previsível pelo contexto ao final da sentença, (2c) trazia um nome imprevisível. Os autores detectaram, em (2c) à altura do adjetivo, um padrão de onda relativo à inconsistência entre a marcação de gênero deste modificador e a marcação de gênero relacionada ao nome previsível. Tal resultado, segundo Lau (2009), seria compatível com a hipótese de pré-ativação, entendida, nesse caso, como a facilitação resultante da expectativa por um determinado elemento. Além de trabalhos já apresentados na seção 3.2.2, resultados de outros estudos podem ainda sugerir a previsão de informação concernente a gênero (Wicha et al., 2003, 2004; Otten et al., 2007), a animacidade (Szewczyk, 2006) e de natureza fonológica (DeLong, Urbach e Kutas, 2005). Esse tipo de evidência demonstra que o processador parece ter a capacidade de prever propriedades de material subsequente, o que pode ser entendido nos termos de um mecanismo de préativação.

(2a) The burglar had no trouble finding the secret family safe.

(2b) Of course it was behind a big NEU $_{\text {painting }}$ NEU.

(2c) Of course it was behind a big COM $_{\text {bookcase }}$ COM.

No que diz respeito especificamente à proposta de pré-ativação de informação temática, pré-requisitos seriam necessários para sustentar a hipótese de que DPs poderiam pré-ativar informação desse gênero. A primeira delas é de que informação temática de material já processado seja mantida e acessível à recuperação. A segunda é a de que DPs possam promover a recuperação desta informação.

Resultados experimentais já demonstram a possibilidade de influência de informação temática prévia no processamento subsequente (Chang, Bock e Goldberg, 2003). Em um recente experimento de rastreamento ocular com 
crianças de 4 anos, foi contrastada a influência de preâmbulos com diferentes estruturas temáticas no tempo de fixação em objetos durante a compreensão de sentenças (Thothathiri e Snedeker, no prelo). O prêambulo (3a) apresentava, na primeira posição seguida ao verbo, um DP locativo como papel temático de alvo, enquanto, em (3b), o primeiro DP locativo era um tema. Após a apresentação de um desses preâmbulos, diante de um painel no qual eram apresentadas duas entidades animadas (eg. cavalo e coelho) e duas entidades inanimadas (eg., buzina e bola), os participantes poderiam ouvir dois tipos de instruções trazendo um dativo seguido ao verbo "Now you can send the horse the ball" ou "Now you can send the horn to the bunny". Para as duas instruções, houve uma tendência de que as crianças olhassem por mais tempo para os objetos inanimados, a partir do DP dativo ("the horse" ou "the horn"), quando apresentadas ao preâmbulo que trazia o tema em primeiro lugar (3b). Uma vez que, no contexto visual apresentado, os objetos - e não os personagens animados - eram os candidatos mais prováveis ao papel de tema, foi considerado que o maior tempo de fixação nestes objetos seria um reflexo da expectativa, gerada pela configuração temática do preâmbulo, de que um tema fosse apresentado em seguida ao verbo na sentença alvo, sugerindo a possibilidade de priming temático.

(3a) They loaded the truck with the hay.

(3b) They loaded the hay on the truck.

Embora os verbos tenham um papel importante na recuperação de informação temática (Altmann e Kamide, 1999; Ferretti, McRae e Hatherell, 2001), há resultados indicando que nomes, por si só, poderiam permitir a recuperação deste tipo de informação na memória de longo prazo (McRae, Hare e Ferretti, 2001). Numa tarefa na qual nomes eram apresentados como primes para o reconhecimento de verbos pela leitura em voz alta, agentes e pacientes típicos, por exemplo, facilitaram o reconhecimento de verbos relacionados (eg., nun -> praying; dice -> rolled), um indício de que informação temática poderia ser recuperada por meio de um DP. Esse mecanismo de recuperação de informação temática implica não só a possibilidade de que DPs possam promover a préativação de um papel temático recuperado anteriormente a partir de informação contextual discursiva, mas também de que o acesso lexical a verbos relacionados 
a essa informação temática seja facilitado ${ }^{58}$. Tempos de leitura no processamento de relativas do inglês Omaki et al. (no prelo; Cf. seção 3.2.1) e japonês Aoshima (2004) também parecem indicar que DPs são capazes de predizer determinado verbo.

A possibilidade de que informação temática prévia seja mantida e de que DPs possam recuperá-la estabelecem os pressupostos necessários para que um mecanismo de pré-ativação de informação temática possa atuar no processamento das relativas de objeto. $\mathrm{Na}$ medida em que se trata de um mecanismo baseado no resultado de processamento prévio e em informação armazenada na memória, os efeitos desse tipo de informação no curso da análise de uma sequência - como a previsão de facilitação do processamento de verbos que trazem uma grade temática compatível com informação pré-ativada - poderão estar sujeitos à competição com outros fatores dos quais já se obteve evidência de influência no curso do processamento, tais como os que desencadeiam efeitos de priming estrutural ou semântico. Contudo, ainda assim, resultados indicam que a não convergência de informação temática prévia em relação a uma relativa poderia reduzir o efeito de facilitação proporcionado pelo discurso.

Em um estudo de leitura auto-monitorada foram apresentadas relativas de sujeito e de objeto ( $4 \mathrm{~b}$ e $4 \mathrm{c}$ ) introduzidas ou não por um preâmbulo (4a) (Fedorenko, Piantadosi e Gibson, 2012). Foi verificado que, conforme já documentado na literatura (Cf. seção 3.3), as relativas de objeto apresentaram um maior tempo de leitura que as relativas de sujeito. Além disso, houve também um efeito de facilitação da informação contextual, resultante de um menor tempo de leitura das relativas apresentadas após o preâmbulo quando comparadas à sentenças apresentadas em um contexto nulo (sem preâmbulo). Contudo, a diferença no tempo de leitura entre relativas de objeto e de sujeito foi ampliada diante da apresentação de informação contextual (Figura 19).

(4a) At the press-conference, a senator and two reporters got into an argument. The senator attacked one of the reporters and then the other reporter attacked the senator.

\footnotetext{
${ }^{58}$ Embora os resultados em questão possam ser resultantes, no caso de alguns pares testados, de uma facilitação proporcionada por uma associação semântica (de natureza não temática) entre os nomes e verbos envolvidos, ainda assim, indicam a possibilidade de que nomes podem facilitar o acesso a verbos tematicamente relacionados.
} 
(4b) I heard that the reporter that attacked the senator admitted to making an error.

(4c) I heard that the reporter the senator attacked admitted to making an error.

Figura 19 - Tempos médios de leitura por segmento (Fedorenko, Piantadosi e Gibson, 2012)

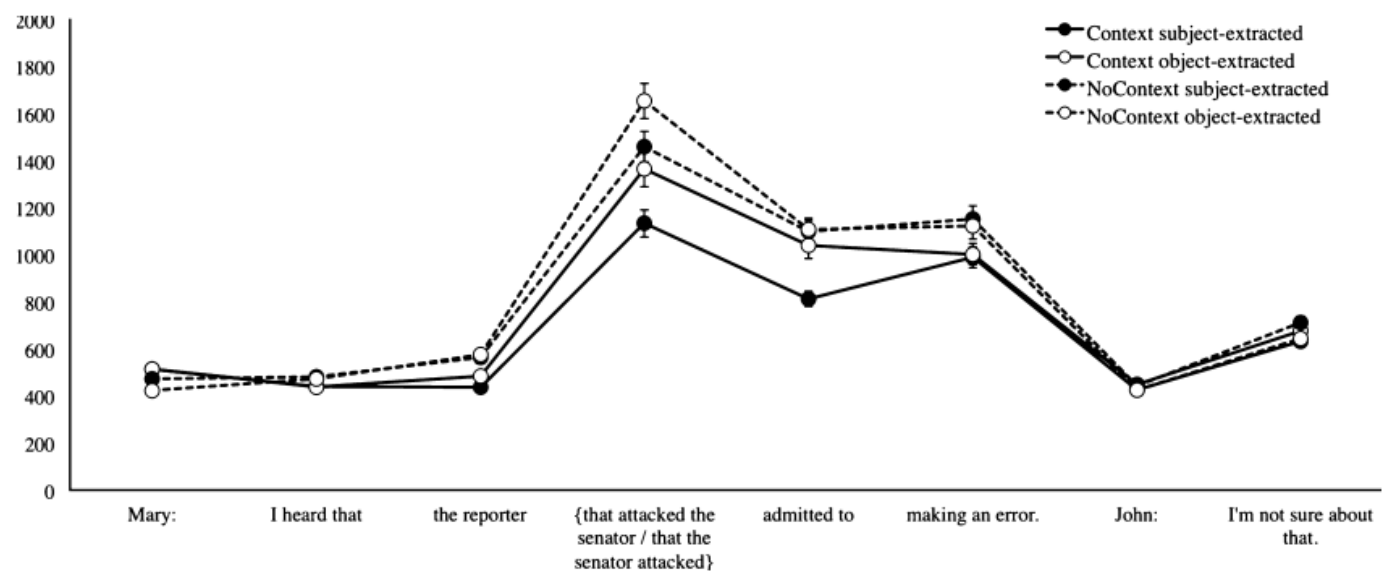

A hipótese de priming sintático-lexical foi uma das explicações consideradas para estes resultados. O preâmbulo traz sequências SVO, como "senator attacked reporter" e "reporter attacked senator", que correspondem à ordem das relativas de sujeito, mas não traz qualquer sequência OSV, que corresponderia à ordem das relativas de objeto ${ }^{59}$. A identidade entre as sequências do preâmbulo e a ordem das relativa de sujeito, poderia, assim, explicar a amplitude do efeito do tipo de extração. A hipótese de pré-ativação temática também pode sugerir uma possível explicação para estes dados. No preâmbulo em (Xa), os DPs envolvidos na relativa, reporter e senator, recebem, em sua última ocorrência, respectivamente, os papéis temáticos de agente e paciente. Contudo, estes papéis temáticos são imcompatíveis com aqueles que estes DPs receberão na relativa, na qual reporter passará a ser paciente e senator agente da ação denotada

\footnotetext{
${ }^{59}$ A respeito desses resultados, os autores comentam: "these results support interference-based and word- and NP-type-based decay working memory accounts of RC complexity, and they are not consistent with a decay-based account where decay is a function of constructing new discourse referents for elements that intervene between the relevant syntactic dependents. Such an account predicts that RC complexity effects should be eliminated (or, at least, greatly reduced) in supportive contexts compared with null contexts, but the reverse is true". A hipótese de que o custo nas relativas de objeto seria ocasionado pela introdução de novos referentes entre o DPnúcleo e o verbo, defendida por Gibson e colaboradores (Gibson, 1998; Warren e Gibson, 2002; Cf. seção 3.3), é considerada, pelos próprios autores, como incompatível com os dados do trabalho em questão. Resultados possivelmente contrários a esta hipótese foram encontrados também por Vasith (2003), que reporta, no hindi e no alemão, a diminuição de tempos de resposta em sentenças que exigiam a introdução de novos referentes.
} 
por attacked. Na hipótese do preâmbulo ter suscitado a pré-ativação de papéis temáticos, a ampliação da diferença entre relativas de sujeito e de objeto pode ser entendida como resultante dessa discrepância entre os papéis temáticos assumidos no preâmbulo e na relativa, que reduziria, nas relativas de objeto, a facilitação proporcionada pelo contexto discursivo, ampliando o tempo de resposta associado a essas sentenças ${ }^{60}$.

A proposta apresentada até o momento sugere a possibilidade de emergência de processos antecipatórios na compreensão de relativas por meio do envio gradual de informações às interfaces e da pré-ativação de informação temática com base em informação contextual. Em termos de custo de processamento, um mecanismo dessa natureza, associado a um parser autônomo, apresenta como vantagem a possibilidade de realizar uma computação sintática de baixo custo com base em um número limitado de traços lexicais, nomeadamente os traços formais, evitando a necessidade de manutenção de representações sintáticas paralelas no curso do processamento. Além disso, a incorporação de um mecanismo de pré-ativação a um parser dessa natureza poderia apresentar como vantagem a redução de custo de processamento pela necessidade de reacesso a representações e a diminuição do número de erros.

$\mathrm{Na}$ compreensão de relativas, uma evidência nesta direção vem de um dos experimentos reportados em Lau (2009). Em função de um estudo (Wagers, Lau, \& Phillips, 2009) que detectou, na compreensão, erros de atração em sentenças como (5a), resultantes da influência da marcação plural do núcleo da relativa na flexão do verbo encaixado, foi conduzido um experimento de leitura automonitorada no qual se detectou que, em comparação com versões sem erros de concordância das sentenças (5a) e (5b), somente em (5b) havia um aumento do tempo de leitura.

(5a) *The musicians who the reviewer praise...

(5b) *The musician who the reviewer praise...

\footnotetext{
${ }^{60}$ No que diz respeito a resultados indicando a facilitação promovida pela plausibilidade da relação entre fillers e verbos, na ausência de informação contextual, conforme reportado na seção 3.2.1, a informação temática, neste caso, poderia ser recuperada a partir da memória de longo prazo relacionada ao armazenamento de itens lexicais, conforme podem sugerir os resultados de (McRae, Hare, Ferretti, 2001).
} 
Esses resultados são interpretados como evidência para um possível mecanismo de pré-ativação. A presença de um elemento com uma marcação de concordância, como o sujeito de uma relativa, dispararia a previsão da marcação de número para outros elementos subsequentes (nos termos do modelo para compreensão de relativas proposto no início deste capítulo, esta previsão poderia ser feita simultaneamente à previsão da necessidade de uma posição para o verbo encaixado). Em razão desta previsão, no caso de sentenças gramaticais, ie. sem erros de atração, o parser precisaria apenas checar a previsão estabelecida, sem a necessidade de reacessar informação de concordância relativa a outros elementos. Contudo, em sentenças como (5a) e (5b), nas quais a previsão feita a partir do sujeito (singular) contrasta com a informação de número trazida pelo verbo (plural), haveria necessidade de recuperar informação prévia. Nestes casos o erro de detectar a agramaticalidade de (5a) poderia ser fruto de um mecanismo de recuperação (Badecker \& Lewis, 2007) no qual a interferência da informação de número do atrator mantido na memória de trabalho, isto é, o núcleo da relativa, poderia levar ao licenciamento inadequado de (5a), conforme evidenciado pela aceitação de (5a) em comparação à dificuldade de leitura registrada em (5b), que indicaria a rejeição desta sentença em função da ausência de um atrator com marcação de plural. Com base em resultados dessa natureza, Lau (2009) argumenta que um mecanismo preditivo para o processamento de dependências sintáticas poderia conduzir a um processamento mais preciso - dispensando o parser da necessidade de recuperação de informação da memória, que poderia levar a erros de interferência tais como o detectado em (5a) - e também reduziria a necessidade de computação a partir da análise de itens lexicais subsequentes.

É possível argumentar que a hipótese de pré-ativação temática, enquanto um mecanismo de antecipação no processamento de relativas, traria vantagens semelhantes ao processo de compreensão. Diante da possibilidade do envio gradual de material aos sistemas interpretativos e, mais especificamente, da possibilidade de que os DPs núcleo e sujeito da relativa sejam incrementalmente enviados, é possível considerar que informação temática precedente seja recuperada a um baixo custo pelos sistemas interpretativos, uma vez que o estabelecimento da referência definida exige que estes recuperem informação discursiva. Nessa hipótese, os sistemas interpretativos poderiam prever os requerimentos temáticos do verbo subsequente, dispensando a necessidade de 
recuperação de informação no estabelecimento de relações temáticas, o que poderia, seguindo o raciocínio de Lau (2009), tornar o processamento mais eficiente.

Note-se que, embora a proposta em questão ressalte o papel de DPs para a emergência de processos preditivos, ainda assim, distingue-se claramente de teorias lexicalistas (eg. MacDonald, Pearlmutter e Seidenberg, 1994; Cf. seção 3.2.2), pois reserva ao processamento sintático um estágio específico, de modo que o acesso à informação não estrutural é tido como posterior ao estágio de processamento sintático.

\section{3. \\ Mapeamento de referentes no curso do processamento sintático}

Considerando que o envio incremental de informações do processador sintático à interface conceitual intencional poderia permitir acesso a informação não estrutural no curso da computação sintática e, além disso, considerando que a pré-ativação temática, com base em informação discursiva, permitiria a antecipação de processos interpretativos, no momento em que um DP, como bombeiro em (1) tivesse sido enviado pela sintaxe aos sistemas de interface, deveria haver informação suficiente para que fosse possível desambiguizar a referência do DP em questão.

Dessa forma, no que diz respeito aos resultados que indicam a possibilidade de mapeamento antecipado de um DP complexo em um referente visualmente apresentado - experimentos 1 e 2 - a questão que deve ser respondida é a de como a informação resultante do processamento linguístico poderia permitir o mapeamento incremental da referência em uma entidade visualmente apresentada, ou seja, como a informação desambiguizadora possivelmente disponível nos sistemas de interface poderia ser relacionada a informação obtida a partir do sistema óculo-motor?

O principal requisito para que este mapeamento seja possível está na acessibilidade de representações derivadas do sistema visual. Uma das possibilidades de que representações dessa natureza possam se fazer acessíveis seria por meio da concepção de uma interface que pudesse relacionar informação conceitual à informação visual. Uma proposta nesta direção é a de Jackendoff (2002, 2007), que, embora dissonante da proposta defendida aqui no que diz 
respeito à arquitetura interna do processador sintático ${ }^{61}$, é compatível com a proposta de um processador sintático especializado, no qual a interação entre componentes modulares é realizada por níveis de interface. Assumindo uma arquitetura paralela, Jackendoff $(2002,2007)$ postula a existência de uma interface na qual estrutura conceitual e informação visual poderiam interagir. De acordo com essa perspectiva, haveria uma espécie de codificação semântica das entidades e eventos apresentados visualmente, um processo que teria por finalidade, por exemplo, permitir a referência, por meio da língua, a estes objetos. O nível de representação responsável por esta tarefa, chamado de estrutura espacial ${ }^{62}$, faria interface com o nível semântico. Algumas relações entre estes dois níveis poderiam ser armazenadas na memória de longo prazo ou estabelecidas durante o processamento on-line. Uma entidade como gato, por exemplo, além de estar associado, na estrutura semântica, a uma categoria específica que agrupa animais estaria, na estrutura espacial, associada a certa informação imagética a respeito das propriedades físicas estereotípicas deste tipo de entidade (Jackendoff, 2007). A relação entre representações dessa natureza poderia ser armazenada na memória de longo prazo. Por sua vez, o mapeamento entre representações semânticas e visuais de um contexto imediato poderia, nesta perspectiva, ser computada online por uma partição da memória de trabalho especializada na codificação de estímulos visuais correntes. Na presença de informação contextual relevante no processamento online, o objetivo do processador seria estabelecer um mapeamento entre a representação construída na estrutura espacial e aquela derivada do processamento do estímulo verbal.

Uma interface nestes moldes propiciaria não somente a possibilidade de mapeamento incremental de representações de natureza conceitual em referentes apresentados visualmente, mas poderia também acomodar resultados indicando desambiguização de estruturas por meio de informação visual (Trueswell et al., 1999; Tanenhaus et al., 1995). Nessa direção, Knoeferle et al. (2004) encontraram evidência de que, na presença de informação visual desambiguizadora, a ambiguidade de caso de DPs femininos no alemão parece poder ser resolvida com

\footnotetext{
${ }^{61}$ Dentre outras incompatibilidades, segundo a proposta de Jackendoff $(2002,2007)$, não haveria distinção entre gramática e léxico e não haveria, a rigor, operações gramaticais. As estruturas seriam construídas com base em templates estruturais, aos quais o autor chama de trelets, armazenados na memória de longo prazo.

${ }^{62}$ Tradução livre de spatial structure.
} 
base na informação visual disponível. Testando sentenças como Die Prinzessin wäscht offensichtlich den Pirat (A princesa $a_{\text {sujeito/objeto lava aparentemente o }}$ pirata), que possuem uma ambiguidade de caso no DP que inicia a sentença (que pode ser interpretado como nominativo ou acusativo), observou-se a ocorrência de movimentos oculares indicativos de antecipação, diante de um contexto visual como na Figura 20. À altura do advérbio, havia uma tendência de que os participantes direcionassem seu olhar com mais frequência ao pirata, o que seria um indicativo da antecipação da interpretação de pirata como paciente, em consequência da associação da princesa ao papel de agente ${ }^{63}$. Estes resultados poderiam, conforme apontam Knoeferle et al. (2004), ser facilmente acomodados por uma proposta como a de Jackendoff (2002), partindo da concepção de uma interface que relaciona informação conceitual e visual. As restrições impostas pelo contexto visual apresentado permitiriam não só a resolução incremental da ambiguidade de caso antes que o elemento desambiguizador (ie., den pirat) fosse apresentado, mas também antecipação de informação temática relativa à entidadepaciente da ação.

Figura 20 - Estímulo visual apresentado em Knoeferle et al. (2004)
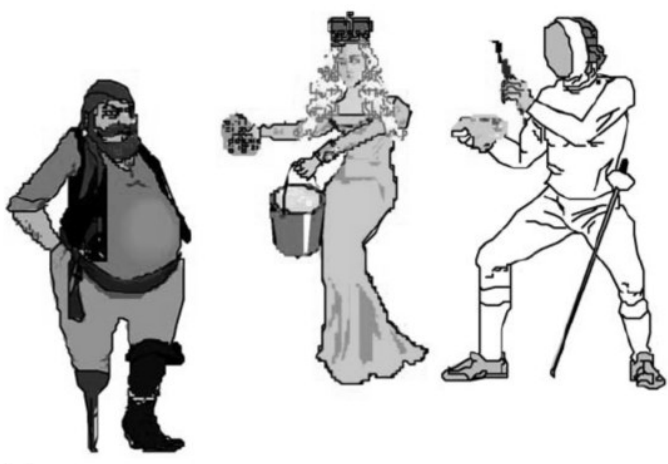

Nos termos da proposta de pré-ativação temática apresentada neste capítulo, é possível considerar que uma interface dessa natureza poderia possibilitar a articulação entre informação percebida visualmente e informação linguística. Um canal de comunicação entre o sistema visual e os níveis conceituais permitiria que informação semântica visual pudesse promover a préativação de informação temática, assim como no caso de informação recuperada a

63 Note-se que, no experimento em questão, não foram utilizadas ações prototipicamente relacionadas ao agente ou paciente representado nas ilustrações, de forma a não suscitar a recuperação de informações temáticas a partir da memória de longo prazo. 
partir do contexto discursivo. Em parcial conformidade com o que vem sendo defendido aqui, na concepção de Jackendoff (2002), o nível sintático não seria diretamente influenciado por informação de natureza visual. Contudo, a interface conceitual com a sintaxe poderia influenciar o nível sintático a partir de informação recebida por meio da interface com o sistema visual, inibindo a computação de alternativas estruturais incorretas. A hipótese de um envio gradual de informação à interface conceitual por meio de unidades semelhantes a fases prescindiria dessa interferência para dar conta da interpretação incremental de orações contendo relativas, uma vez que a pré-ativação de informação temática seria condição suficiente para explicar os efeitos de antecipação derivados de informação contextual visual ou discursiva.

\section{4 . \\ Circunstancialidade da emergência de processos antecipatórios no curso do processamento}

Resultados como os reportados nos experimentos 1 e 2 parecem se encaixar claramente na possibilidade de pré-ativação temática. Em função da apresentação de informação contextual discursiva e visual, teria havido o mapeamento antecipado de referentes, indicando que informação a respeito da estrutura do evento esteve disponível e acessível a sistemas exteriores à sintaxe para proporcionar tal mapeamento. Os resultados obtidos no experimento 3, entretanto, foram em uma direção contrária, uma vez que DPs complexos contendo relativas de objeto, estando encaixados em verbos bitransitivos em estruturas temporariamente ambíguas, pareceram limitar a possibilidade de antecipação.

Em primeiro lugar, verificou-se que os resultados da tarefa offline, em consonância com resultados obtidos anteriormente por Ferreira e colaboradores (Cf. seção 3.2.1), revelaram a ocorrência consistente de uma estratégia de aposição mínima, tal qual prevista por modelos de natureza determinística (Cf. seção 3.2.1).

Conforme apresentado na seção 4.4.3, uma das explicações possíveis para a diferença entre os resultados obtidos no experimento 3 e aqueles obtidos nos experimentos anteriores poderia estar no fato de que a introdução de uma ambiguidade por meio do verbo poderia ter restringido a possibilidade de mapeamento antecipado. Essa ambiguidade (além de fazer com que a expectativa 
de modificação no experimento 3 fosse menor do que aquela criada no contexto do experimentos 1 e 2), conforme previsto por abordagens de processamento em dois estágios, poderia conduzir à atuação de princípios de resolução de ambiguidade de natureza estrutural, como a aposição mínima, que, no caso em questão, favoreceria uma análise completiva, restringindo a possibilidade de "escolha" de um referente.

No experimento 3, observa-se também que, mesmo nos casos nos quais não houve evidência da manutenção de uma análise de aposição mínima (ie., os casos nos quais foram registradas respostas offline condizentes com uma leitura relativa), não foram obtidos resultados que poderiam sinalizar a desambiguização da referência por meio de informação discursiva e contextual prévia, em vista do baixo número de rodadas (trials) com fixação e da indiferenciação entre os resultados obtidos em relativa e completivas. Considerando a hipótese de préativação temática, a restrição ao mapeamento incremental, nesse contexto do experimento 3, poderia ainda ser explicada pela atribuição conflitante de papéis temáticos ao DP-núcleo da relativa, que, a partir da informação do verbo principal, poderia ter o papel temático de alvo atribuído inicialmente. Nessas circunstâncias, a emergência da pré-ativação considerada no caso experimentos 2 e 3 poderia ser restringida, limitando, assim, a possibilidade de mapeamento antecipado da sentença no referente-alvo da relativa.

No experimento 3, observou-se que a condição contendo uma relativa que permitiria a desambiguização no sujeito não esteve correlacionada a um número maior de fixações nem à altura do sujeito da relativa, nem à altura do verbo. Este resultado pode indicar que, sequer com a identificação do verbo que teria o DPnúcleo da relativa como argumento, o mapeamento do DP complexo em seu referente seria possível. Este resultado toca na questão da circunstancialidade da emergência de processos antecipatórios no processamento online.

Resultados anteriores identificaram a facilitação do processamento de relativas em contextos que implicavam em restrição (Grodner, Gibson e Watson, 2005; van Berkum, Brown e Hagoort, 1999; van Berkum, Hagoort e Brown, 2000), o que é interpretado, em geral, como indicativo de um processamento interativo, no qual restrições discursivas atuariam incrementalmente e dirigiriam a análise inicial do processador. Neste capítulo foi defendida uma abordagem alternativa para esse fenômeno segundo a qual essa facilitação poderia ser 
possível por meio de um mecanismo estrutural de envio gradual de informação às interfaces associado a um mecanismo de pré-ativação com base em informação discursiva ou visual. Contudo, a eficiência deste mecanismo de pré-ativação parece limitada pela presença de informação conflitante, conforme indicariam os resultados do terceiro experimento que, em certa medida, contradizem resultados anteriores nos quais se observou a ocorrência de processos preditivos.

Evidência contrária à possibilidade de antecipação do mapeamento de referentes é apresentada também em outro estudo de rastreamento ocular conduzido por Di Nardo $(2005,2011)$. Em um dos experimentos reportados, foram testadas sentenças como "Before making the dessert, the cook will crack/examine the egg that is in the bowl", contrastando a presença de verbos causativos e psicológicos na oração matriz. Estas sentenças eram ouvidas concomitantemente a cenas dinâmicas, nas quais se apresentavam um possível tema (eg., um pacote com ovos) e agente relacionados à ação denotada pelo verbo da oração principal. Nesses vídeos, o agente poderia se mover em direção ao objeto-tema, se afastar dele ou permanecer em uma posição neutra. De acordo com os resultados, não foi verificado efeito da variável tipo de verbo, à exceção da condição na qual o agente movia-se em direção ao possível tema, o que significa que os participantes tenderam ao mesmo comportamento tanto diante de um verbo psicológico quanto diante de um verbo causativo (que poderia implicar em uma ação) nas duas outras condições. Além disso, não foram detectados indícios de antecipação, uma vez que, em média, as sacadas foram direcionadas ao objeto-tema apenas depois do offset do DP crítico.

Comparando esses resultados àqueles obtidos em estudos anteriores, Di Nardo (2011), defendendo a antecipação como um fenômeno resultante da integração pós-perceptual de representações linguísticas e visuais, argumenta que, em estudos como o de Altmann e Kamide (1999), as representações ativadas por sets de objetos estáticos seriam também estáticas, de forma que o sistema cognitivo central e o sistema atencional poderiam voltar seus recursos para as transformações que se desenvolvem progressivamente na representação linguística, ao contrário do que aconteceria em cenas dinâmicas, nas quais as representações de natureza visual construídas seriam também dinâmicas e, portanto, teriam de ser atualizadas constantemente. Considera-se assim que a integração entre informação visual e linguística ocorreria pela intermediação de 
um processador central, cuja rapidez da integração estaria condicionada a fatores como a complexidade das representações envolvidas (de Almeida, 2012).

Analisando o contexto experimental dos experimentos 1 e 2 , frente ao experimento 3, observa-se que, embora o participante devesse executar uma mesma tarefa em todos os casos, há, neste último, conforme assinalado na seção 4.4.3, possivelmente, uma maior demanda cognitiva associada a uma menor previsibilidade dos estímulos entre diferentes rodadas (trials), dada em função da alternância dos tipos de estruturas, do tipo de interrogativa apresentada ao final das rodadas (trials), do maior número de estímulos, além da presença de estruturas ambíguas e mais complexas. Assim, em conformidade com o que sugere Di Nardo (2011), a inibição do mapeamento referencial a partir da informação potencialmente desambiguizadora do sujeito da relativa, mesmo com o prosseguimento da sentença, nas circunstâncias do experimento 3, pode ter sido ocasionada por fatores relacionados à complexidade das circunstâncias experimentais, que limitariam os recursos atencionais possivelmente necessários para um processo de integração pós perceptual entre informação linguística e visual, tal qual o que vem sendo proposto aqui.

Em resumo, a emergência de uma estratégia de aposição mínima e a restrição da possibilidade de mapeamento imediato parecem indicar, em conjunto, que, em primeiro lugar, o processamento na compreensão é conduzido considerando, prioritariamente, informação de natureza estrutural, de forma que a primeira passagem do parser, diante de informação estrutural ambígua, atua implementando escolhas iniciais potencialmente mais econômicas para o processador (Cf. seção 3.2.1). A prioridade de informação estrutural parece limitar, assim, a emergência de processos preditivos de natureza interpretativa e, consequentemente, a possibilidade de mapeamento antecipado. No que diz respeito, especificamente, ao processamento de relativas, esta limitação é indicada não só pelo efeito de aposição mínima detectado nesse experimento, mas também por resultados como os de Omaki et al. (no prelo), nos quais se verificou que restrições estruturais à possibilidade de ocorrência de relativas podem levar o processador a não conduzir processos de predição estrutural, como o active filler strategy. Além disso, resultados como os de Di Nardo $(2005 ; 2011)$ e mesmo os resultados obtidos no experimento 3 parecem evidenciar que a possibilidade de integração de informação contextual, em especial informação de natureza visual, 
parece ser resultante de um processo de integração pós-perceptual. Nesse sentido, a proposta apresentada ao longo deste capítulo, da possibilidade de integração de informação contextual por meio de um mecanismo de pré-ativação baseado no envio incremental de informações às interfaces, parece permitir uma possível interpretação para os dados obtidos neste trabalho que, por um lado, indicam a emergência de processos integrativos e antecipatórios ao longo do processamento sintático em circunstâncias de baixa demanda e, por outro, sugerem a atuação de princípios de base estrutural e a limitação de processos integrativos em circunstâncias de maior demanda. 


\section{6 Considerações Finais}

Este trabalho buscou investigar o processamento de relativas restritivas de objeto, avaliando a possibilidade da emergência de processos integrativos e antecipatórios no processamento online desse tipo de estrutura. Considerando as vantagens de cunho teórico da adoção da concepção de um processamento sintático autônomo, tais quais sua viabilidade em termos computacionais (Barrett e Kurzban, 2006) e epistemológicos (Fodor, 2000), conforme discutidas no capítulo 3, partiu-se da proposta do Modelo Integrado da Computação Online (MINC; Corrêa e Augusto, 2006; 2007) com o objetivo de investigar em que medida evidências de processos preditivos e integrativos incrementais baseados em informação não estrutural (Altmann e Kamide, 1999; 2007; Kamide et al. 2003; Marslen-Wilson e Tyler, 1991; Nieuwland e Van Berkum, 2006; van Berkum, Hagoort e Brown, 2000) poderiam ser verificáveis no processamento de relativas de objeto e, em que medida seriam compatíveis com a proposta de processamento sintático autônomo.

Nesse sentido, foram conduzidos experimentos de rastreamento ocular nos quais foi avaliada a possibilidade de que informação contextual de natureza visual e discursiva pudesse permitir a antecipação do referente visual de um DP complexo contendo uma relativa restritiva de objeto. Em especial, verificou-se, nos resultados dos experimentos 1 e 2, que informação desambiguizadora de natureza contextual poderia permitir o mapeamento do DP complexo em um referente tão logo estivesse disponível. Por outro lado, no experimento 3 , foi observado que, diante de uma ambiguidade estrutural, a possibilidade de mapeamento do DP complexo parece ser restringida, principalmente, pela atuação de princípios estruturais de resolução de ambiguidade.

Diante desses resultados, foi apresentada a proposta de que o envio gradual de informação do processador aos níveis interpretativos (Corrêa, Augusto, Longchamps e Forster, 2012), associado a um mecanismo de pré-ativação de informação temática com base em informação contextual, poderia ser capaz de 
conciliar um processamento sintático autônomo, sugerido principalmente pelos resultados do experimento 3 , às evidências de mapeamento antecipado de referentes evidenciado, em especial, pelos experimentos 1 e 2 .

Conforme discutido no capítulo 3, a natureza da proposta apresentada caminha numa direção já trilhada por outras propostas de modelos de processamento em estágio único: repensar o processamento sintático autônomo, considerando o envio mais constante de informação potencialmente menos estruturada aos sistemas interpretativos (Frazier e Clifton Jr., 1996; Christianson et al., 2001; Ferreira et al., 2001). Nesse sentido, este trabalho apresentou, com base em desenvolvimentos já propostos em Corrêa, Augusto, Longchamps e Forster (2012), a proposta de se assumir, no âmbito do MINC, a noção de fases e, em especial, a de DPs como fases, para dar conta dos resultados que reportamos neste trabalho e que parecem ser, à extensão do que se pôde verificar, ainda incompatíveis com propostas anteriores de um processamento autônomo modular.

O mecanismo de integração incremental de informação interpretativa considerado neste trabalho consiste em uma abordagem "passiva" para fenômenos relacionados a processos preditivos e integrativos baseados em informação não estrutural no curso do processamento sintático na perspectiva de um processador autônomo. Nesse sentido, não se propõe a existência de um mecanismo adicional ou destinado especificamente ao estabelecimento de previsões no curso da computação sintática. A simples possibilidade de pré-ativação de informação não estrutural, beneficiada por um envio constante de informações do parser aos níveis interpretativos, parece assim dar conta de resultados a princípio contraditórios, como o mapeamento antecipado do referente de um DP complexo contendo uma relativa, conforme observado nos experimentos 1 e 2 e, por outro lado, a preservação de princípios de natureza estrutural, conforme observado nos experimento 3. Conforme discutido no capítulo 5, o tratamento de processos antecipatórios como um fenômeno pós-perceptual parece dar conta, ainda, da circunstancialidade da emergência desses processos, que parecem ser limitados a condições de baixa demanda cognitiva.

Note-se, contudo, que o tipo de abordagem proposta aqui pode ser ainda compatível com uma abordagem "ativa" para a emergência de processos preditivos e antecipatórios, conforme a delineada em Corrêa, Augusto, Longchamps e Forster (2012). Nesse trabalho, explora-se a ideia de 
sombreamento (inspirada em resultados experimentais obtidos por MarslenWilson $(1973 ; 1975)$ e retomando a essência da proposta de Rodrigues (2006) para o formulador sintático), segundo a qual se propõe que as representações geradas pelo parser poderiam ser paralelamente acompanhadas de um processo de formulação do enunciado, conduzido por um ouvinte que assume a perspectiva de falante, gerando assim previsões que seriam checadas com as representações geradas por um processador sintático autônomo. Embora a proposta de préativação temática, considerada no âmbito deste trabalho, tenha o potencial de acomodar os dados que obtivemos no processamento de orações relativas restritivas de objeto, sua futura articulação com uma abordagem tal qual a proposta por Corrêa, Augusto e Forster (2012) pode vir a operacionalizar a compatibilidade de um processador autônomo a, ainda, outros processos de natureza integrativa e antecipatória.

Como já amplamente discutido ao longo deste trabalho, outra forma de captar processos dessa natureza no curso do processamento sintático advém da proposta de modelos interativos, como aqueles das teorias baseadas em restrições (MacDonald, Pearlmutter e Seidenberg, 1994; Trueswell \& Tanenhaus, 1994; Stevenson, 1994; Spivey e Tanenhaus 1998). Conforme pode ser observado pelas previsões de trabalhos como o de van Berkum, Hagoort e Brown (2000), embora a arquitetura de propostas dessa natureza seja potencialmente adequada para interpretar fenômenos relacionados à predição e antecipação, elas se mostram, em grande parte, incompatíveis com resultados que evidenciam a prioridade de informação estrutural, especialmente quando em desfavor de informação de natureza interpretativa potencialmente diretiva. Contudo, é possível, em um extremo, argumentar ainda, assumindo a perspectiva dessas propostas, que, em certas circunstâncias, informação de natureza estrutural poderia ser considerada prioritariamente, uma vez que informação sintática também atua na avaliação das representações construídas paralelamente por processadores de natureza interativa, sem uma definição precisa da forma de interação desse tipo de dado com outros tipos de informação consideradas, conforme se pode perceber na afirmação de MacDonald (1994): "There is little evidence available about the range of probabilistic constraints that affect ambiguity resolution, the relative strength of these constraints, or how they interact with one another". Em função dessa falta de precisão, tem-se argumentado pela infalseabilidade de modelos de 
natureza interativa (Frazier, 1995; Cf. McRae e Matsuki, 2012). Assim, na medida em que, a partir de um processador autônomo, se possa explicar não só princípios derivados da atuação de um processador sintático que atua com base em um conjunto limitado de informação, mas também a possibilidade de que informação de não estrutural possa ser integrada incrementalmente, o programa de investigação de um processamento modular parece apresentar-se como uma abordagem adequada para os fenômenos observados na compreensão de sentenças, beneficiando-se ainda dos argumentos recuperados aqui (Barrett e Kurzban, 2006; Chomsky, 1965; Ferreira, 2003; Fodor, 1983, 2000; Gigerenzer e Selten, 2001) que sugerem sua adequação em termos de processos computacionais implementados por um aparato cognitivo intrinsecamente limitado.

Nesse sentido, a proposta aqui apresentada mostra-se promissora para o entendimento da arquitetura do processador linguístico humano e seu modo de operação. Desdobramentos da presente proposta podem ser antevistos no contraste de previsões relativas à natureza dos processos antecipatórios, a serem exploradas tanto por metodologias da pesquisa psicolinguística quanto da neurociência cognitiva da linguagem. Futuros desenvolvimentos desse trabalho, assim, incluem (i) a avaliação da previsão de que contextos temáticos precedentes convergentes com a sentença em processamento contribuem para a emergência de processos integrativos e antecipatórios, (ii) a avaliação da previsão de que a manipulação de fatores relacionados à complexidade das circunstâncias experimentais pode facilitar ou dificultar a antecipação de referentes visuais, (iii) a conciliação da proposta apresentada com um possível mecanismo de sombreamento (Corrêa, Augusto, Longchamps e Forster, 2012), com vistas a ampliar o potencial explanatório da hipótese considerada, e (iv) a exploração entre outros pontos de articulação entre modelos de competência e desempenho linguístico ainda não explorados no âmbito do presente trabalho, como uma possível conciliação entre a distinção entre relações primárias e secundárias no âmbito de propostas estruturais de parser (Frazier e Clifton Jr., 1996) e a distinção entre pair-merge e set-merge no âmbito da proposta minimalista (Chomsky, 2001) ${ }^{64}$.

\footnotetext{
${ }^{64}$ Agradeço aos membros da banca examinadora desta tese pela sugestão de alguns dos futuros tópicos a serem investigados.
} 


\section{7 Referências bibliográficas}

ALlOPENNA, P. D.; MAGNUSON, J. S.; TANENHAUS, M. K. Tracking the time course of spoken word recognition using eye movements: evidence for continuous mapping models. Journal of Memory and Language, v. 38, p. 419439, 1998.

ALTMANN, G. Modularity and Interaction in Sentence Processing. In: GARFIELD, J. L. (Ed.). Modularity in knowledge representation and natural language understanding. Cambridge: MIT Press, 1987.

History of Psycholinguistics. In: Brown, K. (Ed.). The Encyclopedia of Language and Linguistics. Elsevier, 2006.

ALTMANN, G.; KAMIDE, Y. Incremental interpretation at verbs: restricting the domain of subsequent reference. Cognition, v. 73, p. 247-264, 1999.

ALTMANN, G.; KAMIDE, Y. Now you see it, now you don't: mediating the mapping between language and the visual world. In: HENDERSON, J.; FERREIRA, F. (Eds.). The integration of language, vision and action. Psychology Press, 2004, p. 347-386.

ALTMANN, G.; KAMIDE, Y. The real-time mediation of visual attention by language and world knowledge: Linking anticipatory (and other) eye movements to linguistic processing. Journal of Memory and Language, v. 57, p. 502-518, 2007.

ALTMANN, G.T.M.; STEEDMAN, M. J. Interaction with context during human sentence processing. Cognition, v. 30, p. 191-238, 1988.

ALTMANN, G. T. M.; VAN NICE, K. Y.; GARNHAM, A.; HENSTRA, J. Late closure in context. Journal of Memory and Language, v. 38, p. $459-484,1998$.

AOSHIMA, S.; PHILlIPS, C.; WEINBERG, A. Processing filler-gap dependencies in a headfinal language. Journal of Memory and Language, v. 51, p. 23-54, 2004.

AUGUSTO, M. R. A.; CORREAA, L. M. S.; FORSTER, R. An argument for DPs as phases in an integrated model of on-line computation: the immediate mapping of complex DPs with relative clauses. Revista Virtual de Estudos da Linguagem - ReVEL, v. 10, n. 06, 7-26, 2012.

BADECKER, W.; LEWIS, R. A new theory and computational model of working memory in sentence production: agreement errors as failures of cue-based retrieval. 20 $^{\text {th }}$ Annual CUNY Conference on Human Sentence Processing, La Jolla, CA, 2007.

BALLARD, D. H.; HAYHOE, M. M.; POOK, P. K.; RAO, R. P. N. Deictic codes for the embodiment of cognition. Behavioral and Brain Sciences, v. 20, p. 723$767,1997$. 
BAR, M. Visual objects in context. Nature Reviews Neuroscience, 2004.

BARRETT, C. H.; KURZBAN, R. Modularity in cognition: Framing the debate. Psychological Review, v. 113, p. 628-647, 2006.

BARTON, E. G.; BERWICK, R. C. Parsing with Assertion Sets and Information Monotonicity. In: INTERNATIONAL JOINT CONFERENCE ON ARTIFICIAL INTELLIGENCE, 9, 1985, Los Angeles, CA. Proceedings... Los Angeles: 1985.

BEVER, T. G. The cognitive basis for linguistic structures. In: HAYES, J. R. (Ed.). Cognition and the development of language. New York: Wiley, 1970, p. 279-362.

BEVER, T. G.; POEPPEL, D. Analysis by Synthesis: a (re-)emerging program of research for language and vision. Biolinguistics, v. 4, p. 174-200, 2010.

BINDER, J. R.; FROST, J. A; HAMMEKE, T. A.; COX, R. W.; RAO, S.M.; PRIETO, T. Human brain language areas identified by functional magnetic resonance imaging. The Journal of Neuroscience, v. 17, n.1, p. 353-362, 1997.

BOLAND, J. D.; TANENHAUS, M. K.; GARNSEY, S. M.; CARLSON, G. N. Verb argument structure in parsing and interpretation: Evidence from whquestions. Journal of Memory and Language, v. 34, p. 774-806, 1995.

BRANIGAN, H. P.; PICKERING, M. J.; LIVERSEDGE, S. P.; STEWART, A. J.; URBACH, T. P. Syntactic priming: Investigating the mental representation of language. Journal of Psycholinguistic Research, v. 24, p. 489-506. 1995.

BROWN, C; HAGOORT, P. On the electrophysiology of sentence comprehension: Implications for the human language system. In: CROCKER, M. W.; PICKERING, M. J.; CLIFTON JR, C. (Ed.). Architectures and Mechanisms for Sentence Processing. Cambridge: Cambidge University Press, 2000, p. 213-237.

BRUCE, V.; GREEN, P. R.; GEORGESON, M. Visual Perception: Physiology, Psychology and Ecology. New York: Psychology Press, 2003.

BRYSBAERT, M.; MITCHELL, D.C. Modifier attachment in sentence parsing: Evidence from Dutch. Quarterly Journal of Experimental Psychology, v. 49A, p. 664-695, 1996.

BRYSBAERT, M.; MITCHELL, D. C. The failure to use gender information in parsing: A comment on van Berkum, Brown, and Hagoort (1999). Journal of Psycholinguistic Research, v. 29, p. 453-466, 2000.

BUBIC, A.; VON CRAMON, D. Y.; SCHUBOTZ, R. I. Prediction, cognition and the brain. Frontiers in Human Neuroscience, v. 4, 2010.

CANÇADO, M.; MOREIRA, C.; SILVA, E.; BERG, M. A Proposta de Franchi: teoria generalizada dos papéis temáticos. Estudos Linguísticos, v. 31, 2002.

CAPLAN, D.; ALPERT, N.; WATERS, G.; OLIVIERI, A. Activation of Broca's area by syntactic processing under conditions of concurrent articulation. Human Brain Mapping, v. 9, n. 2, p. 65-71, 2000.

CAPLAN, D.; VIJAYAN, S.; KUPERBERG, G.; WEST, C.; WATERS, G.; GREVE, D.; DALE, A. M. Vascular responses to syntactic processing: Eventrelated fMRI study of relative clauses. Human brain mapping, v. 15, n.1, p. 2638, 2002. 
CARAMAZZA, A; ZURIF, E. B. Dissociation of Algorithmic and Heuristic Processes in Language Comprehension: Evidence from Aphasia. Brain and Language. v.3, n.4, p. 572-82, 1976.

CARNIE, A.; BARSS, A. Phases and Nominal Interpretation. Research in Language, v. 4, p. 127-132, 2006.

CARRUTHERS, P. The Architecture of the Mind. Oxford: Oxford University Press, 2006.

Simple heuristics meet massive modularity. In: CARRUTHERS, P.; LAURENCE, S.; STICH, S.P. The Innate Mind: Culture and Cognition. Oxford University Press, 2006 b.

CHANG, F.; BOCK, K.; GOLDBERG, A. E. Can thematic roles leave traces of their places? Cognition,v. 90, p. 29-49, 2003.

CHRISTIANSON, K.; HOLLINGWORTH, A.; HALLIWELL, J.; FERREIRA, F. Thematic roles assigned along the garden-path linger. Cognitive Psychology, v. 42, p. 368-407, 2001.

CHOMSKY, N.. Syntactic Structures. The Hague: Mouton, 1957.

. Aspects of the theory of syntax. Cambridge, MA: MIT Press, 1965.

The minimalist program. Cambridge, MA: MIT Press, 1995.

. Derivation by Phase. MIT Working Papers in Linguistics, 1999.

. Beyond explanatory adequacy. MIT working papers in linguistics, 2001.

. On phases. Mass: MIT Press. 2005.

Of minds and Language. Biolinguistics, v.1, 2007.

CHOMSKY, N.; MILLER, G. A. Introduction to the formal analysis of natural languages. In: LUCE, R. D.; BUSH, R. R.; GALANTER, E. (Ed.). Handbook of mathematical psychology, v. 2. New York: Wiley, 1963, p. 269-321.

CLIFTON C. JR.; DUFFY, SA. Sentence and text comprehension: roles of linguistic structure. Annual Review of Psychology. v. 52, p.167-96, 2001.

COHEN, L.; MEHLER, J. Click monitoring revisited: an on-line study of sentence comprehension. Memory and Cognition, v. 24, p. 94-102, 1996.

COLHEART, M. Modularity and cognition. Trends in Cognitive Sciences, v.3, n.3, 1999 .

CORRÊA, L. M. S. An alternative account of children's comprehension of relative clauses. Journal of Psycholinguistic Research, v. 24, p. 183-203, 1995a.

The Relative Difficulty of Children's Comprehension of Relative Clauses: A Procedural Account. In: NELSON, K.; RĖGER, Z. (Org.). Children's Language. Hillsdale, N.Jersey: Lawrence Erlbaum Assoc., 1995b, p. 225-244.

Relação processador lingüístico-gramática em perspectiva: problema de unificação em contexto minimalista. D.E.L.T.A., v. 24, p. 231-282, 2008.

CORRÊA, L. M. S.; AUGUSTO, M. R. A. Computação linguística no processamento on-line: em que medida uma derivação minimalista pode ser incorporada em modelos de processamento? In: ENCONTRO NACIONAL DA 
ANPOLL, 21, 2006. Texto para discussão na sessão Inter-GTs (Psicolinguística e Teoria de Gramática), 2006.

CORRÊA, L. M. S.; AUGUSTO, M. R. A. Computação linguística no processamento on-line: soluções formais para a incorporação de uma derivação minimalista em modelos de processamento. Cadernos de Estudos Linguísticos, v. 49, p. 167-183, 2007.

CORRÊA, L. M. S.; AUGUSTO, M. R. A. Custo de processamento e comprometimento da linguagem: movimento sintático na computação on-line e minimalidade relativizada em orações relativas e perguntas-QU. In: CONGRESSO INTERNACIONAL DA ABRALIN, 7, 2011, Curitiba. Anais... Curitiba: 2011.

CORRÊA, L. M. S.; AUGUSTO, M. R. A. DEL-Sintático e a Hipótese do Custo de Processamento: Orações relativas na identificação de problemas de linguagem e em. In: CONGRESO INTERNACIONAL DE LA ALFAL, 16, 2011, Alcalá de Henares. Documentos... Alcalá de Henares: 2011.

CORRÊA, L. M. S.; AUGUSTO, M. R. A.; LONGCHAMPS, J.; FORSTER, R. Referência Anafórica com relativas restritivas de objeto: custo relativizado na interface gramática-pragmática. Revista Linguística, v. 8, n. 2, 2012.

COSTA, J.; LOBO, M; SILVA, C. Subject-object asymmetries in the acquisition of Portuguese relative clauses: adults vs. children. Lingua, p. 1-18, 2011.

COTRELL. G. Connectionist parsing. In: ANNUAL CONGERENCE OF THE COGNITIVE SCIENCE SOCIETY, 7, 1985. Proceedings... HiIIsdale: Erlbawn. 1985.

COULSON, S; KING, J.; KUTAS, M. Expect the unexpected: Event-related brain responses to morphosyntactic violations. Language and Cognitive Processes, v. 13, p. 493-513, 1998.

CUETOS, F.; MITCHEL, D. C. Cross-linguistic differences in parsing. Restrictions on the use of Late Closure strategy in Spanish. Cognition, v. 30, p. 73-105, 1988.

CUETOS, F.; MITCHEL, D. C.; CORLEY, M. M. B. Parsing in different languages. In: CARREIRAS, M.; GARCIA-ÁLBEA, J.; GALLÉS, S. Languages processing in Spanish. Mahwah, NJ: Lawrence Erlbaum, 1996.

DAHAN, D.; MAGNUSON, J. S.; TANENHAUS, M. K. Time course of frequency effects in spoken word recognition: evidence from eye movements. Cognitive Psychology, v. 42, p. 317-367. 2001.

De ALMEIDA, R. Looking for objects of verbs in true scenes: linguistic and visual context effects. In: WORKSHOP DE RASTREAMENTO OCULAR DO LAPAL, 2012. Slides do... Rio de Janeiro. Rio de Janeiro: 2012.

DELONG, K.; URBACH, T. P.; KUTAS, M. Probabilistic word pre-activation during language comprehension inferred from electrical brain activity. Nature Neuroscience, v. 8, p. 1117-1121, 2005.

DEMBERG, V.; KELLER, F. Data from eye-tracking corpora as evidence for theories of syntactic processing complexity. Cognition, v. 109, 2008. 
DEUBEL, H.; SCHNEIDER, W. X. Saccade target selection and object recognition: Evidence for a common attentional mechanism. Vision Research, v. 36, p. 1993-1997. 1996.

Di NARDO, J. Eye movements as a function of spoken sentence comprehension and scene perception. Dissertação (Master of Arts Psychology) - Concordia University, Montreal, Quebec, Canadá, 2005.

Building event meanings from linguistic and visual representations: evidence from eye movements. Tese (Doutorado em Psicologia) - Departament of Psychology, Concordia University, Montreal, Quebec, Canadá, 2011.

DISNER, S. G.; BEEVERS, C.; HAIGH, E. A. P.; BECK, A. T. Neural mechanisms of the cognitive model of depression. Nature Reviews: Neuroscience, v. 12, p. 467-477. 2010.

DUCHOWSKY, A. Eye-tracking methodology: theory and practice. [S.1.]: Springer, 2007.

EDWARDS, D. C.; GOOLKASIAN, P. A. Peripheral vision location and kinds of complex processing. Journal of Experimental Psychology, v. 102, p. 244-249. 1974.

ELMAN, J. L.; MCCLELLAND, J. L. Speech perception as a cognitive process: The interactive activation model. In: LASS, N. (Ed.). Speech and Language. New York: Academic Press, 1984.

ERICSSON, K. A.; KINTSCH, W. Long-term working memory. Psychological Review. v. 102, p. 211-245, 1995.

ELSABBAGH, M.; KARMILOFF-SMITH, A. Modularity of mind and language. In: BROWN, K. (Ed.). The Encyclopedia of Language and Linguistics. Oxford: Elsevier, 2004.

FEDORENKO, E; PIANTADOSI, S. T.; GIBSON, E. The interaction of syntactic and lexical information sources in language processing: The case of the noun-verb ambiguity. Journal of Cognitive Science, 2012.

FERREIRA, F. Syntax in language production: an approach using tree-adjoining grammars. In: WHEELDON, L. (Ed.). Aspects of language production. Cambridge: MIT Press, 2000, p. 291-330.

. The misinterpretation of noncanonical sentences. Cognitive Psychology, v. 47, p. 164-203, 2003.

review, 2005.

Psycholinguistics, formal grammars, and cognitive science. Linguistic

FERREIRA, F.; BAILEY, K. G. D; FERRARO, V. Good-Enough representations in language comprehension. Current Directions in Psychological Science, v. 11, p. 11-5, 2002.

FERREIRA, F.; CHRISTIANSON, K.; HOLLINGWORTH, A. Misinterpretations of garden-path sentences: implications for models of sentence processing and reanalysis. Journal of Psycholinguistic Research, v. 30, n. 1, p. 3-20, 2001.

FERREIRA, F.; ENGELHARDT, P. E.; JONES, M. W. Good enough language processing: A satisficing approach. In: TAATGEN, Y.; RIJN, H.; NERBONNE, 
J.; SCHOMAKER, L. (Ed.). Proceedings of the 31st Annual conference of the Cognitive Science Society. Austin, TX: Cognitive Science Society, 2009.

FERREIRA, F.; PATSON, N. The good enough approach to language comprehension. Language and Linguistics Compass, v. 1, p. 71-83, 2007.

FERREIRA, F.; TANENHAUS, M. K. Introduction to special issue on languagevision interactions. Journal of Memory and Language, v. 57, p. 455-459, 2007.

FERRETTI, T. R.; MCRAE, K.; HATHERELL, A. Integrating verbs, situation schemas and thematic role concepts. Journal of Memory and Language, v. 44, p. 516-547, 2011.

FINDLAY, J. M. Eye scanning and visual search. In: HENDERSON J. M.; FERREIRA, F. The interface language, vision and action: eye movements and the visual world. Nova Iorque: Psychology Press, 2004.

FINDLAY, J.; WALKER, R. Human saccadic eye movements. Scholarpedia. 2011. Disponível em: <http://www.scholarpedia.org/w/index.php?title=Human saccadic_eye_movements\&action=cite\&rev=122018. Acesso em: set. 2012.

FODOR, J. Modularity of mind. Cambridge, MA: MIT Press, 1983. 2000 .

A. The Mind Doesn't Work That Way. Cambridge, MA: MIT Press,

FODOR, J.; BEVER, T.; GARRETT, M. The psychology of language. New York: McGraw Hill, 1974.

FODOR, J.; GARRETT, M. Some syntactic determinants of sentential complexity. Perception and Pychophysics, v. 2, p. 289-296, 1967.

FODOR, J. A.; PYLYSHYN, Z. Connectionism and cognitive architecture: A critical analysis. Cognition, v. 28, p. 3-71, 1988.

FODOR, J. D. Empty categories in sentence processing: A question of visibility. In: ALTMANN, G; SHILLCOCK, R. (Eds.). Cognitive models of speech processing: The Sperlonga Meeting II. Hove, England: Erlbaum, 1993.

Prosodic disambiguation in silent reading. In: HIROTANI, M. (Ed.). Proceedings of the North East Linguistic Society 32. Amherst: University of Massachusetts, 2002a.

Psycholinguistics cannot escape prosody. In: SPEECH PROSODY CONFERENCE, 2002, Aix-en-Provence, França. Proceedings... 2002b.

FONG, S. Computation with Probes and Goals: A Parsing Perspective. In: Di SCIULLO, A.; DELMONTE, R. (Eds.). UG and External Systems. Amsterdam: John Benjamins, 2005.

FORSTER, R. Morfologia flexional, sentenças complexas e não canônicas na produção de afásicos não fluentes. Dissertação (Mestrado em Letras) - Instituto de Letras, Universidade do Estado do Rio de Janeiro. Rio de Janeiro, 2008.

FRAZIER, L. Sentence Processing: A tutorial review. In: COLTHEART, M. (Ed.). Attention and performance XII: The psychology of reading. Hillsdale, NJ: Lawrence Erlbaum Associates, 1987, p. 559-586. 
. Theories of sentence processing. In: GARFIELD, J. (Ed.). Modularity in Knowledge Representation and Natural-Language Processing. Cambridge: MIT Press, 1987b, p. 291-307.

FRAZIER, L.; CLIFTON, JR, C. Construal. Cambridge, MA: MIT Press, 1996.

FRAZIER, L.; FLORES D'ARCAIS, F. G. Filler-Driven Parsing: A Study of GapFilling in Dutch. Journal of Memory and Language, v. 28, p. 331-344, 1989.

FRAZIER, L.; FODOR, J. D. The Sausage machine: A new two-stage parsing model. Cognition, p. 291-235. 1978.

FRAZIER, L.; RAYNER, K. Making and correcting errors during sentence comprehension: Eye movements in analysis of structurally ambiguous sentences. Cognitive Psychology, v. 14, p. 178-210, 1982.

FRIEDMANN, N.; BELLETTI, A.; RIZZI, L. Relativized relatives: Types of intervention in the acquisition of A-bar dependencies. Lingua, v.119, p. 67-88, 2009.

FRIEDMANN, N.; GRODZINSKY, Y. Tense and agreement in agrammatic production: pruning the syntactic tree. Brain and Language, n. 56, p. 397-425, 1997.

FRIEDMANN, N.; NOVOGRODSKY, R. The acquisition of relative clause comprehension in Hebrew: A study of SLI and normal development. Journal of Child Language, v. 31, p. 661-681, 2004.

FRY, D. The linguistic evidence of speech errors. BRNO Studies of English, v. 8, p. 69-74, 1969.

GARNSEY, S. M .; TANENHAUS, M . K ; CHAPMAN, R. M . Evoked potentials and the study of sentence comprehension. Journal of Psycholinguistic Research, v. 18, p.51-60, 1989.

GARRETT, M. F. Syntactic processes in sentence production. In: WALES, R. J.; WALKER, E. (Ed.). New approaches to language mechanisms. Amsterdam: North-Holland, 1976.

GERTH, Sabrina; GRABEN, Peter. (2009). Unifying syntactic theory and sentence processing difficulty through a connectionist minimalist parser. Cognitive Neurodynamics, 3(4), pp. 297-316. Manuscript

GIBSON, E. Linguistic complexity: Locality of syntactic dependencies. Cognition, v.68, p.1-76. 1998.

. The dependency locality theory: A distance-based theory of linguistic complexity. In MARANTZ, A.; MIYASHITA, Y.; O'NEIL, W. (Ed.). Image, language, brain: Papers from the first mind articulation project symposium. Cambridge, MA: MIT Press, 2000. p. 95-126.

GIBSON, E.; DESMET, T.; GRODNER, D.; WATSON, D.; KO, K. Reading Relative Clauses in English. Cognitive Linguistics, v. 16, p. 313-53, 2005.

GIBSON, E.; PEARLMUTTER, N. Distinguishing serial and parallel parsing. Journal of Psycholinguistic Research, v. 29, p. 231-240, 2000.

GIGERENZER, G.; GAISSMAIER. W. Heuristic Decision Making. Annual Review of Psychology, v. 62, p. 451-482, 2011. 
GIGERENZER, G.; SELTEN, R. (Eds.). Bounded rationality: The adaptive toolbox. Cambridge, MA: MIT Press, 2001.

GIGERENZER, G.; TODD, P. M.; THE ABC GROUP. Simple heuristics that make us smart. New York: Oxford University Press, 1999.

GILBOY, E.; SOPENA, J. M.; CLIFTON, C.; FRAZIER, L. Argument structure and association preferences in Spanish and English complex NPs. Cognition, v. 54, p. 131-167, 1995.

GLICHRIST, I. D. Saccades. In: LIVERSEDGE, S. P.; GLICHRIST, I. D.; EVERLING, S. (Ed.). The Oxford Handbook of eye movements. OUP: Oxford, 2011.

GORDON, P. C.; HENDRICK, R.; JOHNSON, M. Memory interference during language processing. Journal of Experimental Psychology: Learning, Memory, and Cognition, v. 27, 2001.

GORDON, P. C.; HENDRICK, R.; JOHNSON, M. Effects of noun phrase type on sentence complexity. Journal of Memory and Language, v. 51, 2004.

GORDON, P. C.; HENDRICK, R.; JOHNSON, M.; LEE, Y. Similarity-Based Interference During Language Comprehension: Evidence from Eye Tracking During Reading. Journal of Experimental Psychology: Learning, Memory, and Cognition, v. 32, 2006.

GORRELL, P. Syntax and Parsing. Cambridge: Cambridge University Press, 1995.

Sentence Processing. In: WILSON, R. A.; KEIL, F. C. The MIT Encyclopedia of Cognitive Sciences. Cambridge: MIT Press, 1999. p. 748-751.

GRICE, H. P. Logic and conversation. In: COLE, P.; MORGAN, J. L. (Org.). Syntax and Semantics. New York: Academic Press, 1975.

GRODNER, D.; GIBSON, E.; WATSON, D. The influence of contextual contrast on syntactic processing: Evidence for strong-interaction in sentence comprehension. Cognition, v. 95, p. 275-296, 2005.

GRODZINSKY, Y. Agrammatic Comprehension of relative Clauses. Brain and Language, v. 37, 1989.

GRODZINSKY, Y. Theoretical Perspectives on Language Deficits. Cambridge, MA: MIT Press, 1990.

GRODZINSKY, Y.; SANTI, A. The battle for Broca's region. Trends in Cognitive Sciences, v. 12, p. 474-480, 2008.

GROHMANN, K. Phases and interfaces. In: GROHMANN, K. (Ed.). InterPhases: Phase-Theoretic Investigations of Linguistic Interfaces. Oxford: Oxford University Press, 2009. p. 1-22.

GUHE, M. Incremental Conceptualization for Language Production. Lawrence Erlbaum Associates: USA, 2007.

HAGOORT, P.; Van BERKUM, J. Beyond the sentence given. Phil. Trans. R. Soc, v. 362, p. 801-811, 2007.

HALE, J. A probabilistic earley parser as a psycholinguistic model. In: MEETING OF THE NORTH AMERICAN CHAPTER OF THE ASSOCIATION 
FOR COMPUTATIONAL LINGUISTICS, 2, 2011, Pittsburgh, PA. Proceedings... Pittsburgh, PA: 2001.

HALLE, M.; STEVENS, K. Speech recognition: A model and a program for research. IRE Transactions on Information Theory, n. 8, p. 155-159, 1963.

HAUSER, M.; CHOMSKY, N.; FITCH, T. The faculty of language: what is it, who has it and how did it evolve? Science, v. 298, p. 1569-1579, 2002.

HAYHOE, M. M. Advances in relating eye movements and cognition. Infancy, v. 6, p. 267-274, 2004.

HEISER M.; IACOBONI M.; MAEDA F.; MARCUS J.; MAZZIOTTA J. C. The essential role of Broca's area in imitation. Eur J Neurosci., v. 5, p. 1123-8, 2003.

HEMFORTH, B; KONIECZNY, L.; SCHEEPERS, C. Syntactic attachment and anaphor resolution: Two sides of relative clause attachment. In: CROCKER, M.; PICKERING, M.; CLIFTON, C. (Ed.). Architecthures and Mechanisms for Language Processing. Cambridge: Cambidge University Press, 2000.

HENDERSON J. M.; FERREIRA, F. Scene perception for psycholinguists. In: (Eds.). The interface language, vision and action: eye movements and the visual world. Nova Iorque: Psychology Press, 2004.

HENDERSON, J. M.; HOLLINGWORTH, A. High-level scene perception. Annual Review of Psychology, v. 50, p. 243-271, 1999.

HILDEBRANDT, B.; EIKMEYER, H.; RICKHEIT, G.; WEIß, P. Inkrementelle Sprachrezeption. In: WACHSMUTH, I; JUNG, B. (Ed.). KogWis: Proceedings der 4. Fachtagung der Gesellschaft fur Kognitionswissenschaft. 1999.

HIRAIWA, K. Dimensions of Symmetry in Syntax. Ph.D. Dissertation Massachusetts Institute of Technology, 2005.

HUETTIG, F.; ALTMANN G. Word meaning and the control of eye fixation: semantic competitor effects and the visual world paradigm. Cognition, v. 96, p. 23-32, 2005.

IRWIN, D. E. Lexical processing during saccadic eye movements. Cognitive Psychology, v. 36, p. 1-27. 1998.

Fixation location and fixation duration as indices of cognitive processing. In: HENDERSON J. M.; FERREIRA, F. The interface language, vision and action: eye movements and the visual world. Nova Iorque: Psychology Press, 2004.

ITTI, L.; KOCH, C. A saliency-based search mechanism for overt and covertshifts of visual attention. Vision Research, v. 40, p. 1489-1506. 2000.

ITTI, L.; KOCH, C. Computational modeling of visual attention. Nature Reviews: Neuroscience, v. 2, p. 194-203. 2001

JACKENDOFF, R. Foundations of Language: Brain, Meaning, Grammar, Evolution. Oxford: Oxford University Press, 2002

A Parallel Architecture Perspective on Language Processing, Brain Research, v. 1146, p. 2- 22, 2007. 
KAMIDE, Y.; ALTMANN, G.; Haywood, S. L. The time-course of prediction in incremental sentence processing: Evidence from anticipatory eye-movements. Journal of Memory and Language, v. 49, p. 133-59, 2003.

KESS, J. F. Psycholinguistics: Psychology, linguistics, and the study of natural language. John Benjamins Publishing, 1992.

KIMBALL, J. Seven principles on surface structure parsing in natural language. Cognition, v. 2, p. 15-47. 1973.

KING, J.; JUST, M. Individual differences in syntactic processing: the role of working memory. Journal of Memory and Language, v. 30, p. 580-602, 1991.

KING, J. W.; KUTAS, M. Who Did What and When? Using Word- and ClauseLevel ERPs to Monitor Working Memory Usage in Reading. Journal of Cognitive Neuroscience, v. 7, p. 376-95, 1995.

KINTSCH, W. Comprehension: a paradigm for cognition. Cambridge, UK: Cambridge University Press, 1998.

KNOEFERLE, P.; CROCKER, M. W.; SCHEEPERS; C.; PICKERING, M. J. The influence of the immediate visual context on incremental thematic roleassignment: evidence from eye-movements in depicted events. Cognition, v. 95, p. $95-127,2005$.

KVERAGA; GHUMAN; BAR. Top-down predictions in the cognitive brain. Brain and cognition, v. 65, 2007.

LAU, E. The Predictive Nature of Language Comprehension. PhD dissertation, University of Maryland, 2009.

LEVELT, W. Speaking: From Intention to Articulation. Cambridge: The MIT Press, 1989.

LEVELT, W. Models of word production. Trends in Cognitive Sciences, vol. 3, n. $6,1999$.

LEVELT, W.; ROELOFS, A.; MEYER, A. A theory of lexical access in speech production. Behavioral and Brain Sciences, v. 22, p. 1-75, 2001.

LEVY, R. Expectation-Based syntactic comprehension. Cognition, v. 106, n. 3, p. 1126-1177, 2008.

LOURENÇO-GOMES, M. C. Efeito de comprimento do constituinte na interpretação final de orações relativas estruturalmente ambíguas: um estudo baseado na Hipótese da Prosódia Implícita. 2003. Dissertação (Mestrado em Linguística) - Faculdade de Letras, Universidade Federal do Rio de Janeiro (UFRJ), 2003.

LOVE, T.; SWINNEY, D. Coreference Processing and Levels of Analysis in Object-Relative Constructions: Demonstration of Antecedent Reactivation with the Cross-Modal Priming Paradigm. Journal of Psycholinguistic Research, v. 25, 1996.

MACDONALD; PEARLMUTTER; SEIDENBERG. Lexical Nature of Syntactic ambiguity resolution. Psychological Review, v. 10, p. 676-703, 1994. 
MAESS, B.; KOELSCH, S.; GUNTER, T. C.; FRIEDERICI, A. D. Musical syntax is processed in Broca's area: An MEG study. Nature Neuroscience, v. 4, p. 540-545, 2001.

MAIA, M. Gramática e Parser. In: CONGRESSO INTERNACIONAL DA ABRALIN, 2, 2001, Fortaleza. Anais... Fortaleza: Imprensa Universitária UFC, 2001. p. 188-192.

Processos bottom-up e top-down no rastreamento ocular de imagens. Revista Veredas, v. 2, p. 1-15, 2008.

MAIA, M.; COSTA, A.; FERNÁNDEZ, E.; LOURENÇO-GOMES, M. do C. A compreensão de orações relativas ambíguas em português brasileiro e europeu: um estudo comparativo. Revista da ABRALIN, v. 3, p. 11-39, 2005.

MAIA, M.; FERNÁNDEZ, E.; COSTA, A.; LOURENÇO-GOMES, M. Early and late preferences in relative clause attachment in Portuguese and Spanish. Journal of Portuguese Linguistics, v. 6, n. 1, p. 227-250, 2007.

MAK, W. M.; VONK, W.; SCHRIEFERS, H. The Influence of Animacy on Relative Clause Processing. Journal of Memory and Language, v. 47, p. 50-68, 2002.

MAK, W. M.; VONK, W.; SCHRIEFERS, H. Animacy in processing relative clauses: The hikers that rocks crush. Journal of Memory and Language, v. 54, p. 466-490, 2006.

MARCUS, M. A theory of syntactic recognition for natural language. Tese (Doutorado) - Department of Electrical Engineering and Computer Sciences, Massachusetts Institute of Technology, 1978.

MARCUS; MITCHELL P.; DONALD; FLECK. D-theory: Talking about talking about trees. In: ANNUAL MEETING ON ASSOCIATION FOR COMPUTATIONAL LINGUISTICS. ASSOCIATION FOR COMPUTATIONAL LINGUISTICS, 21, 1983. Proceedings of... 1983.

MARSLEN-WILSON, W.; TYLER, L. K. Againist Modularity. In: GARFIELD, J. L. (Ed.). Modularity in Knowledge Representation and Natural-Language. The MIT Press, 1991.

MARTINEZ-CONDE, S.; MACKNIK, S. L.; HUBEL, D. H. The role of fixational eye movements in visual perception. Nature Reviews Neuroscience, v. 5, p. 229-240. 2004.

MATIN, E.; SHAO, K.; BOFF, K. Saccadic overhead: information processing time with and without saccades. Perception \& Psychophysics, v. 53, p. 372-380. 1993.

MCCAULEY, R. N.; HENRICH, J. Susceptibility to the Müller-illusion, theoryneutral observation, and the diachronic penetrability visual input system. Philosophical Psychology, v. 19, p. 79-101, 2006.

MCCLAMROCK, R. Modularity. In: NADEL, L. (Ed.). The Encyclopedia of Cognitive Science. Nature Publishing Group, 2003.

MCCLELLAND, J. L.; ELMAN, J. L. The TRACE model of speech perception. Cognitive Psychology, v. 18, p. 1-86, 1986. 
MCCLELLAND, J. L.; KAWAMOTO, A. H. Mechanisms of sentence processing: Assigning roles to constituents of sentences. In: McClelland, J. L.; Rumelhart, D. E. (Eds.). Parallel Distributed Processing. Explorations in the Microstructure of Cognition. Cambridge, Mass.: MIT Press, 1986.

MCGURK, H.; MACDONALD, J. Hearing lips and seeing voices. Nature, v. 264, p. 746-748, 1976.

MCRAE, K.; HARE, M.; FERRETTI, T. R.; ELMAN, J. L. Activating verbs typical agents, patients, instruments, and locations via event schemas. In: ANNUAL CONFERENCE OF THE COGNITIVE SCIENCE SOCIETY, 23, 2001. Proceedings... Mahwah, NJ: Erlbaum, 2001.

MCRAE, K.; MATSUKI, K. Constraint-based Models of Sentence Processing. In VAN GOMPEL, R. (Ed.). Sentence Processing. Psychology Press, 2012.

MECKLINGER, A.; SCHRIEFERS, H.; STEINHAUER, K.; FRIEDERICI, A. D. Processing relative clauses varying on syntactic and semantic dimensions: An analysis with event-related potentials. Memory \& Cognition, v. 23, n. 4, p. 477494, 1995.

MITCHELL, D. C.; CUETOS, F.; ZAGAR, D. Reading in different languages: Is there a universal mechanism for parsing sentences? In: BALOTA, D.; FLORES D'ARCAIS, G. B.; RAYNER, K. (Eds.). Comprehension processes in reading. Hillsdale, N.J.: Erlbaum, 1990, p. 285-302.

MIYAMOTO, E. T. Relative clause attachment in Brazilian Portuguese. Cambridge, MA: Massachussets Institute of Technology, 1999. Manuscrito não publicado.

MIYATA, Y.; SMOLENSKY, P.; LEGENDRE, G. Distributed representation and parallel processing of recursive structures. In: ANNUAL CONFERENCE OF THE COGNITIVE SCIENCE SOCIETY, 15, 1993, Boulder. Proceedings of the... Boulder: 1993.

NEWCOMBE, N .S.; RATLIFF, K. R.; SHALLCROSS, W.; TWYMAN, A. Is cognitive modularity necessary in an evolutionary account of development? In: TOMMASI, L.; NADEL, L.; PETERSON, M. A. (Eds.). Cognitive biology: Evolutionary and developmental perspectives on mind, brain and behavior, Vienna Series in Theoretical Biology (pp. 105-126). Cambridge, MA: The MIT Press. (2009).

NIEUWLAND, M. S.; VAN BERKUM, J. J. A. When peanuts fall in love: N400 evidence for the power of discourse. Journal of Cognitive Neuroscience, v. 18, p. 1098-1111, 2006.

OMAKI, A.; LAU, E.; WHITE, I. D.; PHILLIPS, C. Hyper-Active Gap-Filling: Pre-Verbal Object Gap Creation in English Filler-Gap Dependency Processing. Pôster apresentado no Congresso da AMLaP 2010, York, UK, 2010.

ONNIS, L.; CHRISTIANSEN, M.; CHATER, N. Connectionist models of language processing. In: SQUIRE, L. (Ed.). The New Encyclopedia of Neuroscience. Elsevier, 2008.

O'REGAN, J. K. Solving the 'real' mysteries of visual perception: the world as an outside memory. Canadian Journal of Psychology, v. 46, p. 461-488, 1992. 
OTTEN, M.; NIEUWLAND, M. S.; VAN BERKUM, J. J. A. Great expectations: Specific lexical anticipation influences the processing of spoken language. BMC neuroscience, v. 8, 2007.

PAPADOPOULOU, D. Cross-linguistic variation in sentence processing: evidence from RC attachment preferences in greek. Dordrecht, The Netherlands: Springer, 2006.

PATSON, N. D.; SWENSEN, N. M.; FERREIRA, F. Individual differences in syntactic reanalysis. Poster apresentado no Annual CUNY Conference on Human Sentence Processing. New York, 2006.

PEARLMUTTER, N. J.; MENDELSOHN, A. Serial versus parallel sentence comprehension, 1999. Manuscrito não publicado.

PHILLIPS, C. Order and Structure. PhD. dissertation, MIT, 1996.

Linear order and constituency. Linguistic Inquiry, v. 34, 2003.

PICKERING, M. J.; CLIFTON JR., C.; CROCKER, M. W. Architectures and Mechanisms in Sentence Comprehension. In: CROCKER, M. W.; PICKERING, M. J.; CLIFTON JR., C. (Ed.). Architectures and Mechanisms for Language Processing. Cambridge: Cambidge University Press, 2000, p. 2-28.

PICKERING, M. J.; GARROD, S. Do people use language production to make predictions during comprehension? Trends in Cognitive Sciences, v. 11, p. 105$110,2007$.

PICKERING, M. J.; TRAXLER, M. J. Evidence against the use of subcategorisation frequency in the processing of unbounded dependencies. Language and Cognitive Processes, v. 18, n. 4, p. 469-503, 2003.

PICKERING, M. J.; TRAXLER, M. J. Strategies for processing unbounded dependencies: Lexical information and verb-argument assignment. Journal of Experimental Psychology, v. 27, p. 1401-1410, 2001.

PINKER, S. How the Mind Works. New York: Norton, 1997.

. Words and Rules. New York: Harper Perennial, 1999.

PINKER, S.; PRINCE, A. On language and connectionism: Analysis of a parallel distributed processing model of language acquisition. Cognition, v. 28, p. 73-193, 1988.

PRINZ, J. J. Is the mind really modular? In: STAINTON, R. (Ed.). Contemporary Debates in Cognitive Science. Oxford: Blackwell, 2006, p. 2236.

RAYNER, K.; CARLSON, M.; FRAZIER, L. The interaction of syntax and semantics during sentence processing: Eye movements in the analysis of semantically biased sentences. Journal of Verbal Learning and Verbal Behavior, v. 22, p. 358-374, 1983.

RAYNER, K.; CASTELHANO, M. Eye-movements. In: Scholarpedia. 2007. Disponível em: <http://www.scholarpedia.org/article/Eye_movements $>$. Acesso em: 4 jun. 2010.

RAYNER, K.; POLLATSEK, A. The psychology of reading. Prentice-Hall, Erlbaum, 1989. 
RIBEIRO, A. J. A abordagem Good-Enough e o processamento de frases do PB. In: Encontro Nacional da ANPOLL, 23, 2008, Goiânia. Caderno de resumos... Goiânia, 2008.

RICHARDSON, D.; DALE, R.; SPIVEY, M. Eye movements in language and cognition: A brief introduction. In: GONZALEZ-MARQUEZ, M.; MITTELBERG, I.; COULSON, A.; SPIVEY, M. (Eds.). Methods in cognitive linguistics. [S.1.]: John Benjamins, 2007.

RICHARDSON, D.; SPIVEY, M. J. Eye-tracking: characteristics and methods. In: WNEK, G.; BOWLING, G. (Eds.). Encyclopedia of biomaterials and biomedical engineering. Nova Iorque: Informa Healthcare, 2004.

RIZZI, L. Relativized Minimality. Cambridge: MIT Press, 1990.

RIZZOLATTI, G.; FOGASSI, L.; GALLESE, V. Neurophysiological mechanisms underlying the understanding and imitation of action. Nature Reviews Neuroscience, p. 661-670, 2001.

ROHDE, H.; LEVY, R.; KEHLER, A. Anticipating Explanations in Relative Clause Processing. Cognition, v. 11, p. 339-358, 2011.

RUMELHART, D. E.; MCCLELLAND, J. L.; PDP research group. Parallel distributed processing: Explorations in the microstructure of cognition. Cambridge, MA: MIT Press, 1986.

SACHS, J. S. Recognition memory for syntactic and semantic aspects of connected discourse. Perception and Psychophysics, v. 2, p. 437-442, 1967.

SHALOM, D. B.; POEPPEL, D. Functional Anatomic Models of Language: Assembling the Pieces. Neuroscientist, v. 14, 2008.

SHELDON, A. The Role of Parallel Function in the Acquisition of Relative Clauses in English. Journal of Verbal Learning and Verbal Behavior, 1974.

SMALL, S.; COTTRELL, G.; SHASTRI, L., Toward Connectionist Parsing. In: NATIONAL CONFERENCE ON ARTIFICIAL INTELLIGENCE, 1982. Proceedings of the... Pittsburgh: 1982.

SNIDER, N.; RUNNER, J. Structural Parallelism aids ellipsis and anaphora resolution: evidence from eye-tracking. In: Annual Conference on Architectures and Mechanisms for Language Processing, 16, 2010, York (UK). Abstracts... York: University of York, 2010. p. 25.

SPIVEY, M. J.; TANENHAUS, M. K. Syntactic ambiguity resolution in discourse: Modeling the effects of referential context and lexical frequency. Journal of Experimental Psychology: Learning, Memory and Cognition, v. 24, p. 1521-1543, 1998.

SPIVEY, M. J.; TANENHAUS, M. K.; EBERHARD, K. E.; SEDIVY, J. C. Eye movements and spoken language comprehension: Effects of visual context on syntactic ambiguity resolution. Cognitive Psychology, 2000.

STAUB, A. The parser doesn't ignore intransitivity, after all. Journal of Experimental Psychology: Learning, Memory, and Cognition, v. 33, n. 3, p. 55069, 2007. 
STEVENSON, S. Competition and recency in a hybrid network model of syntactic disambiguation. Journal of Psycholinguistic Research, v. 23, p. 295322, 1994.

STEVENSON, S.; MERLO, P. Lexical Structure and Parsing Complexity. Language and Cognitive Processes, v. 12, 1997.

STOWE, L. A. Parsing WH-constructions: Evidence for online gap location. Language and Cognitive Processes, n.1, p. 227-245, 1986.

SVENONIUS. On the Edge. In: ADGER; CAT; TSOULAS. Syntactic Edges and their Effects. Dordrecht: Kluwer, 2004.

SZEWCZYK, J. Anticipating animacy? An event-related brain potentials study of grammatic and semantic integration in Polish sentence reading. In: ANNUAL MEETING OF THE SOCIETY FOR PSYCHOPHYSIOLOGICAL RESEARCH, 2006, Vancouver. Abstracts... Vancouver: 2006.

TANENHAUS, M. K.; MAGNUSON, J. W.; DAHAN, D.; CHAMBERS, C. Eye movements and lexical access in spoken-language comprehension: evaluating a linking hypothesis between fixations and linguistic processing. Journal of psycholinguistic research, v. 29, p. 557-580, 2000.

TANENHAUS, M. K.; SPIVEY-KNOWLTON, M. J.; EBERHARD, K. M.; SEDIVY, J. E. Integration of visual and linguistic information in spoken language comprehension. Science, v. 268, p. 1632-1634, 1995.

THEEUWES, J.; KRAMER, A. F.; HAHN, S.; IRWIN, D. E. Our eyes do not always go where we want them to go: Capture of the eyes by new objects. Psychological Science, v. 9, p. 379-385. 1998.

THOTHATHIRI M, SNEDEKER J. The role of thematic roles in sentence processing: evidence from structural priming in young children. [Internet]. In Press. Disponível em: <http://www.wjh.harvard.edu/ lds/pdfs/Thothathiri\%20 $\& \% 20$ Snedeker\%20under\%20review.pdf $>$

TOWNSEND, D. J.; BEVER, T. G. Sentence Comprehension: The Integration of Habits and Rules. MIT Press, 2001.

TRAXLER, M.; MORRIS, R.; SEELY, R. Processing Subject and object relative clauses: evidence from eye movements. Journal of Memory and Language, $v$. 47, p. 69-90, 2002.

TRUESWELL, J. C.; SEKERINA, I.; HILL, N. M.; LOGRIP, M. L. The kindergarten-path effect: studying on-line sentence processing in young children. Cognition, v. 73, p. 89-134, 1999.

TRUESWELL, J. C.; TANENHAUS M. K. Consulting temporal context during sentence comprehension: evidence from the monitoring of eye movements in reading. In: ANNU. CONF. COGN. SCI. SOC., 1992. Abstracts... 1992.

TRUESWELL, J. C.; TANENHAUS, M. K. Toward a lexicalist framework for constraint-based syntactic ambiguity resolution. In: CLIFTON; FRAZIER; RAYNER (Ed.). Perspectives on Sentence Processing. Hillsdale, NJ: LEA Press, 1994, p. 155-179. 
TRUESWELL, J. C.; TANENHAUS, M. K.; GARNSEY, S. Semantic influences on parsing: Use of thematic role information in syntactic disambiguation. Journal of Memory and Language, v. 33, p. 285-318. 1994.

URIAGEREKA, J. Multiple spell-out. In: EPSTEIN, S. D; HORNSTEIN, N. (Ed.). Working minimalism. Cambridge, MA: MIT Press, 1999, p. 251- 282.

VAN BERKUM, J. J. A.; BROWN, C. M.; HAGOORT, P. Early referential context effects in sentence processing: Evidence from event-related brain potentials. Journal of Memory and Language, v. 41, p. 147-182, 1999a.

VAN BERKUM, J. J. A.; BROWN, C. M.; ZWITSERLOOD, P.; KOOIJMAN, V.; HAGOORT, P. Anticipating upcoming words in discourse: Evidence from ERPs and reading times. Journal of Experimental Psychology: Learning, Memory, and Cognition, v. 31, p. 443-467, 2005.

VAN BERKUM; HAAGOORT; BROWN. The use of referential context and grammatical gender in parsing: a reply to Brysbaert and Mitchell (2000). Journal of Psycholinguistic Research, v. 29, n. 5, 2000.

VAN BERKUM, J. J.; ZWITSERLOOD, P.; HAGOORT, P.; BROWN, C. M. When and how do listeners relate a sentence. to the wider discourse? Evidence from the N400 effect. Cognitive Brain Research, v. 17, p. 701-718, 2003.

VASISHTH, S. Quantifying processing difficulty in human sentence parsing: The role of decay, activation, and similarity-based interference. In: EUROCOGSCI CONFERENCE, 2003, Osnabrueck, Germany. Proceedings of the... Osnabrueck, 2003.

VILLARINHO, C. A seleção de pacientes em estudos linguísticos sobre o agramatismo e a afasia de Broca: problemas e soluções para o debate sobre estudos de caso e de grupo. Dissertação (Mestrado em Letras) - Instituto de Letras, Universidade do Estado do Rio de Janeiro, Rio de Janeiro, 2008.

WAGERS, M. W., LAU, E., \& PHILLIPS, C. Agreement attraction in comprehension: representations and processes. Journal of Memory and Language, 2009.

WAGERS, M. W.; PHILLIPS, C. J. Multiple dependencies and the role of the grammar in real-time comprehension. Linguistics, v. 45, p. 395-433, 2009.

WANNER, E.; MARATSOS, M. An ATN approach to comprehension. In: M. HALLE, J.; BRESNAN, G.; A. MILLER (Ed.). Linguistic Theory and Psychological Reality. Cambridge, MA: MITPress, 1978, p. 119-161.

WARREN, T.; GIBSON, E. The influence of referential processing on sentence complexity. Cognition, v. 85, p. 79-112, 2002.

WARREN, T.; GIBSON, E. Effects of NP type in reading cleft sentences in English. Language and Cognitive Processes, v. 20, 2005.

WEINBERG, A. Parameters in the theory of sentence processing: Minimal commitment theory goes East. Journal of Psycholinguistic Research, v. 22, p. 339-364, 1993.

A Minimalist Theory of Human Sentence Processing. In: EPSTEIN, S.; HORNSTEIN, N. (Ed.). Working Minimalism. Cambridge, Mass.: MIT Press, 1999. 
WICHA, N. Y. Y.; BATES, E. A.; MORENO, E. M.; KUTAS, M. Potato not Pope: human brain potentials to gender expectation and agreement in Spanish spoken sentences. Neuroscience letters, v. 346, p. 165-168, 2003.

WICHA, N. Y. Y.; MORENO, E. M.; KUTAS, M. Anticipating Words and Their Gender: An Event-related Brain Potential Study of Semantic Integration, Gender Expectancy, and Gender Agreement in Spanish Sentence Reading. Journal of Cognitive Neuroscience, v. 16, p. 1272-1288, 2004.

WUNDT, W. Grundzüge der physiologischen Psychologie. Leipzig: Engelmann, 1893. 


\section{Apêndice A: \\ Estímulos experimentais dos experimentos 1 e 2}

Os estímulos apresentados a seguir dizem respeito ao experimento 2. No experimento 1, foram utilizados os mesmos estímulos visuais, só que sem o terceiro slide da sequência experimental, de forma que a sentença experimental e a interrogativa foram apresentadas concomitantemente ao segundo slide, no lugar das sentenças declarativas ${ }^{65}$.

\section{Condição 1}
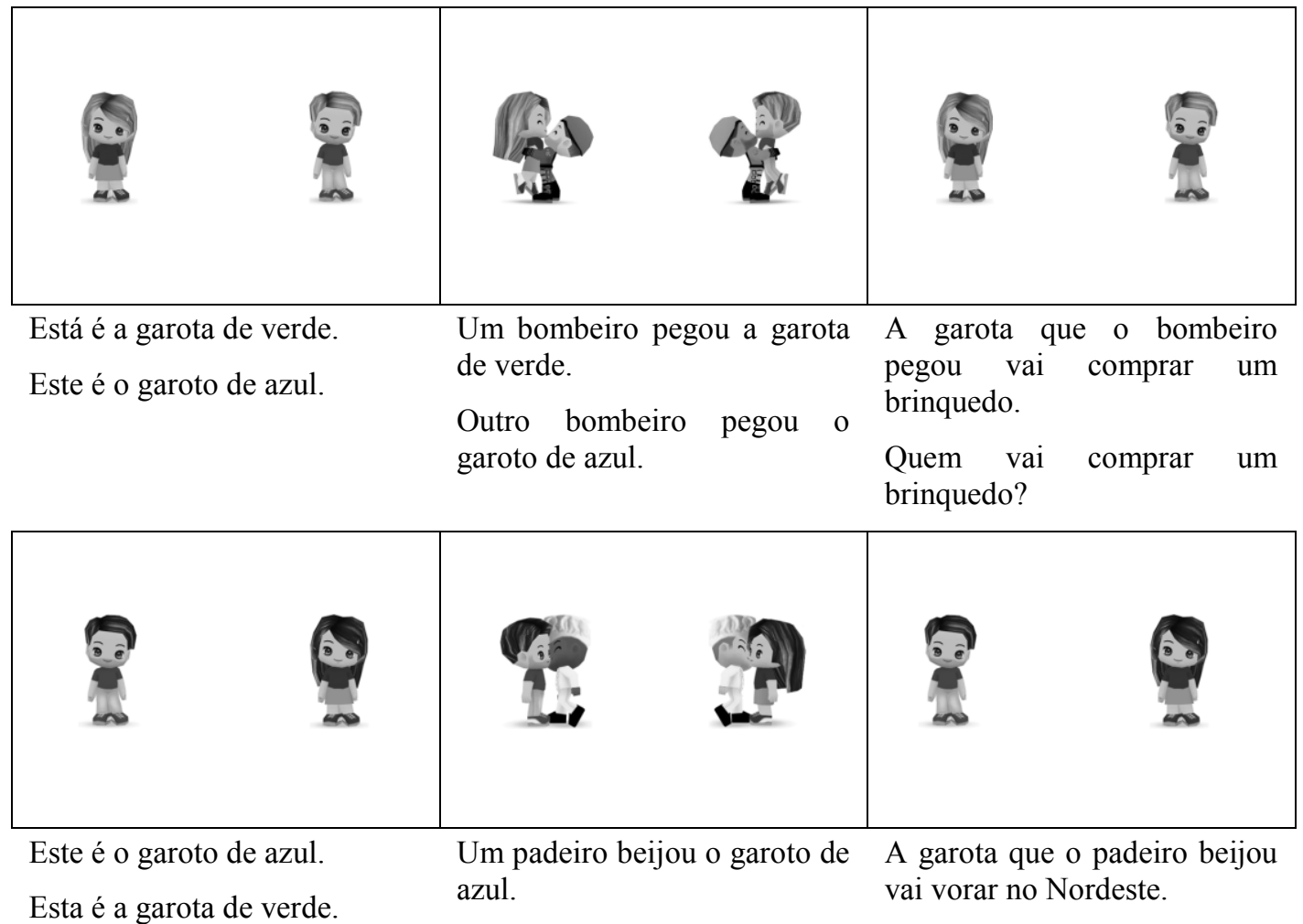

Outro padeiro beijou a garota Quem vai morar no Nordeste? de verde.

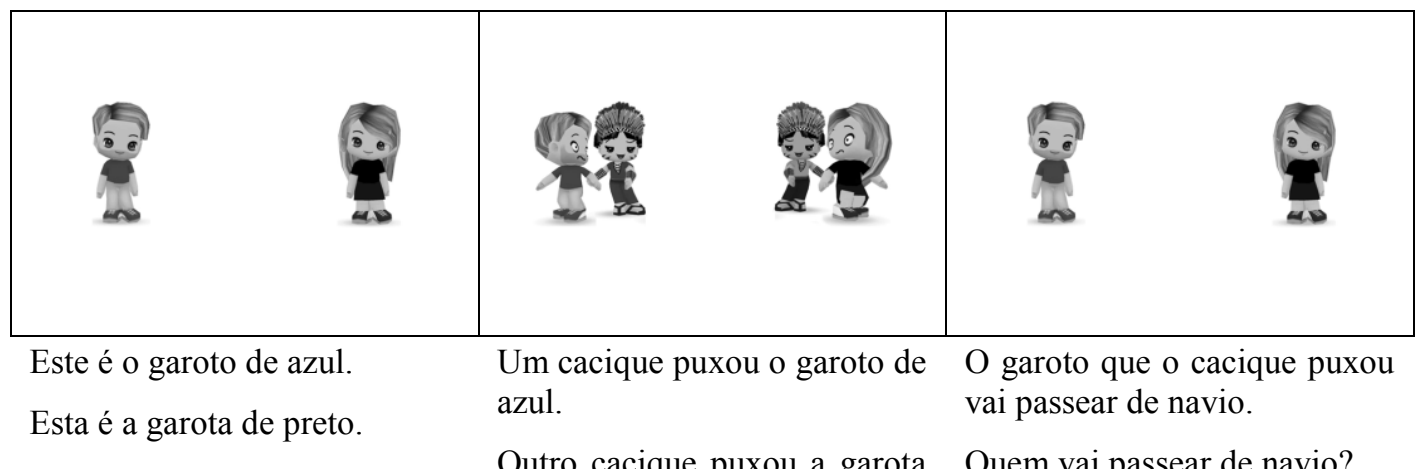

Outro cacique puxou a garota Quem vai passear de navio? de preto.

\footnotetext{
${ }^{65}$ Estímulos coloridos no original.
} 


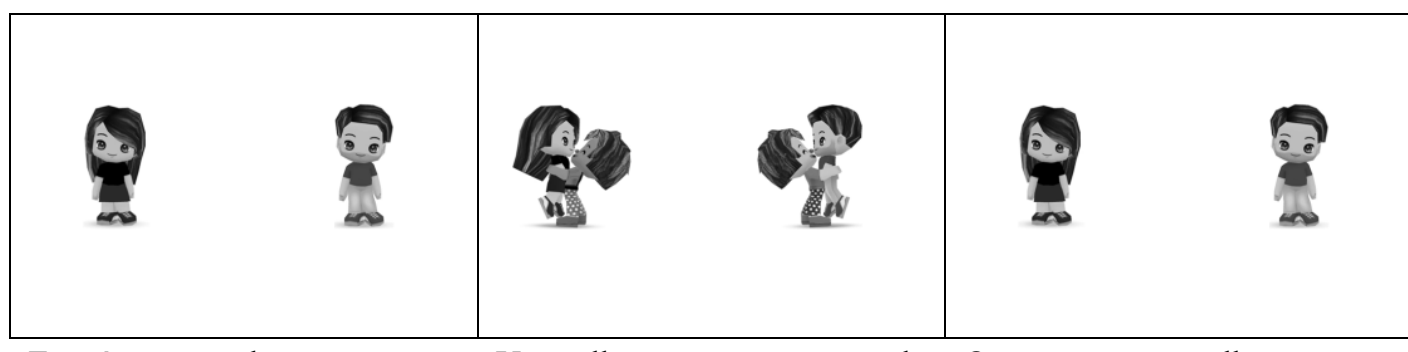

Esta é a garota de preto. Um palhaço pegou a garota de O garoto que o palhaço pegou

Este é o garoto de azul. preto.

vai ganhar uma surpresa.

Outro palhaço pegou o garoto Quem vai ganhar uma de azul. surpresa?

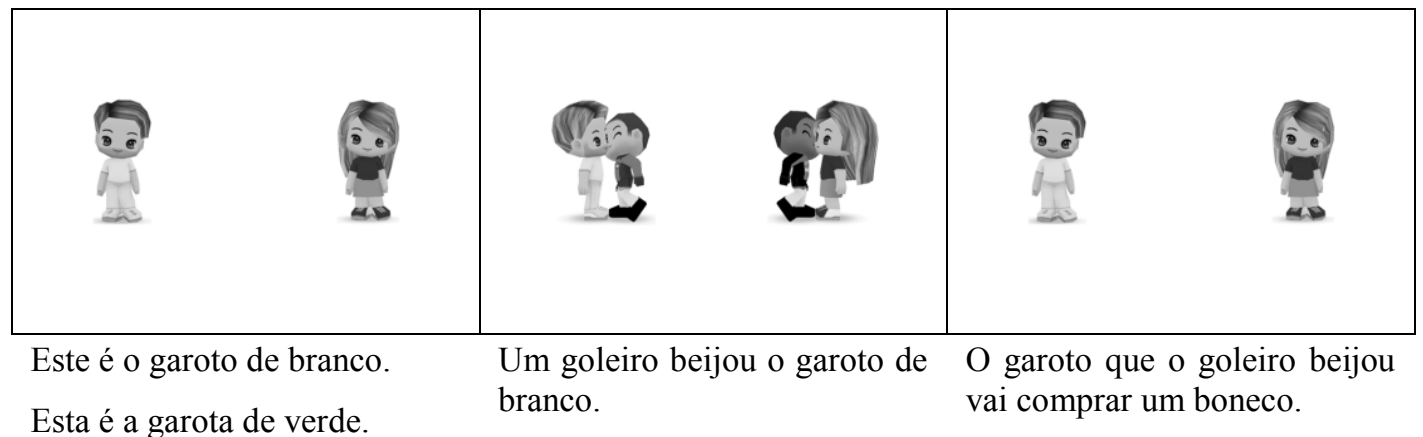

Outro goleiro beijou a garota Quem vai comprar um de verde. boneco?

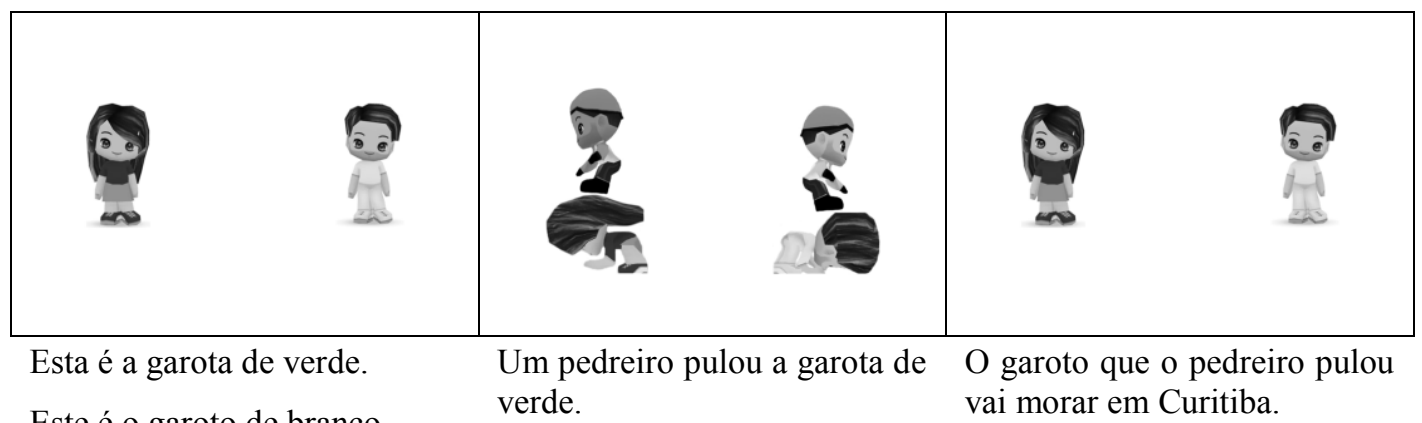

Este é o garoto de branco.

Outro pedreiro pulou o garoto Quem vai morar em Curitiba? de branco.

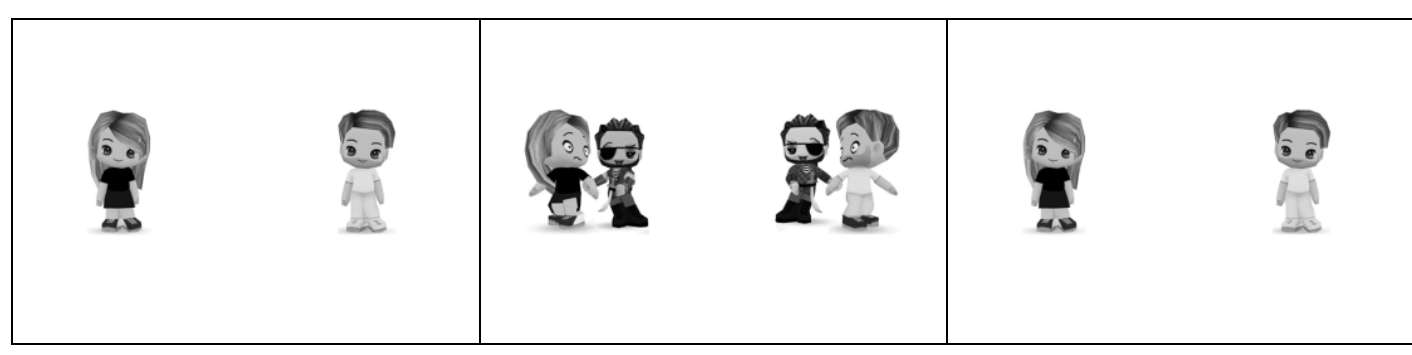

Esta é a garota de preto.

Este é o garoto de branco.
Um pirata puxou a garota de A garota que o pirata puxou preto. Outro pirata puxou o garoto de Quem vai passear no parque?
branco. 


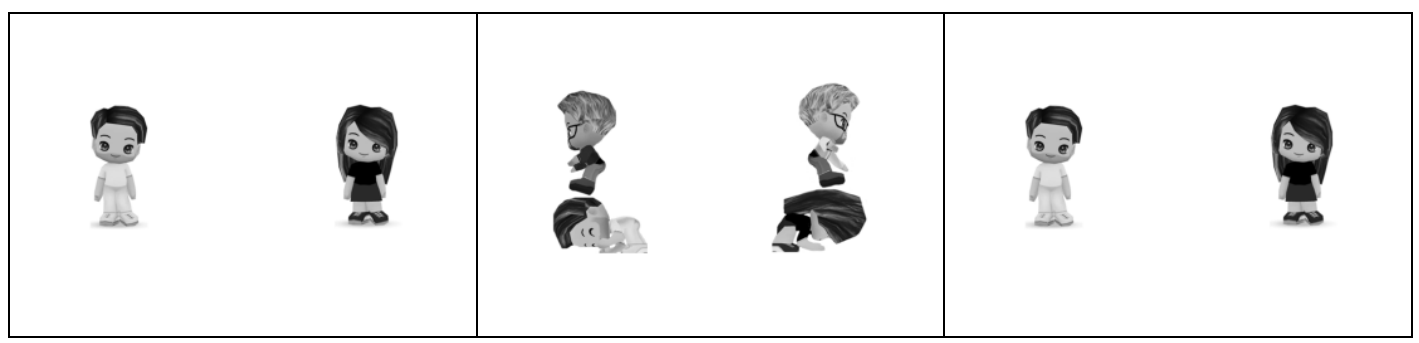

Este é o garoto de branco. Um professor pulou o garoto $\mathrm{A}$ garota que o professor

Esta é a garota de preto.

de branco.

Outro professor pulou a garota de preto. pulou vai ganhar um presente.

Quem vai ganhar um presente?

\section{Condição 2}

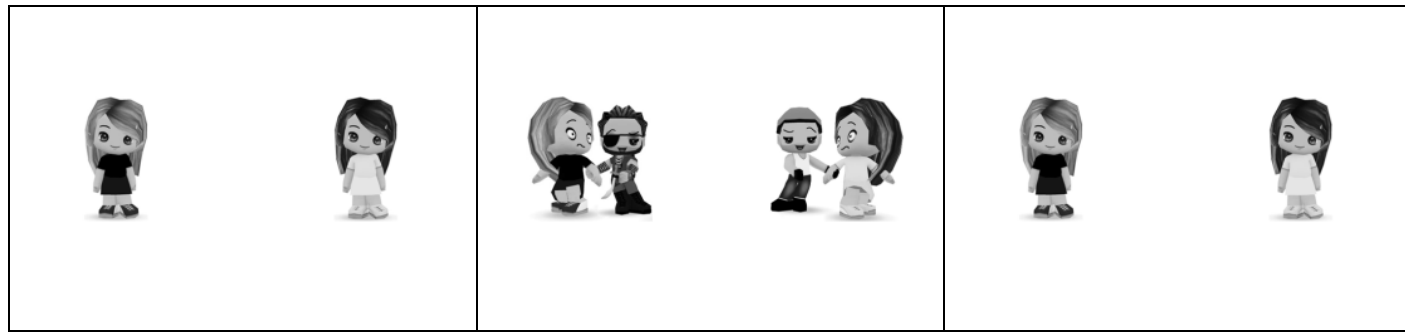

Esta é a garota de preto. Um pirata puxou a garota de A garota que o pirata puxou

Esta é a garota de branco. preto.

vai passear no parque.

E um pedreiro puxou a garota Quem vai passear no parque? de branco.
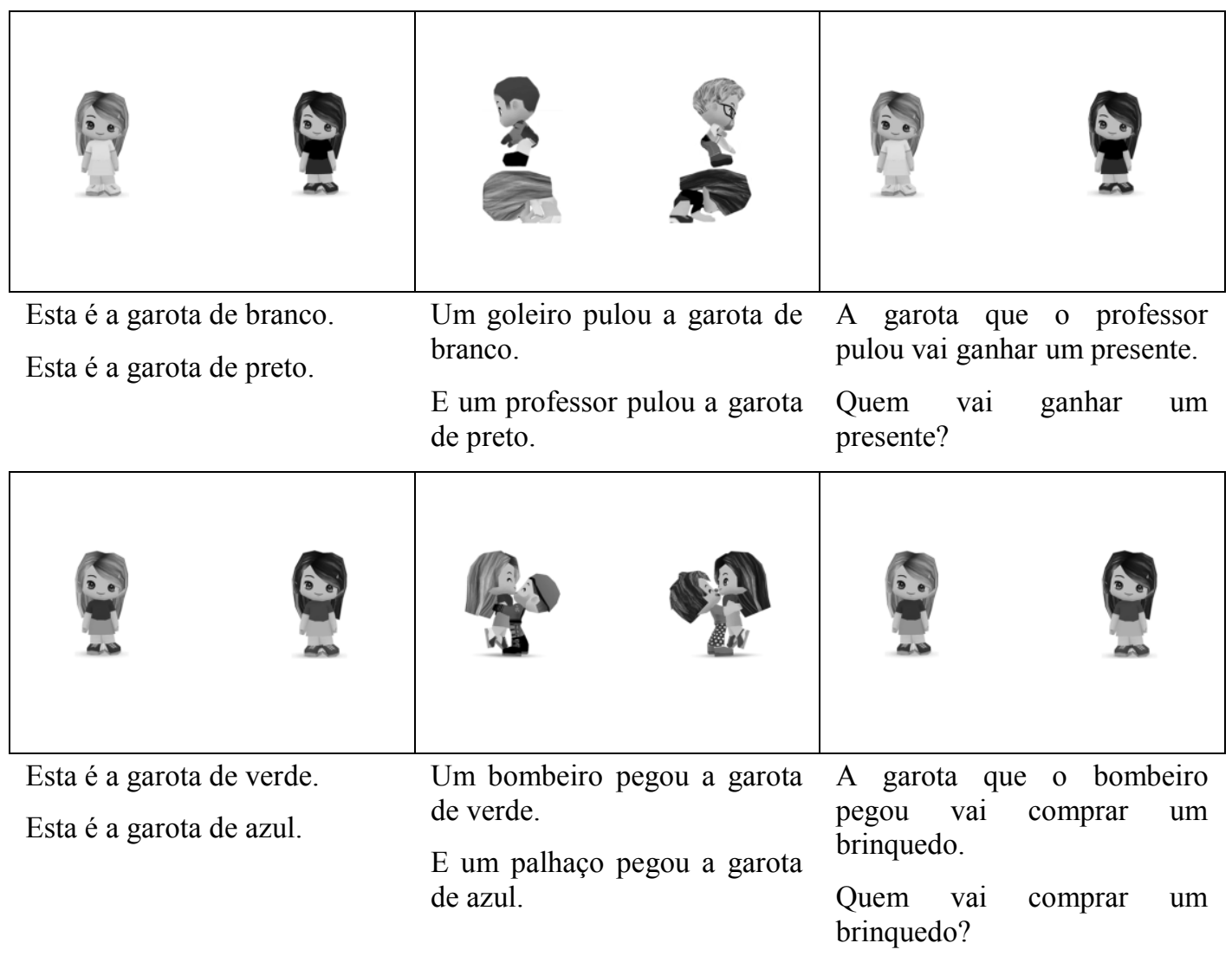


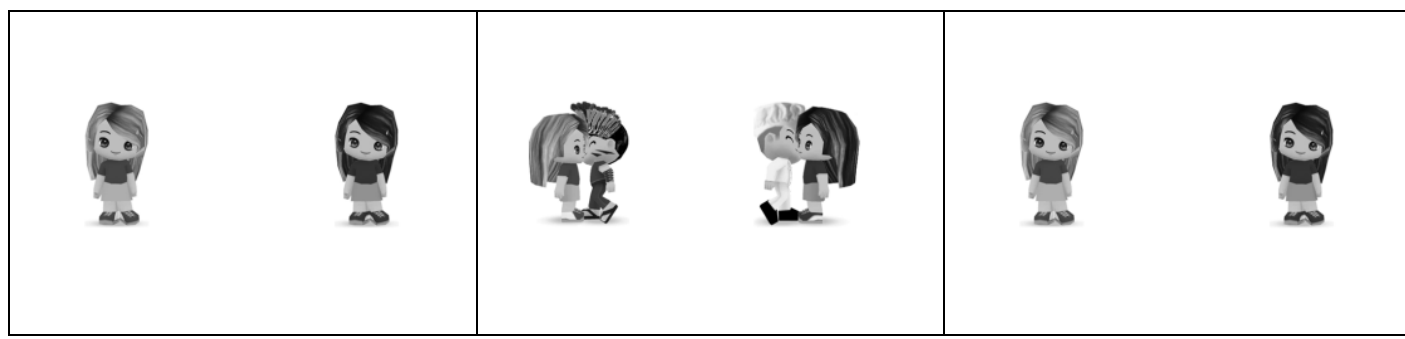

Esta é a garota de azul.

Esta é a garota de verde.

Este é o garoto de branco.

Este é o garoto de verde.

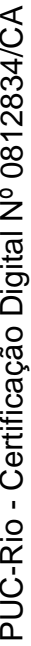
Este é o garoto de branco.
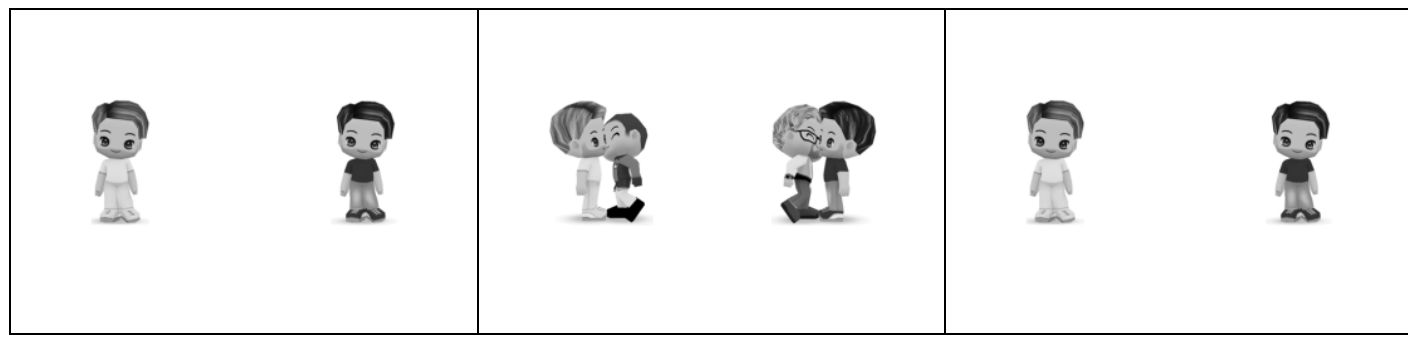

Um cacique beijou a garota de A garota que o padeiro beijou azul. vai morar no Nordeste.

E um padeiro beijou a garota Quem vai morar no Nordeste? de verde.
Um goleiro beijou o garoto de branco.

E um professor beijou o Quem vai comprar um garoto de verde. garoto que o goleiro beijou vai comprar um boneco.

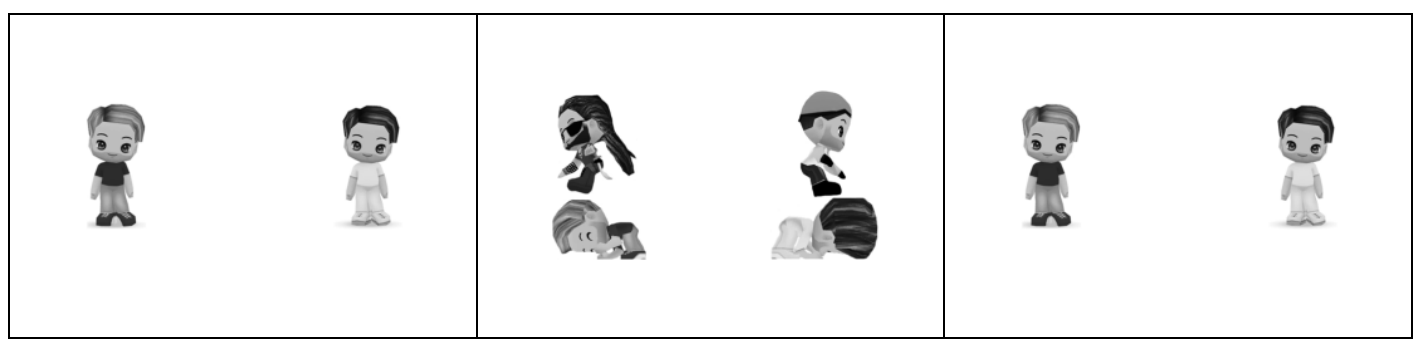

Este é o garoto de verde. Um pirata pulou o garoto de $\mathrm{O}$ garoto que o pedreiro pulou verde. vai morar em Curitiba.

E um pedreiro pulou o garoto Quem vai morar em Curitiba? de branco.

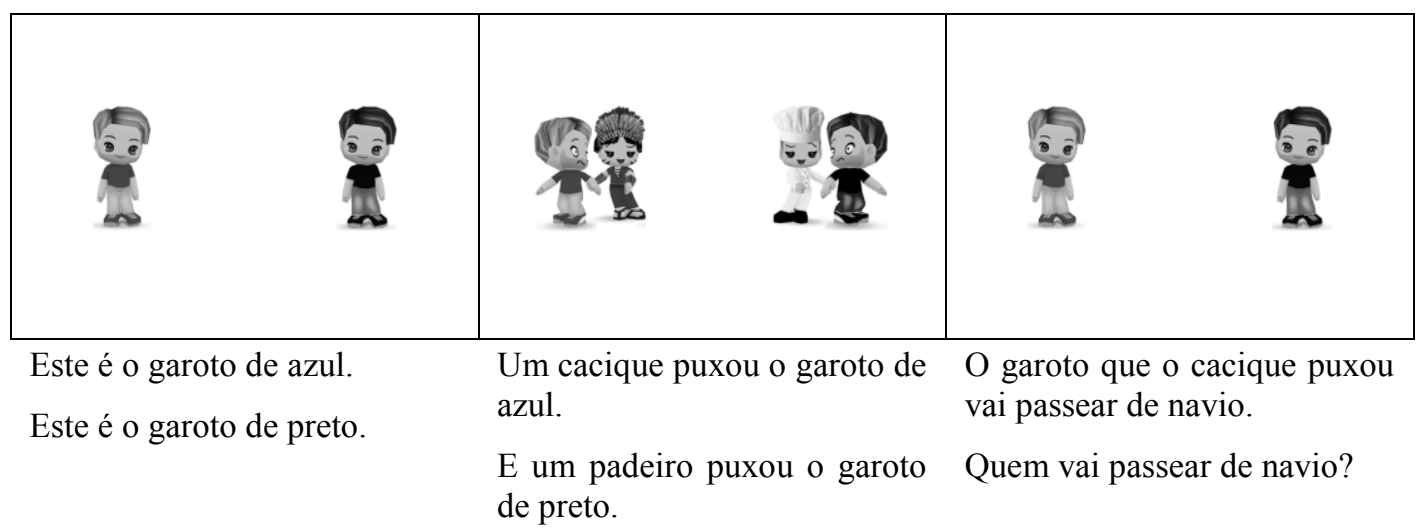




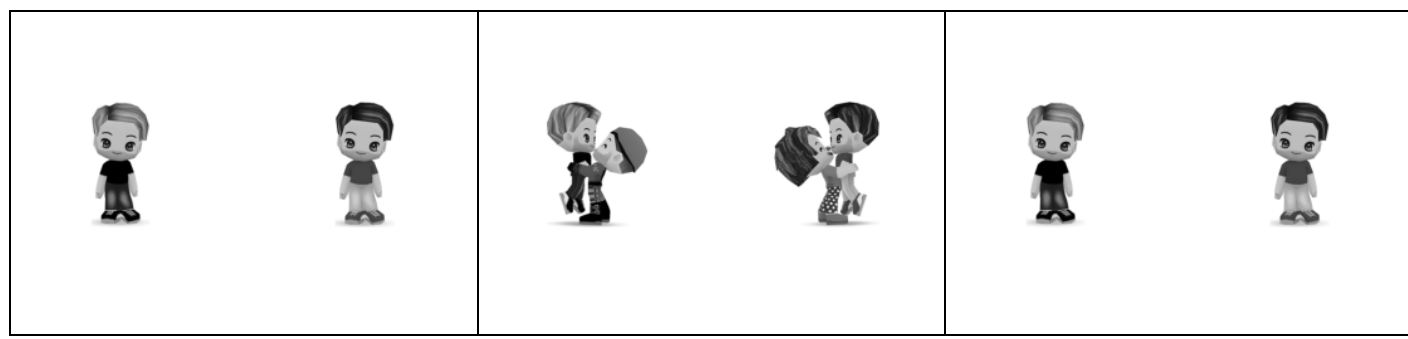

Este é o garoto de preto. Um bombeiro pegou o garoto $\mathrm{O}$ garoto que o palhaço pegou

Este é o garoto de azul. de preto. vai ganhar uma surpresa.

E um palhaço pegou o garoto Quem vai ganhar uma de azul. surpresa?

\section{Condição 3}

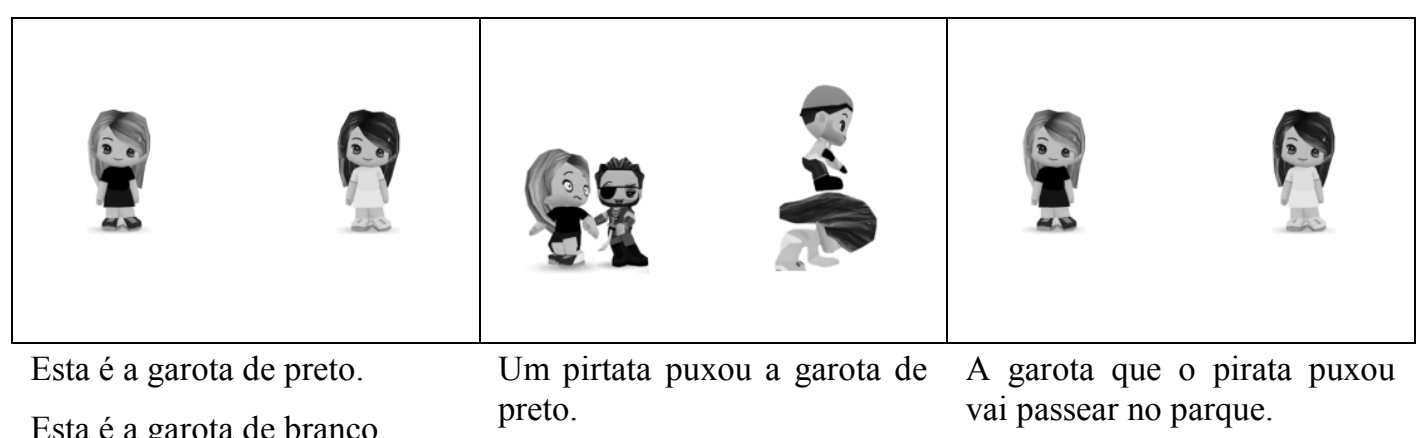

Esta é a garota de branco.

E um pedreiro pulou a garota Quem vai passear no parque? de branco.
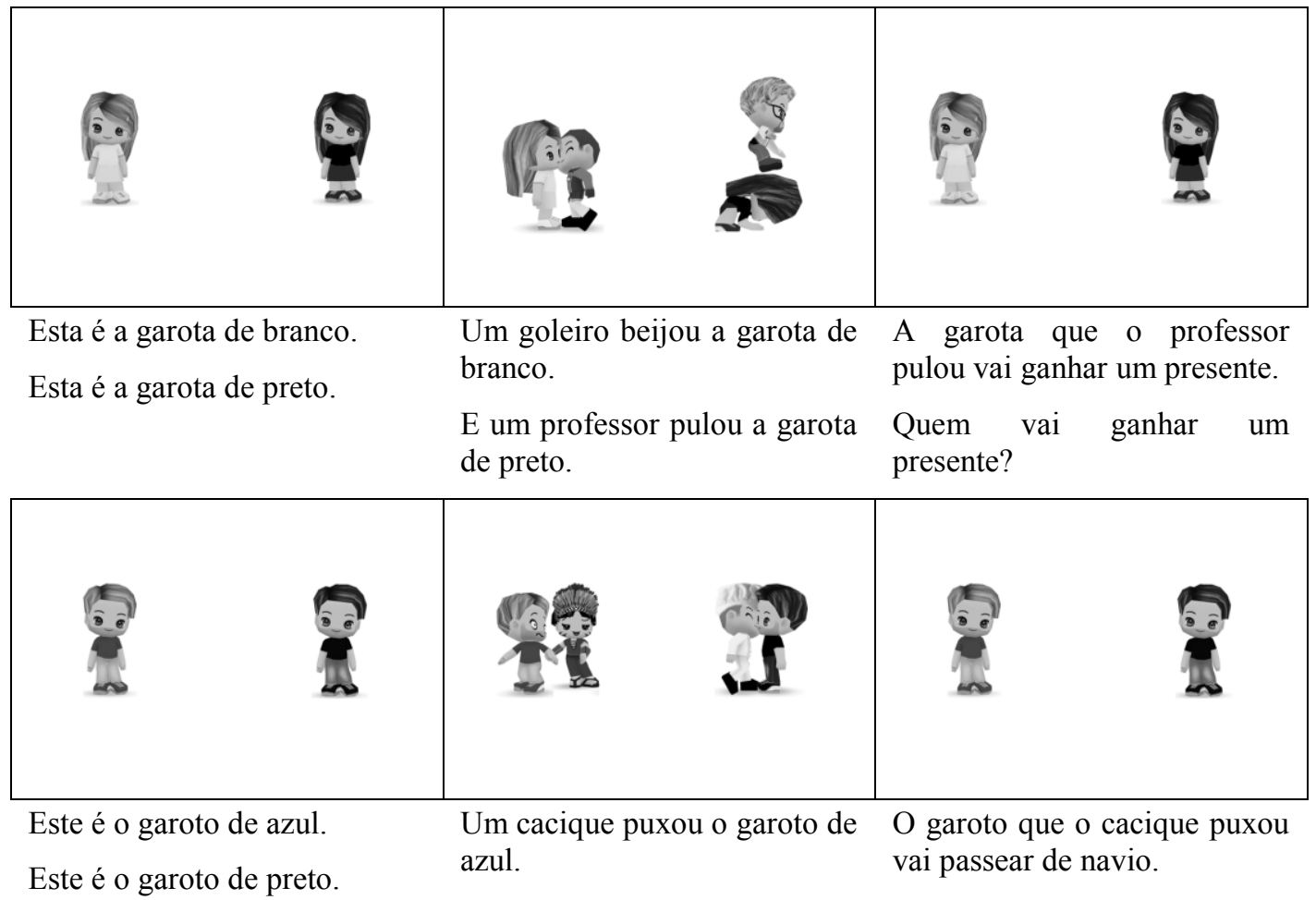

E um padeiro beijou o garoto Quem vai passear de navio? de preto. 


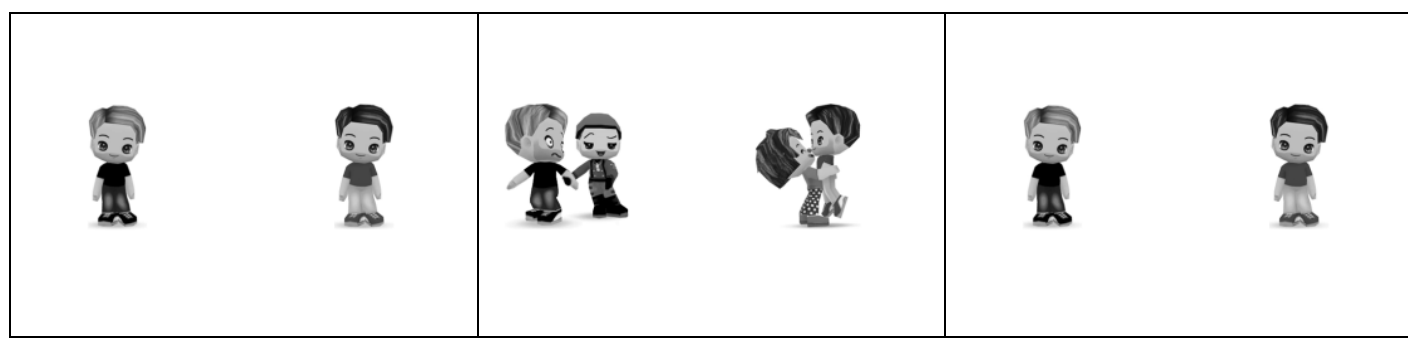

Este é o garoto de preto. Um bombeiro puxou o garoto $\mathrm{O}$ garoto que o palhaço pegou

Este é o gatoto de azul. de preto. vai ganhar uma surpresa.

E um palhaço pegou o garoto de azul.

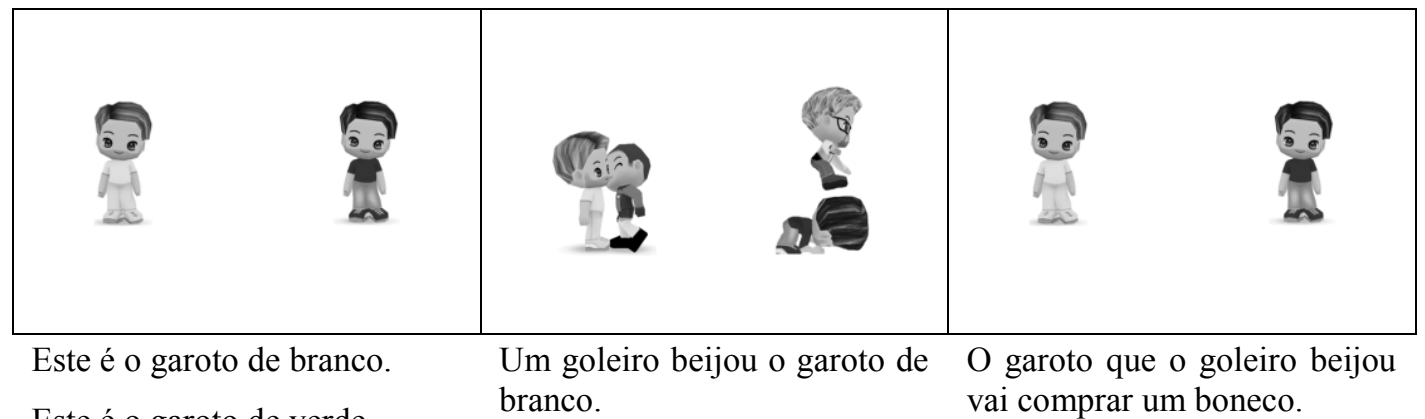

Este é o garoto de verde.

E um professor pulou o garoto Quem vai comprar um de verde. boneco?

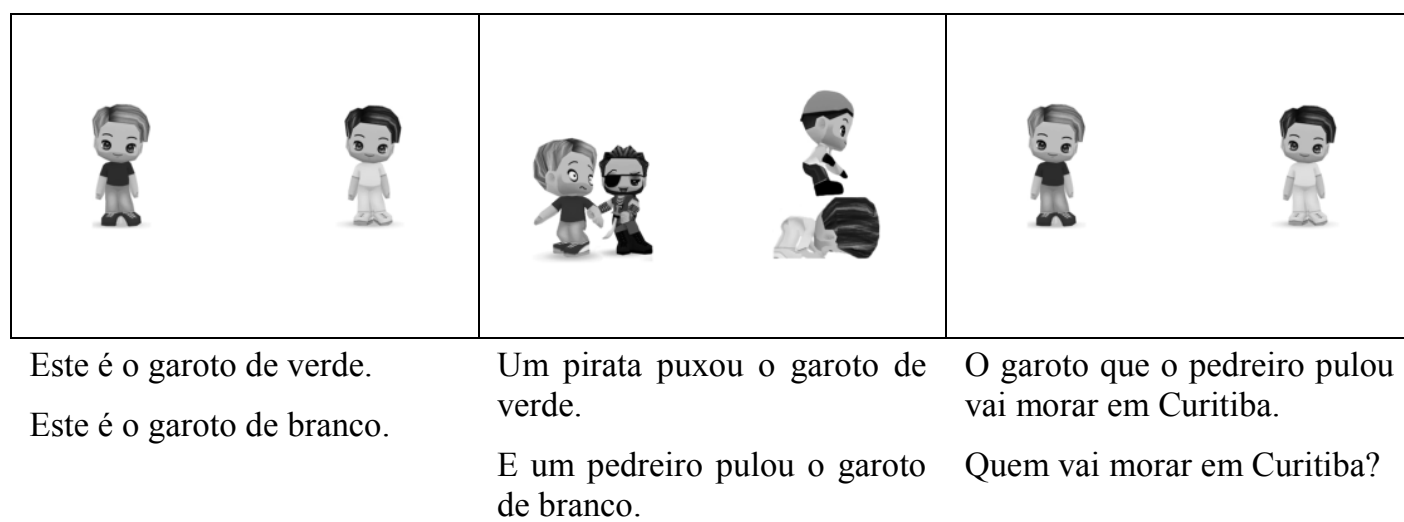

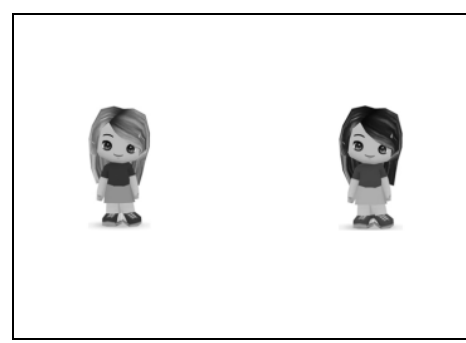

Esta é a garota de verde.

Esta é a garota de azul de branco.

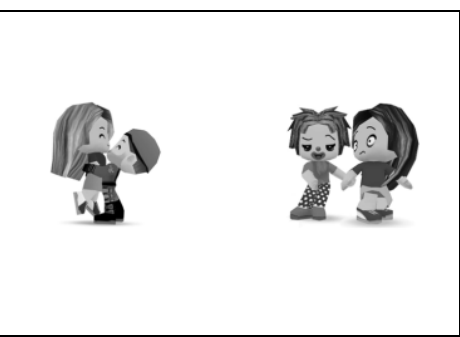

Um bombeiro pegou a garota de verde.

E um palhaço puxou a garota de azul.
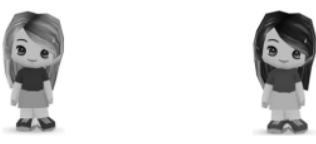

A garota que o bombeiro pegou vai comprar um brinquedo.

Quem vai comprar um brinquedo? 


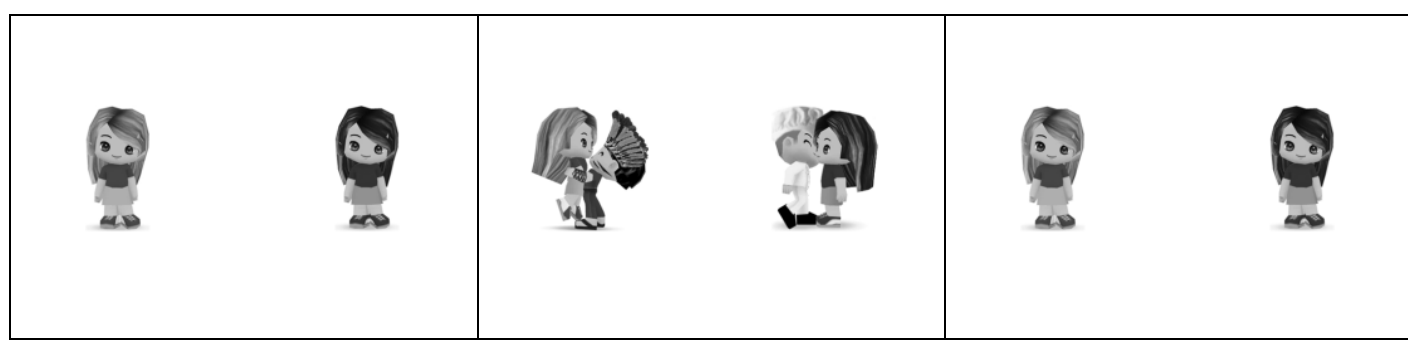

Esta é a garota de azul.

Esta é a garota de verde.
Um cacique pegou a garota de A garota que o padeiro beijou azul.

E um padeiro beijou a garota Quem vai morar no Nordeste? de verde.

\section{Condição 4}

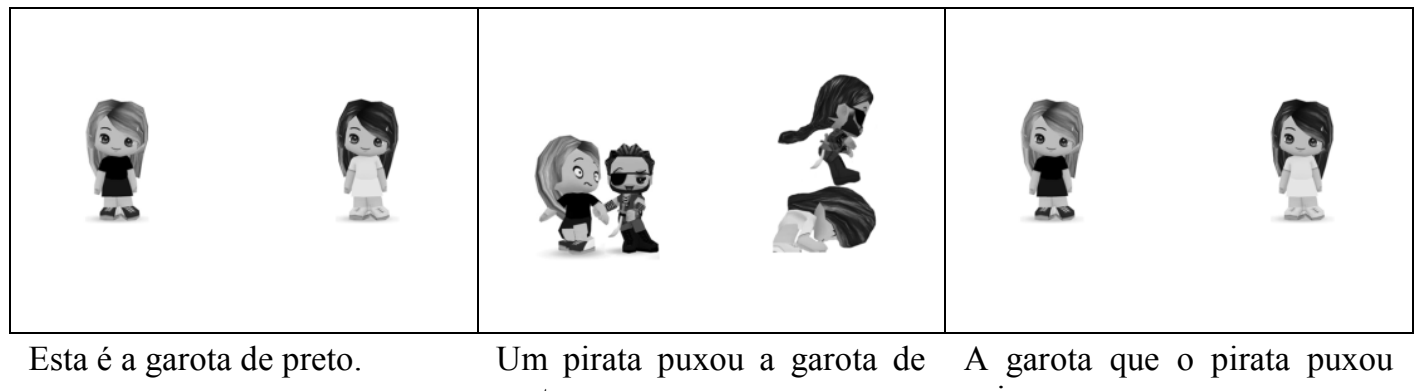

Esta é a garota de branco. preto.

vai passear no parque.

E outro pirata pulou a garota Quem vai passear no parque? de branco.
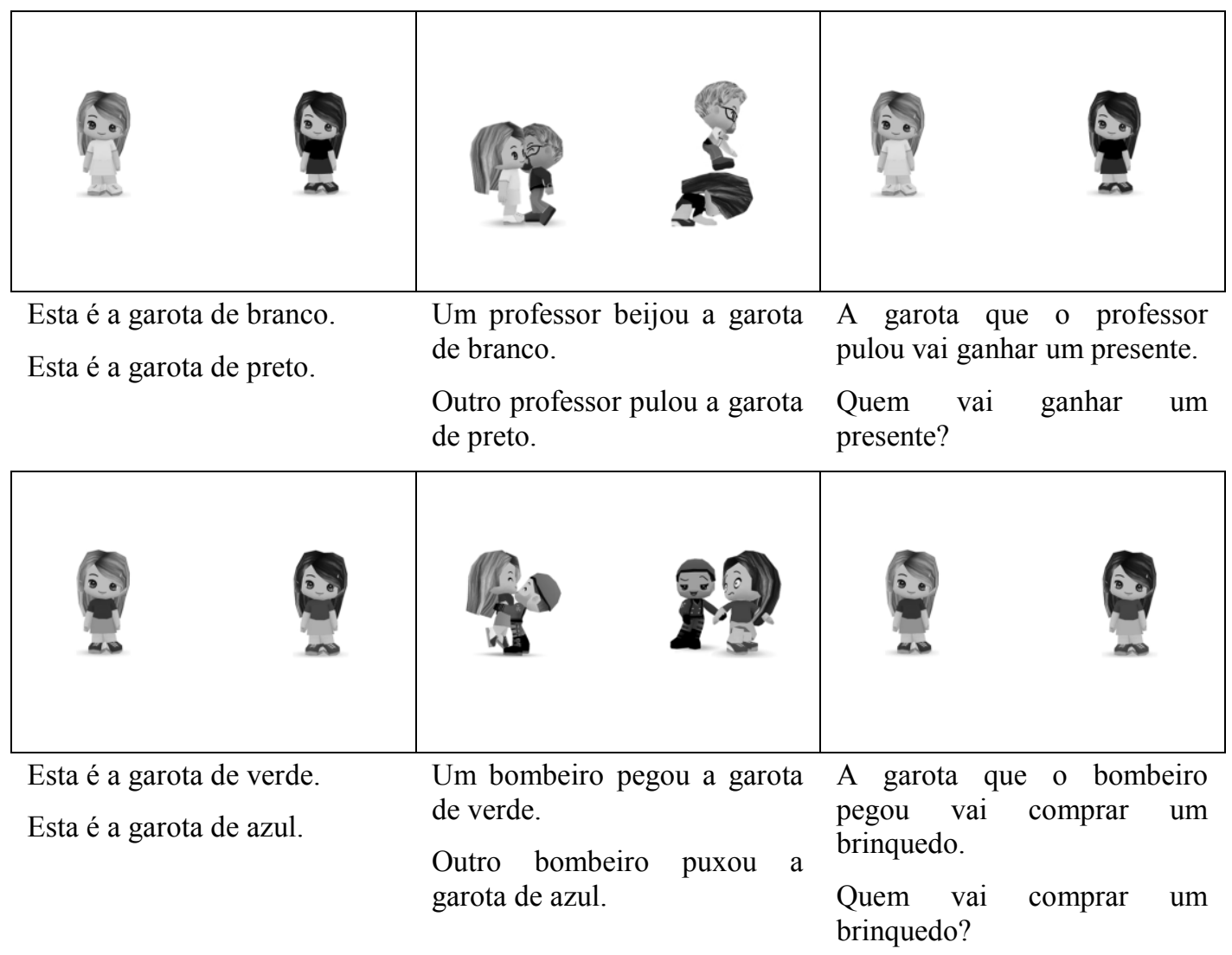


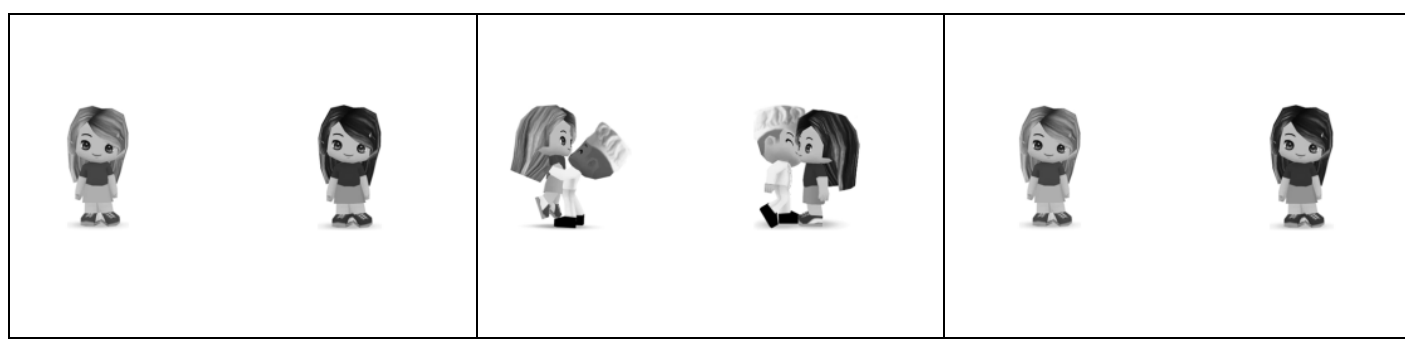

Esta é a garota de azul.

Esta é a garota de verde. azul.

Outro padeiro beijou a garota Quem vai morar no Nordeste? de verde.

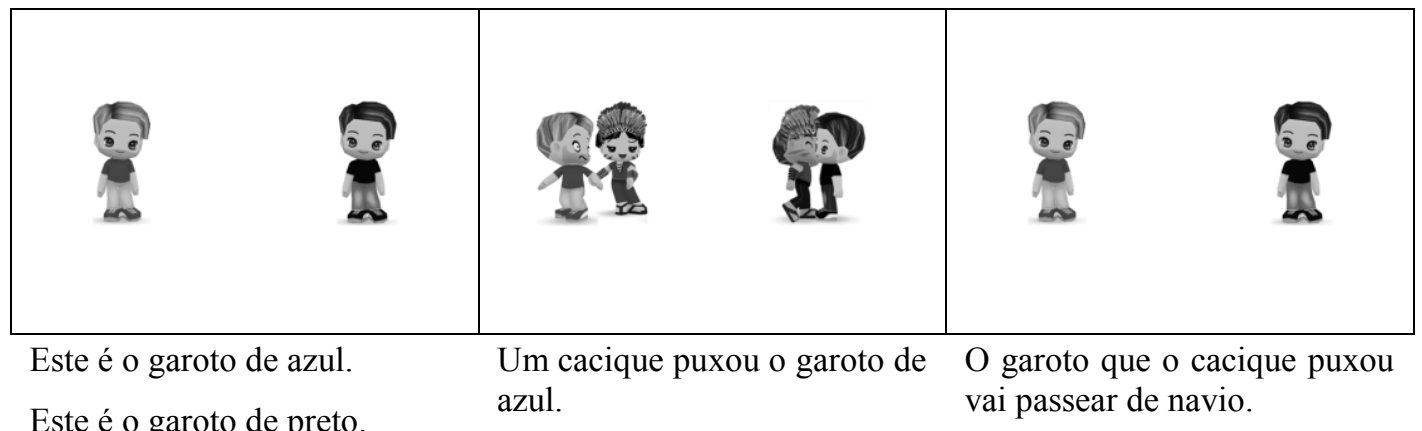

Este é o garoto de preto.

Outro cacique beijou o garoto Quem vai passear de navio? de preto.

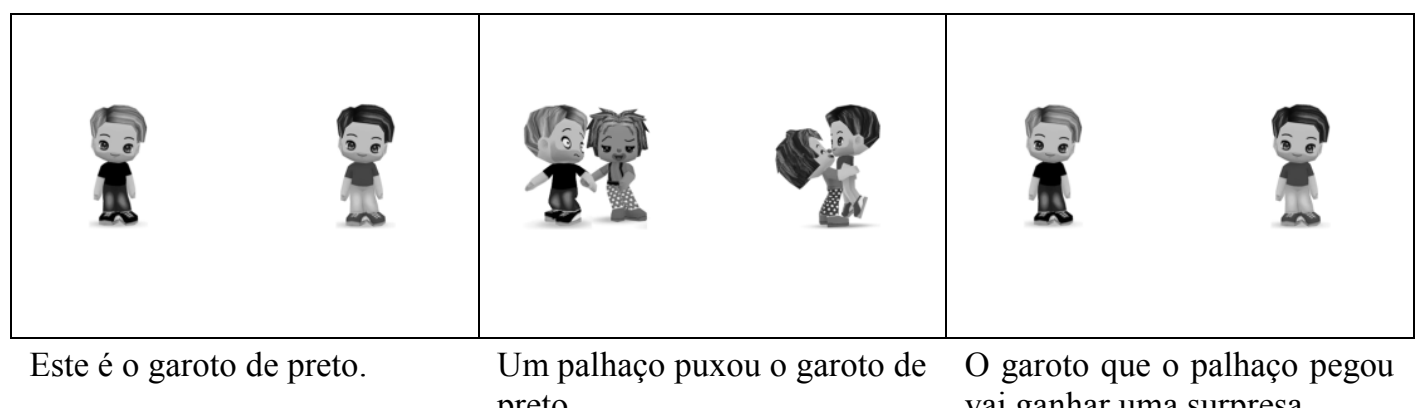

Este é o garoto de azul. preto. vai ganhar uma surpresa.

Outro palhaço pegou o garoto Quem vai ganhar uma de azul. surpresa?

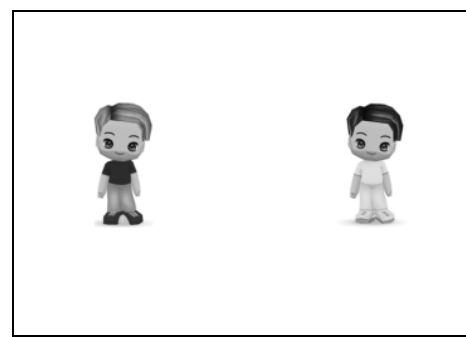

Este é o garoto de verde.

Este é o garoto de branco.

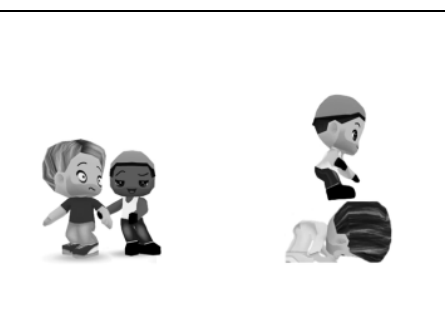

Um pedreiro puxou o garoto de verde.

Outro pedreiro pulou o garoto Quem vai morar em Curitiba? de branco. 


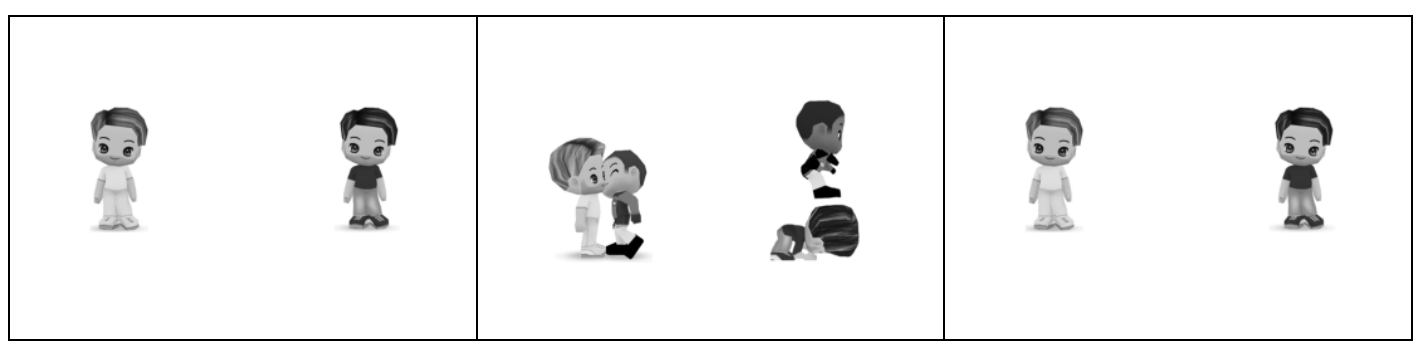

Este é o garoto de branco.

Um goleiro beijou o garoto de

$\mathrm{O}$ garoto que o goleiro beijou

Este é o garoto de verde.

branco.

Outro goleiro pulou o garoto de preto. vai comprar um boneco.

Quem vai comprar um boneco? 


\title{
Apêndice B:
}

\section{Estímulos experimentais do experimento 3}

\author{
Condições 1 e $2^{66}$
}

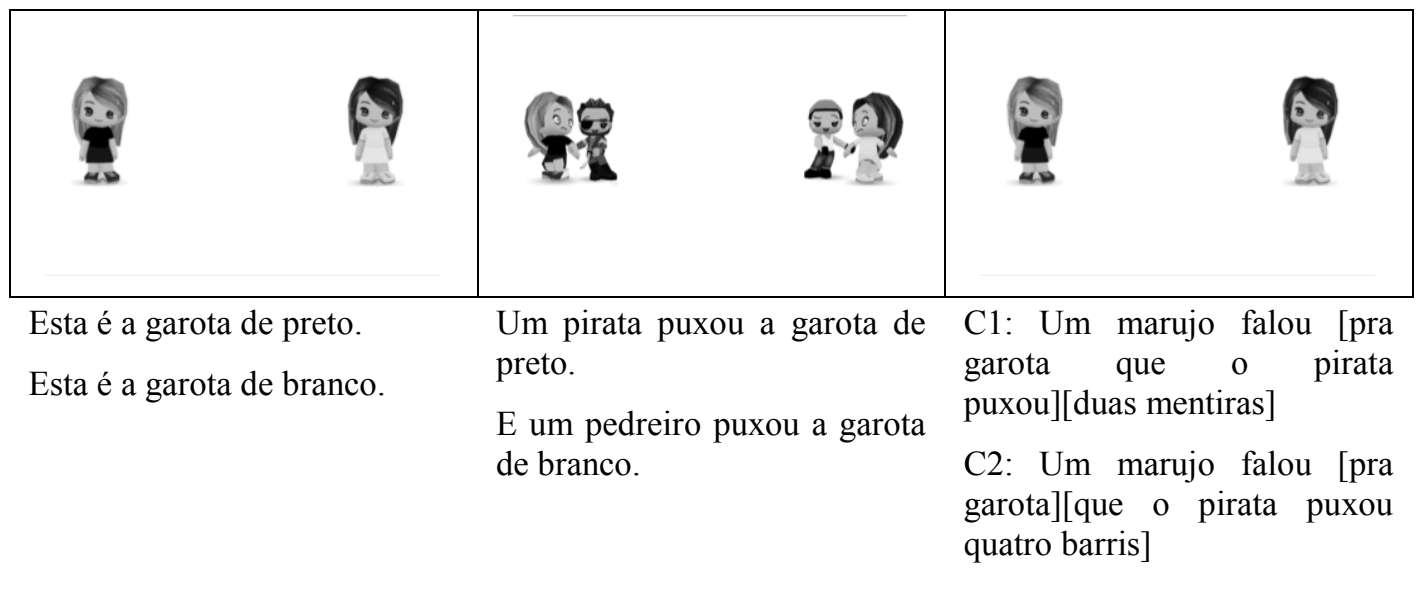

O que o marujo falou?

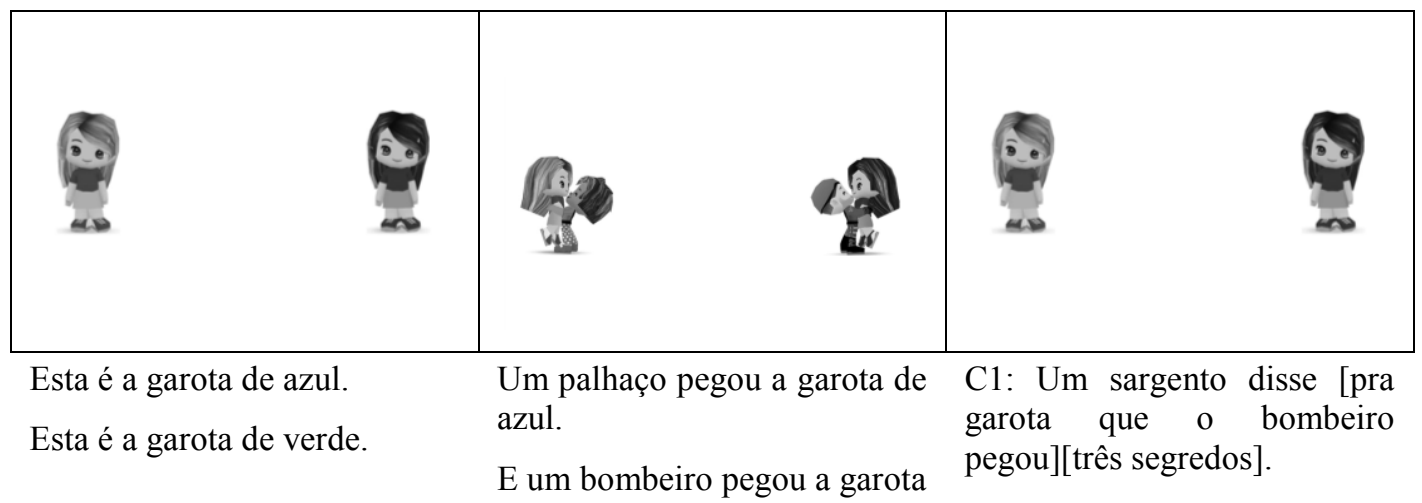
de verde.

C2: Um sargento disse [pra garota][que o bombeiro pegou quatro caixas].

O que o sargento disse?

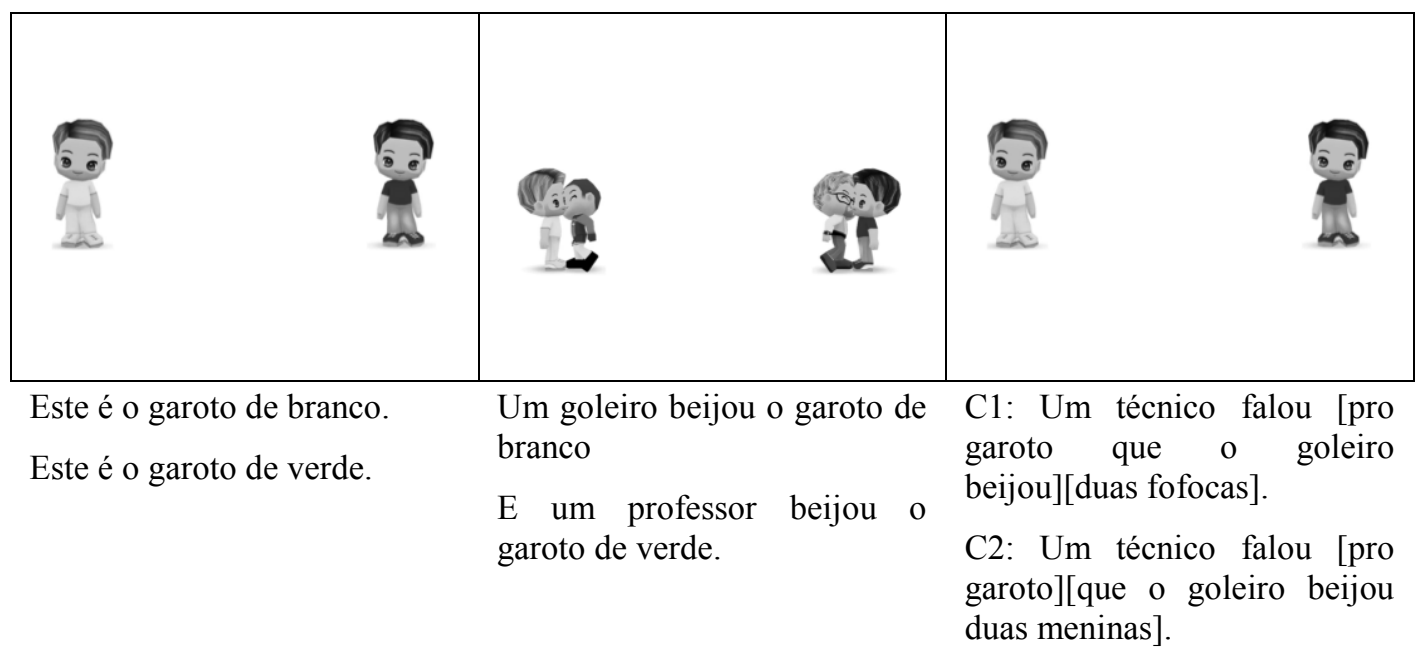

O que o técnico falou?

\footnotetext{
${ }^{66}$ Estímulos coloridos no original.
} 


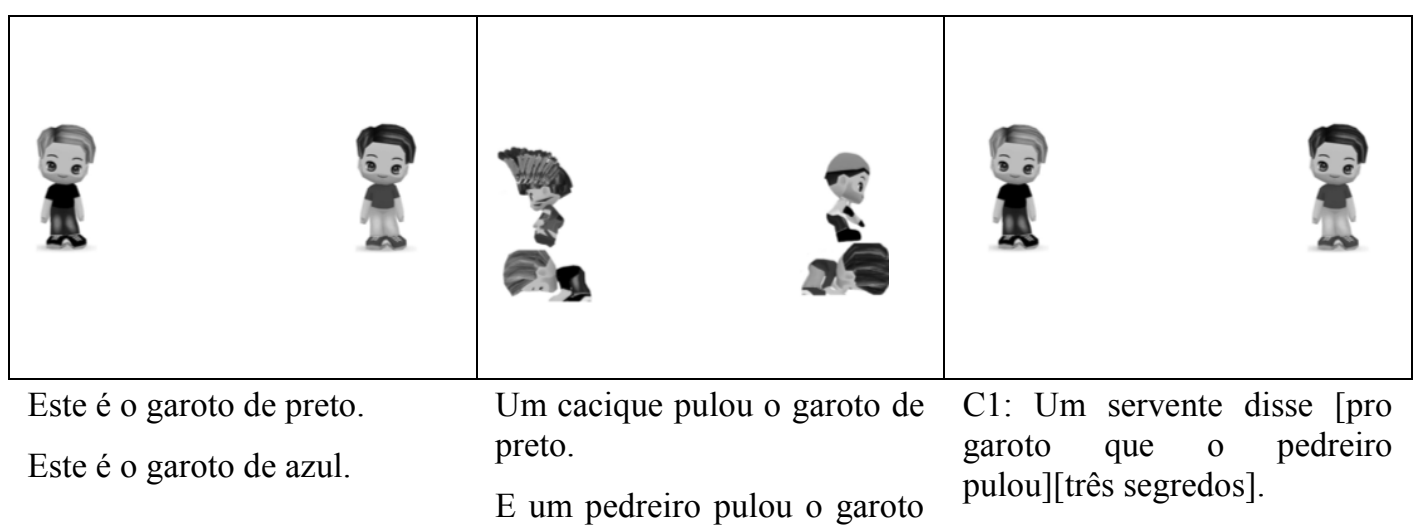
de azul.

C2: Um servente disse [pro garoto][que o pedreiro pulou três barreiras].

O que o servente disse?

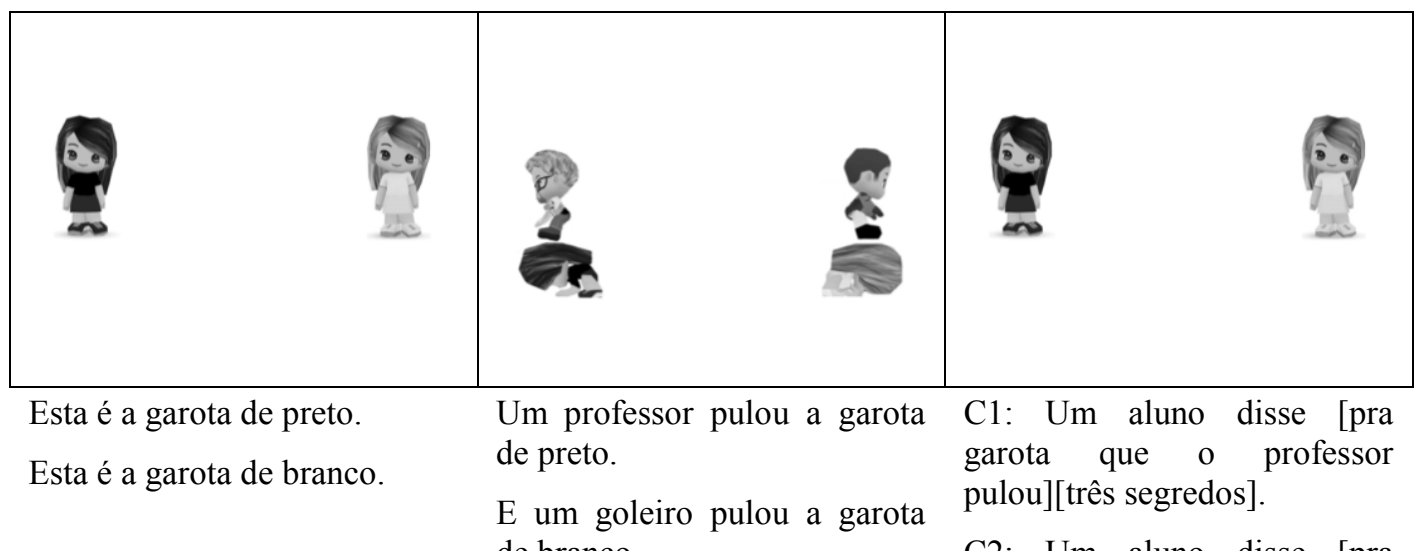
de branco.

C2: Um aluno disse [pra garota][que o professor pulou três barreiras].

O que o aluno disse?

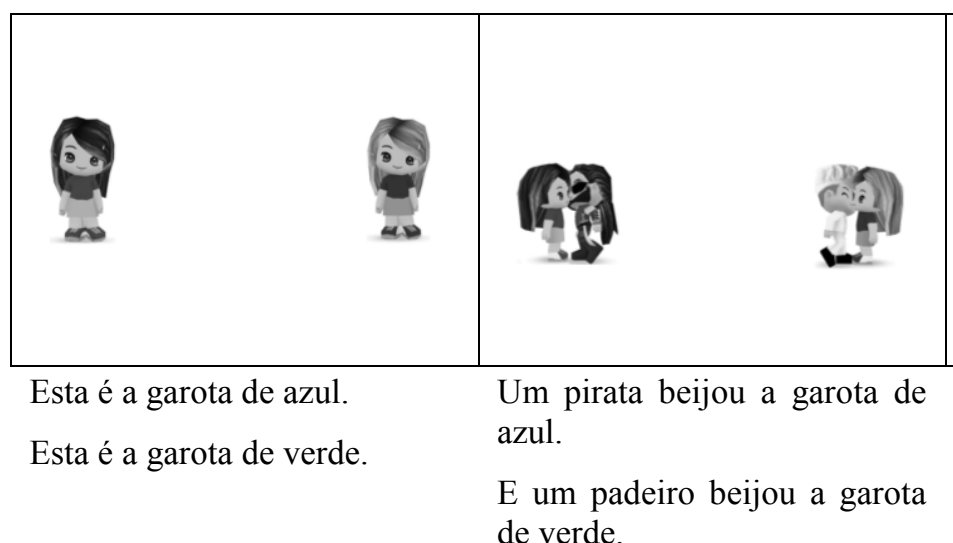
de verde.

C1: Um feirante falou [pra garota que $o$ padeiro beijou][duas fofocas].

C2: Um feirante falou [pra garota][que o padeiro beijou duas meninas].

O que o feirante falou? 


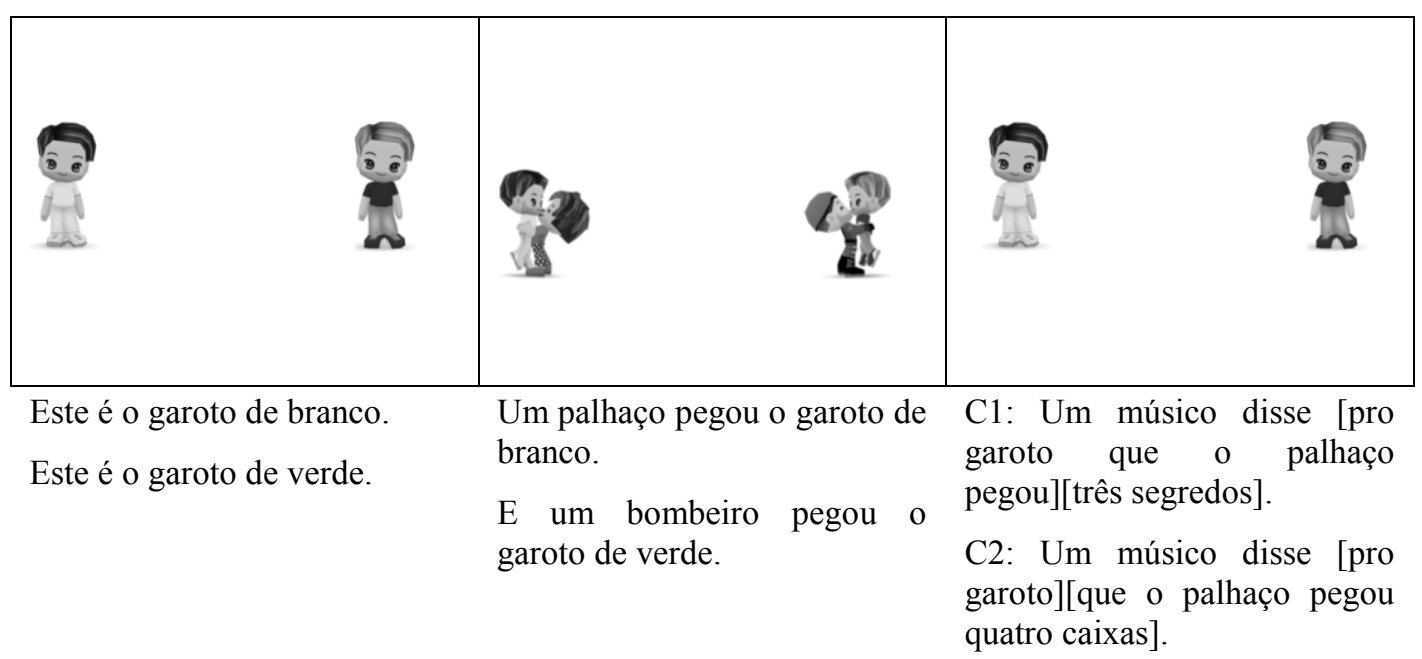

O que o músico disse?

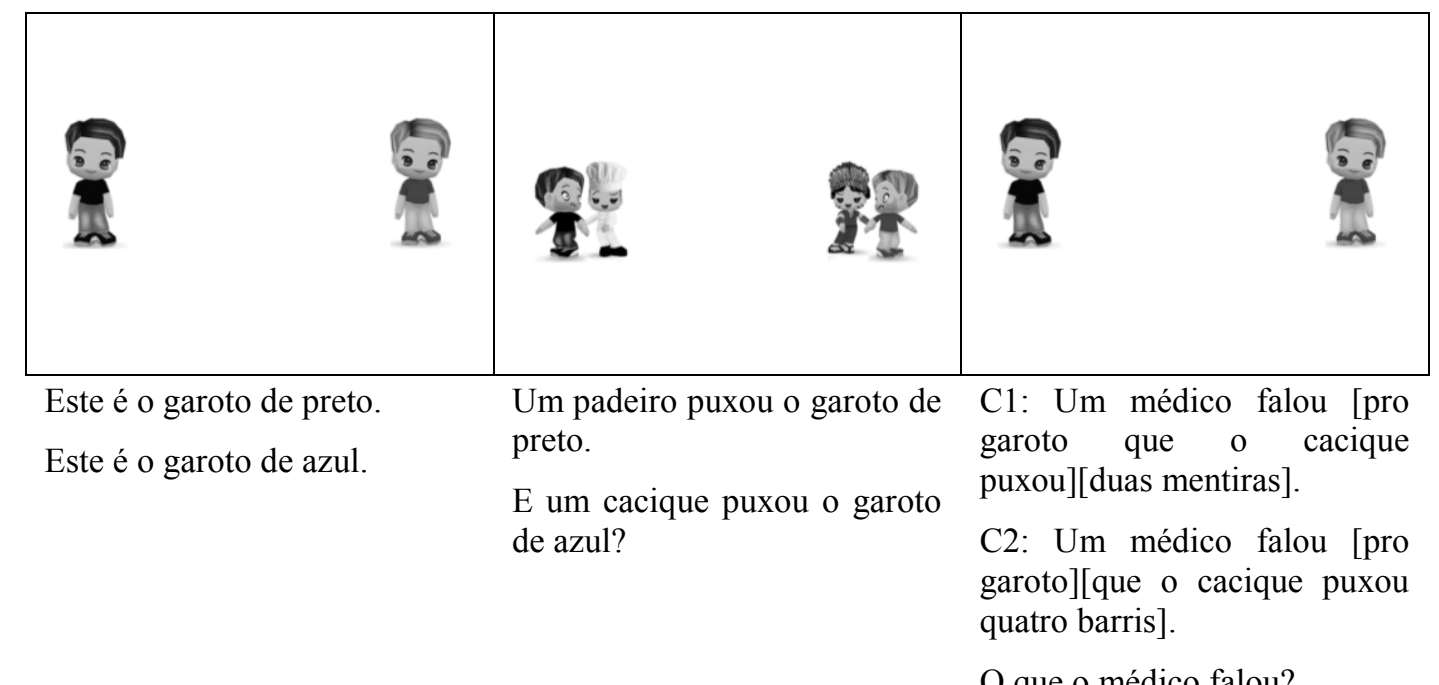

Condições 3 e 4

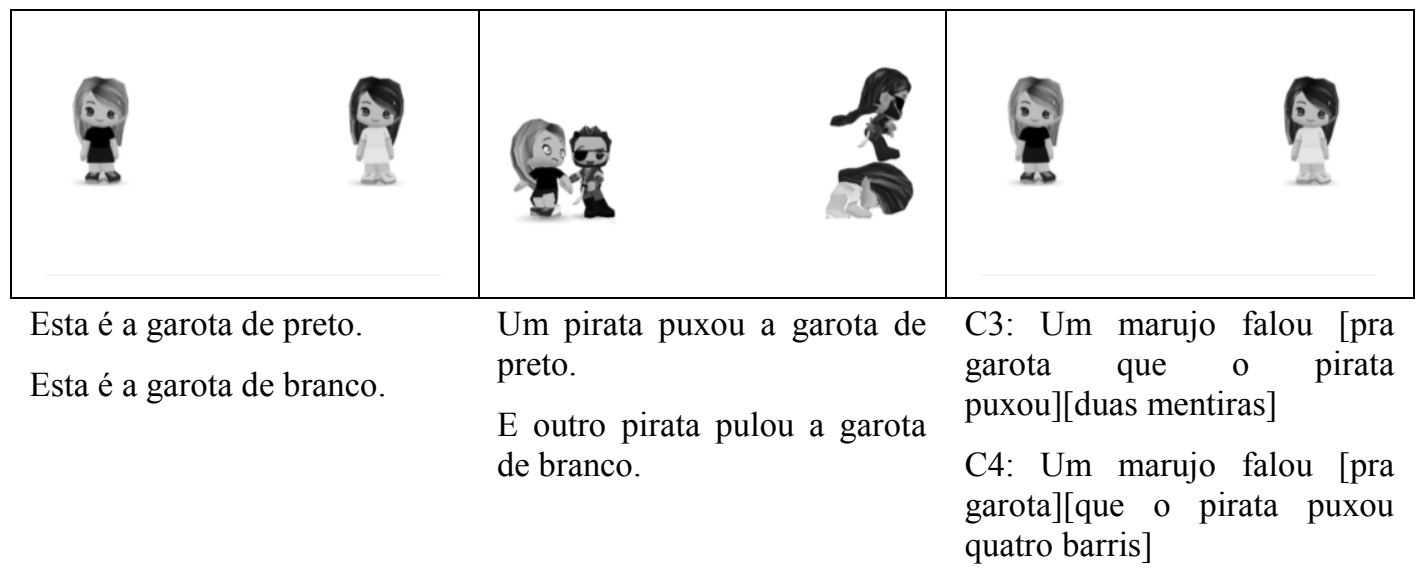

O que o marujo falou? 


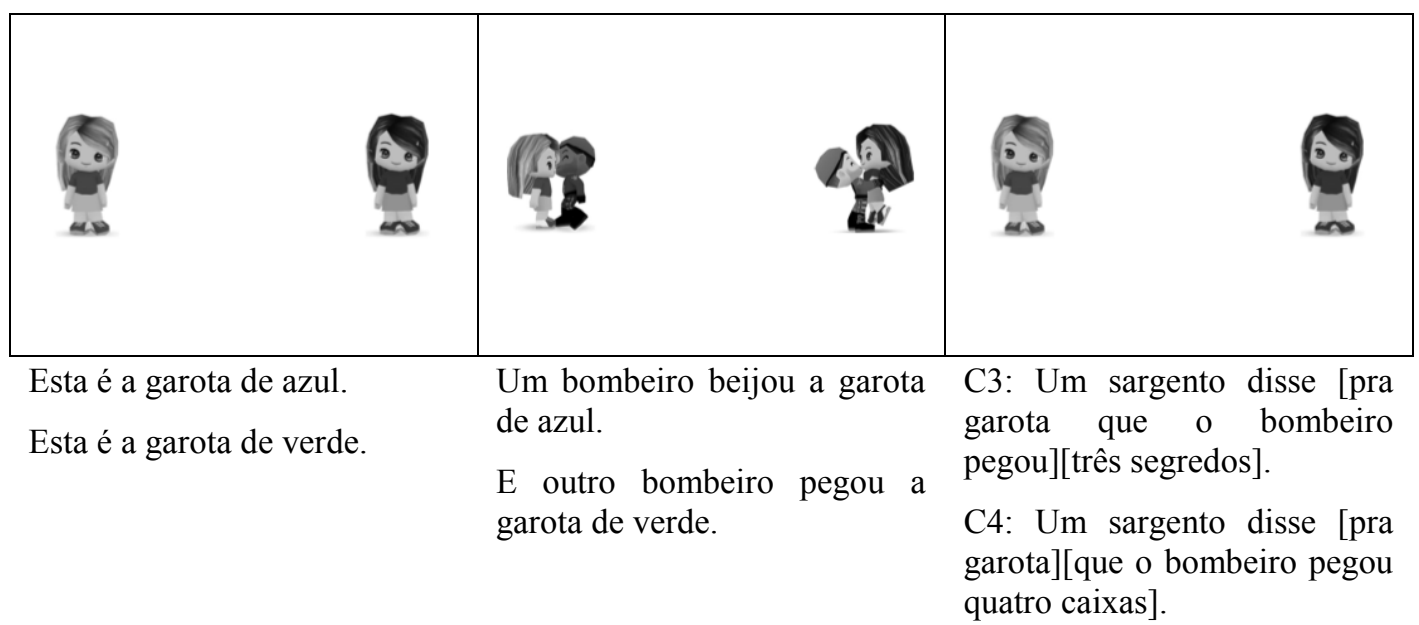

O que o sargento disse?

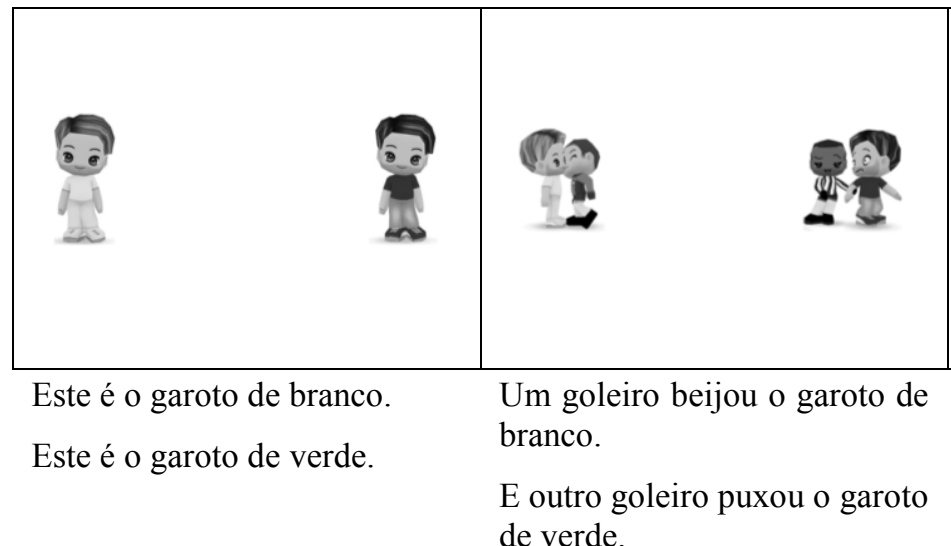

C3: Um técnico falou [pro garoto que o goleiro beijou][duas fofocas]. de verde.

C4: Um técnico falou [pro garoto][que o goleiro beijou duas meninas].

O que o técnico falou?

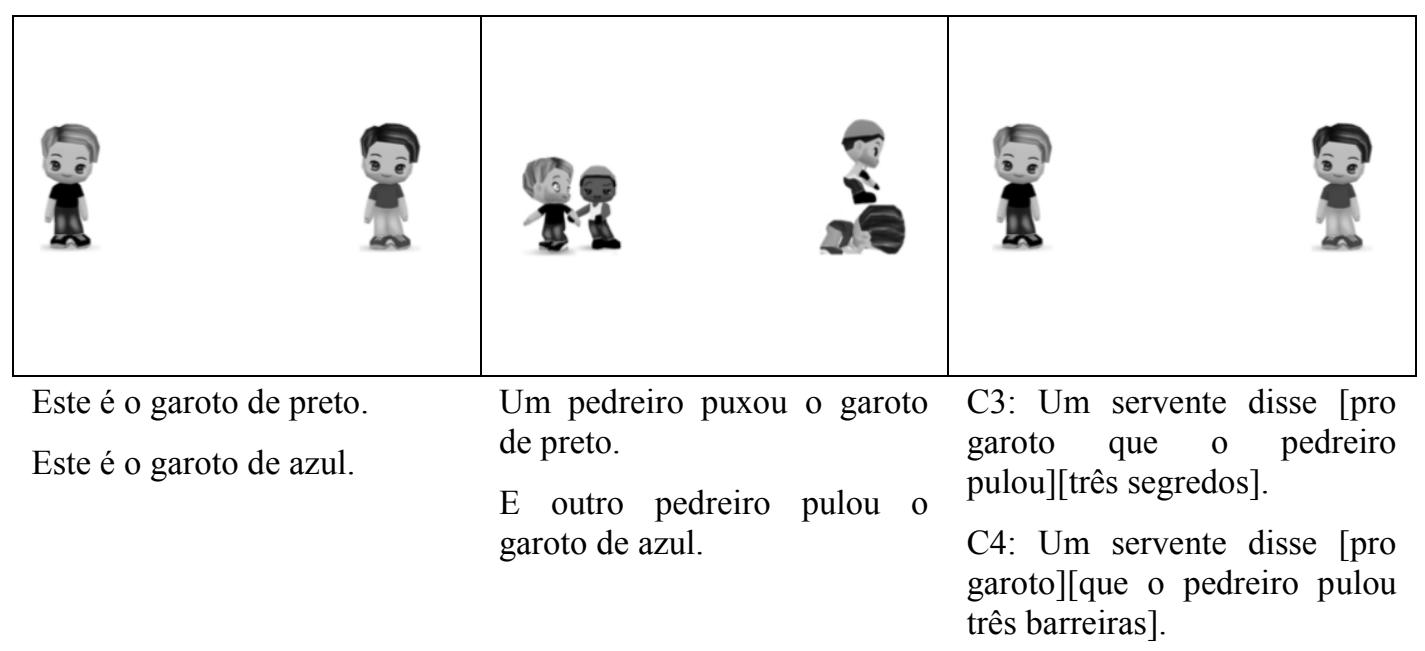

O que o servente disse? 


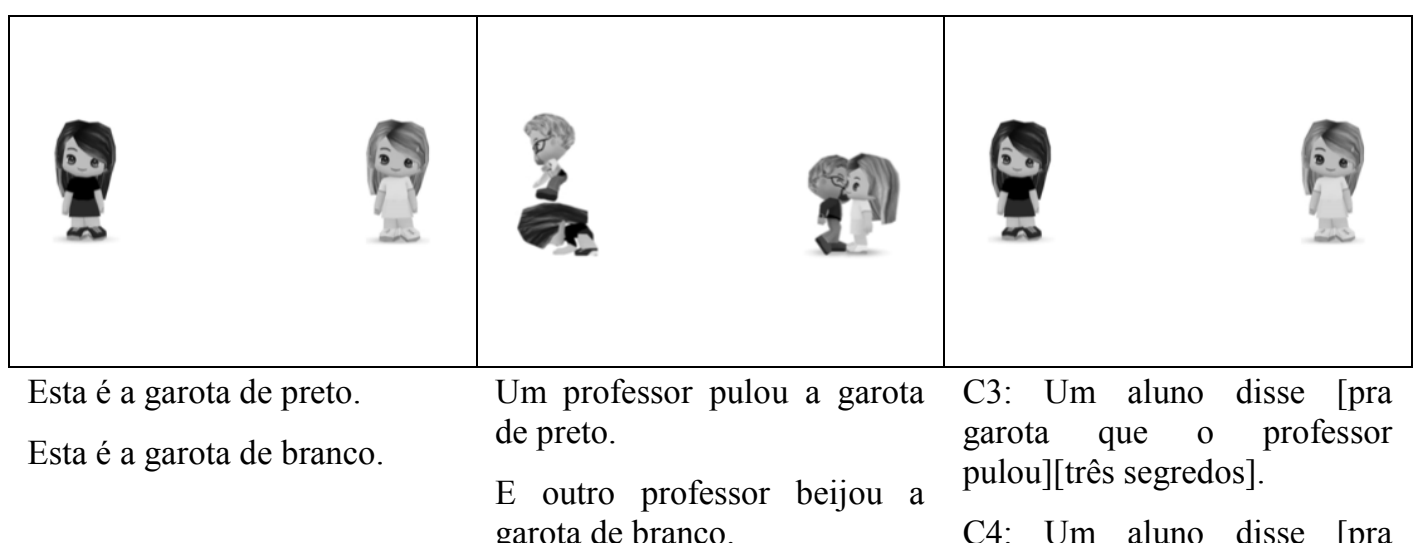
garota][que o professor pulou três barreiras].

O que o aluno disse?

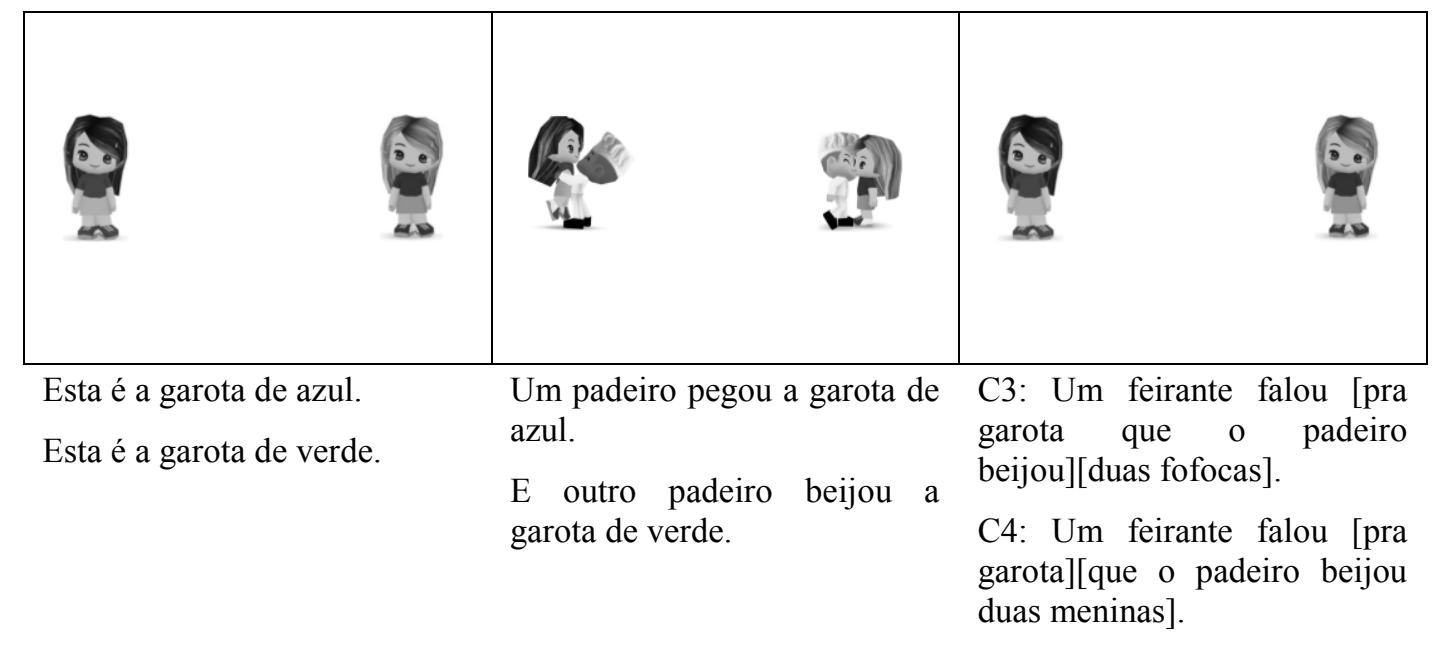

O que o feirante falou?

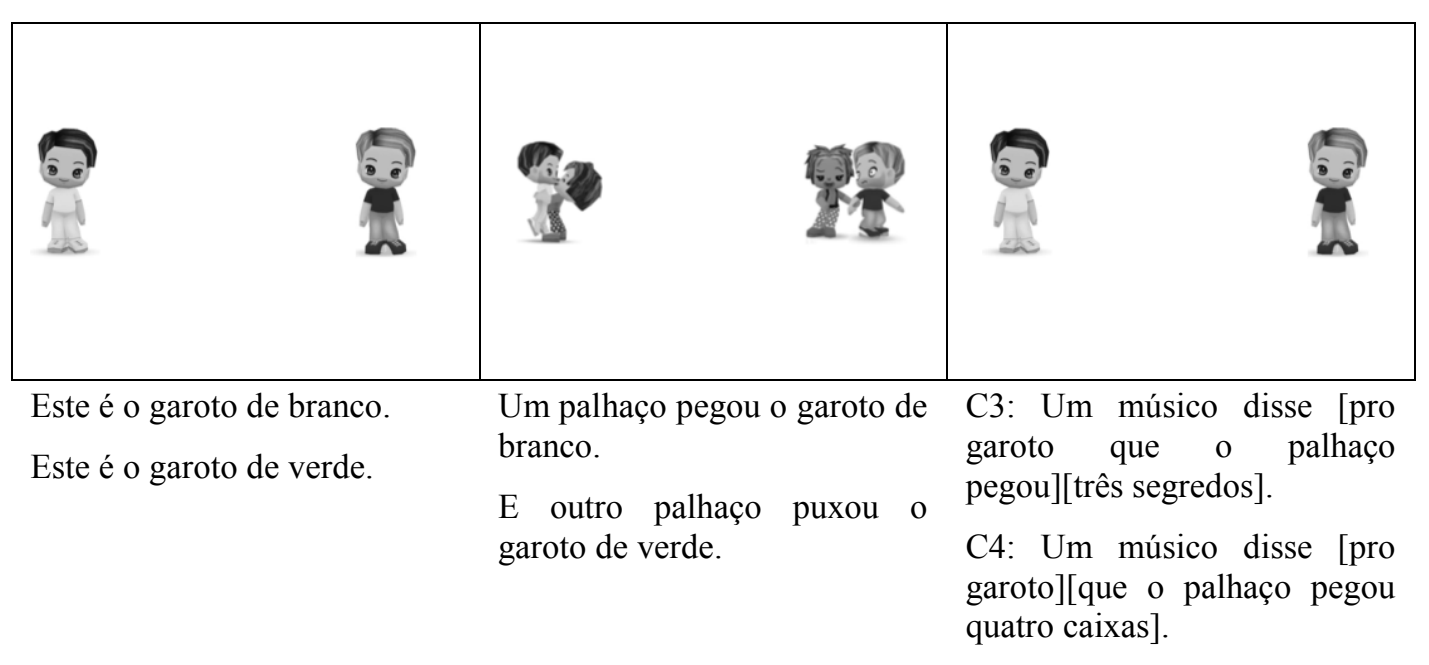

O que o músico disse? 


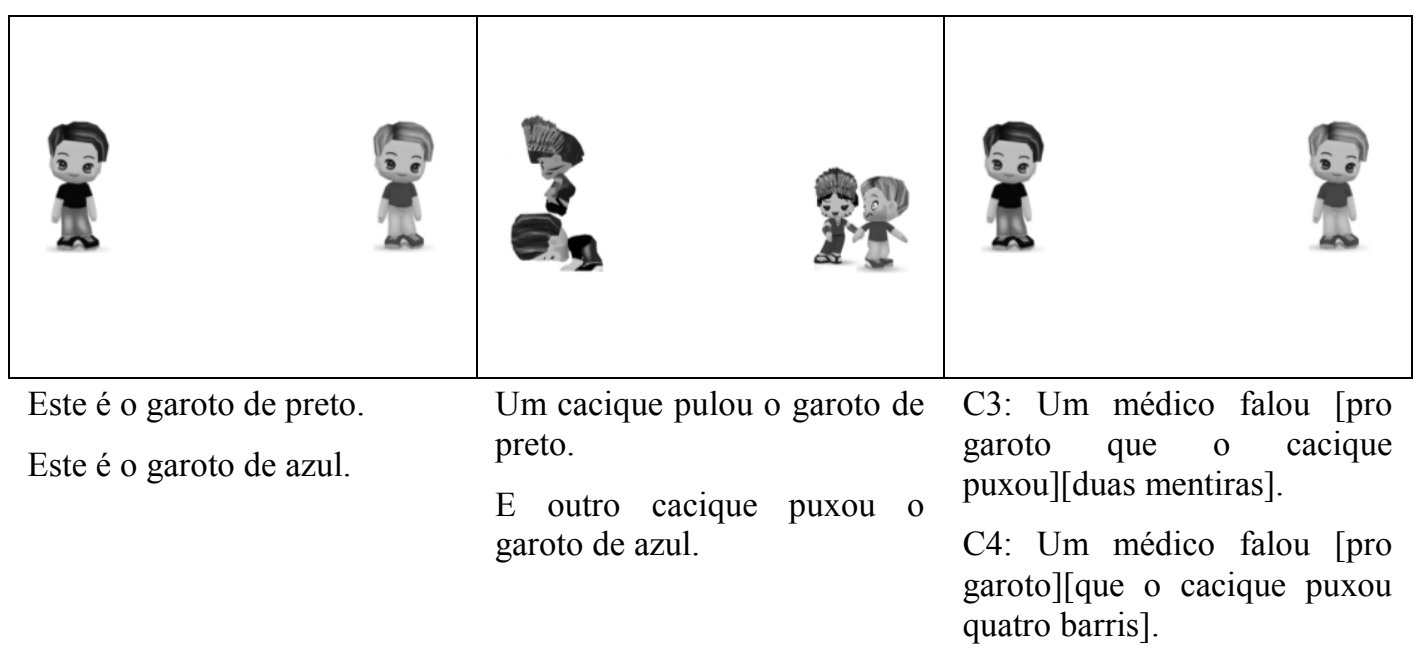

O que o médico falou? 